University of Louisville

ThinkIR: The University of Louisville's Institutional Repository

Electronic Theses and Dissertations

$5-2018$

\title{
An assessment of the disaster preparedness knowledge of emergency medical services providers in Hajj of 2016.
}

Ahmed Meaiwedh Al-Otaibi

University of Louisville

Follow this and additional works at: https://ir.library.louisville.edu/etd

Part of the Medicine and Health Sciences Commons

\section{Recommended Citation}

Al-Otaibi, Ahmed Meaiwedh, "An assessment of the disaster preparedness knowledge of emergency medical services providers in Hajj of 2016." (2018). Electronic Theses and Dissertations. Paper 2993. https://doi.org/10.18297/etd/2993

This Doctoral Dissertation is brought to you for free and open access by ThinkIR: The University of Louisville's Institutional Repository. It has been accepted for inclusion in Electronic Theses and Dissertations by an authorized administrator of ThinkIR: The University of Louisville's Institutional Repository. This title appears here courtesy of the author, who has retained all other copyrights. For more information, please contact thinkir@louisville.edu. 


\title{
AN ASSESSMENT OF THE DISASTER PREPAREDNESS KNOWLEDGE OF EMERGENCY MEDICAL SERVICES PROVIDERS
}

IN HAJJ OF 2016

\author{
By \\ Ahmed Meaiwedh Al-Otaibi \\ B.S.EMS, Eastern Kentucky University, 2009 \\ M.S., University of Evansville, 2011

\begin{abstract}
A Dissertation
Submitted to the Faculty of the

School of Public Health and Information Sciences of the University of Louisville in Partial Fulfillment of the Requirements for the Degree of
\end{abstract} \\ Doctor of Philosophy in Public Health Science \\ Department of Health Management and Systems Sciences \\ University of Louisville \\ Louisville, Kentucky
}

May 2018 
Copyright 2018 by Ahmed Al-Otaibi

All rights reserved 



\title{
AN ASSESSMENT OF THE DISASTER PREPAREDNESS KNOWLEDGE OF EMERGENCY MEDICAL SERVICES PROVIDERS \\ IN HAJJ OF 2016 \\ By
}

\author{
Ahmed Meaiwedh Al-Otaibi \\ B.S. Eastern Kentucky University, 2009 \\ M.S., University of Evansville, 2011
}

A Dissertation approved on

March 22, 2018

by the following Dissertation Committee:

Dissertation Director

Susan Allen, Ph.D.

Dr. Robert Esterhay, MD

Dr. William P. Mckinney, MD

Sandy Hunter, Ph.D., NRP

Bert Little, Ph.D. 


\section{DEDICATION}

This dissertation is dedicated to my loving parents, Meaiwedh and Mazna Alotaibi who have surrounded me with their eternal love, support, and sincere prayers; to my loving wife Jamlah who has encouraged me to pursue my dreams and has been supportive and patient throughout my doctoral studies; and to my wonderful son, Ziyad and daughter, Rasel who have given my life new meaning.

I thank you all from the bottom of my heart, I love you all. 


\section{ACKNOWLEDGMENTS}

First of all, I thank Allah, he is the Mighty and the Majestic, who has blessed me with his willing and grace to pursue my dreams and to earn the $\mathrm{Ph} . \mathrm{D}$. degree.

Putting this dissertation together took nearly two years of hard work: from concept to survey development, implementation to analysis, and writing to defense. It would not have been possible without the help of many incredibly talented and dedicated scholars who took a personal interest in my academic success. I am truly thankful for my dissertation committee members. Mentor and chair, Dr. Susan Allen, I own her gratitude for her continued support and constant encouragement on this academic journey. You helped me acquire a strong professional identity as leader and scholar in my field.

I would like express my deepest thanks and appreciation to Dr. Robert Esterhay for providing me with his support and pearls of wisdom, especially during my most difficult times. Dr. Esterhay is a true motivational leader who taught me to be persistent and goaloriented, which enabled me to achieve my academic goal to obtain the Ph.D. degree. I would also like to express my deepest thanks and appreciation to Dr. William P. Mckinney for always providing me with just the right amount of challenge, support, encouragement. He has always been there to listen and give his best advice.

I would also like to express my deepest thanks and appreciation Dr. Sandy Hunter who has been my mentor for the past ten years. Dr. Hunter, your understanding of the 
complex world of EMS field was pivotal to this study. While I was reluctant at first to change the methodology, your suggestions and guidance have made this a solid study.

Thank you for your focus and advice. My sincere gratitude and thanks also go to Dr. Bert Little for teaching me and guiding me to select and apply the appropriate statistical methods, which made my dissertation meaningful and worthwhile.

I would also like to thank all of my friends who have kept me in their thoughts and encouraged me during my academic years study in the U.S since I began pursuing my B.S degree in August 2007. Special thanks go to my friend Dr. Hajed Alotaibi for his support and encouragement and for his constant international phone calls to cheer me up and to ask about my progress.

My graduate studies would not have been the same without the social and emotional support of my great friends and student colleagues in the School of Public Health and Information Sciences at University of Louisville. Special thanks go to my fellow cohort members: Dr. Joe Bohn, Dr. Murthy Kotagiri, and Dr. Maresa Cowder. Thank you for helping me get through this my sanity relatively intact.

I would like to thank all the staff at Saudi Red Crescent Authority who facilitated the approval and access to date for my research study. Special thanks go to Dr. Sattam AlAnezy, General Director of EMS services at SRCA for his warm reception and immediate assistance in giving me access to SRCA system. Special thanks go to Dr. Ahmed AlZahrani, Head of Research and Development Unit at SRCA for unlimited support and assistance me to data collection.

I would like to acknowledge Prince Sultan Bin Abdulaziz College for Emergency Medical Services at King Saud University (PSCEMS-KSU) for supporting my Ph.D. 
scholarship. Special thanks go to Dr. Khalid Fouda former dean of PSCEMS, and Dr. Hashim bin Salleeh, present Dean of PSCEMS who have put their trust in me become a member of the college. Special thanks go to Dr. Osama Samarkandi, Chairman of Basic Sciences Development at PSCEMS for supporting me and helping me for dissemination of my online survey. 


\begin{abstract}
AN ASSESSMENT OF THE DISASTER PREPAREDNESS KNOWLEDGE OF EMERGENCY MEDICAL SERVICES PROVIDERS

IN HAJJ OF 2016

Ahmed Alotaibi

$03 / 22 / 2018$
\end{abstract}

Objectives: 1) Assess knowledge regarding disaster preparedness for mass gathering among SRC-EMS providers during the Hajj 2016 2) Explore the relationship between the demographic variables and knowledge about disaster preparedness among SRC-EMS providers during the Hajj 2016 3) Explore the sources of knowledge for SRC-EMS providers about disaster preparedness.

Method: The data collection for this study was a cross-sectional survey using an online Qualtrics survey. It was convenience sample of 1650 respondents. For the analyses descriptive statistics was used, one-way ANOVA and Bonferroni correction for multiple comparisons tests, multiple regression analyses, and Pearson's product coefficients.

Results: The main findings in this study was providers in the age of 35-39 years and master's degree had more general knowledge of disaster preparedness. Paramedics had more general knowledge of disaster preparedness and physicians had more knowledge of the Hajj. The military sector had more knowledge of disaster preparedness than other 
sectors. The trainings, workshops and drills should be held four times per year, the duration should be 6-12 months, trainings no more than 9 hours and workshops and drills more than 20 hours for retaining high knowledge of disasters. Thus, the characteristics of multiple regression analysis model for general knowledge of disaster preparedness are the level of EMS provider, highest level of education, and number of workshops ever attended and characteristics of knowledge of the Hajj model are the number of drills attended and level of EMS providers. Most sources of general knowledge of disaster preparedness are continuing education, university courses the media and the most sources of knowledge of the Hajj are real disasters, continuing education, university courses, and the media.

Conclusion: This study indicates a relationship between the demographic variables with general knowledge of disaster preparedness and knowledge of the Hajj 2016. It provides valuable insights into understanding predictive factors. Also, it defines the sources of knowledge about disaster preparedness for mass gathering among SRC-EMS providers. This study offers recommendations to the Saudi government for improving the knowledge of disaster preparedness for SRC-EMS providers such as improving training and education and changing the scope of practice for Saudi EMS system. 


\section{TABLE OF CONTENTS}

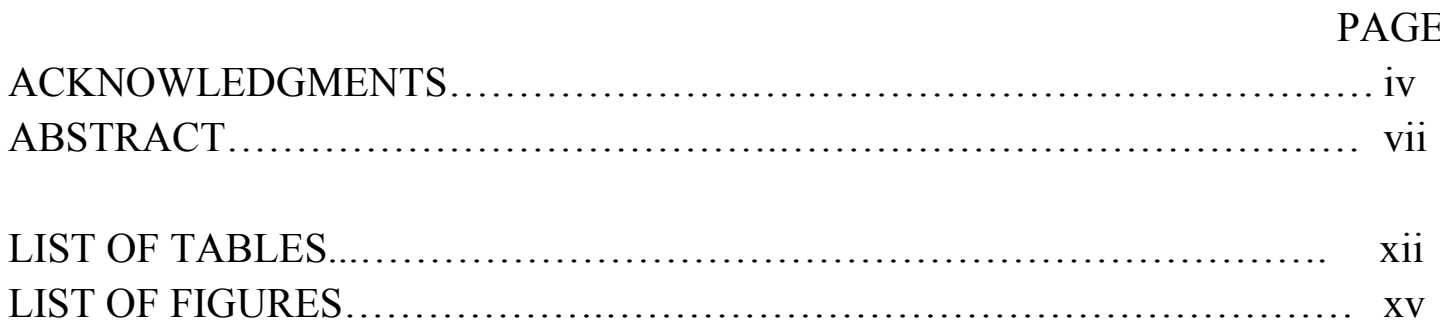

CHAPTER I: INTRODUCTION........................................ 1

Background of the Problem............................................. 4

Health Care System in Saudi Arabia ..................................... 5

The Ministry of Health......................................... 5

Pre-hospital Care in Saudi Arabia................................. 6

Saudi Red Crescent Authority (SRCA) ........................... 7

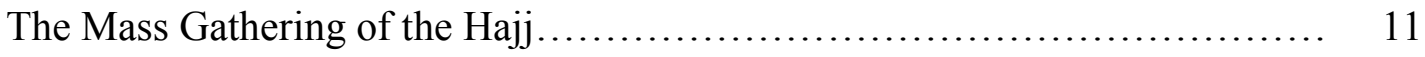

Location........................................................ 11

The Progression of the Hajj.................................... 11

Saudi Arabia's Efforts for Pilgrims....................................... 14

The Management of Hajj......................................... 14

The Supreme Hajj Committee (SHC)..................... 14

The General Hajj Committee (GHC)...................... 15

Role of the Ministry of Health in the Hajj..................... 15

Preventive and Public Health.............................. 16

Therapeutic Medicine Service.............................. 17

Role of the SRCA in the Hajj ............................. 18

History of the Hajj disaster..................................... 19

Statement of Problem.................................................... 21

Purpose of the Study............................................... 22

Research Questions and Hypotheses................................... 22

Definitions of Key Terms............................................ 24

CHAPTER II: LITERTURE REVIEW ................................ 26 
Definitions............................................................. 26

Studies of Mass Gathering............................................... 27

Disaster Preparedness for Mass gathering................................ 31

The Mass gathering of the Hajj.......................................... 40

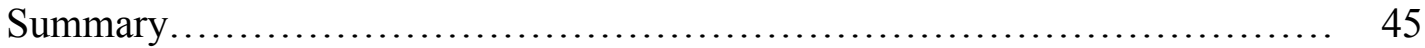

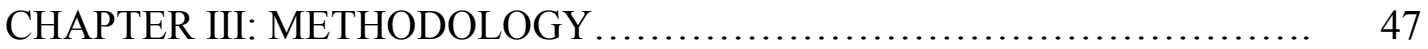

Consent Procedures.......................................................... 47

Research Design........................................................... 47

Data Collection Procedures............................................. 48

Sample Population........................................................ 49

Definition of Research Variables and Instrumentation Development ............ 50

Research Variables........................................... 50

Instrumentation Development.................................. 51

Validity and Reliability......................................... 55

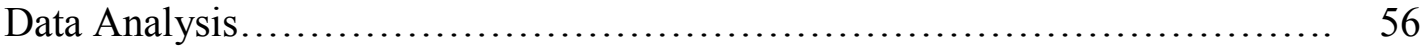

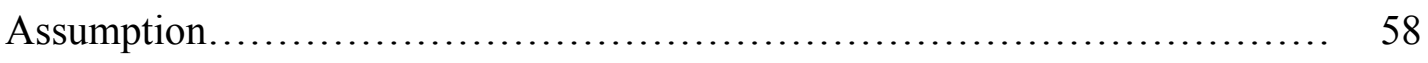

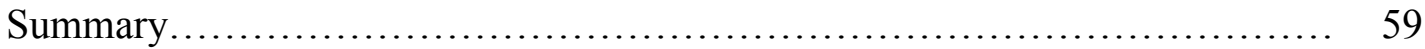

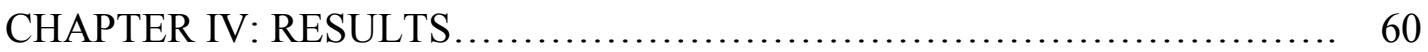

Research Questions.................................................. 60

Hypotheses.............................................................. 61

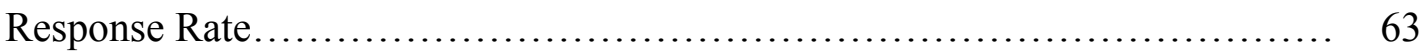

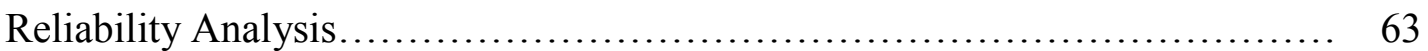

General Sample Descriptive............................................ 64

Section 1: Demographic Information ............................ 64

Section 2: SRCEMS Provider's DPMG Experience and Training ........ 65

Section 3: General Knowledge of DPMG ........................ 71

Section 4: Knowledge of the Hajj 2016........................... 74

Section 5: Sources of Knowledge................................... 77

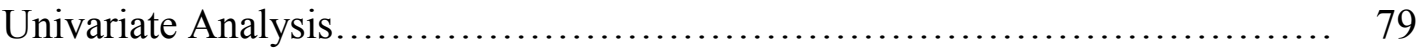

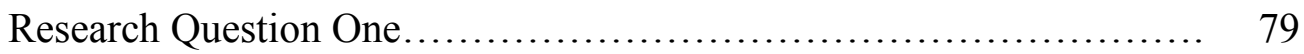

Research Question Two...................................... 82

Research Question Three....................................... 87

Research Question Four....................................... 91

Research Question Five........................................ 93

Research Question Six........................................ 100

Research Question Seven...................................... 103

Multiple Regression Analysis Model...................................... 105

General Knowledge ........................................... 108 
Hajj Knowledge............................................ 110

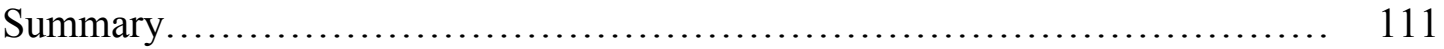

CHAPTER V: DISCUSSION............................................. 114

Demographic Characteristics............................................ 115

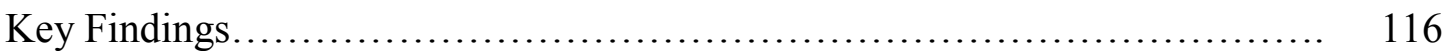

Discussion Summary .................................................. 120

The Age of SRC-EMS providers is Relevant....................... 120

Level of Education............................................ 121

The Category of EMS for SRC-EMS providers is Relevant............ 122

The Training Received by SRC-EMS providers was relevant.......... 122

The Number of Years of Experience............................... 123

Training was Relevant......................................... 123

Source of Knowledge........................................... 125

Predictive Model of the Group General Knowledge of DPMG.......... 126

Predictive Model of the Group Knowledge of Hajj 2016.............. 128

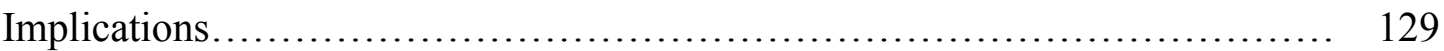

Training/Education.............................................. 129

Prior Experience ............................................... 131

Scope of recommendation for Practice............................ 131

Synthesis and Application of These Results............................. 132

Years of Experience........................................... 132

Certification................................................. 133

Training Content and Delivery................................. 133

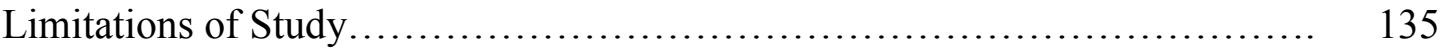

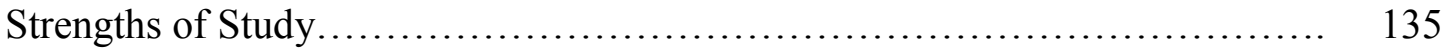

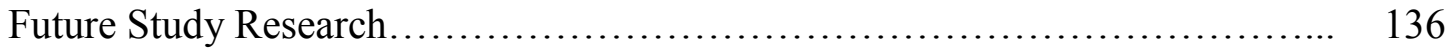

CONCLUSION ........................................................... 136

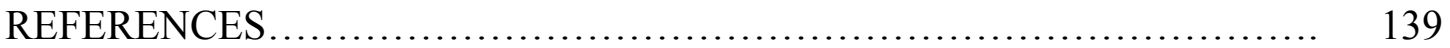

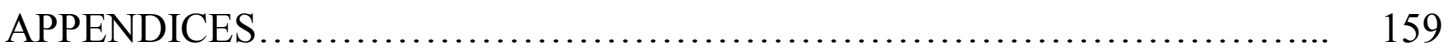

CURRICULUM VITA................................................. 244 


\section{LIST OF TABLES}

Table

PAGE

1.1 Personnel in SRCA by profession.............................. 10

1.2 SRCA, number of Ambulances and Stations ...................... 10

1.3 The largest groups of pilgrims from different countries............. 11

1.4 Stampedes and Fires during the Hajj............................ 20

1.5 Five Key Areas related to Mass Gatherings........................ 29

4.1 Cronbach's Alpha for Dimensions of the Questionnaire............... 63

4.2 Section1: Sample of Demographics Information..................... 64

4.3 Section 2: Sample of SRC-EMS Provider's Disaster Preparedness for Mass Gathering Experience and Training............................ 65

4.4 Continue of Experience and Training ........................... 67

4.5 Continue of Experience and Training.............................. 68

4.6 Experience during Workplace ready to Respond .................... 70

4.7 Section 3: General Knowledge of Disaster Preparedness for MG ....... 71

4.8 General Knowledge of Disaster Preparedness for Mass Gathering ..... $\quad 72$

4.9 Participation in Emergency Plan Drafting, Emergency Planning or know whom to contact for Disaster Situations for the Hajj Season ........... 74

4.10 Section 4: Knowledge of the Hajj 2016........................ 75

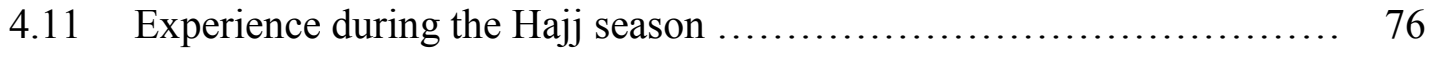

4.12 Section 5: Source of Knowledge ............................. 77

4.13 Courses that improved the knowledge about Disaster Preparedness..... 78

4.14 Educational Courses that should be taken in Preparing for Disaster..... 78

4.15 Differences in General Knowledge of Disaster Preparedness based on Age. 
4.16 Differences in Knowledge of Hajj 2016 based on Age ................ 81

4.17 Differences in General Knowledge of Disaster Preparedness based on level of education............................................. 82

4.18 Differences in Knowledge of Hajj 2016 based on level of education...... 85

4.19 Differences in General Knowledge of Disaster Preparedness based on level

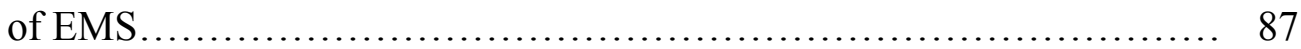

4.20 Differences in Knowledge of Hajj 2016 based on level of EMS.......... 89

4.21 Differences in General Knowledge of Disaster Preparedness based on the sector of EMS training. ...................................... 91

4.22 Differences in Knowledge of Hajj 2016 based on the sector of EMS

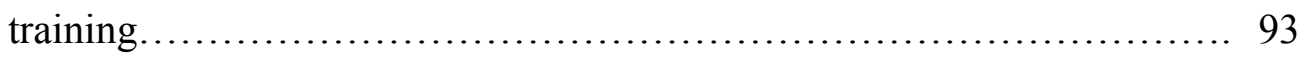

4.23 Differences in General Knowledge of Disaster Preparedness based on years of experience working for SECA........................ 94

4.24 Differences in Knowledge of Hajj 2016 based on years of experience working for SRCA ............................................. 96

4.25 Differences in General Knowledge of Disaster Preparedness based on number of times worked at the Hajj.......................... 98

4.26 Differences in Knowledge of Hajj 2016 based on number of times worked at the Hajj.......................................... 100

4.27 Differences in General Knowledge of Disaster Preparedness based on

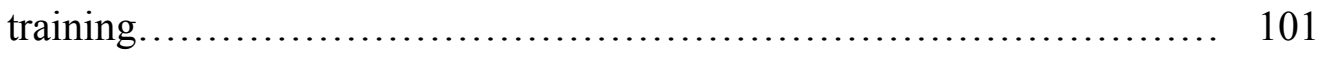

4.28 Differences in Knowledge of Hajj 2016 based on training............... 102

4.29 Source of general knowledge of disaster preparedness ............... 103

4.30 Source of knowledge of Hajj 2016.............................. 104

4.31 Final Stepwise Model for General Knowledge of Disaster Preparedness 108

4.32 Final Stepwise Model for Hajj Knowledge........................ 110

4.33 Hypotheses and Results.................................... 111 


\section{LIST OF FIGURES}

$\begin{array}{ll}\text { Figure PAGE } & \text { PAs }\end{array}$

1.1 Geographical Progression of the Hajj........................................................ 12

$2.1 \quad$ Potential Challenges Posed by mass Gatherings......................................... 30

4.1 Significant General Knowledge of disaster preparedness based on Age

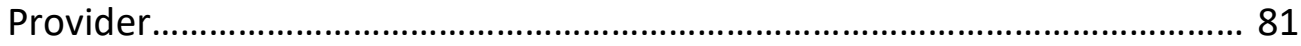

4.2 Significant General Knowledge of disaster preparedness based on Level of

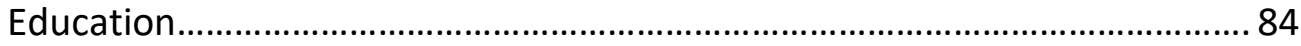

4.3 Significant Knowledge of Hajj 2016 based on Level of Education.................. 86

4.4 Significant General Knowledge of disaster preparedness based on EMS

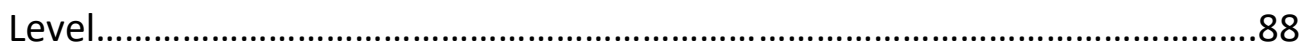

4.5 Significant Knowledge of Hajj 2016 based on EMS Level...............................90

4.6 Significant General Knowledge of disaster preparedness based on sector

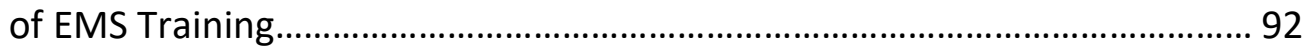

4.7 Significant General Knowledge of disaster preparedness based on years of

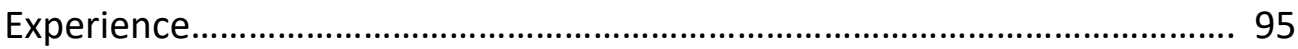

4.8 Significant Knowledge of Hajj 2016 based on years of Experience................ 97

4.9 Significant General Knowledge of disaster preparedness based on number of times worked at the Hajj............................................................................. 99 


\section{CHAPTER I \\ INTRODUCTION}

In recent years, the world has been affected by an increasing incidence of major disasters caused by earthquakes, hurricanes, floods, tsunamis, tornados, storms, fires, terrorism, outbreak of diseases, and accidents at mass gatherings of people. The resulting enormous number of deaths and damage to property have affected the economy of the countries concerned. Worldwide, disasters cause more than 75,000 deaths each year (Deeny \& McFetridge, 2005) and directly impact more than 210,000,000 people per year (International Federation of Red Cross and Red Crescent Societies, 2001). According to Klynman, Kouppari and Mukhier (2007) this number has increased by 17 percent over the past few decades. Besides the large number of deaths and injuries, the cost over the 30 years previous to August 2012 was estimated at $\$ 22$ billion (Singh and Singh, 2012). The staggering number of disasters of all types over the last 15 years has been accompanied by an increased focus on the work of responding health care workers from within the countries directly impacted and in international response teams (Gebbie, Hutton, \& Plummer, 2012). Thus, it is important to assess those who worked on the first line within disaster situations, such as EMS providers.

Haddow, Blullock and Coppola (2008) have defined a disaster as "an event that demands substantial crisis response requiring the use of governmental powers and resources beyond the scope of one line agency or service" and emergency management as "the discipline dealing with risk and risk avoidance" (p27). Today, however, the term is 
used not only refer to natural catastrophes but also to refer to other events such as industrial accidents or transport accidents (Moe and Pathranarakul, 2006). The concept of preparedness during emergency management can be defined as a state of readiness for a disaster, crisis or any other type of catastrophic situation.

According to the United Nations' International Strategy Disaster Reduction, a disaster is "a serious disruption of the functioning of a community or a society causing widespread human, material, economic or environmental losses which exceed the ability of the affected community or society to cope with using its own resources" (UNISDR, 2009). Additionally, the World Health Organization (WHO) defines a disaster as when "normal conditions of existence are disrupted and the level of suffering exceeds the capacity of the hazard-effected community to respond to it" (as cited in Lee, 2010, p. 466).

One significant team of experts on disaster is that comprised of Deshmukh, Rodrigues, and Krishnamurthy who, when writing about the risks and management of earthquakes in 2008, articulated; "Disaster management is an integrated process of planning, organizing, coordinating and implementing measure that are needed for effectively dealing with its impact on people. This includes prevention, mitigation, capacity building, preparedness, response, assessment, rescue and rehabilitation" (p. 2).

Both natural and man-made disasters are generally overwhelming to hospital and emergency services and, in recent decades, more attention has been given to planning the health care response to them(Efstathiou Panos., Papafragkaki, Gogosis, \& Manwlidou, 2009). Both communities and health care workers (HCWs) are essential for the management of injury, death and loss of health services infrastructure due to disasters, leading to an emphasis on awareness and preparedness by communities. 
Mass gatherings present enormous challenges for disaster management. According to the National Association of Emergency Medical Services physicians (NAEMSP), mass gatherings are defined as "Events in which at least 1000 persons are gathered at a specific location for a defined period of time (Soomaroo andMurray, 2012, p. 13). Likewise, the World Health Organization has defined a mass gathering as " An organized or unplanned event where the number of people attending is sufficient to strain the planning and response resources of the community, state or nation hosting the event"(WHO, 2008). Because the Hajj implies large numbers of people, many of whom are elderly, in crowded outdoor circumstances, mass gatherings such as the Hajj require a specific organization of medical services.

In the last decades, both man-made and natural disasters such as terrorist attacks, fires, floods and epidemics have affected Saudi Arabia. Nevertheless, despite the frequent occurrence and the devastation to peoples' lives and prosperity, little attention has been paid to disaster preparedness and management (Abosouliman, Kumar, Alam, \& Rasjudin, 2013). Since 1980, in Saudi Arabia, disasters have caused more than 4,660 deaths, affected 32,000 people, and caused US\$ 4.65 billion in damages (CRED, 2013), so they are costly in both human and fiscal terms (Chakraborty, Mujumdar, Behera, Ohba, \& Yamagata, 2006). For example, "Black Wednesday" in 2009 was a woeful day for the Red Sea port city of Jeddah, gateway to Mecca, when flooding affected more than 25,000 residents and caused 125 deaths, destroying over 7,000 vehicles and 11,000 homes. The lack of an adequate drainage network and the slow response by emergency teams earned the government widespread criticism (Alamri, 2011). 
Another pressing problem in the absolute monarchy of Saudi Arabia is the risk of a terrorist attack because internal tensions tend to rise without any means of release, as the country has modernized, the many interactions with foreigners outside of Saudi Arabia have led to an increase in attacks in the country(Alamri, 2011).

In 2005, the World Health Organization advised all countries to have a clear plan to minimize the effects of disasters and suggested strategies for disaster preparedness which included continuous assessment and monitoring coordination, planning, and implementation (WHO, 2007). A further recommendation was for health care workers in hospitals or in other health facilities to have enough knowledge and skills to be ready for any catastrophe. Usually, the first line of defense against disaster is Health Care Workers (HCWs), especially providers of Emergency Medical Services (EMS) who respond when people ask for help. Hence, it is crucial to know the level of disaster preparedness among EMS providers.

\section{Background of the Problem}

Although Saudi Arabia is in many aspects a developed country, it is, like any nation in the world, susceptible to disasters (Abosuliman, Kumar \& Alam, 2013). The potential for disaster is greatest during the Hajj pilgrimage when Saudi Arabia welcomes more than three million pilgrims from all over the world to perform religious rites in and around the town of Mecca in the Western province (Al-Orainey \& Ibrahim, 2013;

Elachola, Assiri, \& Memish, 2014; Gardouni, 2012; Yamin \& Albugami, 2014). The Hajj is considered one of the largest mass gatherings in the world (Gardouni, 2012; Shafi, Booy, Haworth, \& Memish, 2008) and presents specific dangers because of the enormous numbers of pilgrims present in relatively small spaces at the same time. Given that the 
Islamic calendar is a lunar one, the Hajj season does not correspond to a particular date on the Gregorian solar calendar (Alshenawi, 2014). Rather, the Hajj cycles through the seasons every few years, which can be important in a country where summer temperatures can reach over 120 degrees Fahrenheit (Alamri, 2011). The king of Saudi Arabia, in his role of Custodian of the Two Holy Mosques, assumes the sacred responsibility of caring for the pilgrims and directs his government to prepare for any problems caused by the huge influx of two million temporary visitors from abroad.

Saudi Arabia in 2014 had a population of approximately 28 million, and that number swells during Hajj to more than 30 million (Al-Tawfiq and Memish, 2014). Having had to face multiple catastrophes during fourteen centuries of annual pilgrimages, today the government takes preventative measures such as evacuating houses to allow space for the travelers and distributing cold water to the pilgrims (Alamri, 2011). Nevertheless, due to overcrowding, disease, and the logistics of food and water supplies, public services, including medical services, come under great stress (Alamri, 2011).

\section{The Health Care System in Saudi Arabia}

\section{The Ministry of Health}

The ministry was created in 1950 by a government unsparing in its desire to improve health care in Saudi Arabia (Al-Yousuf, 2002). Currently, the Ministry of Health $(\mathrm{MOH})$ oversees the finances, operations, and supervision of all health care in the country (Amalki, Fitzgerald and Clark, 2011). As time has progressed, the health care system has improved in Saudi Arabia, and emphasis has been placed on advancements in the medical field. The country is divided into 13 regions under the $\mathrm{MOH}$, with a representative for each area (Regional Health Systems Observatory, 2006). There exist challenges to the 
system, however, which include a shortage of professionals, lack of resources, and most specific to mass casualty research, a lack of policy for national crisis management (Amalki, Fitzgerald and Clark, 2011). There is a present push for more native Saudis to become involved in the medical field, as many of the nurses and doctors in the country are foreigners. There is also a current restructuring of health insurance occurring in the country allowing pilgrims to be insured during their visit by a cooperative health insurance system, that is also implemented in three stages for private workers within the country, government employees, and travelers (Amalki et al.) Although in the past the government has been responsible for the healthcare of the country, it is now working towards a publicprivate health partnership (Aljazira Capital, 2013).

Ministry of Health professions also participate in the Advisory Scientific Board, a government committee that manages policies, guidelines and measures that focus on public health-related issues and recommends strategies for scientific research on public health-related diseases. This board also includes members of the National Guard, from King Faisal Specialties Hospitals, and from the Faculty of Applied Medical Sciences at King Abdul-Aziz University, from the private health sector, the Ministry of the Interior, King Saud University, King Fahd Medical City, WHO, USA and the CDC.

\section{Pre-hospital Care in Saudi Arabia}

In addition to deficiencies in prevention, transportation, communication and public education, pre-hospital care along with rehabilitation in Saudi Arabia are considered suboptimal (Al-Naami, Arafah, \& Al-Ibrahim, 2010). Although the Saudi Ministry of Health, along with other governmental hospitals, provides 24-hour emergency care services at their emergency units, they rely on the Saudi Red Crescent Society (SRCS) to 
provide first-aid to trauma victims on the scene and to transport them to hospital emergency departments (Al-Yousuf, 2002).

Saudi Red Crescent Authority (SRCA). The SRCA is a MOH-managed governmental organization, established in 1963, that provides emergency medical services (SRCA, 2013 \& UNHCR, 2007). Although small, it plays an important role in the health care system. It is a free service to extract victims from critical situations such as road traffic accidents, flood, and fire or any disaster. The SRCS provides formal pre-hospital services throughout the country through only 165 ambulance stations (Dhaffar, Sindy, Gazzaz, \& Shabaz, 2005; Sasser, Gibbs, \& Blackwell, 2004). As a result, only few patients are being transported to the hospital via SRCA ambulances and instead, police officers and volunteers transport most trauma victims in Saudi Arabia (Al-Ghamdi, 2002). Moreover, although trauma is the leading cause of death and disability in the country, Saudi Arabia lacks number of trauma centers (Al-Naami, Arafah, Al-Ibrahim, 2010). Emergency Medical Services as an essential part of trauma centers are very limited in the kingdom due to limited numbers of EMS stations and employees (Al-Ghamdi, 2002). In the city of Riyadh, the capital, only seven SRCA emergency stations are operating with fewer than 30 emergency medical technicians (EMTs) (Al-Ghamdi, 2002). Accordingly, the city of Riyadh has "poor" access to pre-hospital services according to a study comparing pre-hospital services in Abu Dhabi with services elsewhere in the Middle East (Sasser et al., 2004).The Saudi MOH has published reports indicating that more than 50,000 emergency cases in Riyadh were transported by police and volunteers in vehicles in 1999, representing half of all emergency calls in Riyadh of that year (Al-Ghamdi, 2002). 
In an attempt to check recent information concerning the SRCA, this author found that their website of SRCA is absolutely outdated, and has no statistical information available. The home page has a banner that says, "Welcome back" to the late King Abdullah, who passed away on January of this year. Moreover, the most recent news was from the year 2010. However, the International Federation of Red Cross and Red Crescent Societies' website has a link to another Saudi Red Crescent Authority website (www.srca.org.sa), which is somewhat updated. Even that website contains no statistical information on EMS stations, emergency calls, or trauma incidents. In contrast, other Red Crescent Societies in the region, for example Qatar Red Crescent, have user-friendly, updated websites that provide statistical information in yearly reports regardless of their subordinate role in each country. The SRCA plays a primary role in Saudi Arabia's EMS, yet it fails to provide appropriate services even at the level of public awareness programs. Educational campaigns seem to be ineffective. In a survey published in 1998 by the SRCA, only 3\% of Saudis know the correct emergency phone number for SRCS: 997. Seventy percent believe that the number is 911 like in the US, and the rest are unaware of any number (Al-Naami et al., 2010). A cross-sectional survey in Jeddah, the largest city in western Saudi Arabia, for which 1534 members of the general public were interviewed, showed that $64 \%$ did not know the emergency dispatch number to call (Hamam, Bagis, AlJohani, \& Tashkandi, 2015). Consequently, most emergency cases are transported by volunteers in private cars, taxis, or police cars to the hospital and not by SRCA (AlNammi, Arafah, \& Al-Ibrahim, 2010). This is a public awareness problem that could be easily solved by health promotion and awareness campaigns. 
According to the Saudi Commission for Health specialties, which the sources of verification for the credentials of Saudi healthcare providers practicing in Saudi Arabia. There are three levels of EMS providers in SRCA (www.scfhs.org.sa): the basic level EMS (EMS-B), and the intermediate level EMS (EMS-I) which are called technicians, and the advanced level EMS (EMS-Paramedic) which are called technologists. The EMS-B are qualified after 18 months of study. Their primary duties are basic life support (BLS), and automated external defibrillation (AED). The EMS-I qualify after two- and-a- half years of study. Their primary duties are all of the ones carried out by EMS-B, plus IV fluid, intubation, AED, and Advanced Life Support. Qualification as an EMS-Paramedic requires four-and-a-half years of study. Their primary duties are: IV, intubation, AED, BLS, ACLS (advanced cardiovascular life support), PALS (pediatric advanced life support), PHTLS (prehospital trauma life support), and advanced medication administration.

Patients are transported to the hospital in one of two ways: by ground ambulance or by air ambulance (helicopter) services. Air ambulance is an emergency medical service to transport critical and injured patients in order to save time (Alharbi, 2015). According to the General Authority for Statistics in the Kingdom of Saudi Arabia, there are 19,676 EMS providers, and 8,632 ambulances based at 1,653 stations throughout the country. Table 1 shows the number of employees hired during the past the five years. The number of hires in 2015 was more than double the number hired in 2011. Table 2 shows the number of ambulances and number of stations that were operational in 2015 (GAS, 2015). 


\section{Table 1.}

Personnel in Saudi Red Crescent Authority by profession.

\begin{tabular}{|c|c|c|c|}
\hline \multirow{2}{*}{ Years } & \multicolumn{2}{|c|}{ Personnel in SRCA by Profession 2011 -2015 } & \multirow{2}{*}{ Total } \\
\cline { 2 - 3 } & Specialist\& & Physicians & \\
\hline 2011 & Technicians & 86 & 2578 \\
\hline 2012 & 2492 & 86 & 3646 \\
\hline 2013 & 3560 & 86 & 3819 \\
\hline 2014 & 3733 & 161 & 4544 \\
\hline 2015 & 4383 & 62 & 5570 \\
\hline Total & 5508 & 481 & 20157 \\
\hline
\end{tabular}

Source: $\underline{w w w . s t a t s . g o v . s a / e n}$

Table 2.

$\underline{\text { Saudi Red Crescent Authority, number of ambulances and stations. }}$

\begin{tabular}{|c|c|c|}
\hline Years & Numbers of Ambulances & Numbers of Stations \\
\hline 2011 & 1572 & 284 \\
\hline 2012 & 1663 & 297 \\
\hline 2013 & 1463 & 328 \\
\hline 2014 & 1963 & 360 \\
\hline 2015 & 1965 & 384 \\
\hline Total & 8632 & 1653 \\
\hline
\end{tabular}

Source: www.stats.gov.sa/en

In Saudi Arabia there exists a general lack of confidence in the services of SRCA due to long times of response (Hamam, Bagis, Aljohani, Tashkandi, 2015). However, when compared to response time in the United States, the time response is around more than 8 minutes (Blanchard et al., 2012). 


\section{The Mass Gathering of Hajj}

\section{Location}

The city of Mecca, also spelled "Makkah," is considered to be the holiest place in Islam. It is located in a desert valley surrounded by rugged mountains in the western part of Saudi Arabia. The climate of Mecca is very hot and typically varies from $66^{\circ} \mathrm{F}$ to $110^{\circ} \mathrm{F}$ (WeatherSpark, 2015). The geography of Mecca can be classified into two types; type one is metro, which is 500 square miles and type two is Urban, which is 330 square miles (Mecca, 2015). The resident population of Mecca in 2017 was around 4.5 million (GAS, 2017).

The following table 3 , demonstrates the current populations from different countries who attend Hajj, traveling from a variety of places around the world.

\section{Table 3.}

The largest groups of pilgrims from different countries

\begin{tabular}{|c|c|}
\hline Country & Numbers Traveling to the Hajj \\
\hline Indonesia & 214,159 \\
\hline India & 173,165 \\
\hline Pakistan & 170,573 \\
\hline Turkey & 134,693 \\
\hline Iran & 111,511 \\
\hline
\end{tabular}

Source:(Khan et al., 2010)

\section{The progression of the Hajj}

The pilgrimage of Hajj consists of six steps that must be performed in sequential order over a period of six days, inside the Great Mosque of Mecca and in nearby areas outside the city. Of significance is the limited time for each step which dictates that all the pilgrims must be in the same places at roughly the same time with ensuing consequences. The following figure1, showed the Geographical Progression of the Hajj. 


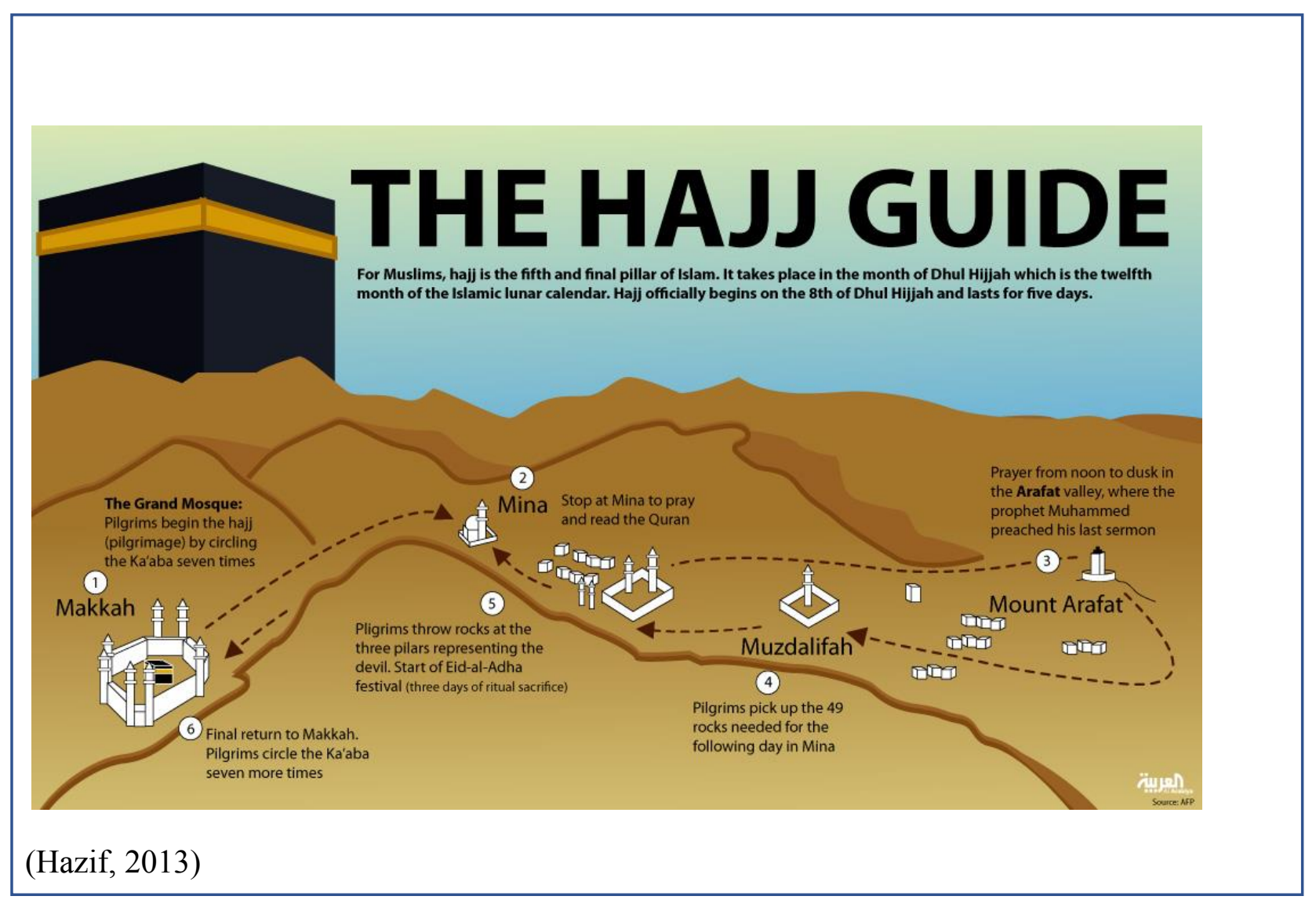

Figure1. The Geographical Progression of the Hajj

Step one: Rites at the Great Mosque. Today, more than three million pilgrims arrive in Mecca before the start of the pilgrimage through one of several gateways; either by sea through the port of Jeddah, by air through the Jeddah airport, or by land from various directions. The pilgrims visit the Great Mosque and circumambulate its center seven times. Then they must walk back and forth between the hills of Safa and Marrah before travelling to Mina, a small city some $10 \mathrm{~km}$ (6 miles) from the center of Mecca.

Step two: Day 1 of Hajj (stay in Mina). Mina is mostly an open desert area on the road from Mecca to the plain of Arafat. It is known as Tent City because after a 1997 fire, 
the Saudi government built 100,000 white, semi-permanent fiberglass tents to accommodate Hajj pilgrims. All of the millions of pilgrims stay one night in Mina.

Step three: Day 2 of Hajj (rites in Arafat and Muzdalifah). The masses of pilgrims move in the morning from Mina to Arafat, a desert plain 12.4 miles southeast of Mecca, by bus, car, rail and on foot. Called Arafat day, it is the most central ritual of Hajj. Shielded under tents, pilgrims spend the whole day in worship and after sunset, move 5.5 miles north to the village of Muzdalifah where they spend the night in tents.

Step four: Day 3 of Hajj (Day of Eid and Jamarat). In the morning, all the pilgrims move from Muzdalifah back to Mina where they change clothes, cut their hair, slaughter an animal to distribute the meat to the poor, and perform the first of the stoning rituals by throwing symbolic pebbles at three stone pillars that represent the devil. Historically, the stoning ritual has been the scene of disasters (BBC News, 2007; BBC News, 2004), as the area is small and the crowds surge to be able to throw their stones from as close as possible to the pillars.

Step five: Days 4 and 5 (Rituals in Mina). On days 4 and 5, pilgrims stay in Mina and perform the stoning ritual, aiming at a different stone pillar each day.

Step 6: Rituals at the Great Mosque in Mecca. On day 6 all three million pilgrims must go back to the Great Mosque in Mecca to circle around its center 7 times and walk or jog 7 times between the hills of Safa and Marwa, final rites to complete their Hajj. The Ministry of Hajj has attempted to organize the pilgrims for performing these last rites. They start with elderly and women pilgrims. 


\section{Saudi Arabia's efforts for pilgrims}

Most visitors come to Saudi Arabia to participate in the Umrah and Hajj. While the Hajj must take place during the annual prescribed days, Umrah, the lesser pilgrimage, can be performed at any time during the year except during Hajj season, according to Islamic law (Colliers International, 2014). The numbers of pilgrims are astronomical; according to government sources, in 2015 around 5 million people performed Umrah (Ministry of Hajj, 2015). To anticipate and facilitate the pilgrimages, the government of Saudi Arabia has established both administrative bodies and policies.

\section{The Management of Hajj}

Organizations Involved in coordinating the Hajj. Multiple agencies in Saudi Arabia contribute to the organization, coordination, and management of the Hajj each year (Al-Ahmadi, Al-Swidi, Abas, and Ghani, 2013). All the organizations that cooperate to organize the Hajj, in which the Ministries of Health and of the Interior play prominent roles (D'Alessandro, Leggo., and Almbarek, 2013). Thus, there are two main committees who incorporate representatives from the different ministries involved in the Hajj: the Supreme Hajj Committee (SHC) and General Hajj Committee (GHC). Each has subcommittees that have independent tasks related to the Hajj plan(Nojoum, 2005).

The Supreme Hajj Committee (SHC). This is the highest Hajj committee and the national level; it is directly in contact with the king of Saudi Arabia and the Council of Ministers for the implementation of policies as well as financial matters. The president of SHC is the Minister of the Interior and the vice president is the governor of Mecca. Other members are professionals from regional governorates and ministries concerned with the provision of the Hajj services and organizing the affairs of the pilgrims. The basic mission 
of the SHC is to study the plans and policies proposed by administrative organizations and operational bodies of the Hajj and to send these on to the Council of Ministers for allocation of resources (J. A. Al-Tawfiq \& Z. A. Memish, 2014; Eid, 2012; Shair \& Karan, 1979).

The General Hajj Committee (GHC). It is the lower and local level of the Hajj administrative authority, presided over by the governor of Mecca with the deputy governor of Mecca as vice president. The basic role of the GHC is to review and examine plans for the Hajj (Al-Ahmadi, Al-Swidi, Abas \& Ghani, 2013). The members of this committee are from the Ministries of Hajj, Finance, Health, Commerce and Industry, Water and Electricity, Transportation, Roads, Economy and Planning, Municipal and Rural Affairs, Communications and Information Technology, the General Directors of Civil Defense, the Chief of Red Crescent Society, the Chief of Civil Aviation, and the General Director of the Mina project (Nojoum, 2005).

Role of the Ministry of Health in Hajj. The MOH is a cornerstone of the preparedness for the Hajj. Its goals are the provision of the best health care for pilgrims and the elaboration, with other relevant entities, of a disaster plan (Eltahir, 2000). The preparations for Hajj season and Madinah by the $\mathrm{MOH}$ focused on prevention and public health, therapeutic medicine services, and supportive services. These areas are of emphasis for the coming seasons, as leaders look to improve current problem areas and support the pilgrims during the mass gatherings $(\mathrm{MOH}, 2015)$. The $\mathrm{MOH}$ plays a main role in the coordination and cooperation with other government ministries such as the Ministry of Defense, the National Guard, the Ministry of Interior, the Ministry of Higher Education, and the King Faisal Specialties Hospital and Research Center. Meanwhile, MOH hosts 
experts and coordinates with international organizations and think tanks such as the American and European disease control centers, WHO, and CDC (Z. A. Memish et al., 2014). Representatives from these organizations come to Mecca and look at all the plans of the Saudi government and analyze the levels of safety and security for the pilgrims during the Hajj season.

Preventive and Public Health. The Hajj, a mass gathering of pilgrims from different countries with diverse epidemiological backgrounds, increases the risk of spread of communicable diseases both to the visiting pilgrims and to their contracts upon their return home (WHO, 2008). Thus, the Ministry of Health pays special attention to the preventive phase of mass gatherings, where there is high risk of outbreaks, epidemics, and exposure to particular air, water and vector-borne diseases (Memish, 2012). Saudi Arabia in collaboration with the World Health Organization (WHO) and the Centers for Disease Control and Prevention (CDC) plan for any change or update on new diseases such as Middle Eastern Respiratory Syndrome (a Coronavirus), a particularly severe issue for the Middle East, as it was being passed through travelers, causing respiratory difficulty and no cases report and 2012 and 2013 (Z. A. Memish et al., 2014). The presence of Coronavirus prompted the $\mathrm{MOH}$ to take a multi-faceted approach to prevention.

A first step to prevention is to disseminate health awareness through the Saudi embassies. Instructions are provided in the local languages for health awareness with information on common diseases, food poisoning, and preventive measures to guide and help pilgrims during the Hajj season in the local languages (Memish \& Al-rabeeah, 2014). Also provided are the health-related steps for pilgrims to follow before coming to Saudi Arabia (Memish \& Al-rabeeah, 2012). 
Although there are screening procedures in place in the originating countries, the $\mathrm{MOH}$ has established centers for disease control at land, air and sea entry points (AlGhamdi \& Kabbash, 2011). These centers are in operation 24 hours a day during the Hajj season to prevent the spread of disease, as many people from around the world gather in a small area. Travelers must demonstrate proof of vaccination and customs officers work to ensure the safety of imported food as well. Recently, the MOH has established 232 specialized quarantine rooms where infectious cases are treated and controlled $(\mathrm{MOH}$, 2015). Finally, the MOH has embarked on vaccination campaigns for Mecca residents each year before the Hajj season.

Therapeutic Medicine Services. With the goal of providing high-quality health services to the Hajj pilgrims, the MOH establishes, furnishes and equips hospitals and primary health care clinics, as well as preventive centers at the Kingdom's points of entry and at the places where pilgrims stay. To date, the $\mathrm{MOH}$ has prepared 25 hospitals, including 4 hospitals in Arafat, 4 hospitals in Mina, 7 hospitals in the holy city of Mecca, and 9 hospitals in the city of Medinah, where the prophet is buried, the second mostvisited city in the kingdom after Mecca (Z. A. Memish et al., 2014). The total number of inpatient beds at the Hajj Sites is approximately 5,000 including 500 IC beds and 550 ER beds (Memish, et al, 2014). There are also 136 permanent and seasonal health centers which support the hospitals during Hajj season: 43 health centers in Mecca, 46 health centers in Arafat, 6 health centers in Muzdalifah, and 26 health centers in Mina ( $Z$. Memish, 2010). The MOH has built 16 emergency health centers along the Jamarat Bridge and three ambulatory centers in the Holy Mosque in Mecca, with 18 medical stations 
distributed in Holy Sites, including six medical stations in Arafat, six medical aid stations in Muzdalifah and six medical stations in Mina (Ministry, 2015).

In 2015, for the Hajj season, the MOH hired 800 physicians and nurses in various specialties from other fields, like the private sectors, to improve the performance of the health facilities. For example, specialists in intensive care, cardiology, nephrology, endoscopy, emergency and infectious diseases were hired to improve the Hajj (MOH, 2015). Some medical teams are assigned to the central area of the Holy Mosque to treat emergencies that arise among the millions of pilgrims concentrated in that area. Eight ambulances are allocated to these emergency medical stations in the central area of the Holy Mosque (MOH, 2015). Most of the critical care cases are transferred to the King Abdullah Medical City which provides full health services to pilgrims and has expanded its cardiac catheterization program and heart surgeries. In addition, it has several departments of Intensive Care and large quantities of different types of blood in the blood bank (MOH, 2015).

Role of the SRCA in the Hajj. SRCA also has a particular role to play during the Hajj to service the pilgrims. In 2016, the SRCA had established 110 ambulance stations in the holy sites (Arafat, Mizdalafah, and Mina) and along the roads leading to them (IFRC, 2016). Six seasonal ambulance stations were established along the express roads used by pilgrims to reach the Grand Mosque. In addition, 290 ambulances and 25 motorbikes were used to provide fast services to pilgrims. Finally, 100 doctors, 1550 paramedics, technicians and first responders were recruited to work for SRCS during Hajj (IFRC, 2016) 
In 2012, two weeks before the Hajj, the SRCA deployed an additional 300 ambulances, 20 advance life support response vehicles, 25 motorcycle units and 100 mobile teams of physicians as part of the Hajj prehospital emergency care services, as well as 1,750 EMS providers and 600 volunteers to respond from 26 ambulance stations (D’Alessandro et al., 2013). That same year during Hajj, the SRCA answered 57, 420 calls from dispatch for assistance, and undertook 20, 210 responses, providing medical care to 18,230 patients, of which $34 \%$ were transported to hospitals and 39\% were treated and released at the scene (D'Alessandro et al., 2013).

\section{History of the Hajj disasters}

With 2-3 million Islamic pilgrims attending the Hajj in Saudi Arabia each year, there are frequent deaths and injuries among the pilgrims in their journey from Arafat to the Great Mosque in Mecca. Table 4 shows the statistics related to deaths and serious injuries for the years from 1975 to 2007 (Al-Ahmadi et al., 2013). In the Hajj of 1975, a fire broke out in one of the pilgrim's tents in Mina. It quickly spread to other tents and caused the explosion of a gas cylinder, resulting in the death of 200 pilgrims (Alamri, 2011). In 1990, pedestrians trapped in a tunnel, leading to 1,426 deaths (Soomaroo, Murray, 2012). More than 1,000 pilgrims died in stampedes on the Jamarat Bridge between 1994 and 2006 (BBC News, 1998; BBC News, 2001; BBC News, 2003; BBC News, 2004; (Ahmed, Barbeschi, \& Memish, 2009; Yaseen M. Arabi. \& Sameer M. Alhamid., 2006)

Working during the Hajj in any capacity is a very unique and challenging situation due to the enormous crowds speaking multiple languages from different regions in the world, each with idiosyncrasies in hygiene, culinary habits, and other customs. Healthcare 
providers, in particular, are usually faced with an overload of admissions at any time. Because the Hajj is a once-in-a-lifetime and expensive religious obligation, many pilgrims are elderly and already sick (Shujaa \& Alhamid, 2015). It is sometimes difficult to find interpreters who understand the particular language of the patient (Shujaa \& Alhamid, 2015). As communication is key to helping the patient, this presents a challenge for medical staff. This wide diversity of the groups can also present additional problems, such as having to track outbreaks of certain diseases in pilgrims from certain regions. Because the event takes place outside in soaring temperatures, often in harsh conditions, and over several days, participants and staff can become ill. Patients frequently experience upper respiratory tract infections. Other illnesses such as asthma and chest pain are also frequent, creating further difficulties for medical staff who must treat multiple cases of severely ill people during the event while facing difficulties in transportation, re-supply, and refrigeration. It should be noted that other serious challenges can occur in the Hajj such as stampedes, natural disasters, weather concerns, in addition to the medical results of overcrowding.

\section{Table 4.}

Stampedes and Fires during Hajj.

\begin{tabular}{|l|c|c|c|}
\hline \multicolumn{1}{|c|}{ Type of Incidents } & Date of Incident & Deaths & Injuries \\
\hline $\begin{array}{l}\text { An exploding gas } \\
\text { cylinder caused a fire in a } \\
\text { tent community }\end{array}$ & December 1975 & 200 pilgrims & $\begin{array}{c}\text { Data not } \\
\text { available. }\end{array}$ \\
\hline $\begin{array}{l}\text { A stampede inside a } \\
\text { pedestrian tunnel (Al- } \\
\text { Ma'aism tunnel) }\end{array}$ & July 2, 1990 & 1,426 pilgrims & N/A \\
\hline $\begin{array}{l}\text { A stampede at the } \\
\text { stoning of the Devil ritual }\end{array}$ & May 23,1994 & 270 pilgrims & N/A \\
\hline A tent fire in Mina & April 15, 1997 & 343 pilgrims & 1,500 injured \\
\hline
\end{tabular}




\begin{tabular}{|l|c|c|c|}
\hline $\begin{array}{l}\text { A stampede at Jamarat } \\
\text { Bridge }\end{array}$ & April 9, 1998 & 118 pilgrims & 180 injured \\
\hline $\begin{array}{l}\text { A stampede at the } \\
\text { stoning of the Devil ritual }\end{array}$ & March 5, 2001 & 35 pilgrims & N/A \\
\hline $\begin{array}{l}\text { A stampede at the } \\
\text { stoning of the Devil ritual }\end{array}$ & February 11, 2003 & 14 pilgrims & N/A \\
\hline $\begin{array}{l}\text { A stampede at the } \\
\text { stoning of the Devil ritual }\end{array}$ & February 1,2004 & 251 pilgrims & 244 injured \\
\hline $\begin{array}{l}\text { A stampede at Jamarat } \\
\text { Bridge }\end{array}$ & January 12, 2006 & 346 pilgrims & 289 injured \\
\hline A stampede at Mina & September 24, 2015 & 769 pilgrims & 934 injured \\
\hline
\end{tabular}

Sources: BBC News, 1998; BBC News, 2001; BBC News, 2003; BBC News, 2004; (Ahmed et al., 2009; Yaseen M. Arabi. \& Sameer M. Alhamid., 2006); Khan and Noji, 2016.

\section{Statement of Problem}

Officials in Saudi Arabia have expressed significant concern regarding disaster management, as evidenced by the great increase in health care providers in the private and public health sectors, in particular in EMS providers in the Hajj season. Currently, there is no national master plan for disaster management in Saudi Arabia (Al-razeeni, 2015) and there is a lack of literature on the provision of EMS during Hajj (Ahmed et al., 2009). A knowledge of disaster preparedness is essential for all health care professionals and is a key concept in disaster management. At present, most healthcare workers in Saudi Arabia lack experience in disaster planning and practical experience responding to disasters (Lund, Gutman, \& Turris, 2011). To assess the knowledge about disaster preparedness before mass gatherings among the different levels of EMS providers (i.e., first responder, EMS-technician, EMS-paramedic and physician) during the Hajj, based on qualification (level of education, training, years of experience, level of EMS, current EMS training was received), it is important to know which areas of disaster preparedness need improvement 
by training or continuing education. No previous study was found that assessed the knowledge of disaster preparedness for mass gathering in EMS providers during the Hajj.

\section{Purpose of the Study}

This study has three main goals: 1) to assess the knowledge regarding mass gathering disaster preparedness among EMS providers during Hajj of 2016;2) to explore the relationship between the demographic variables (age, level of education, working experience, previous disaster education/training and number of trainings) and the knowledge about disasters among EMS providers during Hajj 2016; and 3) to explore the sources of the knowledge about disasters that EMS providers have. This study has the potential to add to SRCA's capability to respond more effectively and competently to disastrous events.

\section{Research Questions and Hypotheses}

This research aimed to provide answers to the following questions:

1. Is there a significant difference in the knowledge of disaster preparedness for mass gatherings (DPMG) between different categories of SRCA-EMS providers based on their age?

H01: There is no significant difference in the knowledge of DPMG between different categories of SRCA-EMS providers based on their age.

Ha1: There is a significant difference in the knowledge of DPMG between different categories of SRCEMS providers based on their age.

2. Is there a significant difference in the knowledge of DPMG between different categories of SRCA-EMS providers based on their level of education? 
H02: There is no significant difference in the knowledge of DPMG between different categories of SRCA-EMS providers based on their level of education.

Ha2: There is a significant difference in the knowledge of DPMG between different categories of SRCA-EMS providers based on level of education.

3. Is there a significant difference in the knowledge of DPMG between different categories of SRCA-EMS providers based on their level of EMS (professional classification)?

H03: There is no significant difference in the knowledge of DPMG between different categories of SRCA-EMS providers based on their level of EMS.

Ha3: There is a significant difference in the knowledge of DPMG between different categories of SRCA-EMS providers based on their level of EMS.

4. Is there a significant difference in the knowledge of DPMG between different categories of SRCA-EMS providers based on the sector of EMS training received?

H04: There is no significant difference in the knowledge of DPMG between different categories of SRCA-EMS providers based on the sector of EMS training received.

Ha4: There is a significant difference in the knowledge of DPMG between different categories of SRCA-EMS providers based on the sector of EMS training received.

5. Is there a significant difference in the knowledge of DPMG between different categories of SRCA-EMS providers based on years of experience?

H05: There is no significant difference in the knowledge of DPMG between different categories of SRCA-EMS providers based on years of experience.

Ha5: There is a significant difference in the knowledge of DPMG between different categories of EMS providers based on years of experience. 
6. Is there a significant difference in the knowledge of DPMG between different categories of SRCA-EMS providers based on previous disaster education/training, the number of trainings and the number of hours of training?

H06: There is no significant difference in the knowledge of DPMG between different categories of SRCA-EMS providers based on previous disaster education/training, number of trainings and number of hours of training.

Ha6: There is a significant difference in the knowledge of DPMG between different categories of SRCA-EMS providers based on previous disaster education/training, number of trainings and number of hours of training.

7. Is there a relationship between the source of knowledge and knowledge acquired regarding DPMG among different SRCA-EMS providers in Hajj of 2016?

H07: There is no relationship between the source of knowledge and knowledge acquired regarding DPMG among different SRCA-EMS providers in Hajj of 2016.

Ha7: There is a relationship between the source of knowledge and knowledge acquired regarding DPMG among different SRCA-EMS providers in Hajj of 2016.

\section{Definitions of Key Terms}

Ministry of Health (MOH): The health department of Saudi Arabia, responsible for healthcare services to citizens and visitors in the country. The Ministry seeks to improve the quality of treatment in the various healthcare sectors, in general hospitals, and during public events such as hajj.

Mass gatherings: These are events where more than 1000 people are congregated at a specific location for a defined period of time (WHO, 2008). 
Hajj: The annual Hajj pilgrimage, one of the world's largest gatherings, for which several millions of people flock to Mecca, Saudi Arabia, to participate in one of the Islam's five pillars of faith.

Training: It procedures for solving the problem through transmitting and receiving the information (Halloran \& D’ouglas, 1987).

Workshop: A meeting of a group of people who share a concern in order to improve their knowledge or skills in a specific area (Akdeniz, 2016).

Disaster drill: "An exercise of demonstration, that tests the readiness and capacity of a hospital, a community, or other system to respond to a public health emergency or other disaster “(U.S. Department of Health and Human Services, 2012).

Medical first responder: "Local emergency medical personal who first arrive on the scene of an incident and take action to save live, protect personnel, and meet basic human needs" (Jester, 2013. Page, 19).

Emergency Medical Technician: "A health-care specialty with skills and knowledge in prehospital emergency medicine" (California Governor's Office of Emergency Services, 2006).

Paramedic: An individual with level of training other than doctors, nurses or physician's assistant, who provides advanced life support, transport and emergency medical care (Wine, 1999).

Disaster Medical Assistance Teams: A team comprised of civilian volunteer medical providers who are part of a National Disaster plan in the USA (Key, 1994). 


\section{CHAPTER II \\ LITERATURE REVIEW}

\section{Mass gatherings}

\section{Definitions}

The concept of a group of people coming together to celebrate, worship, or experience has been often put into practice around the world as people enjoy and gather in mass proportions. Although there are multiple definitions of mass gatherings, the general estimated size ranges from 100 to 25000 people collected in one location (LocohDonou et al., 2013). According to Jaslow, Yancy, and Milsten (2000), however, a mass gathering involves at least 1000 persons at a specific location at the same time. Other definitions are based on the medical perspective: a mass gathering is one large crowd of people which can lead to a delay in emergency response or a difficulty to access any kind of necessary treatment (Paul Arbon, 2004; P. Arbon, 2007). The duration of a mass gathering can be anywhere from one hour to several days, weeks or even months.

Most studies on mass gatherings consist of retrospective descriptive, prospective observational, and planning guidance publications (P. Arbon, 2007; Kathrtn M. Zeitz, 2002; Milsten, Maguire, \& Bissell, 2002). Prospective observational studies are few and mostly attempt to validate retrospectively-derived results (Zeitz, Zeitz, and Arbon, 2005) or evaluate interventions, using comparisons of two populations at the same event, (Morimura, Katsumi, Sugimoto, Fuse, Asai and Yamamoto, 2004) or real "historical controls" from retrospective data. It is also relevant to consider the demographics of 
those attending mass gatherings, the duration of the event, current public health systems in place, as well as the analysis of risk assessments and comparison with similar countries and histories. The extant literature present on mass gatherings usually focuses on a few major events held each year and the systems in place to support those attending the events. Thackaway, Churches, Fizzell, Muscatello, and Armstrong (2009) argue that mass gatherings should be analyzed according to political, religious considerations, event durations, geographic spread, and number of international visitors.

\section{Studies on mass gatherings}

The history of mass gatherings is essential to understanding the steps which have been taken with the objective of ensuring safety and efficient medical care. It is useful also to understand how gatherings have changed, and what can be done to further improve the systems. In one memorable instance, a mass gathering occurred only once, but it was the largest in world history: that of the 2010 World Exposition in Shanghai, China. In a special report on public health preparedness for the event, Yi et al. (2012) explain the actions taken by the Shanghai Municipal Center for Disease Control and Prevention in preparing and responding to health impacts during the event. The exposition lasted for six months, in a venue of 5.28 square kilometers. Because the event took place over a long period of time, had a great number of people present, and carried the risk of high temperatures and typhoons, it created great challenges for safety and health (Yi et al.). It is common for countries hosting large mass gatherings to call on other nations for help in preparedness. In this instance, China and the United States collaborated to develop an approach, including training and technical assistance related to public health emergency management, risk assessment, as well as emergency operations 
planning and disaster exercises (Yongchao, Qinneng and Yi, 2011; Jin, Ljungqvist and Troedsson, 2010). Security groups were built as internal organizational structures, with public awareness campaigns in China, focusing on technical needs and the capacities for laboratories, as well as vaccinations. An extensive risk assessment was conducted to consider public health security needs, emergency exercises, health education and intervention.

Additionally, travel tip handbooks were distributed to travelers and health hotlines were activated (He et al., 2011). With great political cooperation, a careful and effective preparation led to a successful mass gathering with a clear organizational structure and job responsibilities for all.

Looking at mass gatherings and the availability of medical care, other researchers have worked to analyze events and the efficiency of care for the people present. Sanders, Criss, Steckl, and Meslin (1986) conducted an assessment of events at 15 facilities, using surveys to question facilitators about the events and the accessibility of medical care for planned mass gatherings. During survey collection, researchers used telephone calls and patient encounter logs to determine levels of injury and additional information about medical care at the events. One of the issues that arose within the research was the lack of patient encounter logs at some facilities. It also appeared that medical care varied according to the type of event, revealing a lack of standardization in the care provided. For example, researchers found that football arenas generally planned for emergency health care fully, with the presence of physicians, nurses, and EMS providers, whereas the baseball stadium had no emergency health care plan (Sanders et al., 1986). Each venue controls its own medical personnel and facilities, allowing sponsors to control 
what type of medical care to be provided and the level of efficiency they feel is necessary for the event.

In a 2012 study, which excluded extreme weather and environmental disasters, Soomaroo and Murray focused on 21 disasters that happened at mass gatherings throughout the world between the years 1971-2011. The authors analyzed the 21 events and categorized the main learning points into 5 key areas as seen in Table 6 .

\section{Table 2.1}

Five Key Areas related to Mass Gathering

\begin{tabular}{|c|}
\hline Five Key Areas related to mass gathering \\
\hline Overcrowding and Crowd control \\
\hline Fire Access points \\
\hline Fire Safety Measures \\
\hline Medical Preparedness \\
\hline Emergency Response \\
\hline
\end{tabular}

Overcrowding, the main issue identified by the researchers, was found to be improved by several measures that included pre-planning and the creation of seats instead of allowing people to stand.

In a study by Kishore and Soulieres (2012), as part of the Applied Research and Innovation Center, spontaneous behavior at mass gatherings around Toronto was explored as a factor in events that occurred in the area, as well as to gauge awareness of risks within mass gatherings. The study covered the period which included Toronto's G20 insurgence as well as Vancouver's Stanley Cup riots. The authors considered an 
important shift in the safety of mass gatherings- the use of social media. They conclude that social media can cause spontaneous human behaviors and therefore "event crisis and subsequent crowd control has become both a flaming challenge and a matter of public safety and security concern" (Kishore \& Soulieres, 2012, p.5). The results of a survey in which 3500 people were asked about their biggest concerns at mass gatherings indicated that the public is mostly concerned by the twin challenges of safety and security. Below, the graph illustrates the results of the survey which indicate that the public is most concerned by safety and least concerned with property, environment, and public image.

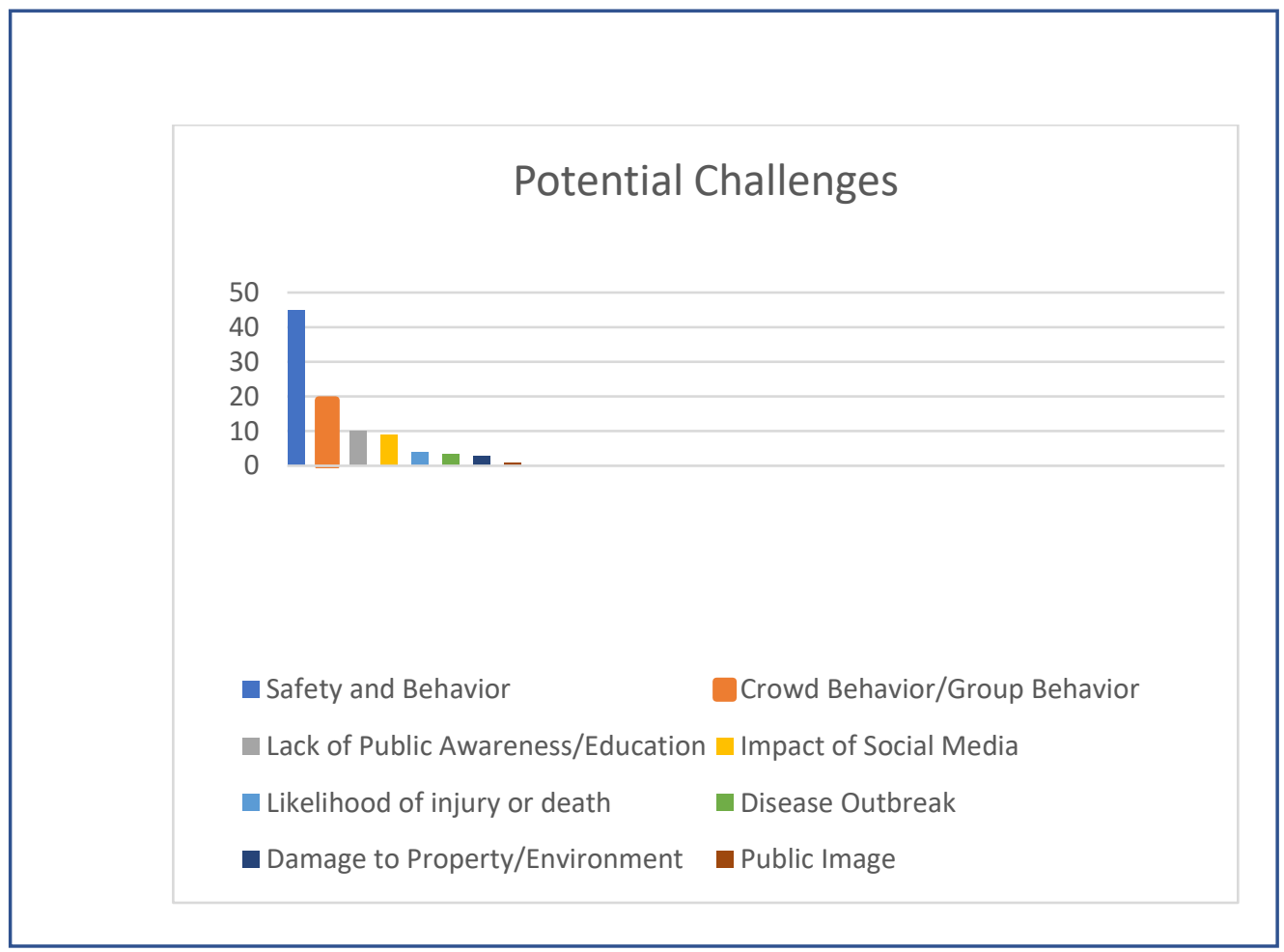

Figure 2.1. Potential Challenges Posed by Mass Gatherings (Kishore \& Soulieres, 2012).

Three fourths of respondents concurred that the most attention should be paid to event planning and response, rather than to public health (preventing disease and threats to health) or health care (hospital, clinics, medical care). The authors of the survey also 
asked about influencing factors for big crowds, with most agreeing that drugs, alcohol, and a rush for seats were by far the most important concerns. Other issues, such as traffic density and access to basic supplies, ranked much lower (Kishore \& Soulieres, 2012). These studies, emphasize the role of medical care for those involved in the mass gathering experience, to include transport for patients from the venue to the hospital, or treatment provided in the on-site facilities (Paul Arbon, 2010; Gutman, Lund, \& Turris, 2011; Yancey, Fuhri, Pillay, \& Greenwald, 2008). Overall, results from the various studies revealed that public concern and perception can be managed through proper safety and awareness, emergency response planning, and corrective actions after safety review (Kishore \& Soulieres, 2012).

\section{Disaster preparedness for mass gatherings}

According to Gebbie and Qureshi (2002), the first step towards preparedness for disaster is the identification of which health care providers should be knowledgeable about the risks, and also which role each provider is expected to play in case of a disaster. Most of studies about disaster preparedness concern health care providers, especially nurses (Al-khalaileh, Bond, Alassad, 2012; Duong, 2009; O’Sullivan et al., 2008; Arbon et al., 2013; Tichy, Bond, Beckstrand and Heise, 2009; Yin, He, Arbon, and Zhu, 2011). There are many variables in the level of disaster preparedness of health care workers such

training, types of training, providers' experience, level of education, as well as the sources of any knowledge they might possess.

One of the earliest studies, undertaken by the Arizona chapter of the American College of Emergency Physicians, was a study of the medical care at 15 venues for public events. Results indicated deficiencies in the documentation of medical cases treated at 
the scene, and also exposed that some EMS providers had attempted medical assessments without consulting physicians (Sanders, Criss, Steckl, \& Meslin, 1986) Overall, the study provides further evidence of a need in standardization for mass gatherings and the reality of medical problems that can occur when issues, such as poor documentation and lack of physician evaluation, take place at events. One conclusion drawn by the researchers was that event organizers have the responsibility of supporting the events by providing emergency medical services for attendees (Sanders, Criss, Steckl, \& Meslin, 1986). According to their findings, additional work is needed to ensure safety and medical preparedness for those attending mass gatherings.

Furbee et al. (2006) compared the training protocols of rural EMS providers to their actual response efforts performed during a disaster. To this effect, the researchers surveyed 768 rural EMS agencies in the U.S. federal emergency Agency (FEMA) Region 3 and FEMA Region 8, plus four other western states in the United States, as suggested by the Critical Illness and Trauma (CIT) Foundation of Bozeman, Montana. Respondents were asked to comment on their self-assessment of preparedness and their actual experiences in a disaster response (Furbee et al., 2006). Thirty-eight percent of rural EMS providers indicated that a mass-casualty incident had overwhelmed them during the past two years, $24 \%$ responded that their disaster plan had been activated during the past two years, and $26 \%$ of respondents had helped the state to declare disaster. Only $4 \%$ had ever worked with a Disaster Medical Assistance Team (DMAT) and only 3\% had worked with a Civil Support Team (CST) although, 8\% had worked a Community Emergency Response Team (CERT) in a disaster response within the past two years. The respondents reported that most of their training had focused on terrorism, outbreaks of infectious 
diseases, riots, bombings, and earthquakes, whereas they received little training on weather emergencies and other common events. In addition, $74 \%$ of participants reported a significant decline in training after September 11th, 2001, especially in training for serious weather incidents of all types (Fubee, Coben, Smyth, Manley, Summers, Sanddal \& Kocsis, 2006). On the other hand, when asked about their training needs, the respondents listed their top five priorities to be training for general disaster, advanced life support, the incident command system, scene safety, and triage. The most important implication of the study was disconnected between the actual experiences of rural EMS organizations and their expectations based on their training.

The results of this study indicated a need for organizations to evaluate their current level of preparedness with a view to improving it, in order to prepare their providers to deal with real disasters. Rural EMS providers need to receive training that is efficient and adequately prepares them to deal with the most common disaster scenarios, in particular in the areas of (1) communications (2) command and control and (3) interagency cooperation (Fubee et al., 2006).

The next year, 2007, saw the publication of a pilot study by Slepski to assess the background knowledge and skills of healthcare providers who had worked in the responses to Hurricanes Katrina and Rita. Two hundred healthcare providers were surveyed at two disaster conferences. The instrument included open-ended questions about the knowledge and skills needed during the disaster responses. Thirty-seven percent of the respondents were registered nurses, $24 \%$ were physicians and $10 \%$ EMTs. Most of respondents reported having 15 or more years of experience in the health care system and knew their role as health care providers. Twenty-two percent reported that 
they did possess a specific skill that had become necessary for the disaster situation. The respondents offered the recommendation to expand the scope of practice by adding some specific courses such as advanced cardiac life support, triage, basic skills, first aid, and wound care. Another recommendation was to improve their "hands-on" clinical skills and group training by, for example, drills and exercises. A third recommendation proposed by the respondents was that health care providers have better personal preparedness. They should prepare themselves and their families mentally for any hardship, in order to be ready to take on any role during the response. Some weaknesses of the study were that the population sampled was very small, and no information was provided about the percentage of EMS providers, even though these are essential to disaster preparedness. Because health care providers have different backgrounds in education and experience, generalization of the results was limited.

A further study by Studnek and Fernandez (2008), supported the conclusion that EMS providers were lacking in preparedness for disasters. For the first time, this research documented the relationship between EMS providers based on community size (rural, urban), and the various types of organizations (e.g., fire department, volunteer EMS, industrial response, other). The researchers surveyed 872 National Registered EMS providers to enquire how many had received training in the management and treatment of patients from chemical, biological, radiological, nuclear or explosive (CBRNE) events as well as structural collapse during the last 24 months. The results revealed that $39.7 \%$ of providers had not received any training on CBRNEs, $48.4 \%$ of NR-EMS providers reported no training in the treatment and management of patients involved CBRNEs, $72.1 \%$ of NR-EMS providers reported not participating in multi-agency disaster drills 
that included scenarios involving CBRNEs. Most importantly, most of NR-EMS providers reported no training within the previous 24 months on disaster preparedness. The study showed that NR-EMS providers who worked in urban areas had received more training than those who worked in rural areas. Also, the NR-EMS providers who worked in urban fire departments were 5.42 times more likely than EMS providers to have received CBRNE training. Results suggested that NR-EMS providers need more training on CBRNEs and other types of training related to disasters. One weakness of the study was that the study did not document the quality of training provided to NR-EMS providers and another was that no questions were asked about the respondents' previous experience in disaster situations.

Still another study conducted in Germany by Fischer et al. (2008), showed good disaster preparedness but a lack of knowledge about nuclear, biological, and chemical (NCB) incidents among emergency physicians, assistants and paramedics. To assess the current state of disaster preparedness of emergency physicians and paramedics for mass casualty incidents (MCI) and (NCBs) among three levels of emergency service professionals as mentioned above. One thousand seven hundred and seven professionals were surveyed, and their levels of knowledge were compared. Most of the participants considered themselves ready for disaster, as $79 \%$ of paramedics had already participated in MCI drills and $88 \%$ of them knew their roles in case of a disaster. However, $46 \%$ of those surveyed did not know the types of injuries that could be expected and how to treat them after a terrorist attack or a NCB contamination, and how to treat them. Germany has a good system for disaster preparedness because, first, the average age of physicians, chief emergency physicians, and leaders of organizations is older than emergency 
assistants and paramedics and they had better training and more experience. A second reason for Germany's good preparedness is that the German Association for Disaster Medicine has developed a curriculum to train medical students to be implemented at all German universities.

In 2009, Duong surveyed 152 South Australian nurses on their disaster education or training, disaster awareness, their confidence in their ability to respond to a disaster, and their previous experience. The most significant result was that $95 \%$ of respondents agreed that although disaster education for emergency nurses was important, limited education opportunities and little previous disaster response experience might be responsible for a lack of confidence and disaster awareness among emergency nurses in South Australia. Sixty-three percent of health professionals surveyed had never been involved in a disaster response in their professional life. The researchers concluded that a good standard of education as well as experience in disaster response are important for health care providers' confidence in their ability to be effective during a disaster.

While it is necessary for health care organizations to be prepared to respond to a disaster, it is important to recognize certain factors that affect the level of preparedness. Lim, Lim, and Vasu in 2013 reported the factors affecting the perception of health care providers with regard to individual and organizational preparedness for disaster and their willingness to attend disaster response training in Tan Tock Seng Hospital in Singapore. Three categories of health care providers were surveyed; doctors, nurses, and allied health workers, for a duration of two months in 2010. Respondents were asked to comment on five areas; leadership preparedness, prior experience, training, peer experience, and family support. The majority of respondents, $80.7 \%$ were willing to 
attend a future disaster incident response training, although only $27.8 \%$ knew how to access these training opportunities. Seventy-four percent felt that being able to respond to disasters fell within their professional capabilities. Results indicated that most health care professionals were not confident in their abilities to respond in case of a disaster, even though they demonstrated a willingness to learn.

Fernandez et al. (2011) surveyed nationally certified EMT-basic and paramedics to assess the amount of training in terrorism and disaster preparedness as well as to know how many had participated in multi-agency disaster drills across the USA. Also included in this study was an evaluation of the correlation between providers' perception of preparedness and the amount of hours training they had received. Results showed that $91 \%$ of EMS providers reported receiving at least 1 hour of disaster preparedness training in the last 24 months. Also, $53 \%$ of respondents had not participated in multi-agency disaster drills with scenarios involving explosive materials or structure collapse in the previous 24 months. Only $38 \%$ of respondents felt ready for any disaster scenario. The study found a significant relationship between hours of training and self-perceptions of preparedness for all types of disasters, including the management of patients exposed to $(\mathrm{BCN})$ events or structural collapse. Finally, the study revealed that the majority of respondents had received less than 1 hour of training in the treatment of patients involved in a structural collapse, and $40 \%$ of respondents had not participated in any multiagency disaster drills in the previous 24 months. The strength of this study was a deep exploration of the preparedness of EMS providers and their understanding of the need for training in disaster management. Because there exists no national standard for training in disaster preparedness, and because training in disaster preparedness is a requirement for 
EMS providers in the US, the practice of how EMS provider organizations manage differs from state to state (NREMT, 2011; Slepski, 2007).

In Jordan, a 2011 study by Al-Khalailh, Bond, and Alasad investigated registered nurses' perceptions of their knowledge, skills, and preparedness for disaster. Using the Arabic version of the DPET, or Disaster Preparedness Evaluation Tool (Tichy et al., 2009), 474 RNs randomly selected from the Jordanian Ministry of Health hospital and two university hospitals were surveyed. Three areas were measured: the pre-disaster preparedness, the mitigation, and the recovery stage of disaster. The pre-disaster preparedness scale measured preparation for disaster and consisted of 25 statements covering knowledge, disaster skills and personal preparedness. The participants were asked to rate their degree of agreement with the statement. The mitigation scale measured response to disaster and consisted of 14 statements covering knowledge and patient management. The recovery scale, measuring post-disaster, consisted of 6 statements covering both knowledge and management.

According to Al-Khalailh, Bond, and Alasad (2011) sixty-five percent of the respondents considered their current disaster preparedness weak, 18\% rated it as medium, $12 \%$ thought it good, and 5\% felt their preparedness was very good. When respondents were asked about their sources of knowledge, $31 \%$ responded that they had obtained their knowledge from undergraduate programs, $8 \%$ from graduate nursing programs, $31 \%$ from facility drills, $22 \%$ from continuing education courses, while $11 \%$ had participated in a real disaster. Most of the respondents, $91 \%$, wanted to learn more about their role in a disaster. The researchers concluded that the knowledge and skills for disaster preparedness in Jordanian RNs needed to improve, and recommended to include disaster 
preparedness courses in the curricula of health care providers, as well as an increase in training and mock disaster drills.

Another study in north Jordan assessed health care providers who worked in primary health centers about their perceptions of their knowledge, skills, and preparedness for disaster management. Using the same survey instrument as the previously mentioned 2011 Al-Khaleilh study in Jordan, Al-Ali and Abu ibaid (2015) surveyed 207 physicians and nurses from 57 health centers. The results indicated that physicians were more knowledgeable and had more skills for disaster management than nurses. Also, $10.6 \%$ of the health care providers reported having experienced a real disaster. Data from the study showed that the majority of participants considered themselves only moderately prepared for disaster management with weak to moderate skills for disaster management. About a third of the participants reported acquiring their knowledge and training from their undergraduate education, 13\% from their graduate studies, $24 \%$ from continuing education courses. Most of them, 37.7\%, had acquired their knowledge and skills from facility drills. Researchers concluded that $80 \%$ of respondents needed more education about their role, scope and skills in disaster situations, $67.6 \%$ needed addition education about potential disaster risks in their communities, and $66.2 \%$ needed further education about resources in their communities such as referral agencies, emergency contacts, chains of command and community shelters.

It should be noted that no research was found to assess EMS providers during mass gatherings, specifically in Saudi Arabia during the Hajj. 


\section{The mass gathering of the Hajj}

The Hajj is known as a major gathering where millions of people come to Western Saudi Arabia from a variety of countries around the world to perform rites simultaneously in a single area (Khan \& Noji, 2016). It is regarded as one of the largest recurring religious mass gatherings in the world, with numbers of travelers increasing each year. The Hajj also has a history of disasters. Much research has been done on Hajj as a mass gathering and how to ensure safety and medical effectiveness for such a large event. A crucial problem at mass gatherings is the issue of event access points, which must be considered during the Hajj when enormous numbers of people congregate inside the city of Mecca. In the Hajj of 1990, a stampede caused the death of 1,426 people when crowds of pilgrims spontaneously attempted to leave Mecca through one exit. In 2006, Ahmed, Arabi, and Memish researched the 1990 incident and found that medical crews had been unable to reach the injured as access to the sites was not adequate, which suggested a future emphasis on access for EMS and medical services at events.

Soomaroo and Murray (2012) suggested that a key factor in improving on-site medical care is to involve the hospital beforehand with planning for the event. For example, they argued that without planning, hospitals may have no major incident plan, become overwhelmed, lack a hospital command center, and may need staff reinforcements. It is necessary to address in advance a lack of organization in medical teams, the presence of the media, and a lack of support for neighboring hospitals.

Gaffer, Achmadi, and Patellongi investigated deaths among Indonesian pilgrims during the Hajj, with the aim of formulating proposals to limit future deaths at the mass gathering. It was found, that seventy percent of Indonesians who died were 60 years old 
or over (Gaffar, Achmadi, Syamsu \& Patellongi, 2013), leading one to question whether it is appropriate to assume that mass gatherings can cause deaths, or rather that because there is a mass grouping of many people, death is inevitable, especially in elderly participants. This study, while not very long extensive, is significant because it addressed a particular demographic, analyzing that group's needs and unique health issues. The Gaffar et al. study can be utilized for other mass gatherings, looking not only at age group demographics, but also at particular countries and their travelers.

Another possible cause of health issues during Hajj is the presence of infectious diseases, particularly the respiratory syndrome Coronavirus (MERS-CoV) which has made an appearance during the last few Hajj events. Al-Tawfiq and Memish (2014) explored the Hajj with regards to risk assessment, by reviewing the current medical infrastructure and highlighting key features in the impact of viruses as well as the plans for preparedness. In reviewing Al-Tawfiq and Memish's work, it was important to note their ideas about appropriate mass gathering preparedness. It is argued that risk assessment, robust surveillance and response (WHO, 2014) are most essential to public health efforts for the Hajj. Information technology such as a local area network is used during the Hajj to conduct surveillance, allowing for an analysis of data to help decisionmaking(J. Al-Tawfiq \& Z. Memish, 2014). With information technology, data can be analyzed much faster and more efficiently than before. As technology, has continued to improve medical preparedness for the Hajj, devices such as the Ambulance Information System (AIS) and the Automatic Vehicle Location (AVL) have proved invaluable. The AIS enables EMS providers to document all medical procedures performed for a patient in the ambulance, and to send the data to the hospital by the Internet. The AIS also can 
estimate the time until the ambulance will arrive to the hospitals. The AVL is a device that enables dispatch to determine the location of an ambulance and to guide it to the hospital by map with live traffic densities (Memish and Al-Rabeeah, 2014).

Saudi Arabia, like any country prone to disasters, has been keen to assess health care providers. Al-Thobaity, Plummber, Innes, and Copnell (2015) surveyed 396 nurses about their knowledge and skills, as well as the sources of their knowledge, related to disaster management in Saudi Arabia. The participants were nurses in emergency departments, in critical care and in surgical units of government and military hospitals in three cities in Saudi Arabia: Taif, Jeddah and Tabuk. The sample inclusion criteria were to hold at least a 3-years diploma in nursing, to be at least 18 years old, have a minimum of one year's experience, and be able to read and write English. Although the nurses in military hospitals appeared more knowledgeable than those who worked in government hospitals, the study revealed that nurses in Saudi Arabia have a moderate knowledge of disaster preparedness as well as the desire to learn more about it. The majority of respondents (71\%) had acquired their knowledge from disaster drills, $47 \%$ from continuing education, $29 \%$ from graduate courses, $27 \%$ from undergraduate courses, and $26 \%$ from being involved in actual disasters. The researchers concluded that nurses in Saudi Arabia need more training about their role in a response to a disaster and were eager for more education in all types of disaster management, both of which can be acquired during disaster drills.

One of the first studies to explore Saudi EMS students' perception regarding their preparedness for disaster management was undertaken by Alrazeeni in 2015 with students of 3rd, 4th and 5th years in the Prince Sultan Bin Abdulaziz College for 
Emergency Medical Services (PSCEMS). This descriptive cross-sectional survey involved a convenience sample of 150 students. The instrument used was the Arabic version of the one used with the nurses (Al-Khalailh et al., 2011). The study provided answers to three research questions; "1) - What knowledge do Saudi EMS students have about disaster management? 2) - What skills do Saudi EMS students have for disaster management? 3) - How do Saudi EMS students perceive their preparedness for disaster management?" (p.111).

The main finding of the study was that Saudi EMS students have inadequate knowledge and skills for disaster preparedness. The mean of Saudi EMS students' knowledge ranged from 2.50 to 3.40 , and the mean of their skills ranged from 2.40 to 3.87. As expected, students in their 5th year displayed higher knowledge and skills than those in 3rd and 4th years. The participants in the study believed that a combination of disaster courses in EMS curricula with practical training would help them to prepare for disasters. The researcher concluded that the Saudi EMS students in PSCEMS needed more training, knowledge and skills and that the undergraduate curriculum should be modified to provide them.

A further cross-sectional study to assess the knowledge of disaster preparedness of health care workers was undertaken by Alzahrani and Kyratsis (2015) with 106 emergency department nurses in government hospitals during the Hajj season in Mecca. Data was collected about five areas: their knowledge and awareness of disasters, their understanding of the role of emergency nurses during mass gatherings, their education and training about disasters, their level of awareness of the department's major incident plan, and their previous experience in disaster response. Of the nurses surveyed, only 
$34 \%$ correctly reported that most victims from a disaster are transported to the hospital by Saudi Red Crescent, only 32\% correctly knew that disease and epidemics often result from the disruption and poor health caused by a major disaster, and only $29 \%$ of the respondents knew that poor people are more affected by disasters than the rich. Furthermore, $20 \%$ of the emergency department nurses knew that, after a disaster at a mass gathering, un-buried dead bodies would cause epidemics and only $16 \%$ were aware that all victims of CBR (chemical, biological, radiological) incidents would need to have dangerous substances removed from their bodies prior to arrival at hospital. Researchers concluded that knowledge and awareness among emergency nurses about Hajj disasters was insufficient. Concerning the role of emergency nurses during mass gatherings; $38 \%$ of respondents reported their role during mass gathering was providing general assessment and caring for patients, $26 \%$ of respondents indicated that their role was performing triage, $26 \%$ doing CPR, $14 \%$ saw their roles as providing leadership, while $1 \%$ felt their role was to provide psychological care. All the respondents reported that they had received limited training about disaster preparedness for mass gathering. Some $34 \%$ of respondents had attended training in the previous $6-12$ months, $23 \%$ had been trained in the previous $12-24$ months, and $43 \%$ had been trained more than 2 years previous to the survey. The emergency nurses had acquired their knowledge about disasters from various sources; $43 \%$ from hospital education sessions, $27 \%$ from government-sponsored emergency management courses, and 11\% from mini-courses offered by private schools.

Alzahrani and Kyratsis (2015) reported that, shockingly, 53\% of the emergency nurses in Mecca had not read the major incident plan, and some of them were not aware 
of its existence. However, 99\% of participants had had prior experience of some type of disaster response. Among them, 47\% had experienced disasters caused by fire, $24 \%$ had participated in the transport of patients from disaster situations, $22 \%$ had experienced disaster caused by a building collapse, $16 \%$ had been involved in a disaster caused by food, $12 \%$ had responded to a stampede, $12.3 \%$ to an epidemic outbreak, $9 \%$ to a biological or chemical disaster, and 7\% had experience of response to other kinds of disasters. Nevertheless, the researchers concluded that emergency nurses in Mecca public hospitals displayed a lack of knowledge of disasters but, due to their experiences, had a high level of awareness of their roles.

\section{Summary}

There is still much work to do in assessing and preparing for safety at mass gatherings. At present, no international standards are clearly defined, and guidelines for disaster preparedness training do not exist (Rudman, Clarke \& Metzl, 2003; Everly, 2002; Farmer \& Carlton, 2006; Rubin, 2006; Veenema, 2003). According to Waeckerle (2004), there is no single authoritative source or approved body of knowledge for training that can be followed internationally, so it is unclear which knowledge, skills, or professional competencies may be essential in case of a disaster (Slepski, 2007). As a result, knowledge on disaster management strategies appears fragmented, illustrating the gap between information coordination and sharing. Most knowledge and experiences of disaster practitioners remain in "individual or institutional domains" (Seneviratne et al., 2010, no page). Furthermore, it appears from extant research that should a disaster occur, most workers across the world would be inadequately prepared. 
The mass gathering of the Hajj shares some of characteristics of other recurring mass gatherings across the world, but it is unique in its diversity, the sheer numbers of people involved, its geographical limitations, its climatic conditions, and to some extent, in its demographic composition. Due to the fact that visitors come to Saudi Arabia from all over the globe, there is increased risk of disease. As their religion demands they perform rites in circumscribed locations within certain time frames, pilgrims risk stampedes, crowd surges and other accidents. The harsh climate in Western Saudi Arabia, where even in winter temperatures can rise to dangerous levels, and the presence at the Hajj of large numbers of elderly pilgrims, both contribute to the potential for various kinds of disasters. The ever-increasing numbers of attendees as well as its history of disasters have made critical the need for disaster preparedness, in particular for health care workers.

There is an urgency for the standardization of the education and training of healthcare workers for disaster preparedness (GAO, 2003). With a view to better prepare EMS providers for future Hajj gatherings, this study will assess their knowledge about disaster preparedness during the Hajj 2016. 


\section{CHAPTER III}

\section{METHODOLOGY}

This chapter provides a detailed discussion on the methodology utilized in this research and includes the consent procedures, research design, data collection procedures, sampling techniques, definitions of measures and variables, issues of validity and reliability, and the plan for data analysis.

Prior to collection of data, two main approvals were obtained: (1) the University of Louisville's Institution Review Board (IRB), (2) and that of the Saudi Red Crescent Authority (SRCA). After approval, the researcher traveled to Mecca in Saudi Arabia to collect data.

\section{Consent procedures}

Participation in the research was completely voluntary as described in the Informed Consent document. The participants were free to drop out the study at any point if they chose to do so. The researcher guaranteed that participants' responses on the questionnaire were anonymous and would be used for scientific purposes only. Consent was obtained from EMS-providers who had worked for the Saudi Red Crescent Authority during the Hajj season of 2016.

\section{Research design}

The main purposes of this study were to 1) assess the knowledge regarding Disaster Preparedness for Mass Gatherings (DPMG) among SRC- EMS providers during the Hajj of 2016; 2) explore the relationship between the demographic variables as 
independent variables (age, level of education, working experience, previous disaster education/training, number of trainings and number of hours of training), the knowledge about DPMG among SRC- EMS providers during the Hajj of 2016 as dependent variables, general knowledge and Hajj knowledge; and 3) explore the sources of knowledge about DPMG that the SRC- EMS providers possess.

For this study, a cross-sectional survey design was utilized. Babbie (2015), defined cross-sectional as involving "observations of a sample, or cross section, of a population or phenomenon made at one point in time" (p. 106). The quantitative research method is appropriate for the several reasons, as follow. First, quantitative methods in general afford a researcher a reliable objectivity, second, a cross-sectional survey is appropriate for analysis of data obtained from a large sample, third, it allows the researcher to generalize results to larger populations (Trochim, Donnelly, and Arora, 2015).

An online survey provided inexpensive and efficient access to a large population sample. All of EMS-providers from SRCA who worked during the Hajj of 2016 were invited to participate voluntarily in the survey by sending the link of the survey to their cell-phone as a text message. Finally, the surveys were scored and analyzed for descriptive and significant statistics.

\section{Data Collection Procedures}

After receiving IRB approval and according to standard legal and ethical guidelines, the researcher conducted an online Qualtrics survey to collect data. Participants were informed about the study, and could answer survey questions after providing informed consent (Appendix A). For widely-distributed populations such the 
SRC-EMS providers, who are recruited from across Saudi Arabia and who return to their home bases after Hajj season, prior research has shown benefits attached to online survey as compared to paper-based surveys, such as low cost and flexibility (Cobanoglu, Warde, and Moreco, 2001; Dilman et al., 2009; Kaplowitz, Hadlock, and Levine, 2004; Wright, 2005). Social network technology and electronic communication were utilized to invite the SRC-EMS providers to be research participants. Prospective participants received the survey questions by e-mail or by receiving a broadcast link. To encourage them to respond and participate, the link led to a Qualtrics survey in which data can be entered anonymously every two weeks. Participants received no financial reward or compensation for involvement in this study. The survey was distributed to the prospective sample from March until May 2017.

\section{Sample population}

The target population for this study was the SRC-EMS providers who worked in the Hajj of 2016. Based on IFRC, there were 1,550 SRC EMS-providers plus 100 physicians who worked in the Hajj of 2016 (IFRC, 2016). EMS-providers engaged by any other employers during Hajj season, such as by the Ministry of Health hospitals, the National Guard hospital, and the Ministry of Defense military hospital, were not included in this study.

To be a part of this study, the participants had to meet the following criteria: 1) be 21 years old or older; 2) be currently licensed by the Saudi Health Commission as a certified EMS provider or as a Paramedic, and 3) be a full-time employee of SRCA.

The participants were a convenience sample of the 1,650 SRC-EMS providers, selected on availability rather than probability (Wrench, Thomas-Maddox, Richmond, \& 
McCroskey, 2008). Efficiency in time and cost informed the choice of this method. Nevertheless, it should be noted that although availability selection does not limit the importance of the study, it does limit its generalizability. Hence, even if the results may not represent the whole population, they will add to the literature on subject, even if only in an exploratory view (Wrench, Thomas-Maddox, Richmond, \& McCroskey, 2008). The purpose of exploring the knowledge of disaster preparedness of mass gatherings among this same population also supports the use of a convenience sample.

As indicated by Light et al. (2009), the more people included in your study, the better your chances of finding effects that exist (p.186). An attempt was made to recruit all 1,650 providers who worked in the Hajj season 2016, but the final sample was a convenience sample. To potentially increase the response rate, the researcher sent the link of the survey to the participants by phone text message.

\section{Definition of research variables and instrumentation development}

\section{Research Variables}

There were seven independent variables in this research:

1. Age of SRC-EMS provider

2. Level of education, not including EMS training

3. Level of SRC-EMS provider in the Saudi system.

4. Sector of EMS training is received

There are two main sectors of health education in Saudi Arabia, governmental and private. The government sector includes; Ministry of Health, Ministry of Defense and Aviation, Ministry of Education and the National Guard, however, the private 
sector includes all the private colleges that do receive not support from the government (Al-Hashem, 2016).

5. Years of experience in EMS field

6. Training (Previous disaster education/training, number of trainings and number of hours of trainings).

There were two dependent variables in this research:

1. The measure of general knowledge of disaster preparedness was comprised of 12 items. This DV focused about general disaster situations such as fire, flooded, and multi-car (more than two) accidents.

2. The measure of Hajj knowledge was comprised of 6 items. This DV focused on all types of disaster throughout the Hajj season such as stampedes, fires, terror attacks.

\section{Instrumentation Development}

The instrument used in this research study was compiled and modified by the researcher, based on a comprehensive review of the literature on the topic and on the researcher's own experience in working in the field (Fung, Loke \&Lai, 2008; Tichy, Bond, Beckstrand, Heise, 2009; Lim, Lim \& Vasu, 2013; (Al Khalaileh, Bond, Beckstrand, \& Al-Talafha, 2010). Before distribution, the survey was translated to Arabic by the researcher and reviewed by Arabic-speaking professionals in the field. The survey questionnaire (See Appendix B for English version and Appendix C for Arabic version) completed by participants in this study was comprised of five parts. The first part of the survey was a statement of confidentiality. Participation was entirely voluntary and SRCA-EMS providers had the option to choose to continue or to stop the survey. The 
informed consent (See Appendix D for English version and Appendix E for Arabic version) was given to each participant before administrating the questionnaire.

The second part of survey included four questions regarding the participants' demographic characteristics: (1) the age of provider (less than 25 years- 50 years and above), (2) Marital status (single, married, divorced, widowed), (3) nationality (Saudi, non-Saudi), (4) highest level of education completed, not including EMS training (high school, diploma +2 years, diploma +3 years, Bachelor's degree, Master's, Doctor (Ph.D. or MD).

The third part of survey included ten questions regarding the participant's disaster preparedness for mass gathering experience:(1) the level of EMS for participants (first responder, EMS-Technician, EMS-Paramedic, Physician), (2) current training received (Government sector, Private sector, Military sector, outside of the kingdom of Saudi Arabia), (3) years of working experience (under one year- 20 years and above), (4) Number of the Hajj seasons worked (one season, two seasons, three seasons, four seasons or more), (5) Average number of patients treated daily during the Hajj of 2016 (0-10, 1120, 21-30, 31-40, over 40), (6) Number of training, drill, and workshops ever attended (never, one, two, three, more than three), (7) Number of training, drill, and workshops attended per year (never, one time per year, two times per year, three times per year, four times per year, five times or more per year), (8) Time passed since the last training, drill and workshop (less than six months ago, six months ago to a year ago, more than one year ago, Non Available ), (9) Duration of the last training drill, and workshop ( less than five hours, from five hours but less than 10 hours, from 10 hours but less than 20 hours20 hours or more- N/A), (10) Asked participants to which of the following disasters his 
workplace was ready to respond. Participants could select more than one answer (fire disasters, transport disasters, building collapse disasters, flood disasters, epidemic disasters, stampede disasters, none of the above).

The fourth part of survey was in two parts. Section one included 12 items regarding the general knowledge of participant's disaster preparedness for mass gatherings and two questions as follow: Please read each of the following questions and describe how often you implemented each item during the average year: (1) participation in disaster drills or exercises at workplace, (2) participation in continuing education classes dealing with DPMG, (3) participation in seminars dealing with DPMG, (4) participation in conferences dealing with DPMG or read journal articles related to DPMG. Responses were scored on a Likert scale (never, one, two times, four times or more), (5) I am interested in participating in DPMG offered at workplace or other institutes (e.g., university or community), (7) I am interested in educational classes specifically on DPMG with Likert-scale responses (really not interested, really interested), (8) Finding relevant information about DPMG related to the Hajj season needs is an obstacle to the level of preparedness, (9) I know where to find relevant research or information related DPMG in the Hajj season to fill in gaps in the knowledge, (10) I find that literature on DPMG and management is easy accessible, (11) I find that literature on DPMG is understandable, (12) I am able to refer cases to the correct medical department. Likert-scale responses were (strongly disagree- strongly agree). The final two questions referred to 1) participation in emergency plan drafting or emergency planning for disaster situation for the Hajj season and 2) I know whom to contact (chain 
of command) in a disaster situation in the Hajj season. The possible answers were (yes or no).

Section two included 6 items regarding participant's knowledge of disaster preparedness for the mass gathering of the Hajj and one question, to wit: Please carefully read each of the following items and decide to what extent you agree or disagree by checking the appropriate choice: (1) My knowledge about DPMG for the Hajj season 2016 was sufficient, (2) In my experience during the Hajj of 2016, there was sufficient equipment to respond to accidents, (3) In my experience during the Hajj of 2016, the police presence was sufficient, (4) In my experience during the Hajj of 2016, the presence of the fire department was sufficient, (5) I am aware of the potential risks in the Hajj season (e.g. stampedes, floods, terrors, fires, etc.), (6) I had sufficient knowledge, skills, and authority as an EMS provider to act in disaster situations in the Hajj season of 2016. Possible Likert-scale were responses were (strongly disagree to strongly agree). The question was as follows: Which have you ever experienced during the Hajj season? Participants could select more than one answer from the following: (fire disasters, transport disasters, building collapse disasters, flood disasters, epidemic disasters, stampede disasters, none of the above)

Part five questioned the participants on the sources of their knowledge. It consisted of three questions: Where the participant obtained his knowledge of disaster preparedness for mass gatherings, which materials and activities related to disaster preparedness should be developed to enable EMS providers to prepare for future disasters in mass gatherings, and what kind of educational courses should be taken to prepare for 
disasters in mass gatherings. The answers to these items had scales 1-5 (1= least useful to $5=$ most useful).

A Likert scales, which are considered common reliable than others, are often used when the goal is to evaluate respondents' attitudes toward a specific issues (Leedy \& O'rmrod, 2005). It is also more efficient in terms of time and has high reliability when compared with other scales (Crano \& Brewer, 2002). Therefore, a Likert scale was used in this study with five points that allowed SRC-EMS providers to respond based on level of agreement (Strongly disagree $=1$, Disagree $=2$, Neither agree or disagree $=3$, and Strongly Agree = 5).

\section{Validity and Reliability}

Five experts in the fields of EMS who have worked with SRCA in Saudi Arabia in the areas of disaster preparedness, research, mass gatherings, and measures from University of Louisville reviewed the questionnaire's validity. A cover letter was attached to the questionnaire to explain the purpose of the study, the items on the questionnaire (including a reference list of reviewed literature) and a summary of the methodological procedure of the research. Also, the questionnaire's items were reviewed to ensure a comprehensive evaluation of the levels of knowledge disaster preparedness for mass gatherings among SRC-EMS providers in Hajj season 2016. Furthermore, to increase the validity of the study, a pilot testing of the questionnaire was sent to ten SRCEMS providers not involved in the final sample to discern whether the questionnaire appropriately measured participant perspectives. The pilot group was asked about the clarity of the questions and about the order of the items. Finally, the pilot test participants 
were asked to suggest elements to be included in the survey based on their experience, and education.

To test the appropriateness of the variables, the questionnaire was submitted to a group of experts for feedback (e.g. EMS providers in SRCA, disaster preparedness experts, and mass gathering experts). To obtain reliability indicators, a Cronbach Alpha was computed for each of the four sections/items that target level of knowledge of disaster preparedness for mass gatherings among EMS providers in the Hajj season 2016. Higher scores correspond to more reliable scales. According to Hattie (1985), 0.7 is an accepted reliability coefficient, but lower thresholds are sometimes used in the literature.

\section{Data Analysis}

The data was analyzed using the Statistical Package for the Social Sciences (SPSS-21.0 IBM). Descriptive statistics (e.g., frequencies, mean, standard deviations, ranges, and percentages) were used to analyze data (age, level of education, level of EMS of provider, years of experience etc.). Bar charts, histograms and pie charts were created for all the categorical variables.

A test appropriate for examining the probable strength and direction of the bivariate relationship posed in research questions is the one-way Analysis of Variance (or ANOVA) with the Bonferroni correction for multiple comparison. This common statistical procedure informed which enabled the analysis of the mean values of dependent variables for this study. The ANOVA has been found to be statistically acceptable as long as the ordinal variables have five or more categories, in order that they behave as having interval scales (Boyle, 1970). More specifically, this analysis assisted the researcher to answer questions $1,2,3,4,5$, and 6 
1) Is there a significant difference in the knowledge of disaster preparedness for mass gatherings (DPMG) between different categories of EMS-providers based on their age?

2) 2. Is there a significant difference in the knowledge of DPMG between different categories of SRCA EMS-providers based on level of education?

3) Is there a significant difference in the knowledge of DPMG between different categories of EMS-providers based on their level of SRCA EMS?

4) Is there a significant difference in the knowledge of DPMG between different categories of SRCA EMS-providers based on the current SRCA EMS training received?

5) Is there a significant difference in the knowledge of DPMG between different categories of SRCA EMS-providers based on years of experience?

6) Is there a significant difference in the knowledge of DPMG between different categories of SRCA-EMS providers based on previous disaster education/training, number of trainings and number of hours of training?

The second technique, Pearson's product correlation coefficient (r) was used to assess the relationship between two variables. When squared (r), the coefficient indicated the presence or absence of a relationship and explained of the proportion of the variance in the dependent variable by the independent variables. The value of Pearson's (r) ranges from -1.0 to +1.0 . The closer the value is to zero, the less likely the two variables interrelate. Negative correlations mean that as one variable goes up the other will go down. Positive correlations mean that as one variable moves, the other will move in the same direction. A Pearson's (r) of zero means no association exists between the variables; 
however, a zero correlation does not always indicate the absence of a causal relationship (Cozby, 2012). This technique was used to answer research question seven:

7) Was there a relationship between the sources of knowledge and knowledge acquired regarding DPMG among different SRCA-EMS-providers in the Hajj of $2016 ?$

In addition, one of the final goals of this study was to develop a model to predict important factors that affected the knowledge of disaster preparedness for mass gatherings for SRC-EMS providers. When the intent is to examine the impact of several independent variables on a single dependent variable, multiple regression is the appropriate analysis technique. Stepwise regression analysis allowed the researcher to identify the predictor variables of magnitude of contribution to the variance in general knowledge and Hajj knowledge.

\section{Assumption}

According to Keppel (1991) the researchers were checked on the assumptions of an ANOVA before running the analysis. Thus, the assumptions of independence, normal distribution of scores, and homogeneity of variance were met for each variable (Keppel, 1991). That means all observations were independent of each another. The function of ANOVA test was determined to see if the variables were independent of one another and to make sure the assumption that the null hypotheses are true. The results of statistic revealed that the assumption of independence was not violated; therefore, ANOVA was the most appropriate test for analyzing the data (Lix, Keselman, \& Keselman, 1996).

Regression assumptions were also evaluated and met. These included (1) the continuous dependent variables, (2) more than two independent variables, (3) the 
independence of observations or residuals, (4) the linear relationship between the dependent variable and each of the independent variables, (5) homoscedasticity in the data, (6) the absence of multicollinearity, (7) no significant outliers, and (8) a normal distribution of scores.

\section{Summary}

This chapter included the clarification of methodology used to address the research questions, purpose of the quantitative research, and to identify the relationship between the independent and dependent variables. A cross-section design allowed for an assessment of the relationship between variables, general knowledge of disaster preparedness, knowledge of the Hajj 2016. Furthermore, the instrument used to collect the data was explained. This chapter also outlined and discussed the research design and consent procedures, sample population, definition of variables in this study, instrument

development, validity and reliability, data analysis and assumption. Chapter 4 provide a synopsis of the statistical results from the study. 


\section{CHAPTER IV}

\section{RESULTS}

This study had three main goals: 1) to assess the knowledge regarding disaster preparedness for mass gatherings (DPMG) among SRCA-EMS providers during the Hajj of $2016 ; 2$ ) to explore the relationship between the demographic variables (age, level of education, working experience, previous disaster education/training, number of trainings and number of hours of training), the knowledge about DPMG among SRCA-EMS providers during the Hajj 2016; and 3) to explore the sources of knowledge about disaster preparedness for mass gatherings that SRCA-EMS providers posses. To achieve these goals, the researcher prepared an online questionnaire that was sent to the participants for the study.

\section{Research Questions}

The study specifically focused on the following research questions and hypotheses:

1. Is there a significant difference in the knowledge of disaster preparedness for mass gatherings (DPMG) between different categories of SRCA-EMS providers based on their age?

2. Is there a significant difference in the knowledge of DPMG between different categories of SRCA-EMS providers based on their level of education?

3. Is there a significant difference in the knowledge of DPMG between different categories of SRCA-EMS providers based on their level of EMS? 
4. Is there a significant difference in the knowledge of DPMG between different categories of SRCA-EMS providers based on the sector of EMS training received?

5. Is there a significant difference in the knowledge of DPMG between different categories of SRCA-EMS providers based on years of experience?

6. Is there a significant difference in the knowledge of DPMG between different categories of SRCA-EMS providers based on previous disaster education/training, the number of trainings and the number of hours of training?

7. Is there a relationship between the source of knowledge and knowledge acquired regarding DPMG among different SRCA-EMS providers in the Hajj of 2016?

\section{Hypotheses}

The following hypotheses presented were addressed in relation to the research questions proposed above:

H01: There is no significant difference in the knowledge of DPMG between different categories of SRCA-EMS providers based on their age.

Ha1: There is a significant difference in the knowledge of DPMG between different categories of SRCEMS providers based on their age.

H02: There is no significant difference in the knowledge of DPMG between different categories of SRCA-EMS providers based on their level of education.

Ha2: There is a significant difference in the knowledge of DPMG between different categories of SRCA-EMS providers based on level of education.

H03: There is no significant difference in the knowledge of DPMG between different categories of SRCA-EMS providers based on their level of EMS. 
Ha3: There is a significant difference in the knowledge of DPMG between different categories of SRCA-EMS providers based on their level of EMS.

H04: There is no significant difference in the knowledge of DPMG between different categories of SRCA-EMS providers based on the sector of EMS training received.

Ha4: There is a significant difference in the knowledge of DPMG between different categories of SRCA-EMS providers based on the sector of EMS training received.

H05: There is no significant difference in the knowledge of DPMG between different categories of SRCA-EMS providers based on years of experience.

Ha5: There is a significant difference in the knowledge of DPMG between different categories of EMS providers based on years of experience.

H06: There is no significant difference in the knowledge of DPMG between different categories of SRCA-EMS providers based on previous disaster education/training, number of trainings and number of hours of training.

Ha6: There is a significant difference in the knowledge of DPMG between different categories of SRCA-EMS providers based on previous disaster education/training, number of trainings and number of hours of training.

H07: There is no relationship between the source of knowledge and knowledge acquired regarding DPMG among different SRCA-EMS providers in the Hajj of 2016.

Ha7: There is a relationship between the source of knowledge and knowledge acquired regarding DPMG among different SRCA-EMS providers in the Hajj of 2016.

This chapter includes the results of the study, beginning with reliability analysis, general sample descriptives, knowledge in general directions, knowledge regarding the 
Hajj 2016, and source of knowledge. The results are presented according to the research questions and corresponding hypothesis.

\section{Response Rate}

Based on the survey analysis provided by Qualitrics, the average time for completing the survey was approximately twelve minutes for each respondent. The survey was distributed to 1,650 SRCA-EMS providers who worked for the SRCA in the Hajj season of 2016. A total of 700 surveys were returned, resulting in a $41 \%$ response rate (with follow-up). While this response rate may seem low, it must be noted that the response rate for this research study is not necessarily true or accurate, for reasons described below. In recent years, lower response rates have been observed specifically with internet/web based surveys (Cook, Heath, \& Thompson, 2000; Couper, 2000; Fan \& Yan, 2010; Sax, Gilmartin, \& Bryant, 2003).

\section{Reliability Analysis}

Reliability was established for the questionnaire using internal consistency with Cronbach's alpha. The calculated Cronbach's Alpha for the questionnaire and its dimensions are shown in table 4.1.

\section{Table 4.1.}

Cronbach's alpha for dimensions of the questionnaire

\begin{tabular}{|c|l|c|c|}
\hline No & \multicolumn{1}{|c|}{ Dimension } & $\begin{array}{c}\text { No. of } \\
\text { Statements }\end{array}$ & $\begin{array}{c}\text { Cronbach's } \\
\text { Alpha }\end{array}$ \\
\hline 1 & $\begin{array}{l}\text { PART A: General knowledge for } \\
\text { disaster preparedness for mass } \\
\text { gatherings }\end{array}$ & 12 & 0.845 \\
\hline 2 & PART B: Knowledge of Hajj 2016 & 6 & 0.871 \\
\hline
\end{tabular}




\begin{tabular}{|l|l|l|l|}
\hline 3 & PART C: Sources of knowledge & 20 & 0.832 \\
\hline \multicolumn{2}{|c|}{ Overall Reliability } & 38 & 0.869 \\
\hline
\end{tabular}

According to Bryman and Cramer (2004), the dimension with alpha coefficients values of 0.7 and above are considered a reliable dimension. The output of alpha coefficients for all dimensions is high and above 0.7 , ranging from 0.832 to 0.871 . So, the dimensions are internally reliable.

\section{General Sample Descriptive}

The sample size of the survey consisted of $700(n=700)$ respondents. The demographic information of the sample consisted of two main sections which included: Age, Status, Nationality and Level of Education in section 1, as well as EMS level, Experience and Training details in section 2. This demographics information is shown in the next table. Other sections, general knowledge of disaster preparedness of mass gathering, knowledge of the Hajj 2016, and source of knowledge.

\section{Section 1: Demographics Information}

This section included nationality, status, level of education and age of SRC-EMS providers in this study.

\section{Table 4.2.}

Sample of Demographics Information

\begin{tabular}{|l|l|l|l|}
\hline \multicolumn{1}{|c|}{ Variables } & & Frequency (n) & Percentage (\%) \\
\hline Nationality & Saudi & 690 & 98.6 \\
\cline { 2 - 4 } & Non-Saudi & 10 & 1.4 \\
\hline \multirow{4}{*}{ Status } & Single & 118 & 16.9 \\
\cline { 2 - 4 } & Married & 571 & 81.6 \\
\cline { 2 - 4 } & Divorced & 8 & 1.1 \\
\cline { 2 - 4 } & Widowed & 3 & 0.4 \\
\hline
\end{tabular}




\begin{tabular}{|l|l|l|l|}
\hline \multirow{4}{*}{ Level of Education } & High school & 52 & 7.4 \\
\cline { 2 - 4 } & Diploma +2 years & 198 & 28.3 \\
\cline { 2 - 4 } & Diploma +3yrs & 253 & 36.1 \\
\cline { 2 - 4 } & BS & 169 & 24.1 \\
\cline { 2 - 4 } & MS & 23 & 3.3 \\
\cline { 2 - 4 } Age & Other & 5 & 0.7 \\
\hline \multirow{5}{*}{} & Less than 25 years & 7 & 1 \\
\cline { 2 - 4 } & $25-29$ years & 215 & 30.7 \\
\cline { 2 - 4 } & $30-34$ years & 232 & 33.1 \\
\cline { 2 - 4 } & $35-39$ years & 135 & 19.3 \\
\cline { 2 - 4 } & $40-44$ years & 59 & 8.4 \\
\cline { 2 - 4 } & $45-49$ years & 28 & 4 \\
\cline { 2 - 4 } & 50 years and above & 24 & 3.4 \\
\hline
\end{tabular}

Table 4.2. shows that the highest percent were Saudi nationals (98.6\%) of the total sample, $81.6 \%$ were married as the highest percent in the total sample, $63.8 \%$ were between 25 to 34 years old, and $64.4 \%$ possessed a high school diploma plus either two years or three as the highest percent in the total sample.

\section{Section 2: SRCEMS Provider's Disaster Preparedness for Mass Gathering Experience and Training}

This part presents more details of experience and training of the sample.

\section{Table 4.3.}

SRC-EMS Provider's DPMG Experience and Training

\begin{tabular}{|l|l|l|l|}
\hline \multicolumn{1}{|c|}{ Variables } & & $\begin{array}{c}\text { Frequency } \\
(\mathrm{n})\end{array}$ & \multicolumn{1}{|c|}{$\begin{array}{c}\text { Percentage } \\
(\%)\end{array}$} \\
\hline \multirow{4}{*}{ 5-What is your EMS level? } & First responder & 62 & 8.9 \\
\cline { 2 - 4 } & EMS-TECH & 459 & 65.6 \\
\cline { 2 - 4 } & EMS-Paramedic & 158 & 22.6 \\
\cline { 2 - 4 } & Physician & 21 & 3 \\
\hline \multirow{2}{*}{$\begin{array}{l}\text { 6- Which of the following best } \\
\text { describe the training you } \\
\text { received current EMS training? }\end{array}$} & Government sector & 235 & 33.6 \\
\cline { 2 - 4 } & Private sector & 358 & 51.1 \\
\cline { 2 - 4 } & Military sector & 63 & 9 \\
\cline { 2 - 4 } & Outside of Saudi Arabia & 44 & 6.3 \\
\hline
\end{tabular}




\begin{tabular}{|l|l|l|l|}
\hline \multirow{3}{*}{$\begin{array}{l}\text { 8- How many times have you } \\
\text { worked at Hajj? }\end{array}$} & One season & 127 & 18.1 \\
\cline { 2 - 4 } & Two seasons & 162 & 23.1 \\
\cline { 2 - 4 } & Three seasons & 140 & 20 \\
\cline { 2 - 4 } & Four seasons or more & 271 & 38.7 \\
\hline \multirow{3}{*}{$\begin{array}{l}\text { 9- How many patients did you } \\
\text { treat on the average day during } \\
\text { the Hajj of 2016? }\end{array}$} & $0-10$ & 190 & 27.1 \\
\cline { 2 - 4 } & $11-20$ & 219 & 31.3 \\
\cline { 2 - 4 } & $21-30$ & 124 & 17.7 \\
\cline { 2 - 4 } & $31-40$ & 55 & 7.9 \\
\cline { 2 - 4 } & Over 40 & 112 & 16 \\
\hline 7- How long have you worked & Under one year & 9 & 1.3 \\
\cline { 2 - 4 } as EMS providers for the & $1-5$ years & 196 & 28 \\
\cline { 2 - 4 } Saudi Red Crescent Authority? & $6-9$ years & 244 & 34.9 \\
\cline { 2 - 4 } & $10-14$ years & 64 & 9.1 \\
\cline { 2 - 4 } & $15-19$ years & 55 & 7.9 \\
\cline { 2 - 4 } & 20 years or more & & 132 \\
\hline
\end{tabular}

Table 4.3. shows that the highest percent in the total sample (i.e., 65.6\%) were EMS-Technicians, $51.1 \%$ of the total sample received their current EMS training in the private sector, $38.7 \%$ of the total sample had worked four seasons of Hajj or more, $31.3 \%$ treated an average of 11-20 patients per day during the Hajj of 2016, and 34.9\% had worked between 5-9 years as EMS providers for the Saudi Red Crescent Authority.

Table 4.4. provides more details of trainings received by the providers. It includes how many trainings/workshops/drills about disaster preparedness were attended, and the best way to describe their experience at a trainings/workshops/drills about disaster preparedness. 
Table 4.4.

$\underline{\text { Continue Experience and Training Details }}$

\begin{tabular}{|c|c|c|c|c|}
\hline Variables & & & $\begin{array}{l}\text { Frequency } \\
\text { (n) }\end{array}$ & $\begin{array}{c}\text { Percentage } \\
(\%)\end{array}$ \\
\hline \multirow{15}{*}{$\begin{array}{l}\text { 10- How many } \\
\text { trainings/workshops/drills } \\
\text { about disaster preparedness } \\
\text { have you EVER attended? }\end{array}$} & \multirow{5}{*}{ Training } & Never & 187 & 26.7 \\
\hline & & One & 143 & 20.4 \\
\hline & & Two & 122 & 17.4 \\
\hline & & Three & 87 & 12.4 \\
\hline & & $\begin{array}{l}\text { More than } \\
\text { three }\end{array}$ & 161 & 23 \\
\hline & \multirow{5}{*}{ Workshops } & Never & 285 & 40.7 \\
\hline & & One & 154 & 22 \\
\hline & & Two & 132 & 18.9 \\
\hline & & Three & 55 & 7.9 \\
\hline & & $\begin{array}{l}\text { More than } \\
\text { three }\end{array}$ & 74 & 10.6 \\
\hline & \multirow{5}{*}{ Drills } & Never & 211 & 30.1 \\
\hline & & One & 179 & 25.6 \\
\hline & & Two & 123 & 17.6 \\
\hline & & Three & 62 & 8.9 \\
\hline & & $\begin{array}{l}\text { More than } \\
\text { three }\end{array}$ & 125 & 17.9 \\
\hline \multirow{9}{*}{$\begin{array}{l}\text { 11- Which of the following } \\
\text { best describes the frequency } \\
\text { of your attendance at a } \\
\text { trainings/workshops/drills } \\
\text { about disaster preparedness? }\end{array}$} & Training & Never & 282 & 40.3 \\
\hline & & $\begin{array}{l}\text { One time per } \\
\text { year }\end{array}$ & 245 & 35 \\
\hline & & $\begin{array}{l}\text { Two times } \\
\text { per year }\end{array}$ & 91 & 13 \\
\hline & & $\begin{array}{l}\text { Three times } \\
\text { per year }\end{array}$ & 54 & 7.7 \\
\hline & & $\begin{array}{l}\text { Four times } \\
\text { per year }\end{array}$ & 13 & 1.9 \\
\hline & & $\begin{array}{l}\text { Five times or } \\
\text { more per } \\
\text { year }\end{array}$ & 15 & 2.1 \\
\hline & Workshops & Never & 375 & 53.6 \\
\hline & & $\begin{array}{c}\text { One time per } \\
\text { year }\end{array}$ & 203 & 29 \\
\hline & & $\begin{array}{l}\text { Two times } \\
\text { per year }\end{array}$ & 82 & 11.7 \\
\hline
\end{tabular}




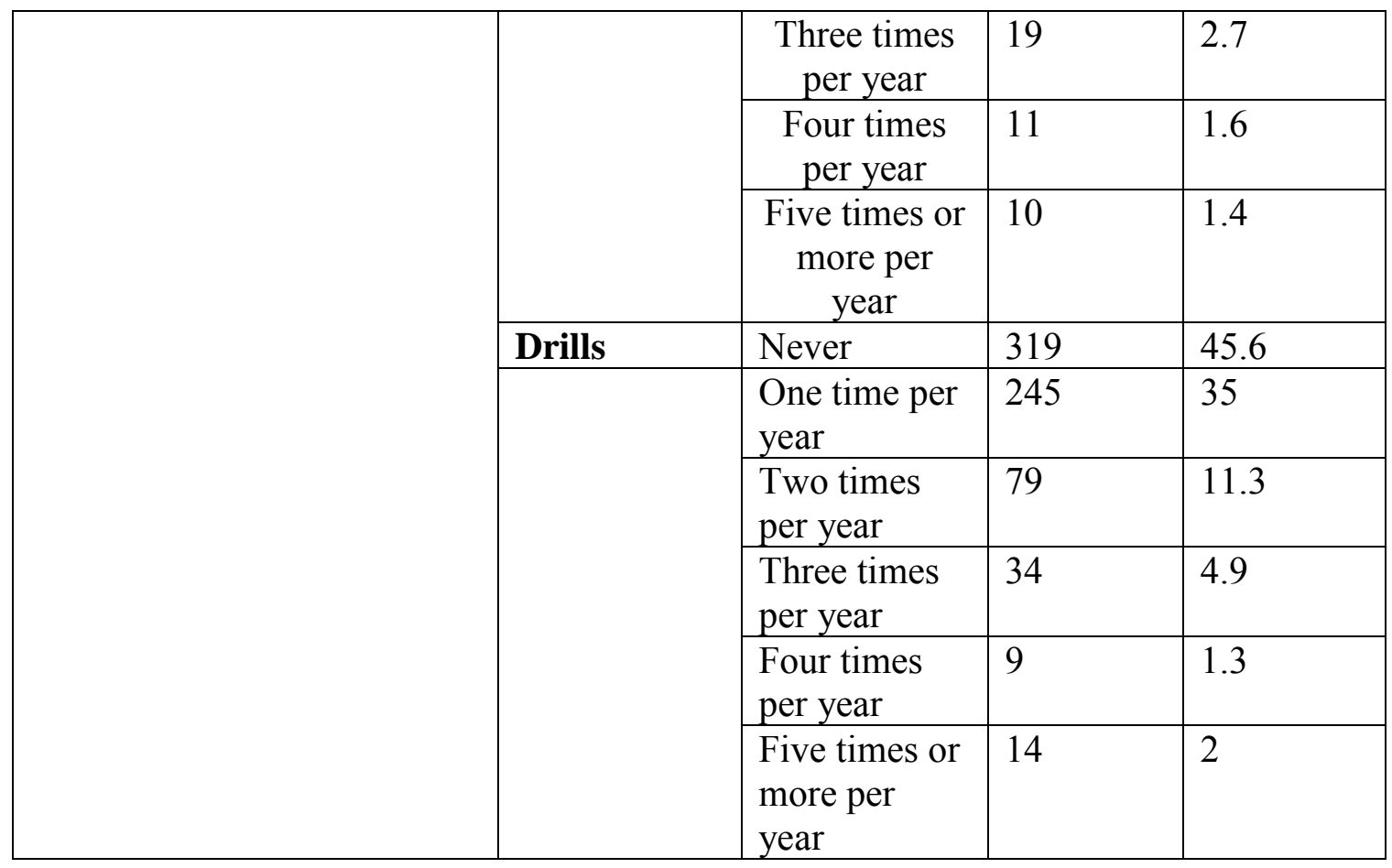

Table 4.4 shows that the highest percent in the total sample for all kinds of trainings/ workshops/ drills were "Never" followed by one time per year. Both choices represent more than $50 \%$ of the responses of the total sample.

Table 4.5 reveals the last time that respondents attended a trainings/ workshops/ drills about disaster preparedness, and the best way to describe their experience.

Table 4.5.

\section{Continue Details of training}

\begin{tabular}{|l|l|l|l|l|}
\hline \multicolumn{1}{|c|}{ Variables } & & \multicolumn{1}{|c|}{$\begin{array}{c}\text { Frequency } \\
(\mathrm{n})\end{array}$} & $\begin{array}{c}\text { Percentage } \\
(\%)\end{array}$ \\
\hline $\begin{array}{l}\text { 12- When was the last time } \\
\text { you attended a training/ } \\
\text { workshop/ drill about } \\
\text { disaster preparedness? }\end{array}$ & \multirow{2}{*}{ Training } & $\begin{array}{l}\text { Less than six } \\
\text { months ago }\end{array}$ & 146 & 20.9 \\
\cline { 3 - 5 } & $\begin{array}{l}\text { Six months ago- } \\
\text { A year ago }\end{array}$ & 165 & 23.6 \\
\cline { 3 - 5 } & $\begin{array}{l}\text { More than one } \\
\text { year ago }\end{array}$ & 177 & 25.3 \\
\cline { 3 - 5 } & N/A & 212 & 30.3 \\
\hline
\end{tabular}




\begin{tabular}{|c|c|c|c|c|}
\hline & & $\begin{array}{l}\text { Less than six } \\
\text { months ago }\end{array}$ & 91 & 13 \\
\hline & Workshops & $\begin{array}{l}\text { Six months ago- } \\
\text { A year ago }\end{array}$ & 170 & 24.3 \\
\hline & & $\begin{array}{l}\text { More than one } \\
\text { year ago }\end{array}$ & 149 & 21.3 \\
\hline & & N/A & 290 & 41.4 \\
\hline & & $\begin{array}{l}\text { Less than six } \\
\text { months ago }\end{array}$ & 102 & 14.6 \\
\hline & Drills & $\begin{array}{l}\text { Six months ago- } \\
\text { A year ago }\end{array}$ & 183 & 26.1 \\
\hline & & $\begin{array}{l}\text { More than one } \\
\text { year ago }\end{array}$ & 173 & 24.7 \\
\hline & & $\mathrm{N} / \mathrm{A}$ & 242 & 34.6 \\
\hline $\begin{array}{l}\text { 13- Which of the following } \\
\text { best describes your }\end{array}$ & Training & $\begin{array}{l}\text { Less than } 5 \\
\text { hours }\end{array}$ & 250 & 35.7 \\
\hline $\begin{array}{l}\text { experience at a } \\
\text { trainings/workshops/drills } \\
\text { about disaster }\end{array}$ & & $\begin{array}{l}\text { From } 5 \text { hours } \\
\text { but less than } 10 \\
\text { hours }\end{array}$ & 151 & 21.6 \\
\hline preparedness? & & $\begin{array}{l}\text { From } 10 \text { hours } \\
\text { but less than } 20 \\
\text { hours }\end{array}$ & 43 & 6.1 \\
\hline & & $\begin{array}{l}20 \text { hours or } \\
\text { more }\end{array}$ & 46 & 6.6 \\
\hline & & N/A & 210 & 30 \\
\hline & Workshops & $\begin{array}{l}\text { Less than } 5 \\
\text { hours }\end{array}$ & 152 & 21.7 \\
\hline & & $\begin{array}{l}\text { From } 5 \text { hours } \\
\text { but less than } 10 \\
\text { hours }\end{array}$ & 181 & 25.9 \\
\hline & & $\begin{array}{l}\text { From } 10 \text { hours } \\
\text { but less than } 20 \\
\text { hours }\end{array}$ & 54 & 7.7 \\
\hline & & $\begin{array}{l}20 \text { hours or } \\
\text { more }\end{array}$ & 26 & 3.7 \\
\hline & & N/A & 287 & 41 \\
\hline & Drills & $\begin{array}{l}\text { Less than } 5 \\
\text { hours }\end{array}$ & 175 & 25 \\
\hline & & $\begin{array}{l}\text { From } 5 \text { hours } \\
\text { but less than } 10 \\
\text { hours }\end{array}$ & 140 & 20 \\
\hline
\end{tabular}




\begin{tabular}{|l|l|l|l|l|}
\hline & $\begin{array}{l}\text { From 10 hours } \\
\text { but less than 20 } \\
\text { hours }\end{array}$ & 116 & 16.6 \\
\cline { 3 - 5 } & $\begin{array}{l}\text { 20 hours or } \\
\text { more }\end{array}$ & 28 & 4 \\
\cline { 2 - 4 } & N/A & 241 & 34.4 \\
\hline
\end{tabular}

Table 4.5 shows that the highest percent in the total sample for all kinds of trainings/ workshops/ drills were (N/A) by more than $30 \%$ of the total sample, while more than $40 \%$ of the responses of the total sample responded (Less than six months ago) and (Six months ago) in all kinds of trainings/ workshops/ drills.

\section{Table 4.6.}

Experience during Workplace Ready to Respond

\begin{tabular}{|c|c|c|c|c|}
\hline \multirow{2}{*}{ Q14 } & Types & N & Percentage & Rank \\
\hline \multirow{4}{*}{$\begin{array}{c}\text { To which of the } \\
\text { following disasters } \\
\text { was your work } \\
\text { place ready to } \\
\text { respond? }\end{array}$} & Transport disaster & 326 & $46.6 \%$ & 1 \\
\cline { 2 - 5 } & Suilding collapse disaster & 178 & $36.6 \%$ & 2 \\
\cline { 2 - 5 } & Fone of above disasters & 236 & $33.7 \%$ & 4 \\
\cline { 2 - 5 } & Epidemic disaster & 63 & $9 \%$ & 5 \\
\cline { 2 - 5 } & Flood disaster & 50 & $7.1 \%$ & 7 \\
\cline { 2 - 5 } & $\begin{array}{c}\text { Bioterrorism/Biological } \\
\text { and Chemical disasters }\end{array}$ & 36 & $5.1 \%$ & 8 \\
\hline
\end{tabular}

Table 4.6 shows that $46.6 \%$ of the sample reported that their workplace was ready to respond to a Transport disaster, followed $36.6 \%$ who were ready to respond to a stampede disaster, followed by $35.7 \%$ who were ready to respond to a Fire disaster, 
whereas only $25.4 \%$ of the total sample were ready to respond to a building collapse disaster, $9 \%$ felt ready to respond to an epidemic disaster, $7.1 \%$ were ready to respond to a Flood disaster, and finally only $5.1 \%$ of the total sample were ready to respond to a Bioterrorism/Biological and Chemical disaster. Furthermore, it should be noted that $33.7 \%$ of the total sample considered that their workplace was ready to respond to none of the above-mentioned disasters.

\section{Section 3: General Knowledge of Disaster Preparedness for Mass Gathering}

Table 4.7 describes how often respondents implemented each item during the average year (Never- Once- Two times- Three times - Four times or more

\section{Table 4.7.}

General Knowledge of Disasters Preparedness for Mass Gathering

\begin{tabular}{|l|c|c|c|}
\hline \multicolumn{1}{|c|}{ Statements of Q15 } & Mean* & $\begin{array}{c}\text { Std. } \\
\text { Deviation }\end{array}$ & Direction \\
\hline $\begin{array}{l}\text { I read journal articles related to disaster preparedness for mass } \\
\text { gatherings. }\end{array}$ & 2.31 & 1.326 & One \\
\hline $\begin{array}{l}\text { I participated in disaster drills or exercises at my workplace } \\
\text { (station, clinical, hospital, etc.) on a regular basis. }\end{array}$ & 2.04 & 1.198 & One \\
\hline $\begin{array}{l}\text { I participate in continuing education classes dealing with } \\
\text { disaster preparedness for mass gatherings. }\end{array}$ & 1.85 & 1.104 & One \\
\hline $\begin{array}{l}\text { I participate in seminars dealing with disaster preparedness for } \\
\text { mass gatherings. }\end{array}$ & 1.83 & 1.104 & One \\
\hline $\begin{array}{l}\text { I participate in conferences dealing with disaster preparedness } \\
\text { for mass gatherings. }\end{array}$ & 1.72 & 1.036 & Never \\
\hline
\end{tabular}

*Average of respondents' answers for every statement.

Table 4.7 shows that the highest mean was for the statement: I read journal articles related to disaster preparedness for mass gatherings with $(\mathrm{M}=2.31, \mathrm{SD}=1.326)$ which represents (One) as a general direction; since the mean (2.31) lies on the interval of 
[1.81-2.60] in the Likert 5-point scale, followed by the statement: I participate in disaster drills or exercises at my workplace (station, clinical, hospital, etc.) on a regular basis with $(\mathrm{M}=2.04, \mathrm{SD}=1.198)$ which represents (One) as a general direction, followed by the statement: I participate in continuing education classes dealing with disaster preparedness for mass gatherings with $(\mathrm{M}=1.85, \mathrm{SD}=1.094)$ which represents (One) as a general direction, followed by the statement: I participate in seminars dealing with disaster preparedness for mass gathering with $(\mathrm{M}=1.83, \mathrm{SD}=1.104)$ which represents (One) as a general direction. While the last rank was for the statement: I participate in conferences dealing with disaster preparedness for mass gathering with $(\mathrm{M}=1.72$, $\mathrm{SD}=1.036)$ which represents (Never) as a general direction; since the mean (1.72) lies on the interval of $[1-1.80]$ in the Likert 5-point scale.

In the next part, we also describe the knowledge in general directions of disasters in terms of (Really not interested-Not interested - Neutral-Interested-Really interested) and (Strongly Disagree- Disagree - Neither Agree nor Disagree - Agree Strongly Agree). Results are shown in Table 4.8.

\section{Table 4.8.}

Continue of General Knowledge of Disasters Preparedness for Mass Gathering

\begin{tabular}{|l|r|r|c|}
\hline \multicolumn{1}{|c|}{ Statements of Q15 } & Mean* & $\begin{array}{c}\text { Std. } \\
\text { Deviation }\end{array}$ & Direction \\
\hline $\begin{array}{l}\text { I am interested in participating in disaster } \\
\text { preparedness for mass gathering training offered at } \\
\text { my workplace or other institutes (e.g. university or } \\
\text { community). }\end{array}$ & 4.11 & 1.152 & Interested \\
\hline $\begin{array}{l}\text { I would be interested in educational classes } \\
\text { specifically on disaster preparedness for mass } \\
\text { gatherings. }\end{array}$ & 4.00 & 1.208 & Interested \\
\hline
\end{tabular}




\begin{tabular}{|l|c|c|c|}
\hline $\begin{array}{l}\text { During disasters, I am able to refer cases to the } \\
\text { correct medical department. }\end{array}$ & 3.52 & 1.291 & Agree \\
\hline $\begin{array}{l}\text { Finding relevant information about disaster } \\
\text { preparedness for mass gatherings related to Hajj is an } \\
\text { obstacle to my level of preparedness. }\end{array}$ & 3.28 & 1.382 & $\begin{array}{l}\text { Neither Agree } \\
\text { nor Disagree }\end{array}$ \\
\hline $\begin{array}{l}\text { I find that literature on disaster preparedness for } \\
\text { mass gatherings is understandable. }\end{array}$ & 3.04 & 1.249 & $\begin{array}{l}\text { Neither Agree } \\
\text { nor Disagree }\end{array}$ \\
\hline $\begin{array}{l}\text { I know where to find relevant research or } \\
\text { information related to disasters preparedness for } \\
\text { mass gatherings in Hajj season to fill in gaps in my } \\
\text { knowledge. }\end{array}$ & 2.82 & 1.273 & $\begin{array}{l}\text { Neither Agree } \\
\text { nor Disagree }\end{array}$ \\
\hline $\begin{array}{l}\text { I find that literature on disaster preparedness for } \\
\text { mass gatherings and management is easily } \\
\text { accessible. }\end{array}$ & 2.67 & 1.252 & $\begin{array}{l}\text { Neither Agree } \\
\text { nor Disagree }\end{array}$ \\
\hline
\end{tabular}

*Average of respondents' answers for every statement.

Table 4.8 shows that the highest mean was for the statement: I am interested in participating in disaster preparedness for mass gathering training offered at my workplace or other institutes (e.g. university or community) with ( $\mathrm{M}=4.11, \mathrm{SD}=1.152)$ which represents (Interested) as a general direction; since the mean (4.11) lies on the interval of [3.41 - 4.20] in the Likert 5-point scale, followed by the statement: I would be interested in educational classes specifically on disaster preparedness for mass gatherings, with $(\mathrm{M}=4, \mathrm{SD}=1.208)$ which represents (Interested) as a general direction. The statement: During a disaster, I am able to refer cases to the correct medical department with $(\mathrm{M}=3.52, \mathrm{SD}=1.291)$ which represents (Agree). The other statements were all Neither agree nor disagree, and the last ranked statement was I find that literature on disaster preparedness for mass gathering and management is easily accessible) with $(\mathrm{M}=2.67, \mathrm{SD}=1.252)$ which represents (Neither Agree nor Disagree) as a general direction; since the mean (2.67) lies on interval of [2.61 - 3.40] in a Likert 5point scale. 
When respondents were asked about their participation in emergency plan drafting or emergency planning for disaster situations in the Hajj season, they answered as reported in the next table 4.9.

\section{Table 4.9.}

Participation in Emergency Plan Drafting, Emergency Planning or know whom to contact for Disaster Situations for the Haji Season

\begin{tabular}{|l|c|c|c|}
\hline \multicolumn{1}{|c|}{ Q16- Q17 } & & $\mathrm{n}$ & $\%$ \\
\hline Q16-I participated in emergency plan drafting or emergency & Yes & 200 & 28.6 \\
\cline { 2 - 4 } $\begin{array}{l}\text { planning for disaster situations in Hajj season. } \\
\text { No }\end{array}$ & 500 & 71.4 \\
\cline { 2 - 5 } & Total & 700 & 100 \\
\hline $\begin{array}{l}\text { Q17- I knew whom to contact (chain of command) in disaster } \\
\text { situations in Hajj season. }\end{array}$ & Yes & 584 & 83.3 \\
\cline { 2 - 5 } & No & 116 & 16.6 \\
\cline { 2 - 5 } & Total & 700 & 100 \\
\hline
\end{tabular}

Table 4.9 shows that the highest average was for "No" when responding to: $I$ participated in emergency plan drafting or emergency planning for disaster situations for the Hajj season with (71.4\%) of the total sample. Additionally, the highest average was for "Yes" when responding to: I knew whom to contact (chain of command) in disaster situations in Hajj season with (83.3\%) of the total sample.

\section{Section 4: Knowledge of the Hajj 2016}

In the next section, the directions of the knowledge of disasters in the Hajj of 2016 are described in terms of (Strangely Disagree, Disagree, Neither Agree nor Disagree, Agree, Strangely Agree). Results are shown in table 4.10.

\section{Table 4.10.}

Knowledge of the Haji 2016 


\begin{tabular}{|l|c|c|c|}
\hline \multicolumn{1}{|c|}{ Statements of Q18 } & Mean* & $\begin{array}{c}\text { Std. } \\
\text { Deviation }\end{array}$ & Direction \\
\hline $\begin{array}{l}\text { I am aware of the potential risks in Hajj season (e.g. } \\
\text { stampede, floods, terror, fire, etc.). }\end{array}$ & 3.77 & 1.140 & Agree \\
\hline $\begin{array}{l}\text { In my experience during Hajj of 2016, the presence of the } \\
\text { fire department was sufficient. }\end{array}$ & 3.63 & 1.101 & Agree \\
\hline $\begin{array}{l}\text { In my experience during Hajj of 2016, the police presence } \\
\text { was sufficient. }\end{array}$ & 3.62 & 1.149 & Agree \\
\hline $\begin{array}{l}\text { My knowledge about disaster preparedness for mass } \\
\text { gathering about the Hajj season 2016 was sufficient. }\end{array}$ & 3.29 & 1.293 & $\begin{array}{c}\text { Agree or } \\
\text { Disagree }\end{array}$ \\
\hline $\begin{array}{l}\text { I knew the limits of my knowledge, skills, and authority } \\
\text { as an EMS provider to act in disaster situations in Hajj } \\
\text { season 2016. }\end{array}$ & 3.14 & 1.226 & $\begin{array}{c}\text { Neither } \\
\text { Agree or } \\
\text { Disagree }\end{array}$ \\
\hline $\begin{array}{l}\text { In my experience during Hajj of 2016, there was } \\
\text { sufficient equipment to respond to accidents. }\end{array}$ & 2.92 & 1.201 & $\begin{array}{c}\text { Neither } \\
\text { Agree or } \\
\text { Disagree }\end{array}$ \\
\hline
\end{tabular}

*Average of respondents' answers for every statement.

Table 4.10 shows that the highest mean was for the statement: I am aware of the potential risks in Hajj season (e.g., stampede, floods, terror, fire, etc.) with

$(\mathrm{M}=3.77, \mathrm{St} . \mathrm{D}=1.140)$ which represents Agree as a general direction; since the mean (3.77) lies on the interval of [3.41-4.00] on the Likert 5-point scale, followed by the statement: In my experience during Hajj of 2016, the presence of the fire department was sufficient with $(\mathrm{M}=3.63, \mathrm{St} . \mathrm{D}=1.101)$ which represents Agree, followed by the statement: In my experience during Hajj of 2016, the police presence was sufficient with $(\mathrm{M}=3.62, \mathrm{St} . \mathrm{D}=1.149)$ which represents Agree, While all other statements were (Neither Agree or Disagree), the last rank was for: In my experience during Hajj of 2016, there was sufficient equipment to respond to accidents with $(\mathrm{M}=2.92, \mathrm{St} . \mathrm{D}=1.201)$ which represents Neither Agree or Disagree as a general direction. 
When respondents were asked about which disaster they had ever experienced during Hajj season, they answered as reported in table 4.6.

Table 4.11.

Experience during Hajj Season

\begin{tabular}{|c|c|c|c|c|}
\hline \multirow{4}{*}{ Q19 } & Types & N & $(\%)$ & Rank \\
\hline \multirow{4}{*}{$\begin{array}{c}\text { Which of the } \\
\text { following have you } \\
\text { ever experienced } \\
\text { during Hajj } \\
\text { season? }\end{array}$} & Stampede disaster & 424 & 60 & 1 \\
\cline { 2 - 5 } & Fire disaster & 325 & 46.4 & 2 \\
\cline { 2 - 5 } & Transport disaster & 322 & 46 & 3 \\
\cline { 2 - 5 } & None of above & 136 & 32.7 & 4 \\
\cline { 2 - 5 } & Flood disaster & 89 & 12.7 & 6 \\
\cline { 2 - 5 } & $\begin{array}{c}\text { Bioterrorism/Biological } \\
\text { and Chemical disaster }\end{array}$ & 46 & 6.6 & 7 \\
\cline { 2 - 5 } & Epidemic disaster & 41 & 5.9 & 8 \\
\hline
\end{tabular}

Table 4.11 shows that the most experienced disaster during the Hajj season was a stampede with $60.6 \%$ of the total sample, followed by a fire disaster with $46.4 \%$ of the total sample, followed by a transport disaster with $46.0 \%$ of the total sample, followed by a building collapse disaster with $32.7 \%$ of the total sample, followed by a flood disaster with $12.7 \%$ of the total sample, followed by a bioterrorism/biological and chemical disaster with $6.6 \%$. The last rank was for epidemic disaster with $5.9 \%$ of the total 
sample, whereas $19.4 \%$ of the total of sample had experienced none of the aforementioned disasters.

\section{Section5: Source of Knowledge}

The sources of knowledge of disasters are described in the following section, from 1 for least useful to 5 as most useful. Results are shown in table 4.12.

\section{Table 4.12.}

$\underline{\text { Sources of Knowledge }}$

\begin{tabular}{|l|c|c|c|}
\hline \multicolumn{1}{|c|}{ Q20 } & Mean* & $\begin{array}{c}\text { Std. } \\
\text { Deviation }\end{array}$ & Rank \\
\hline Real disaster & 4.31 & 0.977 & 1 \\
\hline Drills practice & 4.25 & 1.046 & 2 \\
\hline Continuing education & 4.17 & 1.052 & 3 \\
\hline Co-workers, friends, or family & 4.05 & 1.104 & 4 \\
\hline Institution or University courses & 3.85 & 1.155 & 5 \\
\hline $\begin{array}{l}\text { Media (TV, social media, radio, or } \\
\text { internet) }\end{array}$ & 3.03 & 1.184 & 6 \\
\hline
\end{tabular}

* Average of respondents' answers for every statement.

Table 4.12 shows that the first source of knowledge was Real disaster with $(\mathrm{M}=4.31, \mathrm{SD}=0.977)$, followed by Drills practice with $(\mathrm{M}=4.25, \mathrm{SD}=1.046)$, followed by Continuing education with (M=4.17, $\mathrm{SD}=1.052)$, followed by Co-workers, friends, or family with $(\mathrm{M}=4.05, \mathrm{SD}=1.104)$, followed by Institution or University courses with $(\mathrm{M}=3.85, \mathrm{SD}=1.155)$, followed by Media $(T V$, social media, radio, or internet $)$ with $(\mathrm{M}=3.03, \mathrm{SD}=1.184)$ as the last ranked source of knowledge of disasters.

When respondents were asked about improving their knowledge about disaster preparedness, they answered as shown the table 4.13.

\section{Table 4.13.}


Courses that Improved knowledge about disaster preparedness

\begin{tabular}{|l|c|c|c|}
\hline \multicolumn{1}{|c|}{ Q21 } & Mean* & $\begin{array}{c}\text { Std. } \\
\text { Deviation }\end{array}$ & Rank \\
\hline Disaster management courses & 4.54 & 0.829 & 1 \\
\hline Drills practice & 4.44 & 0.900 & 2 \\
\hline Disaster management protocol & 4.31 & 0.952 & 3 \\
\hline Onsite visit & 4.07 & 1.031 & 4 \\
\hline Information website & 3.20 & 1.169 & 5 \\
\hline Information pamphlets & 3.11 & 1.266 & 6 \\
\hline
\end{tabular}

* Average of respondents' answers for every statement.

Table 4.13 shows that the first source of improving knowledge about disaster preparedness was Disaster management courses with $(\mathrm{M}=4.54, \mathrm{SD}=0.829)$, followed by Drills practice with $(\mathrm{M}=4.44, \mathrm{SD}=0.900)$, followed by Disaster management protocol with $(\mathrm{M}=4.31, \mathrm{SD}=0.952)$, followed by Onsite visit with $(\mathrm{M}=4.07, \mathrm{SD}=1.031)$, followed by Information website with $(\mathrm{M}=3.20, \mathrm{SD}=1.169)$, followed by Informational pamphlets as the last ranked with $(\mathrm{M}=3.11, \mathrm{SD}=1.266)$.

When respondents were asked their opinion about which educational courses should be taken by EMS providers to prepare for disasters, they answered as shown in table 4.14 .

\section{Table 4.14.}

$\underline{\text { Educational Courses That Should be taken in Preparing for disaster }}$

\begin{tabular}{|l|c|c|c|}
\hline \multicolumn{1}{|c|}{ Q22 } & Mean* & Std. Deviation & Rank \\
\hline Incident command system & 4.54 & 0.800 & 1 \\
\hline Field triage & 4.50 & 0.787 & 2 \\
\hline $\begin{array}{l}\text { Advance Trauma Life Support } \\
\text { (ATLS) }\end{array}$ & 4.47 & 0.811 & 3 \\
\hline $\begin{array}{l}\text { Prehospital Trauma Life } \\
\text { Support (PHTLS) }\end{array}$ & 4.30 & 0.879 & 4 \\
\hline $\begin{array}{l}\text { Advance Cardiac Life Support } \\
\text { (ACLS) }\end{array}$ & 4.26 & 0.892 & 5 \\
\hline
\end{tabular}




\begin{tabular}{|l|l|l|l|}
\hline Basic Life Support (BLS) & 4.23 & 0.952 & 6 \\
\hline First Aid & 4.19 & 1.026 & 7 \\
\hline Infection Control & 3.98 & 1.128 & 8 \\
\hline
\end{tabular}

*Average of respondents' answers for every statement.

Table 4.14 shows that, in the opinion of SRC-EMS providers, the first educational course that should be taken in preparing for disaster was Incident command system with $(\mathrm{M}=4.54, \mathrm{SD}=0.800)$, followed by Field triage with $(\mathrm{M}=4.50, \mathrm{SD}=0.787)$, followed by ATLS with (M=4.47, SD=0.811), followed by PHTLS with $(\mathrm{M}=4.30$, $\mathrm{SD}=0.879)$, followed by $A C L S$ with $(\mathrm{M}=4.26, \mathrm{SD}=0.892)$, followed by $B L S$ with $(\mathrm{M}=4.23, \mathrm{SD}=0.952)$, followed by First Aid with $(\mathrm{M}=4.19, \mathrm{SD}=1.026)$, followed by Infection control with $(\mathrm{M}=3.98, \mathrm{SD}=1.128)$ as the last ranked among educational courses.

\section{Research Questions and Hypotheses Answers by using Univariate Analysis}

\section{Research Question 1}

Is there a significant difference in the knowledge of disaster preparedness for mass gatherings between different categories of EMS providers based on their age?

To answer this question, a one-way analysis of variance (ANOVA) was used to determine whether there are any statistically significant differences between the means of three or more independent (unrelated) groups. The test results are shown in table 4.15.

\section{Table 4.15.}

$\underline{\text { Differences in general knowledge of Disasters Preparedness based on age }}$

\begin{tabular}{|c|c|c|c|c|c|}
\hline Age & $\mathbf{N}$ & Mean* & SD & $\begin{array}{c}\text { F } \\
\text { Value }\end{array}$ & $\begin{array}{c}\text { ANOVA } \\
\text { P-value }\end{array}$ \\
\hline Less than 25 years & 7 & 2.916 & 0.695 & \multirow{3}{*}{5.068} & \multirow{3}{*}{0.000} \\
\hline $25-29$ years & 215 & 2.582 & 0.678 & & \\
\hline $30-34$ years & 232 & 2.736 & 0.667 & & \\
\hline
\end{tabular}




\begin{tabular}{|c|c|c|c|}
\hline $35-39$ years & 135 & 2.977 & 0.767 \\
\hline $40-44$ years & 59 & 2.902 & 0.816 \\
\hline 45-49 years & 28 & 2.931 & 0.850 \\
\hline 50 years and above & 24 & 2.923 & 1.041 \\
\hline
\end{tabular}

*Average of respondents' answers for every statement.

Table 4.15 shows that P-value of ANOVA test was $0.000<0.0001$, which enabled the researcher to conclude that there is a statistically significant difference among participants. Thus, there is a difference in the general knowledge of disaster preparedness for mass gatherings between different categories of SRC-EMS providers based on their age.

Use Bonferroni adjustment for multiple Comparisons test was affected to decide which Age group had more knowledge. The results are shown in Figure (4.1) below. 


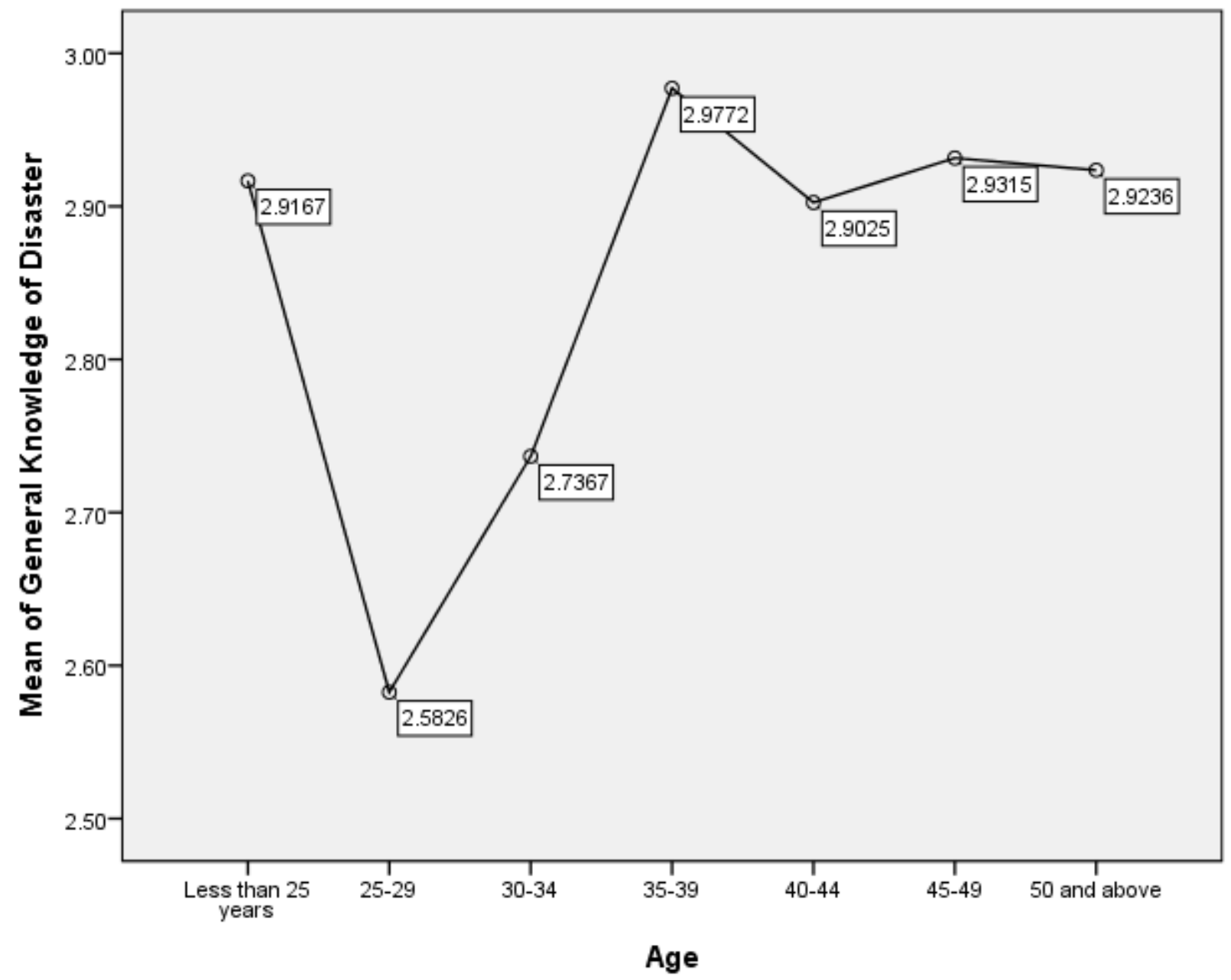

Figure 4.1 Mean knowledge of disaster based on the age

Figure 4.1 shows that there is a statistically significant difference between the age group of 35-39 years and both groups 25-29 and 30-34 years in favor of 35-39 years which has the highest mean of the General Knowledge of Disaster with 2.977, with significant differences 0.240 and 0.394 between the other group respectively (See Appendix F for SPSS result).

Table 4.16.

Difference in Knowledge of Hajj 2016 based on Age. 


\begin{tabular}{|c|c|c|c|c|c|}
\hline Age & $\mathbf{N}$ & Mean* & SD & $\begin{array}{c}\text { F } \\
\text { Value }\end{array}$ & $\begin{array}{c}\text { ANOVA } \\
\text { P-value }\end{array}$ \\
\hline Less than 25 years & 7 & 2.928 & 0.584 & \multirow{7}{*}{1.772} & \multirow{7}{*}{0.102} \\
\hline $25-29$ years & 215 & 3.310 & 0.933 & & \\
\hline $30-34$ years & 232 & 3.357 & 0.934 & & \\
\hline $35-39$ years & 135 & 3.550 & 0.798 & & \\
\hline 40-44 years & 59 & 3.437 & 0.866 & & \\
\hline $45-49$ years & 28 & 3.660 & 1.00 & & \\
\hline 50 years and above & 24 & 3.284 & 1.350 & & \\
\hline
\end{tabular}

*Average of respondents' answers for every statement.

Table 4.16 shows the distribution of knowledge averages according to age; from which $\mathrm{F}=1.772$ with a P-value is $0.102>0.0001$ enabled this researcher to conclude that there is no statistically significant difference in Knowledge of disaster regarding the Hajj of 2016 based on Age (See Appendix G for SPSS result).

\section{Research Question 2}

Is there a significant difference in the knowledge of disaster preparedness for mass gatherings between different categories of EMS-providers based on level of education?

To answer this question, a one-way analysis of variance (ANOVA) was performed, and the results are shown in table 4.17.

Table 4.17.

Difference in general knowledge of disasters preparedness based on level of education.

\begin{tabular}{|c|c|c|c|c|c|}
\hline level of education & $\mathbf{N}$ & Mean* & SD & F-Value & $\begin{array}{l}\text { ANOVA } \\
\text { P-value }\end{array}$ \\
\hline High school & 52 & 2.423 & 0.701 & \multirow{5}{*}{28.863} & \multirow{5}{*}{0.000} \\
\hline Diploma +2 years & 198 & 2.584 & 0.583 & & \\
\hline Diploma +3 years & 253 & 2.618 & 0.634 & & \\
\hline Bachelor's degree & 169 & 3.165 & 0.800 & & \\
\hline Master's degree & 23 & 3.695 & 0.706 & & \\
\hline
\end{tabular}




\begin{tabular}{|c|c|c|c|c|c|}
\hline Other & 5 & 3.183 & 1.053 & & \\
\hline
\end{tabular}

*Average of respondents' answers for every statement.

Table 4.17 showed that the P-value of the ANOVA test was $0.000<0.0001$, enabling this researcher to conclude that there is a statistically significant difference among participants. Thus, there is a statistically significant difference in the general knowledge of disaster preparedness for mass gathering between different categories of EMS-providers based on their level of education.

Use Bonferroni adjustment for multiple Comparisons test was performed to decide which education level was more informed about disaster preparedness. Results are shown in Figure 4.2 below. 


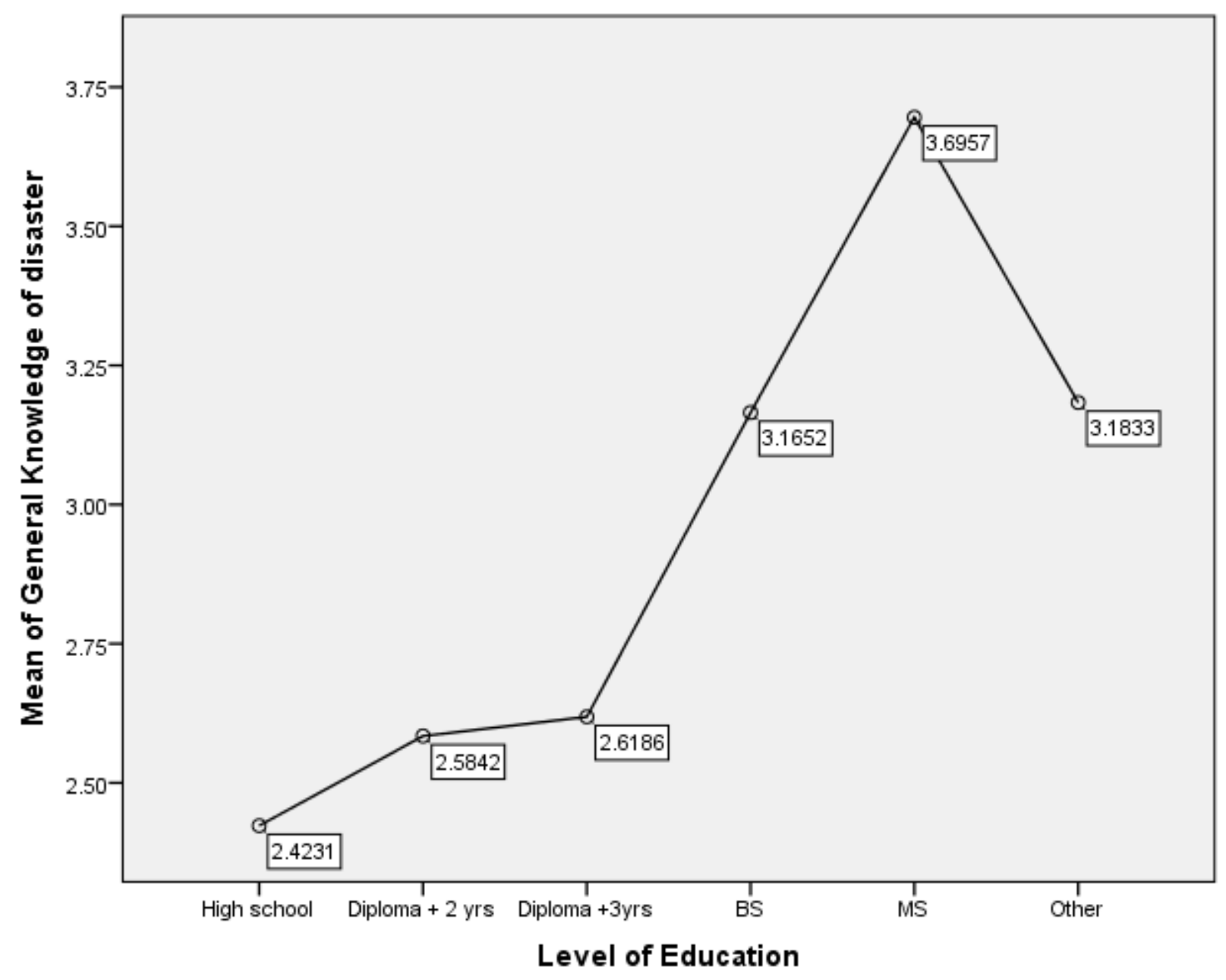

Figure 4.2 Mean general knowledge of disaster based on the level of education

Figure 4.2 shows that there is a statistically significant difference between the Education level Master's degree and the other groups in favor of a Master's degree holders, who had the highest mean of general knowledge of disasters with (3.695), with significant differences 1.272, 1.111, 1.077 and 0.530 between High school, Diploma +2 years, Diploma +3 years and Bachelor's degree respectively. Also, there is a statistically significant difference between the Bachelor's degree and the groups of High school, Diploma +2 years and Diploma +3 years in favor of BS which has 3.165 as a mean of the general knowledge of disasters with significant differences $0.742,0.581$ and 0.546 
between High school, Diploma +2 years and Diploma +3 years respectively (See Appendix H for SPSS result).

\section{Table 4.18.}

Differences in knowledge of Hajj 2016, based on level of education

\begin{tabular}{|c|c|c|c|c|r|}
\hline Level of Education & N & Mean* & SD & \multirow{2}{*}{ F-Value } & $\begin{array}{c}\text { ANOVA } \\
\text { P-value }\end{array}$ \\
\hline High school & 52 & 3.070 & 1.042 & & \\
\cline { 1 - 4 } Diploma + 2 years & 198 & 3.344 & 0.928 & & \\
\cline { 1 - 3 } Diploma +3 years & 253 & 3.332 & 0.947 & \multirow{3}{*}{6.469} & \multirow{2}{*}{0.000} \\
\hline Bachelor's degree & 169 & 3.505 & 0.785 & & \\
\hline Master's degree & 23 & 4.217 & 0.704 & & \\
\hline Other & 5 & 4.033 & 1.138 & & \\
\hline
\end{tabular}

*Average of respondents' answers for every statement.

Table 4.18 shows that the P-value of the ANOVA test is $0.000<0.0001$, leading the researcher to conclude that there is a statistically significant difference among participants. Therefore, there is a statistically significant difference in the knowledge of disaster regarding the Hajj of 2016 directions based on level of EMS providers.

Use Bonferroni adjustment for multiple Comparisons test was performed to decide which education level possessed the most knowledge. The results are shown in Figure 4.3 below. 


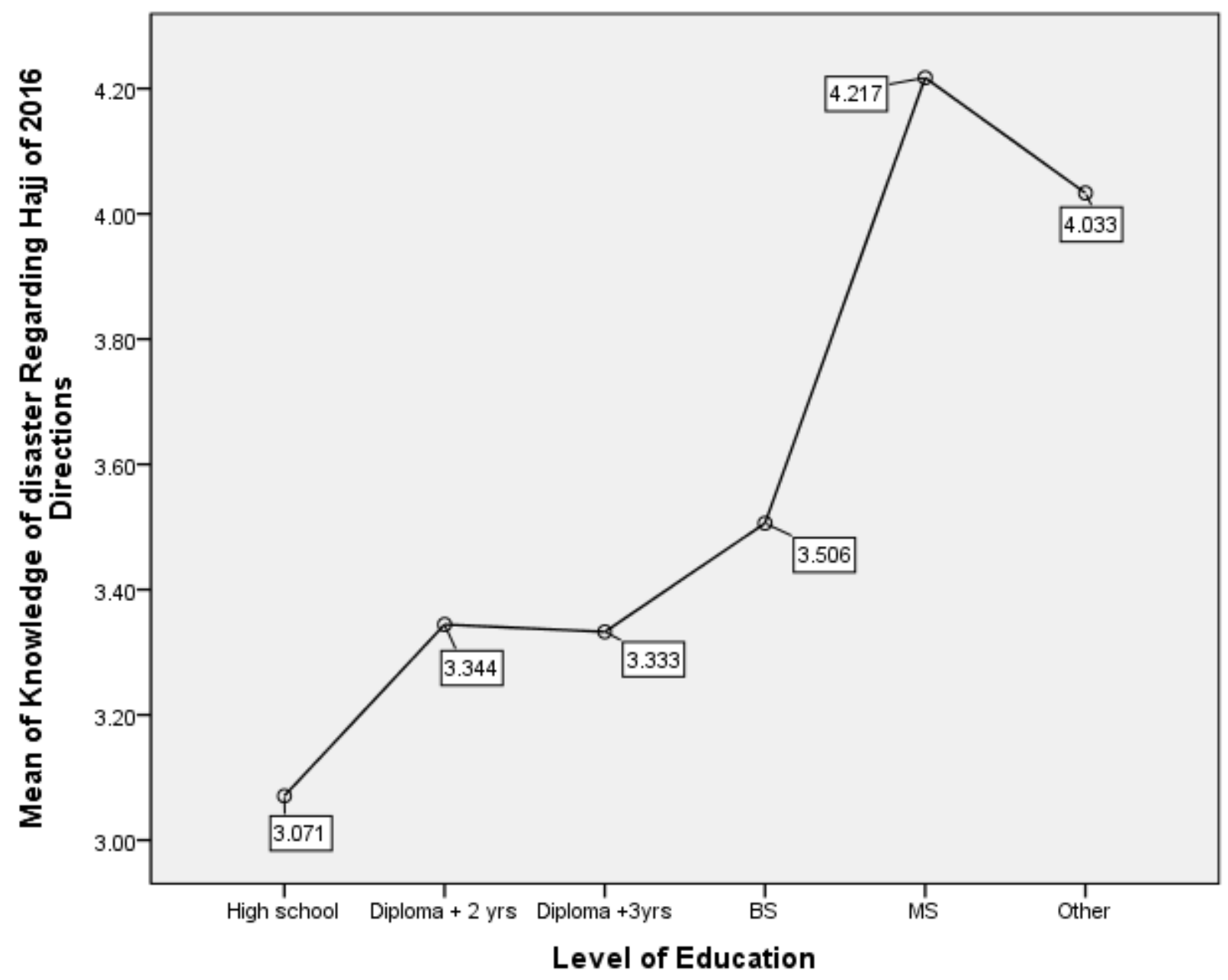

Figure 4.3 Mean of knowledge of disaster regarding the Hajj of 2016 based on level of education

Figure 4.3 shows that there is a statistically significant difference between Master's degree holders and other groups, in favor of Master's degree holders, who had the highest mean of knowledge of disasters regarding Hajj of 2016. The Directions 4.217, indicated significant differences 1.146, 0.873, 0.884 and 0.711 between High school, Diploma +2 years, Diploma +3 years and Bachelor's degree respectively (See Appendix I for SPSS result). 


\section{Research Question 3}

Is there a significant difference in the knowledge of disaster preparedness for mass gatherings between different categories of EMS-providers based on their level of EMS (professional classification)?

To answer this question, a one-way analysis of variance (ANOVA) was performed. The results are shown in the following tables.

\section{Table. 4.19.}

Difference in General Knowledge of disasters preparedness based on level of EMS

\begin{tabular}{|c|c|c|c|c|c|}
\hline level of EMS & $\mathbf{N}$ & Mean* & SD & F-Value & $\begin{array}{c}\text { ANOVA } \\
\text { P-value }\end{array}$ \\
\hline First responder & 62 & 2.524 & 0.741 & & \\
\hline EMS- Technician & 459 & 2.601 & 0.618 & \multirow{2}{*}{44.522} & \multirow{2}{*}{0.000} \\
\cline { 1 - 4 } EMS- paramedic & 158 & 3.278 & 0.794 & & \\
\hline Physician & 21 & 3.210 & 0.815 & & \\
\hline
\end{tabular}

*Average of respondents' answers for every statement.

Table 4.19 shows that $\mathrm{P}$-value of ANOVA test is $0.000<0.0001$, enabling the researcher to conclude that there is a statistically significant difference among participants. Therefore, there is a statistically significant difference in the general knowledge of disaster preparedness for mass gatherings between different categories of EMS-providers based on their level of EMS.

Use Bonferroni adjustment for multiple Comparisons test was performed to decide which EMS level possessed more general knowledge of disaster preparedness for mass gatherings. This is shown in Figure 4.4 below. 


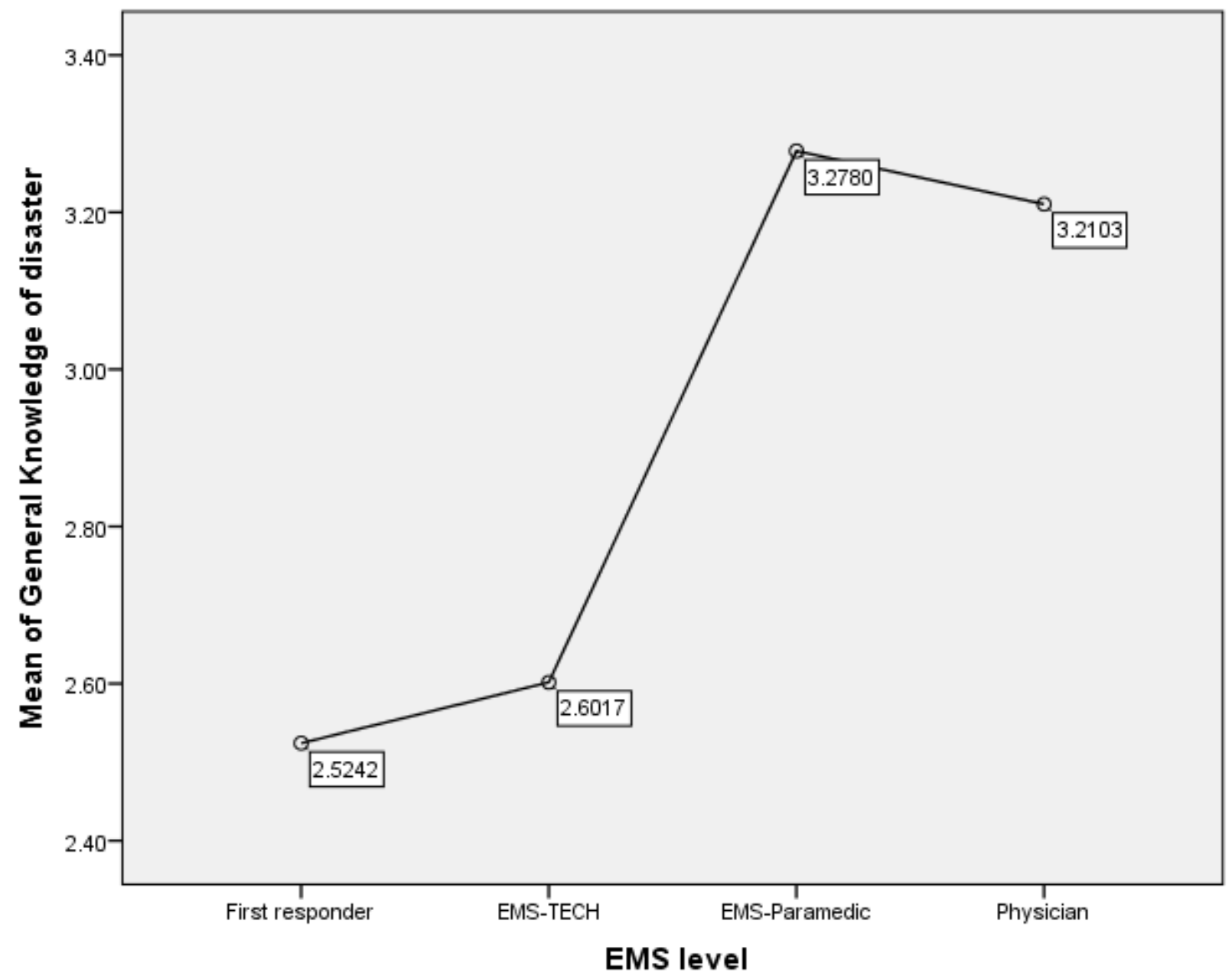

Figure 4.4 Mean of general knowledge of disaster based on EMS level

Figure 4.4 shows that there is a statistically significant difference between EMSparamedic level and the two groups of First responder, EMS- Technician in favor of EMS- paramedic which has the highest mean of the General Knowledge of Disaster with 3.278 , with significant differences 0.753 and 0.676 respectively.

There is a statistically significant difference between EMS-Paramedic level and the two groups of First responder, EMS- Technician in favor of Physician which has 
3.210 as a mean of the General Knowledge of Disaster, with significant differences 0.686 and 0.608 respectively (See Appendix J for SPSS result).

Table 4.20.

Difference in Knowledge the Hajj of 2016 based on the level of EMS.

\begin{tabular}{|c|c|c|c|c|c|}
\hline level of EMS & N & Mean* & SD & $\begin{array}{c}\text { F } \\
\text { Value }\end{array}$ & $\begin{array}{c}\text { ANOVA } \\
\text { P-value }\end{array}$ \\
\hline First responder & 62 & 3.121 & 1.056 & & \multirow{2}{*}{0.000} \\
\cline { 1 - 4 } EMS- Technician & 459 & 3.350 & 0.929 & \multirow{2}{*}{6.767} & \multirow{2}{*}{0.0 .822} \\
\cline { 1 - 3 } EMS- Paramedic & 158 & 3.539 & & \\
\hline Physician & 21 & 4.015 & 0.718 & & \\
\hline
\end{tabular}

*Average of respondents' answers for every statement.

Table 4.20 shows that the P-value of the ANOVA test is $0.000<0.0001$, leading the researcher to conclude that there is a statistically significant difference among participants. Thus, there is a statistically significant difference in knowledge of disasters regarding the Hajj of 2016 Directions based on the level of certification.

Use Bonferroni adjustment for multiple Comparisons test was performed to decide which level of certification possesses more knowledge of disasters regarding the Hajj of 2016. Results are shown in Figure 4.5 below. 


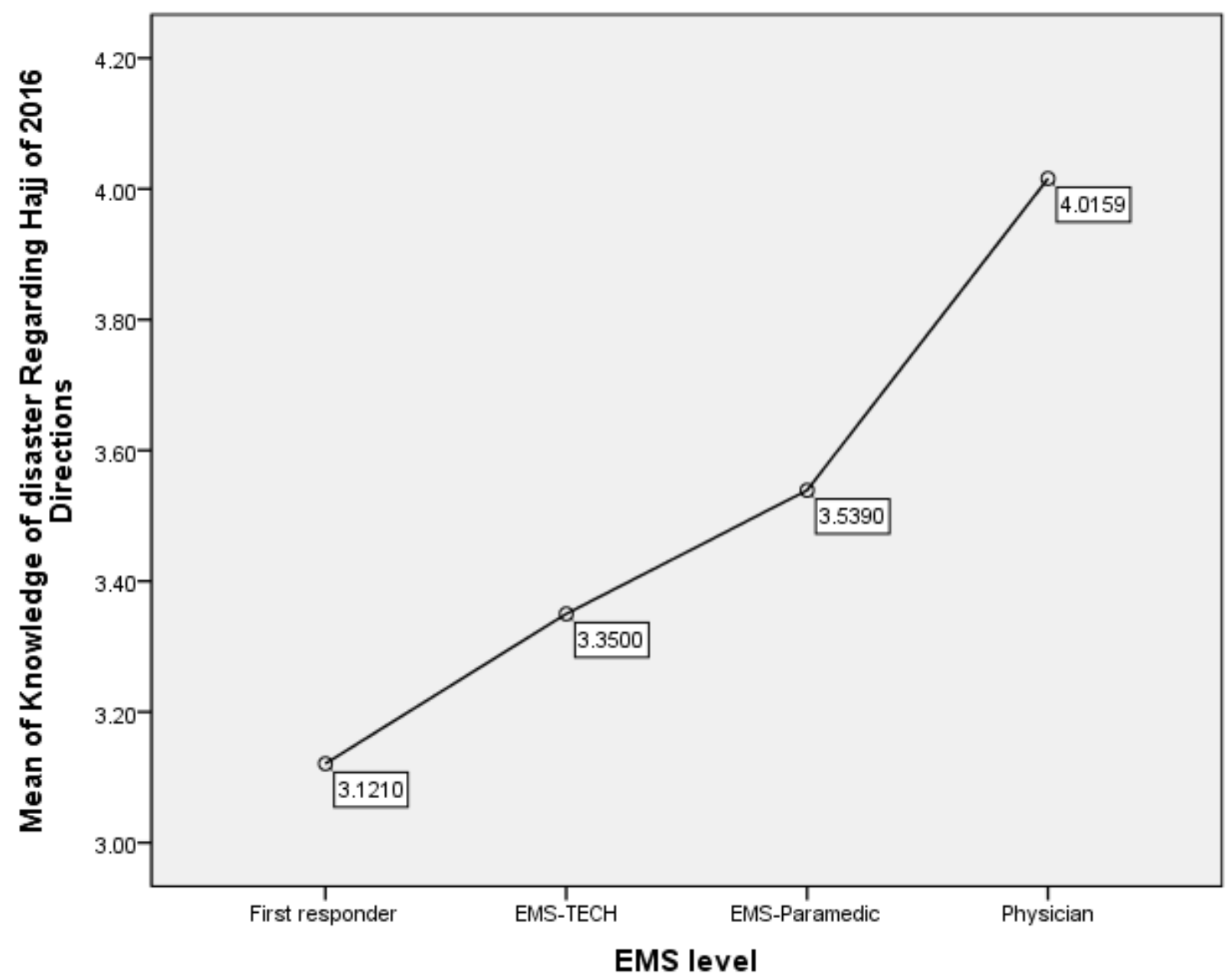

Figure 4.5 Mean of knowledge of disaster regarding Hajj based on level of EMS

Figure 4.5 shows that there is a statistically significant difference of general knowledge about disasters between Saudi Red Crescent EMS providers at the physician level and the other three groups, namely: First responders, EMS- Technicians and EMSparamedics, in favor of Physicians who have 4.015 as the highest mean. There are also significant differences between the other three groups $0.894,0.665$ and 0.476 respectively.

There exists a statistically significant difference between Physicians and the two groups of First responders and EMS-Technicians, in favor of the paramedics who have 
3.539 as a mean of the general knowledge of disasters, with significant differences between the other two groups; 0.418 and 0.188 respectively (See Appendix K for SPSS result).

\section{Research Question 4}

Is there a significant difference in the knowledge of disaster preparedness for mass gatherings between different categories of EMS-providers based on the sector of EMS training received?

To answer this question, a one-way analysis of variance (ANOVA) was performed. The results are shown in table 4.21.

Q6- Which of the following statements best describe the EMS training you received?

Table 4.21.

Difference in General Knowledge of disaster preparedness based on the sector of EMS $\underline{\text { training }}$

\begin{tabular}{|c|c|c|c|c|c|}
\hline Sector of EMS Training & N & Mean* & SD & $\begin{array}{c}\text { F } \\
\text { Value }\end{array}$ & $\begin{array}{c}\text { ANOVA } \\
\text { P-value }\end{array}$ \\
\hline Government sector & 235 & 2.714 & 0.790 & & \\
\hline Private sector & 358 & 2.642 & 0.599 & \multirow{2}{*}{24.407} & \multirow{2}{*}{0.000} \\
\hline Military sector & 63 & 3.366 & 0.878 & & \\
\hline Outside of the Saudi Arabia & 44 & 3.181 & 0.740 & & \\
\hline
\end{tabular}

* Average of respondents' answers for every statement.

Table 4.21 shows that P-value of ANOVA test is $0.000<0.0001$, leading the researcher to conclude that there exists a statistically significant difference among participants. There is a statistically significant difference in the general knowledge of disaster preparedness for mass gatherings between the different categories of EMSproviders based on the sector in which the training was received. 
Use Bonferroni adjustment for multiple Comparisons tests were performed to decide which training is more effective. This is shown in Figure 4.6 below.

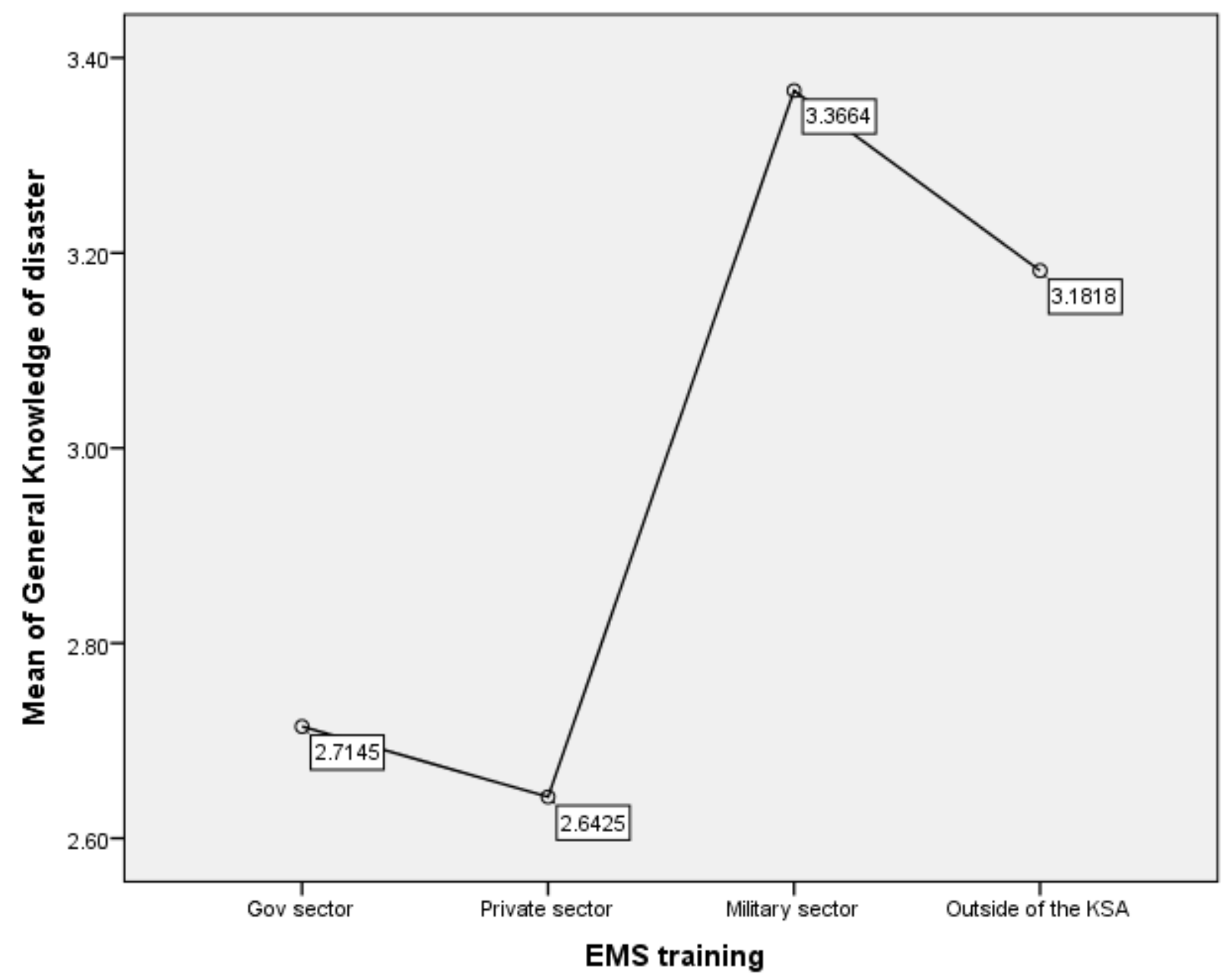

Figure 4.6 Mean of knowledge of disaster based the sector of EMS training received

Figure 4.6 shows that there is a statistically significant difference in disaster knowledge between the EMS providers who were trained in the military sector and both of the other groups who received training in the government sector and in the private sector, in favor of those trained by the military. The providers trained in the military sector had the highest mean of the general knowledge of disasters with 3.366, with significant differences $0.651,0.723$ with Government and Private sectors respectively. 
There is a statistically significant difference between those trained outside of Saudi Arabia and those trained in the government sector or the private sector, in favor of the former. Those trained outside of Saudi Arabia had a mean of 3.181 in General Knowledge of Disasters with significant differences 0.467 , and 0.539 with Government, Private sectors respectively (See Appendix L for SPSS result).

\section{Table 4.22.}

Difference in Knowledge of the Hajj 2016 based on the sector of EMS training.

\begin{tabular}{|c|c|c|c|c|c|}
\hline $\begin{array}{c}\text { Sector of EMS Training } \\
\text { received }\end{array}$ & N & Mean* & SD & $\begin{array}{c}\text { F } \\
\text { Value }\end{array}$ & $\begin{array}{c}\text { ANOVA } \\
\text { P-value }\end{array}$ \\
\cline { 1 - 3 } Government sector & 235 & 3.332 & 1.00 & & \\
\cline { 1 - 3 } Private sector & 358 & 3.379 & 0.881 & \multirow{2}{*}{1.896} & \multirow{2}{*}{0.129} \\
\cline { 1 - 4 } Military sector & 63 & 3.500 & 0.942 & & \\
\hline Outside of the KSA & 44 & 3.662 & 0.788 & & \\
\hline
\end{tabular}

*Average of respondents' answers for every statement.

Table 4.22 shows the distribution and directions of Knowledge of disasters regarding the Hajj of 2016 based on EMS Training; from which F $=1.896$ with P-value is $0.129>0.0001$ leading the researcher to conclude that there is no statistically significant difference in Knowledge of disaster regarding the Hajj of 2016 based on EMS Training (See Appendix M for SPSS result).

\section{Research Question 5}

Is there a significant difference in the knowledge of disaster preparedness for mass gatherings between different categories of EMS providers based on years of experience?

To answer this question, a one-way analysis of variance (ANOVA) was performed, the results of which are shown in table 4.23.

\section{First: Years of experience worked at SRCA}


Q7- How long have you worked as EMS providers for the Saudi Red Crescent?

Table: 4.23.

Difference in General Knowledge of disasters preparedness based on years of experience working for SRCA

\begin{tabular}{|c|c|c|c|c|c|}
\hline Years of Experience & $\mathbf{N}$ & Mean* & SD & $\begin{array}{c}\text { F } \\
\text { Value }\end{array}$ & $\begin{array}{c}\text { ANOVA } \\
\text { P-value }\end{array}$ \\
\hline Under one year & 9 & 2.564 & 0.623 & \multirow{6}{*}{4.790} & \multirow{6}{*}{0.000} \\
\hline 1 - under 5 years & 196 & 2.658 & 0.736 & & \\
\hline 5-under 10 years & 244 & 2.714 & 0.701 & & \\
\hline 10 -under 15 years & 132 & 2.862 & 0.685 & & \\
\hline 15 -under 20 years & 64 & 3.125 & 0.752 & & \\
\hline 20 years and above & 55 & 2.759 & 0.903 & & \\
\hline
\end{tabular}

*Average of respondents' answers for every statement.

Table 4.23 shows that the P-value of the ANOVA test is $0.000<0.0001$, which enables the researcher to conclude that there is a statistically significant difference among participants. Thus, there is a statistically significant difference in the general knowledge of disaster preparedness for mass gatherings between different categories of EMSproviders based on their years of experience.

To decide which group of EMS providers had more knowledge, use Bonferroni adjustment for multiple comparison test was performed. Results are shown in Figure 4.7 below. 


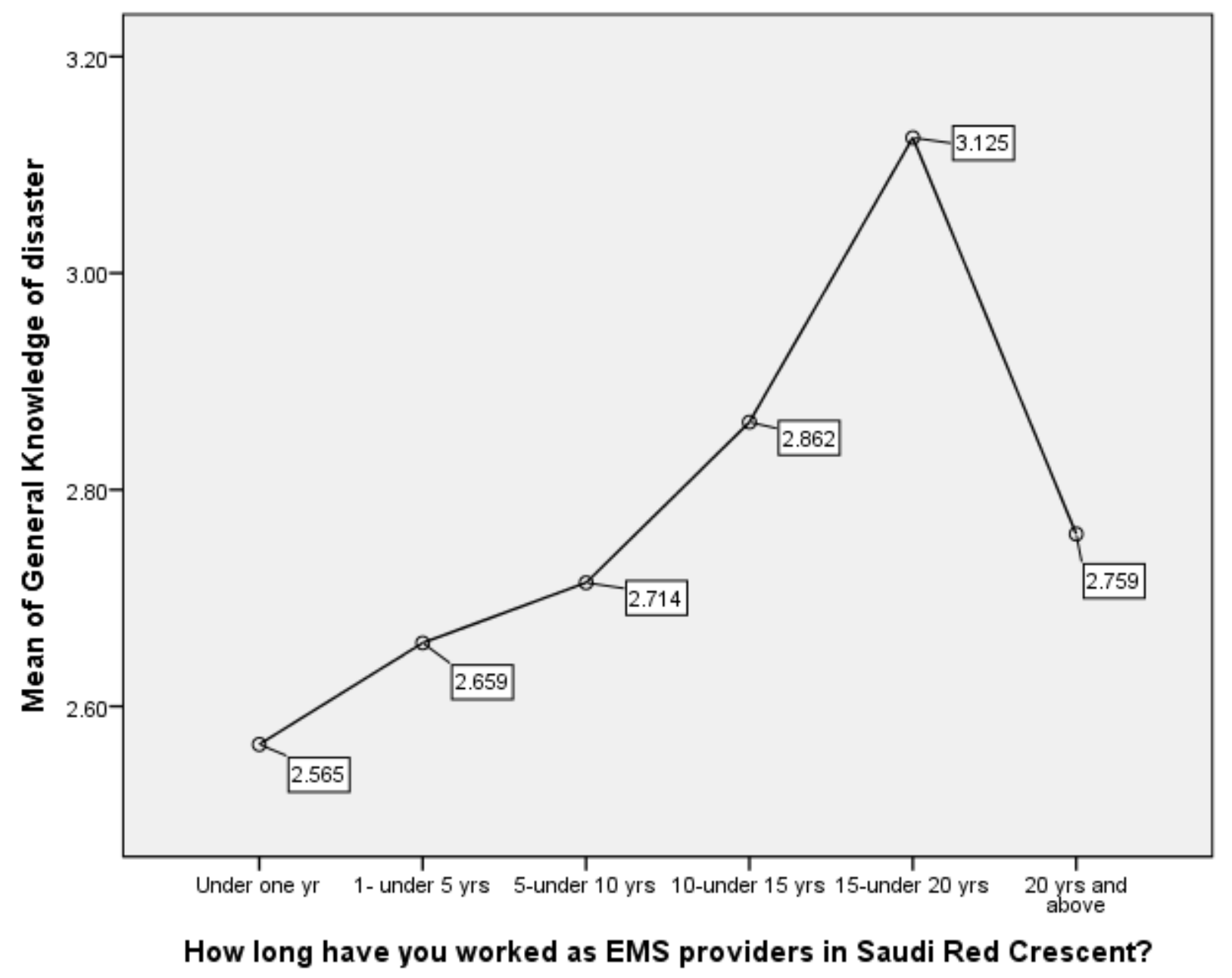

Figure 4.7 Mean of general knowledge of disaster based on years of experience

Figure 4.7 shows that there is a statistically significant difference between the group having 15-less than 20 years of experience with the Red Crescent and all other groups. This group had the highest mean of the General Knowledge of Disaster with 3.12, with significant differences $0.56,0.46,0.41,0.26$ and 0.36 with other groups respectively.

Moreover, there is a statistically significant difference between the group having 10-less than 15 years of experience the group having 1-less than 4 years of experience and in favor of the former, which has 2.86 as a mean of the General Knowledge of 
Disasters, with significant differences 0.20 relative to the group having 1-less than 4 years of experience (See Appendix N for SPSS result).

Table: 4.24 .

Difference in Knowledge of Haij 2016 based on years of experience working for SRCA

\begin{tabular}{|c|c|c|c|c|c|}
\hline Years of Experience & N & Mean* & SD & F-Value & $\begin{array}{c}\text { ANOVA } \\
\text { P-value }\end{array}$ \\
\hline Under one year & 9 & 2.685 & 0.626 & & \\
1- under 5 years & 196 & 3.346 & 1.010 & & \\
\cline { 1 - 4 } 5-under 10 years & 244 & 3.332 & 0.891 & \multirow{3}{*}{3.602} & \multirow{2}{*}{0.003} \\
\cline { 1 - 4 } 10-under 15 years & 132 & 3.471 & 0.737 & & \\
\cline { 1 - 3 } 15-under 20 years & 64 & 3.752 & 0.800 & & \\
\hline 20 years and above & 55 & 3.327 & 1.184 & & \\
\hline
\end{tabular}

*Average of respondents' answers for every statement.

Table 4.24 shows that the P-value of the ANOVA test is $0.003<0.0001$, enabling the researcher to conclude that there is a statistically significant difference among participants. Hence, there is a statistically significant difference in Knowledge of disasters regarding Hajj of 2016 directions based on the years of experience working for the Saudi Red Crescent.

The results of using Bonferroni adjustment for Multiple Comparisons tests are shown in Figure 4.8 below. 


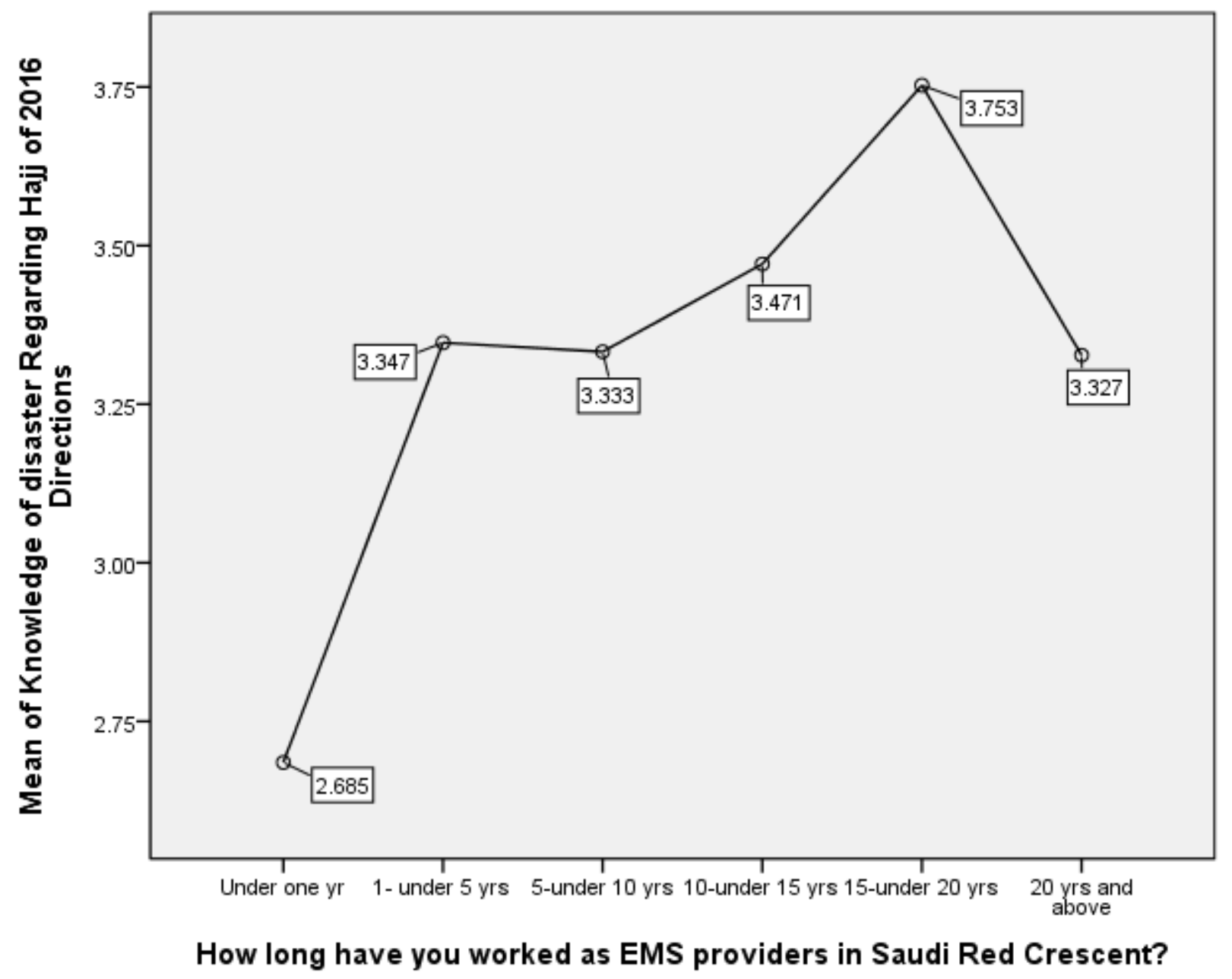

Figure 4.8 Mean of knowledge of disaster regarding Hajj of 2016 based years of experience.

Figure 4.8 shows that there is a statistically significant difference between the group having 15-under 20 years of experience and all the other groups under 1 year, 1under 5 years, 5- under 10 years in favor of the former, which has the highest mean of the General Knowledge of Disasters with 3.75, with significant differences 1.06, 0.40 and 0.41 respectively.

Additionally, there is a statistically significant difference between the group having 10-less than 15 years of experience working as an EMS provider for the Saudi 
Red Crescent and the group having under one year experience in favor of the former which has 3.47 as a mean of the General Knowledge of Disasters, with significant differences 0.78 (See Appendix O for SPSS result).

Second: number of times worked at the Hajj

Q8- How many times have you worked at the Hajj?

\section{Table 4.25.}

Difference in General Knowledge of disasters preparedness based on number of times worked at the Haji

\begin{tabular}{|c|c|c|c|c|c|}
\hline $\begin{array}{c}\text { Experience } \\
\text { How many times have you worked at Hajj? }\end{array}$ & N & Mean* & SD & $\begin{array}{c}\text { F } \\
\text { Value }\end{array}$ & $\begin{array}{c}\text { ANOVA } \\
\text { P-value }\end{array}$ \\
\hline One Hajj season & 127 & 2.570 & 0.691 & & \\
\cline { 1 - 5 } Two Hajj seasons & 162 & 2.793 & 0.731 & \multirow{2}{*}{4.632} & \multirow{2}{*}{0.003} \\
\hline Three Hajj seasons & 140 & 2.731 & 0.828 & & \\
\hline Four Hajj seasons or more & 271 & 2.858 & 0.702 & & \\
\hline
\end{tabular}

*Average of respondents' answers for every statement.

Table 4.25 shows that P-value of ANOVA test is $0.003<0.0001$, thus leading the researcher to conclude that there is a statistically significant difference among participants. There is therefore a difference in the general knowledge of disaster preparedness for mass gatherings between different categories of EMS-providers based on their experience of Hajj.

The results of using Bonferroni adjustment for multiple Comparisons tests to decide which group is more knowledgeable are shown in Figure 4.9 below. 


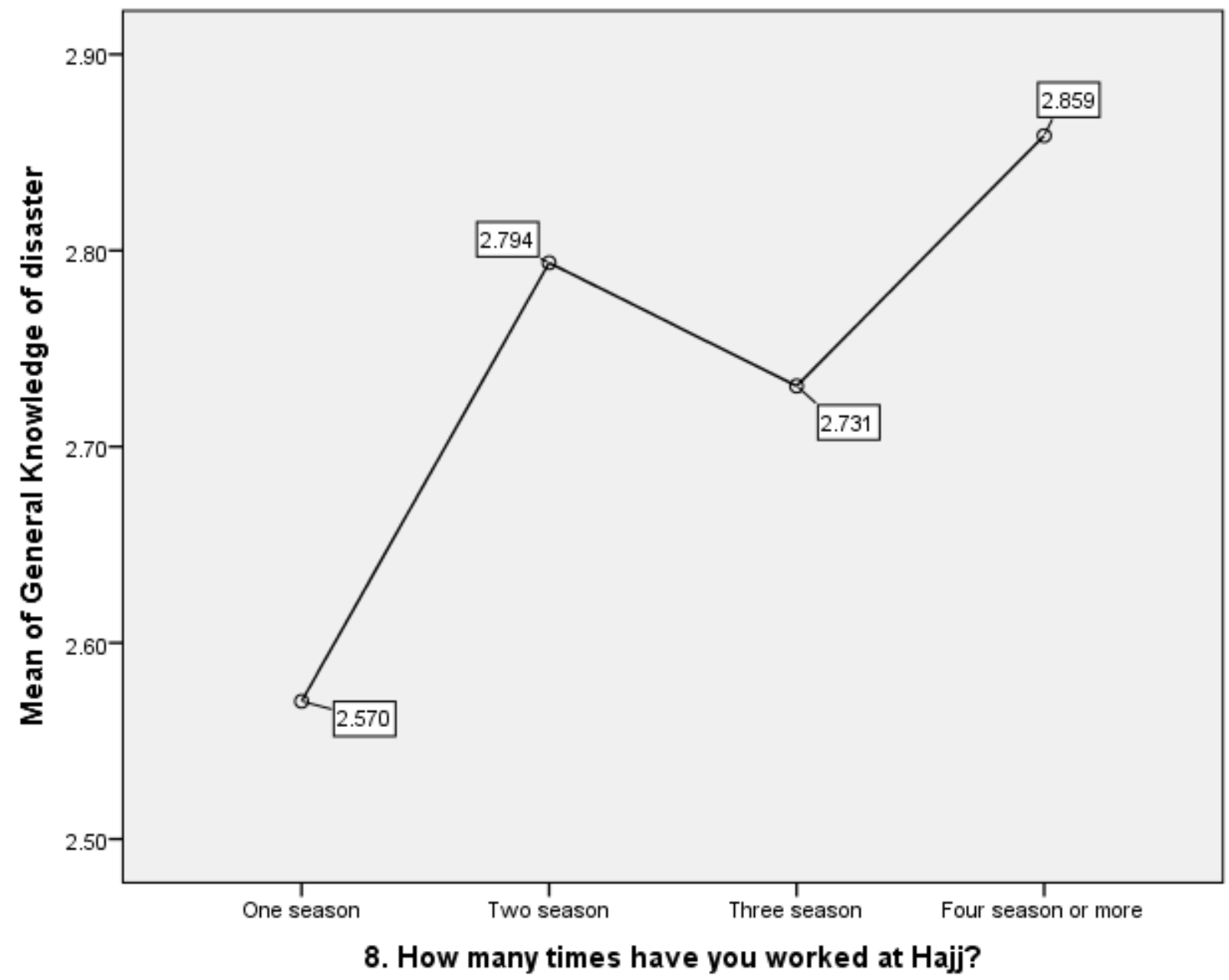

Figure 4.9 Mean of general knowledge of disaster based number of times worked at Hajj

Figure 4.9 shows that there is a statistically significant difference between the

Four seasons or more group and the group having worked only one season in favor of the former, which has the highest mean of General Knowledge of Disasters with 2.859.

Moreover, there is a statistically significant difference between the group having worked at Hajj twice and the group having worked only one season in favor of the former, which has a mean of General Knowledge of Disasters, with significant differences 0.223 (See Appendix P for SPSS result). 
Table 4.26.

Difference in Knowledge of the Haij 2016 based on number of times worked at the

Haji.

\begin{tabular}{|c|c|c|c|c|c|}
\hline $\begin{array}{c}\text { Experience } \\
\text { How many times have you worked at Hajj? }\end{array}$ & N & Mean* & SD & $\begin{array}{c}\text { F } \\
\text { Value }\end{array}$ & $\begin{array}{c}\text { ANOVA } \\
\text { P-value }\end{array}$ \\
\hline One Hajj season & 127 & 3.266 & 0.930 & & \\
\cline { 1 - 4 } Two Hajj seasons & 162 & 3.412 & 0.930 & \multirow{2}{*}{2.260} & \multirow{2}{*}{0.080} \\
\cline { 1 - 4 } Three Hajj seasons & 140 & 3.298 & 0.937 & & \\
\hline Four Hajj seasons or more & 271 & 3.392 & 0.925 & & \\
\hline
\end{tabular}

*Average of respondents' answers for every statement.

Table 4.24 shows the distribution of knowledge averages according with to the Hajj experience. The $\mathrm{F}$ value $=2.260$ with a $\mathrm{P}$-value is $0.080>0.0001$ enables the researcher to conclude that there is no statistically significant difference in Knowledge of disaster regarding the Hajj of 2016 based on years of experience at the Hajj (See Appendix Q for SPSS result).

\section{Research Question 6}

Is there a significant difference in the knowledge of disaster preparedness for mass gatherings between different categories of EMS providers based on training (previous disaster education/training, number of trainings and number of hours of training)?

To answer this question an (ANOVA) Test was performed to compare averages between different categories of EMS providers based on previous disaster education/training, number of trainings and number of hours of training, as follow: 
Table 4.27.

Difference in General Knowledge of Disaster Preparedness Based on training

\begin{tabular}{|c|c|c|c|c|c|c|}
\hline \multicolumn{2}{|c|}{$\begin{array}{c}\text { Training (Education/ Training } \\
\text { Number of trainings } \\
\text { Number of hours of training) }\end{array}$} & \multirow[b]{2}{*}{ Three times } & \multirow{2}{*}{$\begin{array}{l}\text { Mean* } \\
3.08 \\
\end{array}$} & \multirow{2}{*}{$\begin{array}{l}\text { SD } \\
0.72 \\
\end{array}$} & \multirow{2}{*}{\begin{tabular}{|c|} 
F \\
Value \\
29.07 \\
\end{tabular}} & \multirow{2}{*}{$\begin{array}{c}\text { ANOVA } \\
\text { P-value } \\
0.000\end{array}$} \\
\hline \begin{tabular}{|l|}
$10-$ How many \\
\end{tabular} & Training & & & & & \\
\hline $\begin{array}{l}\text { trainings/workshops/drills about } \\
\text { disaster preparedness have you }\end{array}$ & Workshops & $\begin{array}{l}\text { More than } \\
\text { three times }\end{array}$ & 3.29 & 0.84 & 41.41 & 0.000 \\
\hline $\begin{array}{l}\text { ever attended? } \\
\text { (See Appendix R for SPSS } \\
\text { result). }\end{array}$ & Drills & $\begin{array}{l}\text { More than } \\
\text { three times }\end{array}$ & 3.29 & 0.84 & 36.21 & 0.000 \\
\hline \multirow{3}{*}{$\begin{array}{l}\text { 11- Which of the following } \\
\text { best describes the frequency of } \\
\text { your attendance at a } \\
\text { trainings/workshops/drills about } \\
\text { disaster preparedness? N/A } \\
\text { (See Appendix S for SPSS result). }\end{array}$} & Training & $\begin{array}{c}\text { Four times } \\
\text { per year }\end{array}$ & 3.55 & 0.53 & 37.96 & 0.000 \\
\hline & Workshops & $\begin{array}{c}\text { Four times } \\
\text { per year }\end{array}$ & 3.56 & 0.61 & 44.48 & 0.000 \\
\hline & Drills & $\begin{array}{c}\text { Four times } \\
\text { per year }\end{array}$ & 3.61 & 0.79 & 33.04 & 0.000 \\
\hline \multirow{3}{*}{$\begin{array}{l}\text { 12- When was the last time you } \\
\text { attended a trainings/ } \\
\text { workshops/drills about disaster } \\
\text { preparedness? } \\
\text { (See Appendix T for SPSS }\end{array}$} & Training & \begin{tabular}{|c|}
$6-12$ \\
months ago
\end{tabular} & 3.06 & 0.70 & 33.64 & 0.000 \\
\hline & Workshops & $\begin{array}{c}6-12 \\
\text { months ago }\end{array}$ & 3.22 & 0.72 & 56.94 & 0.000 \\
\hline & Drills & $\begin{array}{c}6-12 \\
\text { months ago }\end{array}$ & 3.17 & 0.73 & 51.27 & 0.000 \\
\hline \multirow{3}{*}{$\begin{array}{l}\text { 13- What was the duration of } \\
\text { the last } \\
\text { trainings/workshops/drills about } \\
\text { disaster that you attended? } \\
\text { (See Appendix U for SPSS }\end{array}$} & Training & 5-9 hours & 3.09 & 0.73 & 23.85 & 0.000 \\
\hline & Workshops & $\begin{array}{c}20 \text { hours or } \\
\text { more }\end{array}$ & 3.29 & 0.73 & 43.06 & 0.000 \\
\hline & Drills & $\begin{array}{c}20 \text { hours or } \\
\text { more }\end{array}$ & 3.30 & 0.65 & 43.96 & 0.000 \\
\hline
\end{tabular}

*Average of respondents' answers for every statement.

Table 4.25 shows that all P-values of ANOVA tests are $<0.0001$, enabling the researcher to conclude that there is a statistically significant difference among 
participants. Hence, there is a difference in the general knowledge of disaster preparedness for mass gatherings between different categories of EMS-providers based on training Education/ Training, Number of trainings, and Number of hours of training (See Appendix R, S, T, U for SPSS result)

\section{Table 4.28.}

Difference in Knowledge of Disaster Regarding the Hajj of 2016 Based on training

\begin{tabular}{|c|c|c|c|c|c|c|}
\hline \multicolumn{2}{|c|}{$\begin{array}{c}\text { Education/ Training } \\
\text { Number of trainings } \\
\text { Number of hours of training }\end{array}$} & \multirow[b]{2}{*}{ Three times } & \multirow{2}{*}{\begin{tabular}{|l|} 
Mean \\
3.62 \\
\end{tabular}} & \multirow{2}{*}{\begin{tabular}{|l|}
$\mathrm{SD}$ \\
0.86 \\
\end{tabular}} & \multirow{2}{*}{\begin{tabular}{|c|}
$\mathrm{F}$ \\
Value \\
7.31 \\
\end{tabular}} & \multirow{2}{*}{\begin{tabular}{|r|} 
ANOVA \\
P-value
\end{tabular}} \\
\hline 10- How many & Tra & & & & & \\
\hline $\begin{array}{l}\text { trainings/workshops/drills about } \\
\text { disaster preparedness have you ever }\end{array}$ & Workshops & $\begin{array}{l}\text { Mo } \\
\text { thre }\end{array}$ & 3.70 & 0.93 & 9.16 & 0.000 \\
\hline endix V for SPSS result) & Drills & Thr & 3.69 & 0.78 & 14.81 & 0.000 \\
\hline \multirow{3}{*}{$\begin{array}{l}\text { 11- Which of the following best } \\
\text { describes the frequency of your } \\
\text { attendance at } \\
\text { trainings/workshops/drills about } \\
\text { disaster preparedness? N/A } \\
\text { (See Appendix W for SPSS result). }\end{array}$} & Training & & 4.12 & 0.60 & 10.92 & 0.000 \\
\hline & Works & $\begin{array}{r}F o l \\
p \epsilon\end{array}$ & 4.06 & 1.22 & 10.88 & 0.000 \\
\hline & Drills & $\begin{aligned} \text { Four } \\
\text { per }\end{aligned}$ & 4.35 & 0.69 & 17.51 & 0.000 \\
\hline \multirow{3}{*}{$\begin{array}{l}\text { 12- When was the last time you } \\
\text { attended a trainings/ workshops/ } \\
\text { drills about disaster } \\
\text { preparedness? } \\
\text { (See Appendix X for SPSS result). }\end{array}$} & $\mathrm{g}$ & $\begin{array}{c}\text { 6- } 12 \\
\text { months ago }\end{array}$ & 58 & 0.81 & 10.04 & 0.000 \\
\hline & Wor & $\begin{array}{c}6-12 \\
\text { months ago }\end{array}$ & 3.66 & 0.77 & 14.00 & 0.000 \\
\hline & 15 & $\begin{array}{c}\text { 6- } 12 \\
\text { months ago }\end{array}$ & 3.73 & 0.74 & 22.33 & 0.000 \\
\hline \multirow{3}{*}{$\begin{array}{l}\text { 13- What was the duration of the } \\
\text { last trainings/workshops/drills } \\
\text { about disaster that you attended? } \\
\text { (See Appendix Y for SPSS result). }\end{array}$} & & & 0.01 & 0.87 & 0.43 & 0.00 \\
\hline & W & $\begin{array}{c}20 \text { hours or } \\
\text { more }\end{array}$ & 3.69 & 1.06 & 9.16 & 0.000 \\
\hline & Drills & $\begin{array}{l}20 \text { hours or } \\
\text { more }\end{array}$ & 3.64 & 0.97 & 14.66 & 0.000 \\
\hline
\end{tabular}


Table 4.26 shows that all P-values of ANOVA test are $<0.0001$, so the researcher can conclude that there is a statistically significant difference among participants. Hence, there is a difference in Knowledge of disaster Regarding the Hajj of 2016 Directions between different categories of EMS-providers based on training Education/ Training, Number of trainings, and Number of hours of training (See Appendix V, W, X, Y for SPSS result).

\section{Research Question 7}

Is there a relationship between the sources of knowledge and knowledge acquired regarding disaster preparedness during mass gatherings among different EMS-providers in the Hajj of 2016?

To answer this question, the Pearson Correlation test was performed to find the relationship between the sources of knowledge and knowledge acquired regarding disaster preparedness during mass gatherings among different EMS-providers in the Hajj of 2016. Results are shown in table 4.29.

\section{Table 4.29.}

$\underline{\text { Sources of General Knowledge of Disaster Preparedness }}$

\begin{tabular}{|c|c|c|}
\hline \multicolumn{2}{|c|}{ Sources of knowledge } & $\begin{array}{c}\text { directions of general knowledge of } \\
\text { disaster preparedness }\end{array}$ \\
\hline \multirow{3}{*}{ Drills practice } & Pearson Correlation & .025 \\
\cline { 2 - 3 } & Sig. (2-tailed) & .505 \\
\cline { 2 - 3 } & $\mathrm{N}$ & 700 \\
\hline \multirow{4}{*}{ Real disaster } & Pearson Correlation & -.040 \\
\cline { 2 - 3 } & Sig. (2-tailed) & .295 \\
\cline { 2 - 3 } & $\mathrm{N}$ & 700 \\
\hline \multirow{3}{*}{ Continuing education } & Pearson Correlation & $.161 * *$ \\
\cline { 2 - 3 } & Sig. (2-tailed) & .000 \\
\cline { 2 - 3 } & $\mathrm{N}$ & 700 \\
\hline
\end{tabular}




\begin{tabular}{|c|c|c|}
\hline \multirow{2}{*}{$\begin{array}{c}\text { Institution or University } \\
\text { courses }\end{array}$} & Pearson Correlation & $.168^{* *}$ \\
\cline { 2 - 3 } & Sig. (2-tailed) & .000 \\
\cline { 2 - 3 } & $\mathrm{N}$ & 700 \\
\hline \multirow{2}{*}{$\begin{array}{c}\text { Media (TV, social Media, } \\
\text { Radio, internet) }\end{array}$} & Pearson Correlation & $.084^{*}$ \\
\cline { 2 - 3 } & Sig. (2-tailed) & .026 \\
\cline { 2 - 3 } $\begin{array}{c}\text { Co-workers, friends, or } \\
\text { family }\end{array}$ & $\mathrm{N}$ & 700 \\
\cline { 2 - 3 } & Pearson Correlation & -.010 \\
\cline { 2 - 3 } & Sig. (2-tailed) & .797 \\
\hline
\end{tabular}

Table 4.29 shows that there is a statistically significant relation between the sources of knowledge Continuing education, Institution or University courses, Media and general Knowledge of disaster preparedness; since the p-values of Pearson Correlation tests $=0.029-0.000-0.002-0.000<0.0001$ respectively

However, there is no statistically significant relation between sources of knowledge (Drills practice), (Co-workers, friends, or family) and Knowledge of disaster regarding the Hajj of 2016; since the p-values of Pearson Correlation test $=0.230-0.774$ $>0.0001$ respectively.

Table 4.30.

$\underline{\text { Source of knowledge of Haji } 2016}$

\begin{tabular}{|c|c|c|}
\hline \multicolumn{2}{|c|}{ source of knowledge } & $\begin{array}{c}\text { Directions of Knowledge } \\
\text { of Hajj of 2016 }\end{array}$ \\
\hline \multirow{3}{*}{ Drills practice } & Pearson Correlation & .045 \\
\cline { 2 - 3 } & Sig. (2-tailed) & .230 \\
\cline { 2 - 3 } & $\mathrm{N}$ & 700 \\
\hline \multirow{3}{*}{ Real disaster } & Pearson Correlation & $.082^{*}$ \\
\cline { 2 - 3 } & Sig. (2-tailed) & .029 \\
\cline { 2 - 3 } & $\mathrm{N}$ & 700 \\
\hline \multirow{3}{*}{ Continuing education } & Pearson Correlation & $.145^{* *}$ \\
\cline { 2 - 3 } & Sig. (2-tailed) & .000 \\
\cline { 2 - 3 } & N & 700 \\
\hline & Pearson Correlation & $.117 * *$ \\
\hline
\end{tabular}




\begin{tabular}{|c|c|c|}
\hline \multirow{2}{*}{$\begin{array}{c}\text { Institution or University } \\
\text { courses }\end{array}$} & Sig. (2-tailed) & .002 \\
\cline { 2 - 3 } & $\mathrm{N}$ & 700 \\
\hline \multirow{2}{*}{$\begin{array}{c}\text { Media (TV, social Media, } \\
\text { Radio, internet) }\end{array}$} & Pearson Correlation & $.159 * *$ \\
\cline { 2 - 3 } & Sig. (2-tailed) & .000 \\
\cline { 2 - 3 } & $\mathrm{N}$ & 700 \\
\hline \multirow{2}{*}{$\begin{array}{c}\text { Co-workers, friends, or } \\
\text { family }\end{array}$} & Pearson Correlation & .011 \\
\cline { 2 - 3 } & Sig. (2-tailed) & .774 \\
\cline { 2 - 3 } & $\mathrm{N}$ & 700 \\
\hline
\end{tabular}

Table 4.30 shows that there is a statistically significant relation between source of knowledge Real disaster, Continuing education, Institution or University courses, Media and Knowledge of disaster regarding Hajj of 2016; since p-value of Pearson Correlation test $=0.029,0.000,0.002,0.000<0.0001$ respectively .

However, there is no statistically significant relation between source of knowledge Drills practice, Co-workers, friends, or family and Knowledge of disaster regarding Hajj of 2016; since p-value of Pearson Correlation test $=0.230,0.774>0.0001$ respectively.

\section{Multiple Regression Analysis Model}

A multiple regression analysis was done next to examine how the independent variables collectively relate to dependent variables, as well as exploring their relationship to each other. Until this point the analysis coefficients had been bivariate. The relationship had been examined consecutively, pairing one independent variable (Age, highest level of education, level of EMS, current EMS training received, number of time worked at the Hajj, number of training/workshop and drill EVER attended, number of training/workshop and drill attended, last time attended training/workshop and drill, duration of the last training/workshop and drill) with two dependent variables general knowledge and Hajj knowledge of disaster preparedness for mass gatherings for the 
purpose of determining the empirical relationship between them. These analyses display and interpret the univariate data and document each predictor variable's zero-order correlation with the dependent variables. In general, most variables do not stand alone as they interact with each other; it is important to treat multiple causes that affect the same collective relationship. Therefore, Multiple regression analysis model is a suitable statistical technique for these analyses (Mosteller \& Tukey, 1977).

Multiple regression is a multivariate statistical technique that can be used to examine linear relationships and generate predictive equations when there are multiple independent variables present. Lewis-Beck (1980) notes two ways in which multiple regression is useful:

First, it almost inevitably offers a fuller explanation of the dependent variable, since few phenomena are products of a single cause. Second, the effect of a particular independent variable is made more certain, for the possibility of distorting influences from the other independent variables is removed (p.47). Thus, Questions about the relative importance of each independent variable in causing changes in the dependent variable are answered by multiple regression and a description of how much variance of the independent variable is also explained (Mosteller \& Turkey, 1977).

The beta $(\beta)$ coefficient is the "standardized partial regression coefficient" used to provide an estimate of the relative importance of the predictor variables (Matlack, 1993). One standard deviation change in the independent variable is indicated by a beta value of 0.8 which causes a mean increase of 0.8 in the dependent variable. An increase in the beta value is directly proportional to an increase in the impact of independent variable on 
the independent variable (Brace, Kemp, \& Snelger, 2012). The valence indicating the direction of relationship by beta coefficients range in values from -1.0 to 1.0. This allows comparisons across variables from the same regression equation.

Certain features of the data outside of the model, such as multicollinearity, specification error, and scale unreliability may obscure the true relationship between independent and dependent variables potentially resulting in accurate beta coefficient (Lewis-Beck, 1980). Nevertheless, researchers should carefully construct their conceptual models to avoid these problems, then the beta coefficients can be meaningfully interpreted (Blalock, 1979). Therefore, beta coefficients measure how many units of the dependent variable will change when the independent variable associated with the beta weight changes by one unit while holding all other independent variables constant (Sirkin, 2006).

The multiple correlation coefficient $(\mathrm{R})$ is a measure of explained variance between the observed value of cases and their predicted value (Brace et al., 2000; Neter et al., 2004). As described by Sirkin (2006), the "concept of multiple correlation, R, and

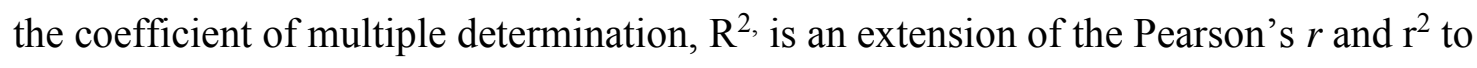
more than two variables" (p. 519). While R can be difficult to interpret, Mueller, Schussler and Costner (1977) nevertheless maintain that it indicates the proportion of variance in the dependent variable that is attributed to the model of all predictor variables acting together. Values for $\mathrm{R}^{2}$ range between zero (i.e., none of the variation is explained) to 1.0 (i.e., $100 \%$ of the variance is explained). The multiple correlation coefficient squared can also be tested for statistical significance using the F-ratio (Abdi, 2007). This 
test assesses whether or not the difference between the observed explained variance $\left(\mathrm{R}^{2}\right)$ is significantly different for zero.

\section{General Knowledge}

Ho: Characteristics "General knowledge” highest level of education, EMS level or provider, number of times worked at Hajj, number of workshop ever attended, last workshop attended, number of workshops and drills attended for disaster preparedness for mass gatherings are not statistically different between SRCA-EMS providers.

$\mathbf{H}_{\mathrm{A}}$ : The level of "General knowledge" is not affected by the highest level of education, EMS level or provider, number of times worked at Hajj, number of workshop ever attended, last time attended workshop, number of workshop and drill attended to disaster preparedness for mass gathering are statistically different between SRCEMSproviders.

The significant characteristics include: highest level of education, EMS level of provider, number of times worked at the Hajj, number of workshops ever attended, last workshop attended, number of workshops and drills attended for disaster preparedness for mass gathering.

\section{Table 4.31.}

$\underline{\text { Final Stepwise Model for General Knowledge of Disaster Preparedness }}$

\begin{tabular}{lllll} 
Predictor & B & SE & Beta & P \\
\hline Number of workshop attended & 0.07 & 0.03 & 0.10 & 0.03 \\
EMS level of Provider & 0.18 & 0.05 & 0.15 & 0.00 \\
Last time attended workshop & $\mathbf{- 0 . 0 7}$ & 0.02 & -0.10 & 0.00 \\
Highest level of education & 0.12 & 0.03 & 0.16 & 0.00 \\
Number of workshop EVER attended & 0.09 & 0.02 & 0.18 & 0.00
\end{tabular}




\begin{tabular}{lllll} 
Number of times worked at Hajj & 0.05 & 0.02 & 0.07 & 0.01 \\
Number of drill attended & 0.09 & 0.03 & 0.13 & 0.00 \\
Constant & 1.618 & 0.171 & & 0.00 \\
\hline
\end{tabular}

Note: Adjusted $R^{2}=0.333,(7,692)=50.776, P<0.000$

In Table 4.31 the final stepwise regression model for prediction of general knowledge of disaster preparedness for mass gathering is presented. The $\mathrm{R}^{2}$ indicates that the explanatory variables accounted for $33.3 \%$ of the variance of general knowledge of disaster preparedness for mass gatherings (DV). The regression is statistically significant $(\mathrm{P}<0.0001)$. Thus, the $\mathrm{H}_{\mathrm{o}}$ was rejected and $\mathrm{H}_{\mathrm{A}}$, accepted. The overall regression equation was significant $(7,692)=50.776, \mathrm{P}<0.0001$. The independent variables have a statistically significant effect on the dependent variable. For example, the DV was significantly predicted by: highest level of education completed, not including EMS training (0.12), the EMS level of the provider (0.18), the number of times worked at the Hajj (0.05), the number of workshops ever attended (0.09), the number of workshops attended (0.07), or the number of drills attended (0.09). These variables predicted an increase in the general knowledge of disaster preparedness for mass gatherings. However, the general knowledge of disaster preparedness for mass gathering was negatively predicted by the last workshop attended (-0.07). The researcher may conclude that the model developed in this research study is appropriate for the data. 


\section{Hajj Knowledge}

$\mathbf{H}_{\mathbf{o}}$ : Characteristics "Hajj knowledge" EMS level of providers, number of drills ever attended, number of drills attended, and duration of the last drill attended for disasters at the Hajj are not statistically different between SRCA-EMS providers.

HA: Characteristics "Hajj knowledge" according to the EMS level of providers, number of drills ever attended, number of drills attended, and duration of last disaster drill at Hajj are statistically different between SRCA-EMS providers.

The significant characteristics include: EMS level of providers, number of drills ever attended, number of drills attended, and duration of last drill about disasters at the Hajj.

\section{Table 4.32.}

Final Stepwise Model for the Knowledge of Hajj 2016

\begin{tabular}{|c|c|c|c|c|}
\hline$\underline{\text { Predictor }}$ & $\mathrm{B}$ & SE & Beta & $\mathrm{P}$ \\
\hline Number of drill attended & 0.12 & 0.03 & 0.14 & 0.00 \\
\hline Duration last time attended drill & -0.06 & 0.02 & -0.12 & 0.00 \\
\hline EMS levels of provider & 0.18 & 0.05 & 0.12 & 0.01 \\
\hline Number of drill EVER attended & 0.06 & 0.03 & 0.09 & 0.03 \\
\hline Constant & 2.875 & 0.189 & & 0.000 \\
\hline
\end{tabular}

Note: Adjusted $\mathrm{R}^{2}=0.110,(4,695)=22.605, \mathrm{P}<0.000$

In Table 4.32 the final stepwise regression model for prediction of knowledge of the Hajj is presented. The $\mathrm{R}^{2}$ indicates that the explanatory variables accounted for $11 \%$ of the variance in knowledge of the Hajj (DV), and the regression is statistically significant $(\mathrm{P}<0.0001)$. Thus, the $\mathrm{H}_{\mathrm{o}}$ was rejected, and the alternative $\mathrm{H}_{\mathrm{A}}$ is accepted. The overall regression equation was significant $(4,695)=22.605, \mathrm{P}<0.0001$. The 
independent variables. have a statistically significant effect on the DV. For example, the DV is significantly predicted by: EMS level of provider (0.18), the number of drills ever attended (0.06), and the number of drills attended per year $(0.12)$. These variables predicted an increase in knowledge of the Hajj. However, the knowledge of the Hajj was negatively predicted by the duration of the last drill $(-0.06)$.

\section{Summary}

This chapter conducting a series of data analysis, provided quantitative data for assessing the knowledge of DPMG for the SRC-EMS providers who worked in the Hajj of 2016 after conducted a series of data analyses. A summary of the hypotheses and results is presented in Table 4.33. The next chapter summarizes the findings, provides a discussion of the results and conclusions related to literature, the limitations of the research, potential implications for the DPMG for SRC-EMS providers, and provides recommendations for further research.

\section{Table 4.33}

$\underline{\text { Hypotheses and Results }}$

\begin{tabular}{|l|l|l|}
\hline Hypothesis & \multicolumn{1}{|c|}{ Descriptive } & Results \\
\hline 1.Age & $\begin{array}{l}\text { GENERAL KNOWLEDGE OF DISASTER } \\
\text { There is no significant difference in the knowledge of DPMG } \\
\text { between different categories of EMS providers based on the age of } \\
\text { EMS providers. } \\
\text { KNOWLEDGE of DISASTER REGARDING the Hajj of 2016 } \\
\text { There is no significant difference in the knowledge of disaster } \\
\text { regarding the Hajj of 2016 between different categories of EMS } \\
\text { providers based on the age of EMS providers. }\end{array}$ & Reject \\
\hline
\end{tabular}




\begin{tabular}{|c|c|c|}
\hline $\begin{array}{l}\text { 2.Level of } \\
\text { Education }\end{array}$ & $\begin{array}{l}\text { GENERAL KNOWLEDGE OF DISASTER } \\
\text { There is no significant difference in the knowledge of DPMG } \\
\text { between different categories of EMS providers based on level of } \\
\text { education. } \\
\text { KNOWLEDGE of DISASTER REGARDING the Hajj of } 2016 \\
\text { There is no significant difference in the knowledge of disaster } \\
\text { regarding the Hajj of } 2016 \text { between different categories of EMS } \\
\text { providers based on level of education. }\end{array}$ & Reject \\
\hline $\begin{array}{l}\text { 3.Level of } \\
\text { EMS }\end{array}$ & $\begin{array}{l}\text { GENERAL KNOWLEDGE OF DISASTER } \\
\text { There is no significant difference in the knowledge of DPMG } \\
\text { between different categories of EMS providers based on level of } \\
\text { EMS. } \\
\text { KNOWLEDGE of DISASTER REGARDING the Hajj of } 2016 \\
\text { There is no significant difference in the knowledge of disaster } \\
\text { regarding of the Hajj of } 2016 \text { between different categories of EMS } \\
\text { providers based on level of EMS. }\end{array}$ & Reject \\
\hline $\begin{array}{l}\text { 4.The sector } \\
\text { EMS training } \\
\text { received }\end{array}$ & $\begin{array}{l}\text { GENERAL KNOWLEDGE OF DISASTER } \\
\text { There is no significant difference in the knowledge of DPMG } \\
\text { between different categories of EMS providers based on the sector of } \\
\text { EMS training received. } \\
\text { KNOWLEDGE of DISASTER REGARDING the Hajj of } 2016 \\
\text { There is no significant difference in the knowledge of disaster } \\
\text { regarding the Hajj of } 2016 \text { between different categories of EMS } \\
\text { providers based on the sector of EMS training is received. }\end{array}$ & Accept \\
\hline $\begin{array}{l}\text { 5.Years of } \\
\text { experience }\end{array}$ & $\begin{array}{l}\text { GENERAL KNOWLEDGE OF DISASTER } \\
\text { There is no significant difference in the knowledge of DPMG } \\
\text { between different categories of EMS providers based on years of } \\
\text { experience. } \\
\text { There is no significant difference in the knowledge of DPMG } \\
\text { between different categories of EMS providers based on number of } \\
\text { times worked at the Hajj. } \\
\text { KNOWLEDGE of DISASTER REGARDING the Hajj of } 2016 \\
\text { There is no significant difference in the knowledge of disaster } \\
\text { regarding the Hajj of } 2016 \text { between different categories of EMS } \\
\text { providers based on years of experience. } \\
\text { There is no significant difference in the knowledge of disaster } \\
\text { regarding the Hajj of } 2016 \text { between different categories of EMS } \\
\text { providers based on number of times worked at the Hajj. }\end{array}$ & $\begin{array}{l}\text { Reject } \\
\text { Reject }\end{array}$ \\
\hline 6.Training & $\begin{array}{l}\text { GENERAL KNOWLEDGE OF DISASTER } \\
\text { There is no significant difference in the knowledge of DPMG } \\
\text { between different categories of EMS providers based on training } \\
\text { (previous disaster education/training, number of trainings and } \\
\text { number of hours of training). } \\
\text { KNOWLEDGE of DISASTER REGARDING the Hajj of } 2016 \\
\text { There is no significant difference in the knowledge of disaster } \\
\text { regarding the Hajj of } 2016 \text { between different categories of EMS } \\
\text { providers based on training (previous disaster education/training, } \\
\text { number of trainings and number of hours of training). }\end{array}$ & Reject \\
\hline
\end{tabular}




\begin{tabular}{|l|l|l|}
\hline $\begin{array}{l}\text { 7.Source of } \\
\text { knowledge }\end{array}$ & $\begin{array}{l}\text { GENERAL KNOWLEDGE OF DISASTER } \\
\text { There is no relationship between the source of knowledge and } \\
\text { knowledge acquired regarding general knowledge for mass } \\
\text { gatherings among different SRCEMS providers. } \\
\text { KNOWLEDGE of DISASTER REGARDING the Hajj of 2016 } \\
\text { There is no relationship between the source of knowledge and } \\
\text { knowledge acquired regarding DPMG among different EMS providers } \\
\text { in the Hajj of 2016. }\end{array}$ & Reject \\
\hline
\end{tabular}




\section{CHAPTER V}

\section{DISCUSSION, IMPLICATIONS, AND CONCLUSION}

This study had three main goals to: 1) assess the knowledge regarding disaster preparedness for mass gatherings DPMG among SRCEMS providers during the Hajj of 2016,2 ) explore the relationship between the demographic variables (age, level of education, working experience, previous disaster education/training, number of trainings and number of hours of training), the knowledge about DPMG among SRC-EMS providers during the Hajj 2016, and 3) explore the sources of knowledge about disaster preparedness for mass gatherings SRCEMS providers possess. To achieve these goals the researcher used an online questionnaire that was sent to the participants for their response. This study assessed the relationship between the general knowledge, knowledge of the Hajj 2016 and demographics information and SRCEMS-providers' disaster preparedness for mass gatherings.

The independent variables for this study were: Age of SRCEMS provider, his level of education, his level of SRCEMS provider, current of EMS training received, years of experience in SREA, number of times worked at the Hajj, training (previous educational/training number of trainings, and number of hours training). The dependent variables were: general knowledge of disaster preparedness for mass gatherings and knowledge of the Hajj 2016. The researcher discusses the findings of the study and examines them in light of the current literature in this chapter. Finally, this chapter outlines implications for the findings of the study in terms of the knowledge of disaster 
preparedness for mass gatherings for SRCEMS providers in SRCA, as well as limitations of the study, its implications, and the conclusions reached by this researcher.

\section{Demographic Characteristics}

The sample for this study consisted of 700 respondents who completed the survey, of whom $64.9 \%$ were between less than 25 to 34 years of age, $64.4 \%$ had a diploma either two or three years. $65.6 \%$ were EMS technicians, and 51.1\% had received their current EMS training in the private sector. Concerning their experience, $34.9 \%$ had from 5 to 9 years of experience and $38.7 \%$ of them had worked in four or more Hajj seasons.

Concerning their experience working for the Saudi Red Crescent, 26.7\% had never attended trainings on disaster preparedness for mass gatherings, $40.7 \%$ had never attended any workshop, and 30\% had never attended any drills on the subject.

Concerning their continuing education, $40.3 \%$ did not attend any training every year, 53.6\% did not attend any workshop every year, and $45.6 \%$ did not participate in any annual drill. Only $25.3 \%$ of the SRC-EMS providers had attended trainings within the last year, $24.3 \%$ had attended workshops between the last six months to a year, and $26.1 \%$ had participated in drills in the last six months to a year. The duration of the last training was less than 5 hours $(35.7 \%)$, the duration of the last workshop was 5 to 9 hours $(25.9 \%)$, and the last drill was less than 5 hours long $(25.0 \%)$.

The most frequent disaster experienced by SRC-EMS providers was a transport disaster, experienced by $46.6 \%$ of the respondents. For the Hajj experience, $60 \%$ of SRCEMS providers had experience with a stampede disaster. However, 71.4\% of SRC-EMS providers did not participate in drafting any emergency plan or in emergency planning for 
disaster for the Hajj season. Only $83.3 \%$ of them know whom to contact (chain of command) in a disaster situation in the Hajj season.

The highest mean for the sources of their knowledge was real disaster $($ mean $=$ 4.31), followed by drills (mean $=4.25$ ). To improve their disaster preparedness, SRCEMS providers first recommended a disaster management course $($ mean $=4.54)$ and secondly drills practice $($ mean $=4.54)$. To increase their knowledge about disasters. SRCEMS providers considered that most needed a course on incident command system (mean $=4.54)$ and secondly, a course on field triage (mean $=4.50)$.

\section{Key Findings}

The study had several key findings and the knowledge of disaster preparedness for mass gatherings varied among of SRCEMS providers according to their age, level of education, professional level of EMS, current EMS training received, years of experience, types of training, and source of knowledge. First, there was a significant difference in the knowledge of disaster preparedness for mass gatherings between different categories of SRCEMS providers according to their age. The group aged 35-39 years possessed a significantly superior general knowledge of disaster preparedness for mass gatherings compared to any other age group. However, there was no statistically significant knowledge of the Hajj 2016 based on age.

Second, there is a significant difference in the knowledge of disaster preparedness between different categories of SRCEMS providers based on level of education. Those possessing a Master's degree were statistically significantly more prepared than other categories of SRCEMS providers, indicating that the graduate level contributed more to their general knowledge of disaster preparedness for mass gatherings than any other level 
of education. Moreover, there is a statistically significant difference in the knowledge of the Hajj 2016 according to their level of education. The holders of Master's degree possessed a knowledge about the Hajj of 2016 which was a significantly superior to other categories of SRCEMS providers. Similarly, one can conclude that graduate studies were more strongly associated with knowledge of the Hajj 2016 than other levels of education.

Third, there was a significant difference in the knowledge of DPMG between the different categories of EMS providers. The paramedic level of EMS had a significantly superior general knowledge of disaster preparedness for mass gatherings compared to other EMS levels. The paramedic level had significantly higher scores on the general knowledge questions compared to the other EMS providers. There was also a significant difference in the knowledge of the Hajj 2016 between categories of EMS providers. Physicians had significantly superior knowledge of the Hajj 2016 compared to other EMS levels.

Four, there was a significant difference in the general knowledge of disaster preparedness for mass gatherings based on the current SRCEMS providers training received. The military sector had significantly better scores on general knowledge than other categories of SRCEMS providers. However, there was no significant difference in the knowledge of the Hajj of 2016 across all providers regardless of which sector they trained in.

Fifth, there was a significant difference in the general knowledge of disaster preparedness for mass gatherings based on years of experience. Scores on general knowledge assessment were significantly higher in the group having 15- 19 years of experience. The general knowledge of disaster preparedness for mass gatherings 
according to number of times worked at the Hajj was also statistically significantly higher among SRC-EMS providers who had worked at the Hajj for four seasons or more. The EMS group with 15-19 years of experience had statistically significantly higher knowledge of the Hajj 2016 compared to other groups. Knowledge of the Hajj in 2016, based on the number of times worked at the Hajj, did not indicate any statistically significantly differences among SRC-EMS providers.

Sixth, the general knowledge of disaster preparedness for mass gatherings based on different levels of training (previous disaster education/training, number of trainings and number of hours of training) was highest among those who had attended three trainings. In the workshops and drills category, the statistical difference in general knowledge of disaster preparedness for mass gatherings among of SRC-EMS favored providers who attended more than three times. The general knowledge of disaster preparedness for mass gatherings among SRCEMS was greater among those who attended four trainings, workshops and drills per year. Those SRC-EMS providers who had attended trainings, workshops or drills in the last 6 months to 12 months possessed statistically more general knowledge of disaster preparedness for mass gatherings than other groups. Additionally, the general knowledge of disaster preparedness for mass gathering was significantly higher among those SRC-EMS providers who had attended a training that lasted from five hours to nine hours. The general knowledge of disaster preparedness for mass gatherings was better for workshops and drills that lasted 20 hours or more but not necessarily 20 hours at one time; the 20 hours could be distributed across several days or months. 
Those SRC-EMS providers who had attended trainings and drills three times had significantly higher knowledge of the Hajj in 2016 scores. In the workshop category, the statistical difference in knowledge of the Hajj 2016 among of SRCEMS favored providers who workshops attended more than three times. Knowledge of the Hajj 2016 was greatest for the group that had attended for trainings, workshops and drills four times per year. SRC-EMS providers who had attended trainings, workshops or drills in the last 6 months to 12 months had statistically more knowledge of the Hajj 2016. Furthermore, knowledge of the Hajj 2016 among SRCEMS providers was significantly better among those who had attended a training lasting from five to nine hours. Knowledge of the Hajj 2016 among SRCEMS providers was significantly better among those who attended a training that lasted from five hours to nine hours. Knowledge of the Hajj 2016 among SRCEMS providers was significantly better among those who attended a workshop or drill lasting 20 hours or more.

Seventh, there is a definite relationship between the source of knowledge and general knowledge for mass gatherings among different SRC-EMS providers. Those who obtained the higher knowledge scores received their training from continuing education, institution or university courses, and the media. The level of knowledge regarding the Hajj of 2016 was higher in those SRC-EMS providers who had received the following types of training; real disaster, continuing education, institution or university courses and media.

Additional findings were obtained by examining, by stepwise regression modeling, how the independent variables collectively predicted the dependent variables. Most importantly, the significant predictors for general knowledge of disaster 
preparedness for mass gatherings include: highest level of education, EMS level of providers, number of times worked at the Hajj, number of workshop ever attended, last workshop attended, and number of workshops and drills attended for disaster preparedness for mass gatherings.

Secondly, multiple regression analysis of knowledge of the Hajj 2016 revealed the following predictors: EMS level of providers, number of drills ever attended, number of drills attended, and duration of last drills attended for a disaster at the Hajj.

\section{Discussion Summary}

From the analysis performed for this study, the following conclusions were reached:

\section{The Age of SRC-EMS providers is relevant}

Evidently, the SRC-EMS providers who were aged 35- 39 years old have sufficient knowledge of disaster preparedness for mass gatherings, which aligns with Chan (2009) who found that young adults age 26-30 had less knowledge and skills than adults aged 31-40 years in clinical management. This could imply that young adults aged less than 34 years might not have yet enough accumulated experience in field of disaster preparedness, leading to limited competency in the specific and advanced clinical skills needed to care for Hajj patients in the field. However, according to Kliegel and Martin (2007) young adults have a better memory higher, a speed of information processing and fewer inhibition that older adults. With these considerations, recruiters for SRC-EMS providers for the Hajj should know that young adults should be encouraged to have continuing education and training emphasizing emergency and disaster to improve their knowledge of disaster preparedness for mass gathering such as the Hajj season. Likewise, Saudi Red Crescent Human Resources officials should provide incentives to incentives 
EMS providers aged 40 or more, such as salary increase or time off days for training, to improve their knowledge of disaster preparedness.

The Level of Education completed, not including EMS training. is relevant.

There was a significant difference in the knowledge of disaster preparedness between different categories of SRCEMS providers based on level of education. Those with a Master's degree are statistically significantly more prepared than the other categories of SRCEMS providers. That means the master level of education contributed more to general knowledge of disaster preparedness for mass gatherings than other levels of education. Similar studies indicated that the graduate level of education for the health care providers were more knowledgeable and willingness to work in disaster situations (Chan, 2009; Fung, Loke\& Lai, 2008; Arbon, Ranse, Cusack, Considine, Woodman, Bahnisch, Kako, Hammand, \& Mitchell, 2013).

The majority of respondents for this study had two or three diplomas and findings suggest that the educational level of SRC-EMS providers might be have played an important role in their knowledge of disaster preparedness. Those at the diploma level displayed limited knowledge for disaster preparedness, in particular dealing with complex issues. They reported insufficient skills in seeking information, and had limited capability to develop advanced clinical skills in response to complicated health problems, which likewise aligned with Chan's 2009 study, that reported healthcare providers at a diploma level showed a lower level of knowledge and skills than bachelor, master or $\mathrm{PhD}$ level students in clinical management. It may be that the level of education of SRC-EMS providers influenced their response to an emergency disaster and their willingness to respond (Evers \& Puzniak, 2005). 
There is a statistically significant difference in the knowledge of the Hajj 2016 based on levels of education. The Master's degree is a significantly superior to other categories of SRCEMS providers, which means that the master level of education was more strongly associated with knowledge of the Hajj 2016 than other levels of education. Saudi Arabia currently does not have master or PhD level that focuses on disaster preparedness for mass gatherings. Usually people with high levels of education are willing to learn and improve their job performance.

\section{The category of EMS for SRC-EMS providers is relevant}

There is a significant difference in the knowledge of DPMG between categories of EMS providers. The paramedic level of EMS is significantly superior in the general knowledge of disaster preparedness for mass gatherings compared to other EMS levels. The paramedic is highest level of EMS providers and the kinds of courses and trainings are different from the first responders and EMS technicians. However, in the Hajj knowledge physicians scored higher than the other EMS levels. Surprisingly, the physicians worked in the field during the Hajj more than the other providers because some patients need advanced care. Previous, similar studies had indicated that physicians had more knowledge of critical situations compared to other EMS levels (Fischer, Kabir, Stein, \& Burger, 2008).

The training received by SRC-EMS providers was relevant

There was a significant difference in the general knowledge of disaster preparedness for mass gatherings based on the current SRCEMS providers training received. Those who had trained in the military sector had significantly better scores on general knowledge about disaster preparedness than other groups, supporting previous 
studies that had found that military healthcare providers had more knowledge of disaster preparedness than the civilian hospital providers (Al-Thobaity, Plumber, Innes, Copnell, 2015). Thus, the SECA should be interested in hiring military-trained EMS providers for their organization.

The number of years of experience

There was a significant difference in the general knowledge of disaster preparedness for mass gatherings based on years of experience. Scores on the general knowledge assessment were significantly higher in the group having 15 to 19 years of experience. More knowledge, more experience and improved readiness increased confidence in disaster preparedness compared to those having little experience, which supports earlier studies indicating that healthcare workers who had many years of experience were more knowledge able about disasters (Al-Khaliah, Bond, \& Alasad, 2012; Lim, Lim, \& Vasu, 2013). In addition, the EMS group with 15 to 19 years of experience had statistically significantly higher knowledge of the Hajj 2016 compared to other groups.

The general knowledge of disaster preparedness for mass gatherings was also statistically higher among SRCEMS providers who had worked in the Hajj at least four seasons or more. Then more times one worked at the Hajj is associated with greater knowledge of disaster preparedness.

$\underline{\text { Training was relevant }}$

The general knowledge of disaster preparedness for mass gatherings was influenced by the training attended by previous disaster education/training, number of trainings and number of hours of training. Those who had three attended trainings had 
significantly higher knowledge scores. In the workshops and drills category, the statistical difference in general knowledge of disaster preparedness for mass gatherings among of SRC-EMS providers favored those who had attended drills more than three times, while those who had had some training had some knowledge more than those who had attended no trainings or workshops aligning with other studies whose results indicated that previous trainings, workshops or drills such as disaster management, BLS, ACLS, BTLS and biological or chemical and terrorism were important to prepare healthcare providers for dealing with disaster situation(Crane, McCluskey, Johnson, \& Harbison, 2010; Husan, Hatthakit, \& Chaowalit, 2011). Moreover, those who attended trainings and drills three times or more had significantly higher scores on knowledge of the Hajj 2016. In the workshop category, the statistical difference in knowledge of the Hajj 2016 among of SRCEMS also favored providers who attended workshops more than three times.

General knowledge of disaster preparedness for mass gatherings and knowledge of Hajj 2016 among SRCEMS was greater among those who attended trainings, workshops and drills four times per year.

Attending trainings, workshops or drills in the last 6 months to 12 months appears to be influential in the general knowledge of disaster preparedness for mass gatherings and knowledge of the Hajj 2016 among of SRC-EMS providers. Those who had attended trainings, workshops and drills in the last 6 months to 12 months had more knowledge of disaster preparedness (Alzahrani, Kyratisis, 2016).

Also, the general knowledge of disaster preparedness for mass gathering and knowledge of Hajj 2016 among of SRCEMS providers was significantly better among 
those who had attended a training of five to nine hours duration. Findings were in accordance with a similar study that indicated, in 2011, increased number of hours of training for disaster preparedness would increase the healthcare providers' knowledge of disaster preparedness (Fernadez, Studnek, Margoils, Crawford, Bentely, \& Marcozzi, 2011). The general knowledge of disaster preparedness for mass gatherings was best who had attended workshops and drills that lasted 20 hours or more.

\section{$\underline{\text { Source of knowledge }}$}

There was a relationship between the source of knowledge and general knowledge for mass gatherings among different SRCEMS providers with the higher knowledge scores for those who were trained by continuing education, institution or university courses, and media (TV, social media, radio, and Internet). These were the main sources of general knowledge of disaster preparedness for mass gatherings that SRCEMS providers used to improve their knowledge. Similar, previous studies had also indicated that the best sources of general knowledge for healthcare providers were continuing education, institution or university, and media (Al-Thobaity, Plummer, Innes, \& Copnell, 2015; McKibbin, Sekula, Colbert, \& Peltier, 2011; Wisniewski, Dennik-Champion, \& Peltier, 2004).

The general knowledge about disaster and knowledge of the Hajj 2016 among different SRC-EMS providers was higher among those who had had following types of training; real disaster, continuing education, institution or university courses and media. Working at Hajj was important for SRC-EMS providers to learn about disasters as a real disaster experience was one of the important sources of knowledge. 
Predictive Model of the group general knowledge of disaster preparedness for mass gatherings

From the regression model on general knowledge of disaster preparedness for mass gatherings, significant predictors include: highest level of education, EMS level of providers, number of times worked at the Hajj, number of workshop ever attended, last workshop attended, number of workshops and drills attended. The highest level of education, not including EMS training, significantly predicted and affected the general knowledge of disaster preparedness among SRCEMS providers. Findings of this study indicated that the Master's degree holder is a significantly superior to other categories of SRC-EMS providers and the amount of increased general knowledge between the level of education would increase $(\beta=0.12)$. For example, the amount of general knowledge of disaster preparedness would be increased 0.12 from bachelors' degree to masters' degree.

Additionally, EMS level of the provider significantly predicted an increased general knowledge of disaster preparedness among SRC-EMS providers. This study, showed that the paramedic level of EMS is significantly superior in the general knowledge of disaster preparedness for mass gatherings compared to other EMS levels and the amount of increased general knowledge between the level of EMS provider would increase $(\beta=0.18)$. for example, the amount of general knowledge of disaster preparedness would be increased 0.18 from first responder to EMT-technician.

The number of times worked at the Hajj significantly predicted an increased general knowledge of disaster preparedness among SRC-EMS providers. In this study, those who worked four seasons or more had statistically significantly higher scores on general knowledge, and the beta was $(\beta=0.05)$. For example, the amount of general 
knowledge would be increased 0.05 from one season at the Hajj, two times to four times if the SEC-EMS providers worked in more Hajj seasons.

The number of workshops ever attended about disaster preparedness also significantly predicted an increase in general knowledge of disaster preparedness among SRC-EMS providers. In this study, the number of workshops ever attended was significant in the general knowledge of disaster preparedness among of SRC-EMS providers, and favored providers who attended more than three times. The amount of general knowledge increase between the number of workshop ever attended was $(\beta=$ 0.09). For example, the disaster preparedness of SRC-EMS providers would be increased 0.09 for each workshop, to two or three.

The number of workshops attended per year significantly predicted and affected the increased general knowledge of disaster preparedness among SRC-EMS providers. In this study, the number of workshops per year affected the general knowledge of disaster preparedness among of SRC-EMS providers, favoring those who attended four times per year and increasing their general knowledge between the number of workshops attended $\operatorname{per} \operatorname{year}(\beta=0.07)$.

The number of drills attended per year also significantly predicted an increased general knowledge of disaster preparedness among SRC-EMS providers. In this study, the number of drills attended made a significant difference in general knowledge of disaster preparedness among of SRC-EMS providers, and favored those who attended four times per year. Their general knowledge increased between the number of drills attended per year $(\beta=0.09)$. 
However, the general knowledge of disaster preparedness for mass gatherings was negatively predicted by the last time participating in a workshop $(\beta=-0.07)$, indicating that the general knowledge of disaster preparedness for SRC-EMS providers would decrease over time since the last time the providers attended a workshop. This study, revealed that attending a workshop in the last 6 months to 12 months was optimal for SRC-EMS providers' general knowledge of disaster preparedness for mass gatherings and knowledge of the Hajj 2016.

Predictive Model of the group knowledge of the Hajj 2016 According to the multiple regression analysis of knowledge of the Hajj 2016, predictors include: EMS level of providers, the number of drills ever attended, the number of drills attended, and duration of the last time attended a drill for a disaster at the Hajj.

EMS level of provider significantly predicted and affected the knowledge of Hajj 2016 among SRC-EMS providers. In this study, physicians had significantly superior knowledge of 2016 Hajj compared to other EMS levels. The increase of general knowledge between the levels of EMS provider would increase $(\beta=0.18)$, meaning that the general knowledge of disaster preparedness would be increased 0.18 from paramedic to physician.

The number of drills ever attended related to Hajj disaster preparedness significantly predicted and affected the knowledge of the Hajj 2016 among SRC-EMS providers. In this study, there was a significant difference in knowledge of 2016 Hajj according to the number of drills ever attended, favoring providers who attended three drills. Knowledge of the Hajj 2016 increased according to the number of drills ever attended $(\beta=0.06)$, indicating, for example, that the knowledge of a SRC-EMS provider 
who attended drills related to the Hajj disaster preparedness would be increased by 0.06 for one time, 0.12 for two times and 0.18 for three times.

Likewise, the number of drills attended per year significantly predicted and affected the knowledge of the Hajj 2016 among SRC-EMS providers. In this study, the number of drills attended affected the knowledge of the Hajj 2016 among of SRC-EMS providers, favoring those who attended four times per year. Their general knowledge would increase according to the number of drills attended per year by $(\beta=0.12)$, indicating that the knowledge of 2016 Hajj SRC-EMS providers would increase by 0.12 each time they participated in a drill per year.

In contrast, the knowledge of the Hajj was negatively predicted by the duration of last drill attended $(\beta=-0.06)$. SRC-EMS providers' knowledge of the Hajj 2016 would decrease as the drill's duration increased. This study showed that knowledge of the Hajj 2016 among SRC-EMS providers decreased among those who attended a drill of 20 hours or more, suggesting that long drills should take place over several days or a week.

\section{Implications}

\section{$\underline{\text { Training / Education }}$}

This study found that the knowledge of disaster preparedness for mass gathering was sub-optimal among SRC-EMS providers. The training and education are imperative approaches to improve the knowledge of disaster management. In this study, $64.9 \%$ of the respondents were less than 25 to 34 years old. The SRC-EMS providers who were more than 40 years old had less than the recommended knowledge, and less than the group age from 35 to 39 years old. That means young (less than 35 years) SRC-EMS providers as well as those older than 40 need more training, workshops, and drills. SRCA 
should encourage members of those age group to attend specific programs focused on disaster preparedness, to include basic epidemiology, patient assessment (Medical and Trauma), crowd control, critical thinking, triage, disaster management, and incident command systems. These programs should be in the form of workshops or drills. Providers should be sent to the Hajj for work to prove their ability to perform in these situations.

The SRCA stations should offer trainings for their providers to be ready when a disaster happens and should be credited as continuing education. It will keep EMS workers up to date about disaster management, especially in the knowledge and skills related to the Hajj season. In addition, training should be supported with workshops and drills to provide familiarity with critical knowledge and skills.

The majority of participants of this study were EMS technicians and had diploma degrees. This group of providers had lower knowledge of disaster preparedness for mass gatherings than the other groups of providers in this study. SRC-EMS technicians need additional trainings on disaster management and leadership. Workshops and drills are critical components of training to ensure the necessary skills for EMS providers. In addition, Incident Command System should be integrated into daily routines to improve first responders and EMS technicians familiarity and allow them to take leadership roles during the disaster situations.

This study showed that $51 \%$ of the participants had current EMS training through the private sector and had lower knowledge of disaster preparedness than those trained by other sectors. The health education provided by private sector needs support from the government and its curricula should be reviewed to assure that they meet the standards of 
EMS training. The government should have standards for private colleges to allow them to teach EMS training. The government should impose standards for private colleges to allow them to teach EMS training and should supervise them from beginner to end. SRCA should assess providers and provide them additional courses and training before they are hired. In this study SRC-EMS providers whose current training was in the military sector had more knowledge than those from other sectors. Future studies should focus on the military experience of health education and study it as a model of how to implement the military experience of health education for other sectors.

\section{Prior Experience}

Saudi EMS providers have unique opportunities for disaster situations during the Hajj each year. It is imperative to encourage them to work during the Hajj. Work during the Hajj season offers a chance to practice and learn numerous skills. Additionally, it is important for SRC-EMS providers to participate in writing disaster plans for the Hajj. Experience in disaster situations such the Hajj will give providers more confidence and increase their knowledge and practice of disaster management.

\section{Scope of recommendation for practice}

The Hajj season is a potential disaster situation and challenge for the Saudi government. The practice of Saudi EMS providers in Saudi Arabia needs to change and improve, so methods of training and education should also change from the very beginning. The curricula of EMS training in school should include additional courses about disaster preparedness for mass gatherings with, for example, courses about disaster management, ICS, crowd medicine, crowd control and triage. Another recommended change is for EMS training to use simulation labs to practice the skills learned in 
classroom lectures. The simulation lab should be set up for the scenario of mass casualty triage and train the providers during a simulated disaster. Following a practicum training, providers should be debriefed to identify mistakes and areas for additional provider training. Also, EMS technicians should have more responsibilities during the Hajj, to include advanced skills of EMS providers such as leadership of treatment and transportation. Decision- makers with the SRCA should establish a research center to study the new EMS field protocol in Saudi Arabia, as EMS research is very weak in Saudi Arabia, especially in SRCA (Al-shammari, Jennings, \& Williams, 2017). Thus, academic professors should be encouraged to publish papers on research into the scope of practice for EMS providers during disaster preparedness for mass gatherings, as this will help the Saudi system improve and fill the gaps of knowledge of disaster preparedness of the Hajj.

\section{Synthesis and Application of these Results}

It is important that the salient findings from this dissertation be communicated to the highest levels of the Saudi Arabian first responders training command. The important findings of this investigation center on the training and characteristics of the EMS workers who are best prepared for working mass gatherings such as the Hajj.

1. Years of Experience: More mature EMS workers (35-39 years old) were superior to less experienced age groups. While this is not a modifiable factor, it provides insight into the current age group with the best knowledge (training, workshops, and degree programs) preparation. Therefore, this finding should provide a template for the training that those 35-39 years have had and assure that 
younger workers are provided the same training, in an attempt to enhance the skills to the level of the 35-39 year old workers.

2. Certification: A strict certification program needs to be implemented because a large proportion ( $26 \%$ to $45.6 \%$ ) of EMS providers did not attend training. The certification program should include mandatory annual training that is documented through a central authority. It may be necessary to implement a regulation that states one MUST NOT BE ALLOWED to be a practicing EMS/first responder without current certification/licensure. Penalties should be attached to non-compliance.

3. Training Content and Delivery: the training of EMS providers should have the goal of delivering advanced training that parallels the skills learned by those who hold a master's degree. There should be incentives for EMS workers to pursue higher education leading to the master's degree. Training should include classroom training, workshops, and disaster drills. The training must be updated and renewed each year because it was found that those whose training was within 12 months was significantly higher than other categories.

Classroom training should be concise and last no more than five contact hours, except when the classroom exercises are part of a structured curriculum leading to the master's degree. It was found that longer training did not increase knowledge. training should be concise and last no more than 9 hours because it was found that workshops that last 5 to 9 hours contributed to knowledge about as much as workshops that lasted 20 hours. Content delivery should be concise and focus on specific emergency types such as stampedes, victim transport, and medical aid. 
Disaster drills should be conducted no fewer than four times per year, and the training drills should last about a day, but should last about 20 hours, but the time can be divided across a month to facilitate work schedules.

Paramedic training should be included for all EMS providers with levels of proficiency noted, and the expectation that the provider will enhance their training annually with the end goal to obtain a master's degree knowledge level or equivalent thereof. The paramedic training is a mandatory skill that EMS providers must acquire, and this skillset must be updated and advanced annually. The Mandated Schedule of training for re-certification should include several types of training with specific frequency. Classroom training should be conducted no less than four times per year. Workshops should be conducted no less than four times per year. Drills should also be conducted no less than four times annually. In summary, the types of training and number of times the activity is conducted annually will be documented. It is recommended that a certification or licensure be implemented and enforced. Continuing education is a critical component of the program because it was found that training that occurred more than a year (more than 12 months) was not significantly associated with increased knowledge. These actions will dramatically increase the proficiency of the EMS workforce in Saudi Arabia for the Hajj, and other mass gatherings. In addition, this program will result in a more highly trained and effective emergency services workforce. 


\section{Limitations of Study}

Limitations of this study include the use of only a self-reported survey, and a $41 \%$ response rate (i.e., 700 respondents to 1650 surveys sent). The most obvious limitation was the use of online self-reporting data collection procedures. For example, the participants' responses to questionnaires might have been biased and the researcher had no control over the environment. In addition, this study was a cross-sectional study in which participants responded to the survey at only one time. Therefore, other factors, such as such as having an unexpected issue on the specific day the survey was completed, might have affected the responses. The second limitation in this study is that the respondents were only Saudi EMS providers who worked in SRCA. This study excluded another Saudi EMS providers who worked in another Ministries in Saudi Arabia such as Ministry of Health, Ministry of Defense and National Guard hospitals. The finial limitation of this study was its focus on Saudi EMS providers in SRCA and did not assess the leaders of SRCA or their knowledge of disaster preparedness for mass gatherings. Future EMS leaders should be the most intensely trained, which will lead to significant and rapid improvement of the system.

\section{Strengths of study}

The strength of this study is that it is the first empirical study on the role of SRCEMS providers in disaster preparedness for the Hajj season in Saudi Arabia. As such, it provides new valuable information on the perceived preparedness of SRCEMS providers during the Hajj against role standards as stated in the emergency plan of SRCA. The study identified specific health education and training programs deemed appropriate and relevant by the SRC-EMS providers. Finally, this study is the first study to investigate 
predictive factors associated with increasing knowledge of disaster preparedness for the SRC-EMS providers.

\section{Future Study Research}

This study was focused on assessment of SRC-EMS providers for disaster preparedness for mass gatherings and found various different levels of knowledge among EMS providers. It will be beneficial if other studies assess other Saudi EMS providers who work for other agencies such $\mathrm{MOH}$, Saudi National Guard, and Ministry of defense because all of them work in second line capacity with SRCA when disasters happen during the Hajj.

As this study found the military sector of education is more efficient and effective for disaster preparedness. Future research should focus on health education within the military sector to find out why their students are more knowledgeable than other students from other sectors.

Finally, this study provides a basis for further research into disaster preparedness as a whole. The results for this specific population of SRC-EMS providers showed a lack of knowledge of disaster preparedness for mass gatherings which has effects on the entire disaster management approval for mass gathering events. It is recommended that a qualitative and mixed methods approaches be taken to identify variables that may influence actions. The influence of knowledge on individual preparedness for disasters should be studied and should include experimentation.

\section{Conclusion}

This study was the first Saudi study that explored the SRC-EMS provider's perception of their readiness for disasters at mass gatherings. The findings indicate a 
relationship between the demographic variables of SRC-EMS providers (age, level of education, level of EMS providers, working experience, previous disaster education/training, number of trainings, number of hours of training) with general knowledge of disaster preparedness and the Hajj knowledge of 2016. All of these variables were related to knowledge of disaster preparedness for mass gatherings. The findings indicate that the best sources of general knowledge of SRC-EMS providers were continuing education, institutional or University courses, and media. However, the best sources for Hajj knowledge of 2016 for SRC-EMS providers were real disasters, continue education, institution or university courses, and media.

This study provides valuable insights into understanding predictive factors associated with better levels of general knowledge of disaster preparedness for mass gathering and disaster preparedness for the Hajj of 2016. These predictive factors determined the level of knowledge of disaster preparedness for SRC-EMS providers. The following characteristics for general knowledge of disaster preparedness should be included; highest level of education, EMS level of provider, number of time working at the Hajj, number of workshops ever attended, time elapsed since last workshop, number of workshops and drills attended for disaster preparedness for mass gatherings. However, the characteristics for knowledge of the Hajj 2016 included; EMS level of provider, number of drills ever attended, number of drills attended, and duration of last drill attended for a disaster in the Hajj.

Finally, this study offers major recommendations to the Saudi government to improve the knowledge of disaster preparedness for mass gathering for SRC-EMS providers, such as improving the training and education, encouraging the providers to 
work in the Hajj, and changing the scope of practice for the Saudi EMS system. Thus, the Saudi government can apply these recommendations to improve the Saudi EMS system. 


\section{REFERENCES}

Abdi, H. (2007). Multiple correlation coefficient. The University of Texas at Dallas.

Abosuliman, S., Kumar, A., Alam, F., \&Rasjudin, R. (2013). Disaster planning and management in Jeddah, Saudi Arabia. In Proc. 2013 International Conference on Economics and Social Science (ICESS 2013), Melbourne, Australia, 20-21.

Ahmed, Q. A., Arabi, Y. M., \& Memish, Z. A. (2006). Health risks at the Hajj. The Lancet, 367(9515), 1008-1015. doi: 10.1016/S0140-6736(06)68429-8

Ahmed, Q. A., Barbeschi, M., \& Memish, Z. A. (2009). The quest for public health security at Hajj: the WHO guidelines on communicable disease alert and response during mass gatherings. Travel Medicine and Infectious Disease, 7(4), 226-230. doi:10.1016/j.tmaid.2009.01.005

Al Thobaity, A., Plummer, V., Innes, K., \& Copnell, B. (2015). Perceptions of knowledge of disaster management among military and civilian nurses in Saudi Arabia. Australasian Emergency Nursing Journal, 18(3), 156-164.

Al-Ahmadi, A., Al-Swidi, A., Abas, Z. \& Ghani, H. (2013). Task complexity of the Civil Defense Directorate in the Context of the Hajj season. British Journal of Arts and Social Sciences. Retrieved from www.bjournal.co.uk

Al-Ali, N. M., \& Abu-Ibaid, A. A. (2015). Health-care providers' perception of knowledge, skills and preparedness for disaster management in primary healthcare centres in Jordan/Perception des prestataires de soins de santé en matière de 
connaissances, de compétences et d'état de préparation à la gestion des catastrophes dans des centres de soins de santé primaires en Jordanie. Eastern Mediterranean Health Journal, 21(10), 713. Retrieved from www.emro.who.int

Alamri, Y. A. (2011). Rains and floods in Saudi Arabia. Crying of the sky or of the people? Saudi medical journal, 32(3), 311-313. Retrieved from www.smj.org.sa

Al-Ghamdi, A. S. (2002). Emergency medical service rescue times in Riyadh. Accident Analysis \& Prevention, 34(4), 499-505.

Al-Ghamdi, A. S., \& Kabbash, I. A. (2011). Awareness of healthcare workers regarding preventive measures of communicable diseases among Hajj pilgrims at the entry point in Western Saudi Arabia. Saudi Medical Journal, 32(11), 1161-1167

Alharbi, R. (2015). A GIS-based decision support system for reducing air ambulance response times: A case study on public schools in Jeddah city. Journal of Geographic Information System, 07(04), 384-391. doi:10.4236/jgis.2015.74030

Al-Hashem, A. (2016). Health Education in Saudi Arabia. Sultan Qaboos University Med $J, 16(3), 286-292$.

Aljazira Capital (2013) Kingdom of Saudi Arabia Medical Healthcare Sector. http://www.aljaziracapital.com.sa

Al Khalaileh, M. A., Bond, A. E., Beckstrand, R. L., \& Al-Talafha, A. (2010). The Disaster Preparedness Evaluation Tool: psychometric testing of the Classical Arabic version. J Adv Nurs, 66(3), 664-672. doi:10.1111/j.1365-2648.2009. 05208.x 
Al-Khalaileh, M. A., Bond, E., \& Alasad, J. A. (2012). Jordanian nurses' perceptions of their preparedness for disaster management. International Emergency Nursing, 20(1), 14-23. doi: 10.1016/j.ienj.2011.01.001

Al-Nami, M., ., Arafah, M., ., \& Al-Ibrahim, F. (2010). Trauma care systems in Saudi Arabia: An agenda for Action. Annals of Saudi Medicine,, 30(1), 50-58. doi $10.4103 / 0256-4947.59374$

Al-Orainey, \& Ibrahim, O. (2013). Tuberculosis infection during Hajj pilgrimage. The risk to pilgrims and their communities. Saudi medical journal, 34(7), 677-680.

Retrieved from http://smj.org.sa/index.php/smj/article/viewFile/1532/637

Alrazeeni, D. (2015). Saudi EMS Students' Perception of and Attitudes toward Their Preparedness for Disaster Management. Journal of Education and Practice, 6(35), $110-116$.

Al-shammari, T., Jennings, P., \&, \& Williams, B. (2017). Evolution of emergency medical services in Saudi Arabia. Journal of Emergency Medicine, Trauma and Acute Care, 2017(4), 2-11.

Alshenawi, S. (2014). An Assessment of the 2012 Hajj Providing Services, Pilgrims and Hajj Agencies Stance An Exploratory Study. (Doctoral dissertation) Indiana State University, Terre Haute, Indiana, USA.

Al-Tawfiq, J. \& Memish, Z. (2014). Mass gathering medicine: 2014 Hajj and Umrah preparation as a leading example. International Journal of Infectious Diseases, 27, 26-31. Retrieved from www.elsevier.com/locate/ijid

Al-Yousuf, M., Akerele.T.M., and Almarzrou. Y.Y,. (2002). Organization of the Saudi Health system. Eastern Mediterranean Health Journal, 8 (4/5) 645-653 
Alzahrani, F., \& Kyratsis, Y. (2016). Investigating the role of emergency nurses and disaster preparedness during mass gathering in Saudi Arabia. World Academy of Science, Engineering and Technology, International Journal of Social, Behavioral, Educational, Economic, Business and Industrial Engineering, 10(3), 752-757. Retrieved from www. scholar.waset.org/1999.31/47246

Akdeniz, C. (2016). Instructional Process and Concepts in Theory and Practice: Improving the Teaching Process. Springer

Amalki, M. Fitzgerald, G., \& Clark, M. (2011). Health care system in Saudi Arabia: An overview. Applied Research and Innovation Project, 1-43. Retrieved from http://apps.who.int/iris/bitstream/10665/118216/1/17_10_2011_0784_0793.pdf

Arbon, P. (2004). The development of conceptual models for mass-gathering health. Prehospital and Disaster Medicine, 19(03), 208-212.

Arbon, P. (2007). Mass-Gathring Medicine: A review of the evidence and future directions for research. Prehospital and Disaster Medicine, 22(2), 131-135.

Arbon, P. (2010). Editorial comments development of a mass-gathering medical resource matrix for a developing world scenario. Prehospital and Disaster Medicine, $25(6), 553$.

Arbon, P., Ranse, J., Cusack, L., Considine, J., Shaban, R. Z., Woodman, R. J., Bahnisch, L., Kako, M., Hammad, K., \&Mitchell, B. (2013). Australasian emergency nurses' willingness to attend work in a disaster: a survey. Australasian emergency nursing journal, 16(2), 52-57.

Authority, S. R. C. Retrieved from http://www.saudiredcrescent.com/

Babbie, E. (2015). The practice of social research. Boston, MA: Cengage Learning. 
Blalock, H. M. (1979). Social statistics (2nd ed.). New York: Mcgraw-Hill.

Blanchard, I. E., Doig, C. J., Hagel, B. E., Anton, A. R., Zygun, D. A., Kortbeek, J. B., \& Innes, G. D. (2012). Emergency medical services response time and mortality in an urban setting. Prehospital emergency care, 16(1), 142-151.

Boyle, R. P. (1970). Path analysis and ordinal data. The American Journal of Sociology, 75(4), 461-480.

Brace, N., Kemp, R., \& Snelgar, R. (2012). SPSS for psychologists. Palgrave Macmillan.

Bryman, A., \& Cramer, D. (2004). Quantitative data analysis with SPSS 12 and 13: A guide for social scientists. Psychology Press.

Chakraborty, A., Mujumdar, M., Behera, S. K., Ohba, R., \& Yamagata, T. (2006). A cyclone over Saudi Arabia on 5 January 2002: a case study. Meteorology and Atmospheric Physics, 93(1-2), 115-122. doi: 10.1007/s00703-005-0183-2

Chan, M. F. (2009). Factors affecting knowledge, attitudes, and skills levels for nursing staff toward the clinical management system in Hong Kong. Computers Informatics Nursing 27(1), 57-65.

Cobanoglu, C., Warde, B., \& Moreo, P. J. (2001). A comparison of mail, fax and webbased survey methods. International Journal of Market Research, 43(4), 441-452. Collier International. (2014). Kingdom of Saudi Arabia: Holy Cities on the Road to ReDevelopment.http://www.colliers.com/media/7447BF6144684A1F8420B5C0348 F25CA.ashx?1a=en-GB

Cook, Heath, \& Thompson, (2000). A meta-analysis of response rates in web-or internetbased surveys. Educational and Psychological Measurement, 60(6), 821-836. 
Crane, J. S., McCluskey, J. D., Johnson, G. T., \&, \& Harbison, R. D. (2010). Assessment of community healthcare providers ability and willingness to respond to emergencies resulting from bioterrorist attacks. Journal of Emergencies, Trauma and Shock, 3(1), 13.

Crano, W. D., \&, \& Brewer, M. B. (2002). Principles and methods of social research (2nd ed ed.). Mahwah, NJ: Lawrence Erlbaum.

Couper, M. P. (2000). Review: Web surveys: A review of issues and approaches. The Public Opinion Quarterly, 64(4), 464-494.

Cozby, P. C. (2012). Methods in behavioral research (11th ed.). New York, NY. McGraw-Hill Humanities. (No. 150.72 C6).

D'alessandro, K., Leggio,L., Almbarek,H,. (2013). Muslim mass pilgrimage poses EMS logistical \& planning challenges. Jems. Retrieved from https://www.researchgate.net/profile/William_Leggio/publication/259649933_Wo rld\%27s_largest_gathering_Muslim_mass_pilgrimage_poses_EMS_logistical_pla nning_challenges/links/54d9bba00cf2970e4e7c9a02.pdf

Deeny, P., \& McFetridge, B. (2005). The impact of disaster on culture, self, and identity: increased awareness by health care professionals is needed. Nursing Clinics North America, 40(3), 431-440, vii. doi:10.1016/j.cnur.2005.04.012

Deshmukh, R., Rodrigues, L. L., and Krishnamurthy, G. R. (2008). Earthquake risk and knowledge management. Journal of Knowledge Management Practice, 9(3).

Dhaffar, K. O., Sindy, A. F., Gazzaz, Z. J., \& Shabaz, J. (2005). Evaluation of an emergency service attempted by the Saudi Red Crescent Society. Saudi medical journal, 26(2), 357-359. Retrieved from www.smj.org.sa 
Dillman, D. A., Phelps, G., Tortora, R., Swift, K., Kohrell, J., Berck, J., \& Messer, B. L. (2009). Response rate and measurement differences in mixed-mode surveys using mail, telephone, interactive voice response (IVR) and the Internet. Social Science Research, 38(1), 1-18.doi: 10.1016/j.aenj.2015.03.001

Efstathiou Panos., Papafragkaki, D., Gogosis, K., \& Manwlidou, Z. (2009). Crisis management in the Health Sector; Qualities and characteristics of Health crisis manager. International Journal of caring sciences, 2(3), 105-107.

Eid, R., . (2012). Towards a high-quality religious tourism marketing: The case of hajj service in Saudi Arabia. Cognizant communication Crop, 17(4), 509-522. doi:DOI: $10.3727 / 108354212 X 13473157390849$

Duong, K. (2009). Disaster education and training of emergency nurses in South Australia. Australasian Emergency Nursing Journal, 12(3), 86-92.

Elachola, H., Assiri, A. M., \& Memish, Z. A. (2014). Sun protection during the Hajj mass-gathering--2013. Travel Medicine Infectious Disease, 12(6 Pt B), 783-784. doi:10.1016/j.tmaid.2014.09.005

EM-DAT. The OFDA/CRED International Disaster Database. Brussels, Belgium 2013: http://www.emdat.be Emergency management in Saudi Arabia: Past, present, and future.

Everly, G. S. (2001). Thoughts on training guidelines in emergency mental health and crisis intervention. International Journal of Emergency Mental Health and Human Resilience, 4(3), 139-141.

Evers, S., \&, \& Puzniak, L. (2005). Bioterrorism knowledge and emergency preparedness among school nurses. The Journal of School Health, 75(6), 232 
Fan, W., \& Yan, Z. (2010). Factors affecting response rates of the web survey: A systematic review. Computers in Human Behavior, 26(2), 132-139

Furbee, P.M., Manley, W. G., Coben, J.H., Smyth, S.K., Summers, D. E., Althouse, R.C., Kimble, R. L., Kocsis, A. T., Helmkamp, J.C. (2006). Realities of disaster preparedness in rural hospitals. Disaster Management \& Response, 4(3), 80-87.

Farmer, J. C., \& Carlton Jr, P. K. (2006). Providing critical care during a disaster: the interface between disaster response agencies and hospitals. Critical care medicine, 34(3), 56-59. doi: 10.1097/01.CCM.0000199989.44467.2E

Fernandez, A. R., Studnek, J. R., Margolis, G. S., Mac Crawford, J., Bentley, M. A., \& Marcozzi, D. (2011). Disaster preparedness of nationally certified emergency medical services professionals. Academic emergency medicine, 18(4), 403-412.

Fischer, P., Kabir, K., Weber, O., Wirtz, D. C., Bail, H., Ruchholtz, S., Stein, M. \& Burger, C. (2008). Preparedness of German paramedics and emergency physicians for a mass casualty incident: a national survey. European journal of trauma and emergency surgery, 34(5), 443-450. doi: 10.1007/s00068-008-8803-4

Fung., L., \& L. (2008). Disaster preparedness among Hong Kong nurses. Journal of Advanced Nursing, 62(6), 698-703. doi:10.1111/j.1365-2648.2008. 04655.x

Gaffar, H., Achmadi, U., Syamsu, \& Patellongi, I. (2013). Hajj Health Management Focusing on the Risk Factors Management. International Journal of Scientific and Research Publications, 1-9. Retrieved from www.ijsrp.org Gardouni, A. (2012). The Mecca Pilgrimage and its medical preparedness. (Unpublished Master's thesis), National and Kapodistrian University of Athens, Greece. 
Gebbie, K. M., \& Qureshi, K. (2002). Emergency and Disaster Preparedness: Core Competencies for Nurses: What every nurse should but may not know. The American Journal of Nursing, 102(1), 46-51.

Gebbie, K. M., Hutton, A., \& Plummer, V. (2012). Update on competencies and education. Annual review of nursing research, 30(1), 169-192. Retrieved from https://doi.org/10.1891/0739-6686.30.169

General Authority for Statistics. http://www.stats.gov.sa/en

Gutman, S. J., Lund, A., \& Turris, S. A. (2011). Medical support for the 2009 World Police and Fire Games: A descriptive analysis of a large-scale participation event and its impact. Prehospital and Disaster Medician, 26(01), 33-40. doi: $10.1017 / \mathrm{s} 1049023 \times 10000117$

Gutret, P., Benkouiten, S., Salaheedine, I., Belhouchat, K., Drali, T., Parola, P., \& Brouqui, P. (2013). Hajj pilgrims' knowledge about Middle East respiratory syndrome coronavirus, August to September 2013. Eurosurveillance, 18 (41), 20604

Haddow, G., Bullock, J., \& Coppola, D. (2008). Introducation to emergency management. Burlington, MA: Elsevier.

Halloran, J., \&, \& D'ouglas, D. (1987). Applied human relations: An organizational approach. Prentice Hall, 326.

Hamam, A. F., Bagis, M. H., AlJohani, K., \& Tashkandi, A. H. (2015). Public awareness of the EMS system in Western Saudi Arabia: identifying the weakest link. International Journal of Emergency Medicine, 8(1), 70. doi:10.1186/s12245-0150070-7 
Hattie, J. (1985). Methodology review; Assessing unidimensionality of tests and items. Applied Psychological Measurement, 9(2), 139-164. Retrieved from http://purl.umn.edu/93227

Hawkins, E., \& Brice, J. (2010). Fire Jumpers: Description of Burns and Traumatic Injuries from a Spontaneous Mass Aghering and Celebratory Riot. The Journal of Emergency Medicine, 38 (2) 182-187. Retrieved from http://www.sciencedirect.com/science/article/pii/S0736467908008664

Hazif, Y. (2013). Hajj 2013, Islam's Pilgrimage To Mecca: Facts, History And Dates Of The Muslim Holiday. Retrieved from Huffington Post: Religion : http://www.huffingtonpost.com/2013/10/11/hajj-2013_n_4064513.html

He, Y., Lin, Q., He, Y., Feng, W., Dong, C., Guo, X., Chen, R., Pan, H., Sun, H., Yuan, Z., \& Wu, F. (2011). A syndromic surveillance system for public health security in Expo 2010 Shanghai China. Journal of Environmental \& Occupational Medicine, 1(28), 1-5. doi: 10.1017/S1049023X12001252

Hristidis, V., Chen, S.-C., Li, T., Luis, S., \& Deng, Y. (2010). Survey of data management and analysis in disaster situations. Journal of Systems and Software, 1701-1714. doi 10.1016/j.jss.2010.04.065 http://services.rmh.med.sa/index.php/smj/article/viewFile/3712/1486

Husan, C., Hatthakit, U., \&, \& Chaowalit, A. (2011). Emergency training, education and perceived clinical skills for tsunami care among nurses in Banda Aceh, Indonesia. Nurse Media Journal of Nursing, 1(1), 75-86.

International Federation of Red Cross and Red Crescent Societies. (2001). World disasters Report focus on Recovery. Retrieved from http:/www.ifrc.org/ 
International Federation of Red Crescent Societies. (2016). More than 2400 Red Crescent volunteers on ground to serve pilgrims during Hajj. Retrieved from http://www.ifrc.org/

Jaslow, D., Yancy, A., \& Milsten, A. (2000). Mass gathering care: position paper, national association of EMS physicians. Prehospital emergency care, 4(4), 359360. doi: $10.1080 / 10903120090941119$

Jin, D., Ljungqvist A, Troedsson H, eds. (2010). The Health Legacy of the 2008 Beijing Olympic Games: Successes and Recommendations; Geneva, Switzerland: World Health Organization; 2010.

Kamel, J., \& Najeh, L. (2012). Functional analysis of congestion state caused by pilgrims crowd using SAFT aiding on the design of a new supervisory system. Journal of Electrical and Electronics Engineering, 5(1)105-111.

Kaplowitz, M. D., Hadlock, T. D., \& Levine, R. (2004). A comparison of web and mail survey response rates. Public Opinion Quarterly, 68(1), 94-101. doi:10.1093/poq/nfh006

Kathrtn M. Zeitz, M., David P.A. Schneider, BN, Dannielle Jarrett, BN. (2002). Mass Gathering Events: Retrospective Analysis of patient Presentations over Seven Years. Prehosp Disaster Med, 17(3), 147-150.

Keppel, G. (1991). Design and analysis: A researcher's handbook (3rd ed.). Upper Saddle River, NJ: Prentice Hall.

Key, G. (1994). Disaster medical assistance teams. Dirección Nacional para la Prevención y Atención de Desastres, 1-6. 
Khan, A. A., \& Noji, E. K. (2016). Hajj stampede disaster, 2015: Reflections from the frontlines. American Journal of Disaster Medicine, 11, (1), 59-68.

Khan, S. A., (2009). Health services during Haj-Is there a scope for improvement? Physicians Academy, 3(10), 104-105. Retrieved from www.physiciansacademy.com

Kishore, S., \& Soulieres, G. (2012). Survey Results.

Kliegel, M., \& Martin, M. (2007). Adult age differences in errant planning: The role task familiarity and cognitive resources. Experimental Aging Research (33), 145-161.

Klynman, Y., Kouppari, N., \& Mukhier, M. (2007). World Disasters Report: Focus on Discrimination: Kumarian Press. Retrieved from http://www.ifrc.org

Leedy, P., \&, O’rmrod. (2005). Practical research. Pearson Custom.

Lewis-Beck, M. (1980). Applied regression: An introduction. Newbury Park, CA: Sage.

Light, R. J., Singer, J. D., \& Willett, J. B. (2009). By design: Planning research on higher education. Cambridge, Mass: Harvard University Press.

Lim, G. H., Lim, B. L., \& Vasu, A. (2013). Survey of factors affecting health care workers' perception towards institutional and individual disaster preparedness. Prehospital and disaster medicine, 28(4), 353. doi:10.1017/S1049023X1300349X

Lix, L. M., Keselman, J. C., \&, Keselman, H. J. (1996). Consequences of assumption violations revisited: A quantitative review of alternatives to the one-way analysis of variance F test. Review of educational research, 66(4), 579-619.

Locoh-Donou, S., Guofen, Y., Welcher, M., Berry, T., O'Connor, R. E., \& Brady, W. J. (2013). Mass-gathering medicine: a descriptive analysis of a range of mass- 
gathering event types. The American Journal of Emergency Medicine, 31(5), 843846. doi:10.1016/j.ajem.2013.01.016

Lund, A., Gutman, S., \& Turris, S. (2011). Mass gathering medicine: a practical means of enhancing disaster preparedness in Canada. CJEM, 13(4), 231-236. doi:10.2310/8000.2011.110305

Matlack, W. F. (1993). Statistics for public managers. Itasca, II: F.E. Peacock Publishers. McGraw-Hill Irwin. Measurement and statistics (pp. 648-651). Thousand Oaks, CA: Sage.

McKibbin, A. E., Sekula, K., Colbert, A. M., \& Peltier, J. W. (2011). Assessing the learning needs of South Carolina nurses by exploring their perceived knowledge of emergency preparedness: evaluation of a tool. J Contin Educ Nurs, 42(12), 547-558. doi:10.3928/00220124-20111003-04

Memish, Z. (2010). The Hajj: communicable and non-communicable health hazards and current guidance for pilgrims. Euro Surveill, 15(39), 19671. 1-4

Memish, Z. A., \& Al Rabeeah, A. A. (2012). Health conditions for travelers to Saudi Arabia for the Umra and pilgrimage to Mecca (Hajj)-2014. Journal of epidemiology and global health, 4(2), 73-75. doi: 10.1016/j.jiph.2013.03.001

Memish, Z. A., Zumla, A., Alhakeem, R. F., Assiri, A., Turkestani, A., Al Harby, K. D., . .. Al-Tawfiq, J. A. (2014). Hajj: infectious disease surveillance and control. The Lancet, 383(9934), 2073-2082. doi:10.1016/s0140-6736(14)60381-0

Milsten, A. M., Maguire, B., \& Bissell, R. A. (2002). Mass-gathering medical care: A review of the literature. Prehospital and Disaster Medicine, 17(3), 151-162. 
Ministry of Hajj. (2015) Ministry of Hajj: Service for Pilgrims. Retrieved from Ministry of Hajj: http://www.haj.gov.sa

Ministry of Health (2013). State of Hajj. Central Department of Statistics and Information.

Ministry of Health. (2015). The Health Communication for Hajj. Retrieved from Ministry of Health: Saudi Arabia: http://www.moh.gov.sa/en/Hajj/Pages/default.aspx

Moe, T. L. \& Pathranarakul, P. 2006. An integrated approach to natural disaster management: Public project management and its critical success factors. Disaster Prevention and Management: An international Journal, 15(3), 396-413. doi.10.1108/09653560610669882

Morimura, N., Katsumi, A., Koido, Y., Sugimoto , K., Fuse, A., Asai, Y., . . . Yamamoto, Y. (2004). Analysis of patient load data from the 2002 FIFA World Cup Korea/Japan. Prehospital and Disaster Medicine, 278-284. doi:10. 10117/S1049023X00001874

Mosteller, F., \& Tukey, J. (1977). Data analysis and regression: A second course in statistics. Reading. Addison-Wesley series in behavioral sciences. Quantitative methods.

Mueller, J., Schussler, K., \& Costner, H. (1977). Statistical reasoning in sociology $\left(3^{\text {rd }}\right.$ ed.). Boston: Houghton Mifflin.

National Registry of Emergency Medical Technicians. EMT-Basic Re-Registration Requirements. Available at: http://www.mobilemedical.org/Docs/EMT.basic. pdf. Accessed Jan 22, 2017. 
Neter, J., Nachtsheim, C., \& Kutner, M. (2004). Applied linear regression models. McGraw-Hill/Irwin.

Nojoum, M. S. (2005). The development of an information management system at the Custodian of the Two Holy Mosques Institute of Hajj Research, Saudi Arabia. (Doctoral), Loughborough University, UK.

O’Sullivan, T. L., Dow, D., Turner, M. C., Lemyre, L., Corneil, W., Krewski, D., ... \& Amaratunga, C. A. (2008). Disaster and emergency management: Canadian nurses' perceptions of preparedness on hospital front lines. Prehospital and Disaster Medicine, 23(3) 11-18.

Phillips, B. (1997). Qualitative methods and disaster research. International Journal of Mass Emergencies and Disasters, 179-195. Retrieved from http://www.safetylit.org/citations/index.php?fuseaction=citations.viewdetails\&cit ationIds $\% 5 \mathrm{~B} \% 5 \mathrm{D}=$ citjournalarticle_56045_4 Publications.

Regional Office for the Eastern Mediterranean, WHO Cairo.(2006). Health System Profile: Saudi Arabia. World Health Organization, Cairo.

Regression, analysis of variance, and experimental design (2nd ed.). New York: retrieved from www.emro.who.int Royal Institute of Chartered Surveyors (2009). The built environment professions in disaster risk reduction and response. Westminster, U.K.: MLC Press, University of Westminster, U.K.

Rudman, W.B., Clarke, R.A., Metzl, J. F. (2003). Emergency responders: drastically underfunded, dangerously unprepared. Council of Foreign Relations, New York, USA. Available at: http://www.cfr.org/pdf/Responders_TF.pdf;2003. 
Salkind, N.J. (2007), Encyclopedia of measurement and statistics (pp. 648-651). Thousand Oaks, CA: Sage Publication.

Sanders, A., Criss, E., Steckl, P., \& Meslin, H. (1986). An analysis of medical care at mass gatherings. Annals of Emergency Medicine, 515-519. doi:10.1016/S0196$\underline{0644(86) 80984-2}$

Sasser, S., Gibbs, M., \& Blackwell, T. (2004). Prehospital emergency care in Abu Dhabi, United Arab Emirates. Prehospital Emergency Care, 8(1), 51-57. doi: $10.1080 / 312703002818$

Saudi Commission for Health Specilities. Available from: http:// www.scfhs.org.sa Saudi Red Crescent Authority. History of SRCA 2013. Available from: http://www.srca.org.sa /History.aspx (accessed 6 January 2018).

Sax, L. J., Gilmartin, S.K., \& Bryant, A. N. (2003). Assessing response rate and nonresponse bias in web and paper surveys. Research in Higher Education, 44(4), 409-432.

Seneviratne, K., Amaratunga, D., Haigh, R. \& Pathirage, C. (2010) Identification of disaster knowledge factors: Preliminary findings. Paper presented at the Construction, Building and Real Estate Research Conference of the Royal Institution of Chartered Surveyors. Paris, 2-3 September 2010.

Serwylo, P., Arbon, P., \& Rumantir, G. (2011). Predicting patient presentation rates at mass gatherings using machine learning. Paper presented at the 8th international ISCRAM Conference, Lisbon, Portugal. 2-10 
Shafi, S., Booy, R., Haworth, E., Rashid, H., \& Memish, Z. A. (2008). Hajj: health lessons for mass gatherings. Journal of Infection and Public Health, 1(1), 27-32 doi: 10.1016/j.jiph.2008.08.008

Shair, I. M., \& Karan, P. P. (1979). Geography of the Islamic pilgrimage. Geo Journal, 3(599-608).

Shujaa, A., \& Alhamid, S. (2015). Health response to Hajj mass gathering from emergency perspective, narrative review. Turk J Emerg Med, 15(4), 172-176. doi:10.1016/j.tjem.2015.02.001

Singh, B. R., \& Singh, O. (2012). Study of Impacts of Global Warming on Climate Change: Rise in Sea Level and Disaster Frequency. INTECH Open Access Publisher. 94-118.doi.10.5772/50464

Sirkin, R. M. (2006). Statistics for the social sciences. Thousand Oaks, CA: Sage Publication.

Slepski, L. A. (2007). Emergency preparedness and professional competency among health care providers during hurricanes Katrina and Rita: pilot study results. Disaster Management \& Response, 5(4), 99-110.

Soomaroo, L., \& Murray, V. (2012). Disasters at mass gatherings: Lessons from history. PLOS Current Disasters, 1-10. doi: 10.1371/currents.RRN1301.

Studnek, J. R., \& Fernandez, A. R. (2007). Organizational description and emergency preparedness of Nationally Registered First Responders. Prehospital and disaster medicine, 23(3), 250-255.

Thackway, S., Churches, T., Fizzell, J., Muscatello, D., \& Armstrong, P. (2009). Should cities hosting mass gatherings invest in public health surveillance and planning?: 
Reflections from a decade of mass gatherings in Sydney, Australia. BMC Public Health, 9(1), 324. doi: 10.1186/1471-2458-9-324.

Tichy, M., Bond, A. E., Beckstrand, R. L., \& Heise, B. (2009). NPs' perceptions of disaster preparedness education: Quantitative survey research. American Journal for Nurse Practitioners, 13(1), 10-22.

Traveling the World. (2014). Islam. Retrieved from Traveling the World: www.islam.abouttravelingtheworld.com/islamic-holidays/hajj/

Trochim, W. M., Donnelly, J. P., \& Arora, K. (2015). Research methods: The essential knowledge base ( $2^{\text {nd }}$ ed). Boston, MA: Wadsworth Publishing.

Turris, S., Bowles, R., \& Ranse, J. (2014). Mass-gathering health researoundational theory: Event modeling for mass gatherings. Prehospital and Disaster Medicine, 29(6), 655-6. doi:10.1017/S1049023X14001216.

United Nations High Commissioner for Refugee. UNHCR Signs agreement with Saudi Red Crescent Society 2007. Available from: http://www.unhcr.org/46264e9e4.html (accessed 29 January 2018).

UNISDR. (2009). Teminology on Disaster Risk Reduction. Retrieved from http://www.unisdr.org/

Veenema, T. G. (2003). Chemical and biological terrorism preparedness for staff development specialists. Journal for Nurses in Staff Development, 19(5) 215-25. doi:1098-7886

Waeckerle, J. A. (2004). Emergency departments: the Achilles heel of domestic preparedness. Paper presentation at the Future of Emergency Care Conference. Washington (DC): Institute of Medicine 
Weather Spark. (2015) information on Saudi Arabia. Retrieved from

http://www.weatherspark.com

WHO. (2008). Communicable disease alert and response for mass gatherings: key considerations [Press release]

Wisniewski, R., Dennik-Champion, G., \&, \& Peltier, J. W. (2004). Emergency preparedness competencies: assessing nurses' educational needs. Journal of Nursing Administration, 34(10), 475-480.

Wrench, J.S., Thomas-Maddox, C., Richmond, V.P., \& McCroskey, J.C. (2008). Quantitative research methods for communication: A hands-on approach. New York: Oxford University Press, Inc. ISBN: 9780195337471.

Wright, K. B. (2005). Researching Internet-based populations: Advantages and disadvantages of online survey research, Online questionnaire authoring software package, and web survey services. Journal of Computer-Mediated Communication, 10(3), 1034. doi:10.1111/j.1083-6101.

Yamin, M., \& Albugami, M. (2014). An architecture for improving Hajj management. International Conference on Informatics and Semiotics in Organizations.4 (19) 187-196. Springer Berlin Heidelberg.

Yancey, A. H., Fuhri, P. D., Pillay, Y., \& Greenwald, I. (2008). World Cup 2010 planning: an integration of public health and medical systems. Public Health, 122(10), 1020-1029. doi:10.1016/j.puhe.2007.11.005

Yaseen M. Arabi., \& Sameer M. Alhamid. (2006). Emergency room to the intensive care unit in Hajj. Saudi medical journal, 27 (7), 937-941. Retrieved from 
Yi, H., Zheng'an, F.,., Fan, W., Xiang, G., Chen, D., Yongchao, H., Xiaodong, S., Hao, P., Mahany, M., \& Keim, M. (2012). Public health preparedness for the world's largest mass gathering: 2010 World Exposition in Shanghai, China. Prehospital and Disaster Medicine , 589-594. doi 10.1017/S1049023X12001252

Yin, H., He, H., Arbon, P., \& Zhu, J. (2011). A survey of the practice of nurses' skills in Wenchuan earthquake disaster sites: implications for disaster training. Journal of Advanced Nursing, 67(10) 2231-2238. doi: 10.1111/j.1365-2648.2011. 05699.x

Yong-chao, H. E., Qing-neng, L. I. N., Yi, H. E., Wei, F. E. N. G., Chen, D. O. N. G.,

Xiang, G. U. O., \& Fan, W. U. (2011). A syndromic surveillance system for public health security in Expo 2010 Shanghai China. Journal of Environmental \& Occupational Medicine, 1(28), 1-5.

Zeitz, K., Zeitz, C., \& Arbon, P. (2005). Forecasting medical work at mass-gathering events: predictive model versus retrospective review. Prehospital and disaster medicine, 20(03), 164-168.

Zeitz, K. M., Schneider, D., \& Jarrett, D. (2002). Mass gathering events: Retrospective analysis of patient presentations over seven years. Prehospital and Disaster Medicine, 17(3), 147-150. doi:10.1017/S1049023X00000376

Zeitz, K., Zeitz, C., Arbon, P., Cheney, F., \& Johnston, R. (2008). Practical solutions for injury surveillance at mass gatherings. Prehospital and Disaster Medicine, 23(1)

76-81. Retrieved from http: pdm.medicine.wise.edu 


\title{
APPENDICES
}

\section{Appendix A}

\section{Approval Form the University of Louisville's Institutional Review Board}

\author{
UNIVEnsIV of of \\ LOUISYILE \\ 느는ㄷㄴ. Louisville, KY 40202-1798 \\ DATE: $\quad$ March 06, 2017 \\ TO: Susan O Allen \\ FROM: $\quad$ The University of Louisville Institutional Review Board \\ IRB NUMBER: $\quad 17.0120$ \\ STUDY TITLE: An Assessment of the disaster preparedness knowledge of Emergency Medical \\ Services providers in Saudi Red Crescent Authority during Hajj of 2016 \\ IRB STAFF CONTACT: Barbara Dearinger, BS, CIP \\ Barbara Dearinger, BS, CIP
(502)852-5987 \\ badear01@louisville.edu
}

This study was reviewed on 03/03/2017 by the Chair/Vice Chair of the Institutional Review Board and approved through the Expedited Review Procedure, according to 45 CFR 46.110(b), since this study falls under Category 7: Research on individual or group characteristics or behavior (including, but not limited to, research on perception, cognition, motivation, identity, language, communication, cultural beliefs or practices, and social behavior) or research employing survey, interview, oral history, focus group, program evaluation, human factors evaluation, or quality assurance methodologies.

This study was also approved through 45 CFR 46.116 (C), which means that an IRB may waive the requirement for the investigator to obtain a signed informed consent form for some or all subjects if it finds either:

- That the only record linking the subject and the research would be the consent document and the principal risk would be potential harm resulting from a breach of confidentiality. Each subject will be asked whether the subject wants documentation linking the subject with the research, and the subject's wishes will govern; or

- That the research presents no more than minimal risk of harm to subjects and involves no procedures for which written consent is normally required outside of the research context.

The following items have been approved:

\begin{tabular}{|l|l|l|l|}
\hline Title & Version \# & Version Date & Outcome \\
\hline New research protocol & Version 1.0 & $02 / 26 / 2017$ & Approved \\
\hline Survey Arabic version & Version 1.0 & $02 / 03 / 2017$ & Approved \\
\hline Survey English version & Version 1.0 & $02 / 03 / 2017$ & Approved \\
\hline informed consent & Version 1.0 & $01 / 31 / 2017$ & Approved \\
\hline
\end{tabular}

This study now has final IRB approval from 03/03/2017 through 03/02/2018.

For guidance on using iRIS, including finding your approved stamped documents, please follow the instructions at https://louisville.edu/research/humansubjects/iRISSubmissionManual.pdf

Site Approval

If this study will take place at an affiliated research institution, such as KentuckyOne Health, Norton Healthcare or University of Louisville Hospital, permission to use the site of the affiliated institution is necessary before the research may begin. If this study will take place outside of the University of Louisville Campuses, permission from the organization 
must be obtained before the research may begin (e.g. Jefferson County Public Schools). Failure to obtain this permission may result in a delay in the start of your research.

Privacy \& Encryption Statement

The University of Louisville's Privacy and Encryption Policy requires such information as identifiable medical and health records: credit card, bank account and other personal financial information; social security numbers; proprietary research data; dates of birth (when combined with name, address and/or phone numbers) to be encrypted. For additional information: http://security.louisville.edu/PolStds/ISO/PS018.htm.

Implementation of Changes to Previously Approved Research

Prior to the implementation of any changes in the approved research, the investigator will submit any modifications to the IRB and await approval before implementing the changes, unless the change is being made to ensure the safety and welfare of the subjects enrolled in the research. If such occurs, a Protocol Deviation/Violation should be submitted within five days of the occurrence indicating what safety measures were taken, along with an amendment to revise the protocol.

Unanticipated Problems Involving Risks to Subjects or Others (UPIRTSOs)

In general, these may include any incident, experience, or outcome, which has been associated with an unexpected event(s), related or possibly related to participation in the research, and suggests that the research places subjects or others at a greater risk of harm than was previously known or suspected. UPIRTSOs may or may not require suspension of the research. Each incident is evaluated on a case by case basis to make this determination. The IRB may require remedial action or education as deemed necessary for the investigator or any other key personnel. The investigator is responsible for reporting UPIRTSOs to the IRB within 5 working days. Use the UPIRTSO form located within the iRIS system to report any UPIRTSOs.

Continuation Review Requirements

You are responsible for submitting a continuation review 30 days prior to the expiration date of your research study. Investigators who allow their study approval to expire have committed significant non-compliance with federal regulations. Such lapses may require reporting to federal agencies, a program audit by compliance auditors to ensure that subjects were not enrolled during the expired period, and may lead to findings of serious and continuing noncompliance if expiration were to occur a second time.

The committee will be advised of this action at a regularly scheduled meeting.

If you have any questions, please contact the IRB analyst listed above or the Human Subjects Protection Program office at hsppofc@louisville.edu.

Sincerely,

Ptce $m$ Lusad

Peter M. Quesada, Ph.D., Vice - Chair

Biomedical Institutional Review Board

Full Accreditation since June 2005 by the Association for the Accreditation of Human Research Protection Programs, Inc.

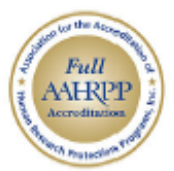


Appendix B

Survey Instrument (English Version)

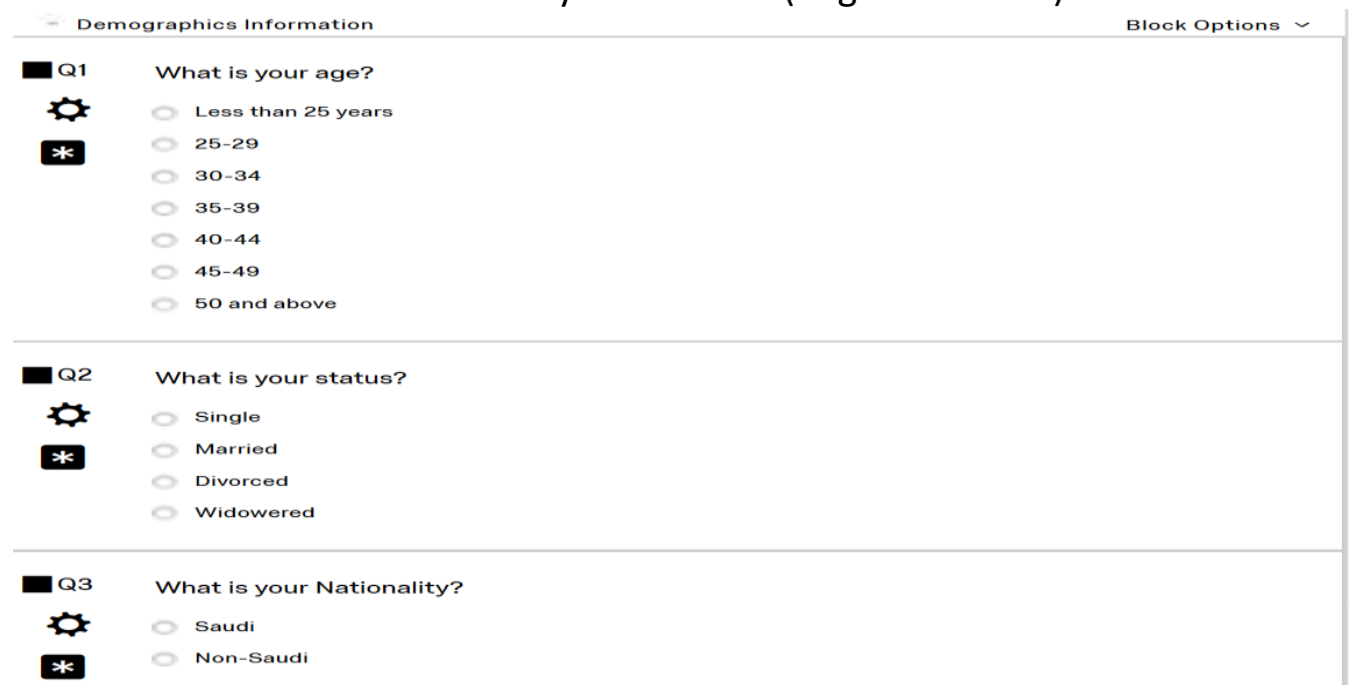

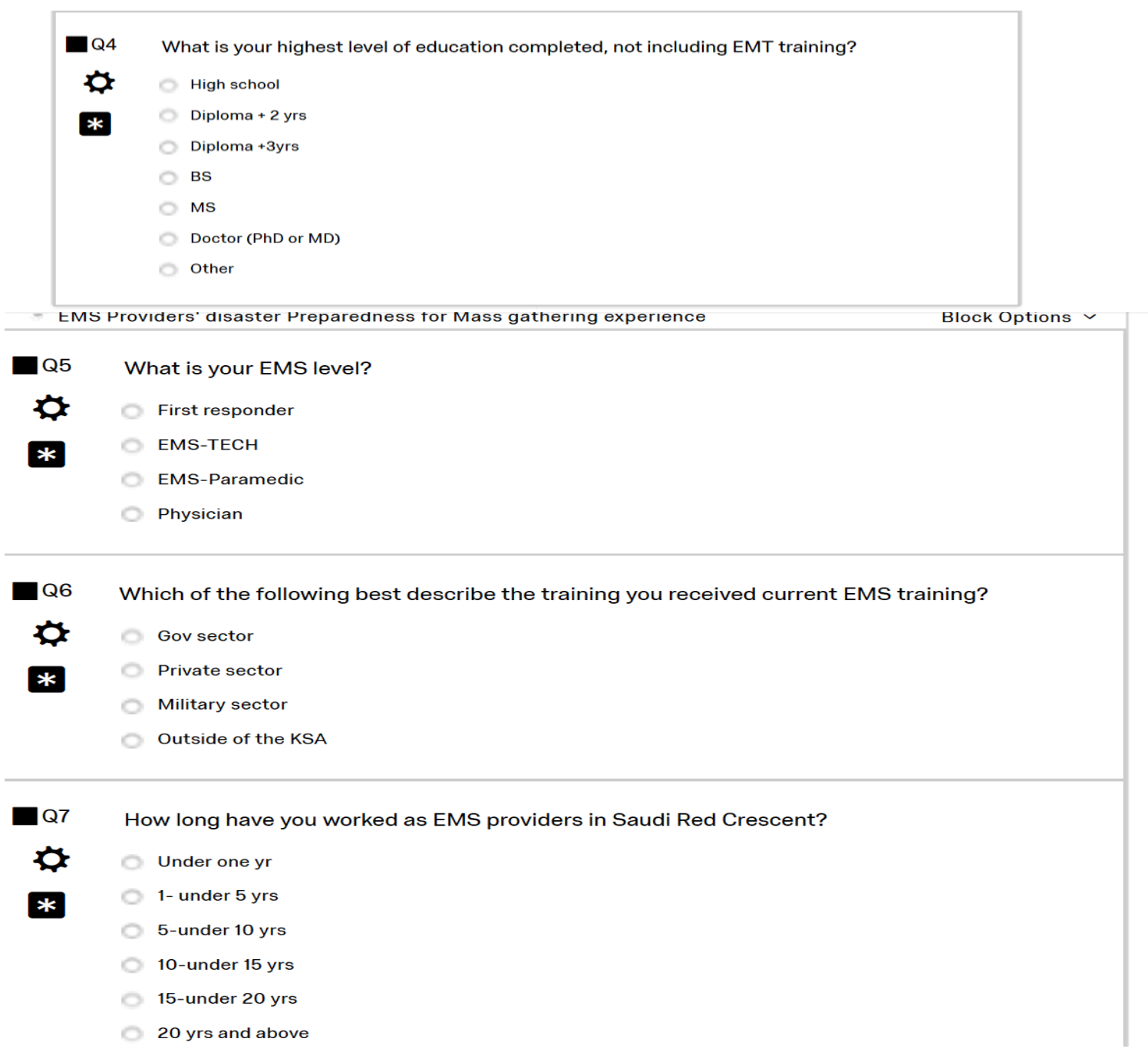




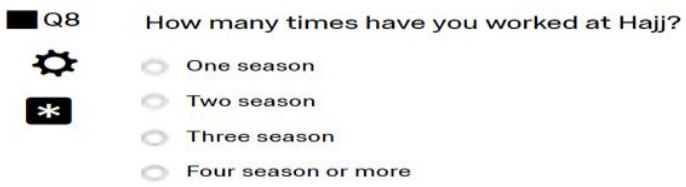

Q9 How many patients did you treat on the average day during the Hajj of 2016?
D. $0-10$
* $11-20$
21-30
$31-40$
Over 40

How many trainings/workshops/drills about disaster preparedness have you ever been Q10 attended?

\begin{tabular}{|c|c|c|c|c|c|}
\hline & Never & One & Two & Three & $\begin{array}{c}\text { More than } \\
\text { Three }\end{array}$ \\
\hline Training & 0 & 0 & 0 & 0 & 0 \\
\hline Workshops & 0 & 0 & 0 & 0 & 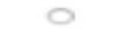 \\
\hline Drills & 0 & 0 & 0 & 0 & 0 \\
\hline
\end{tabular}

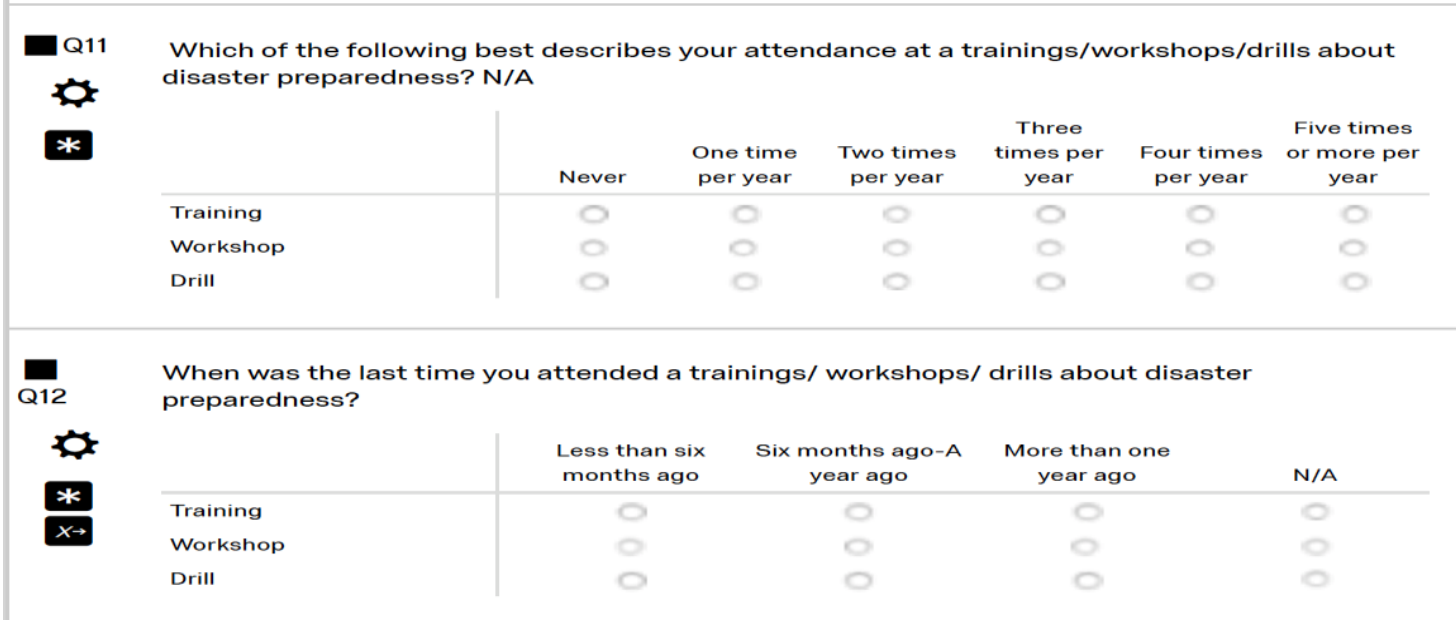

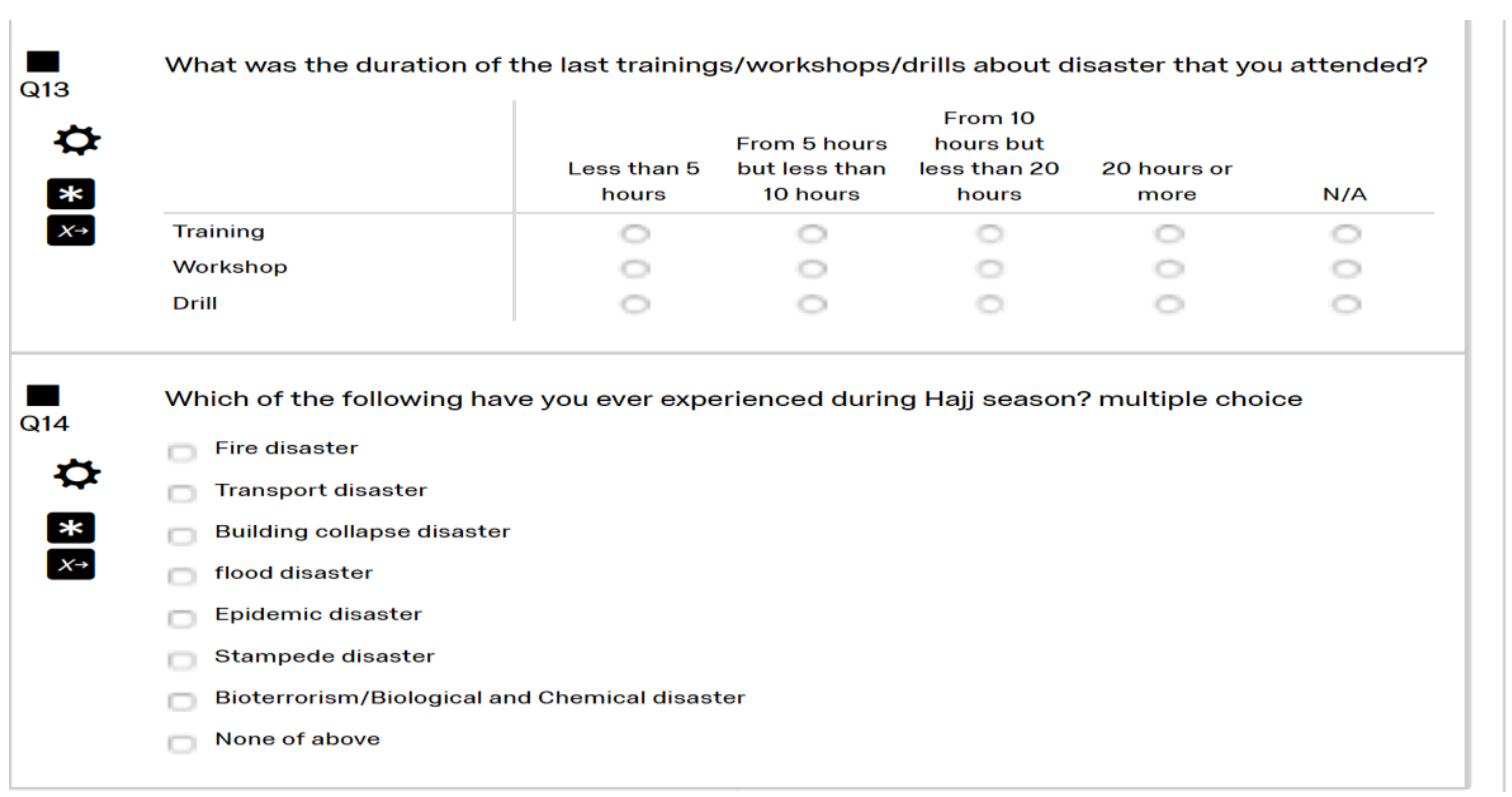




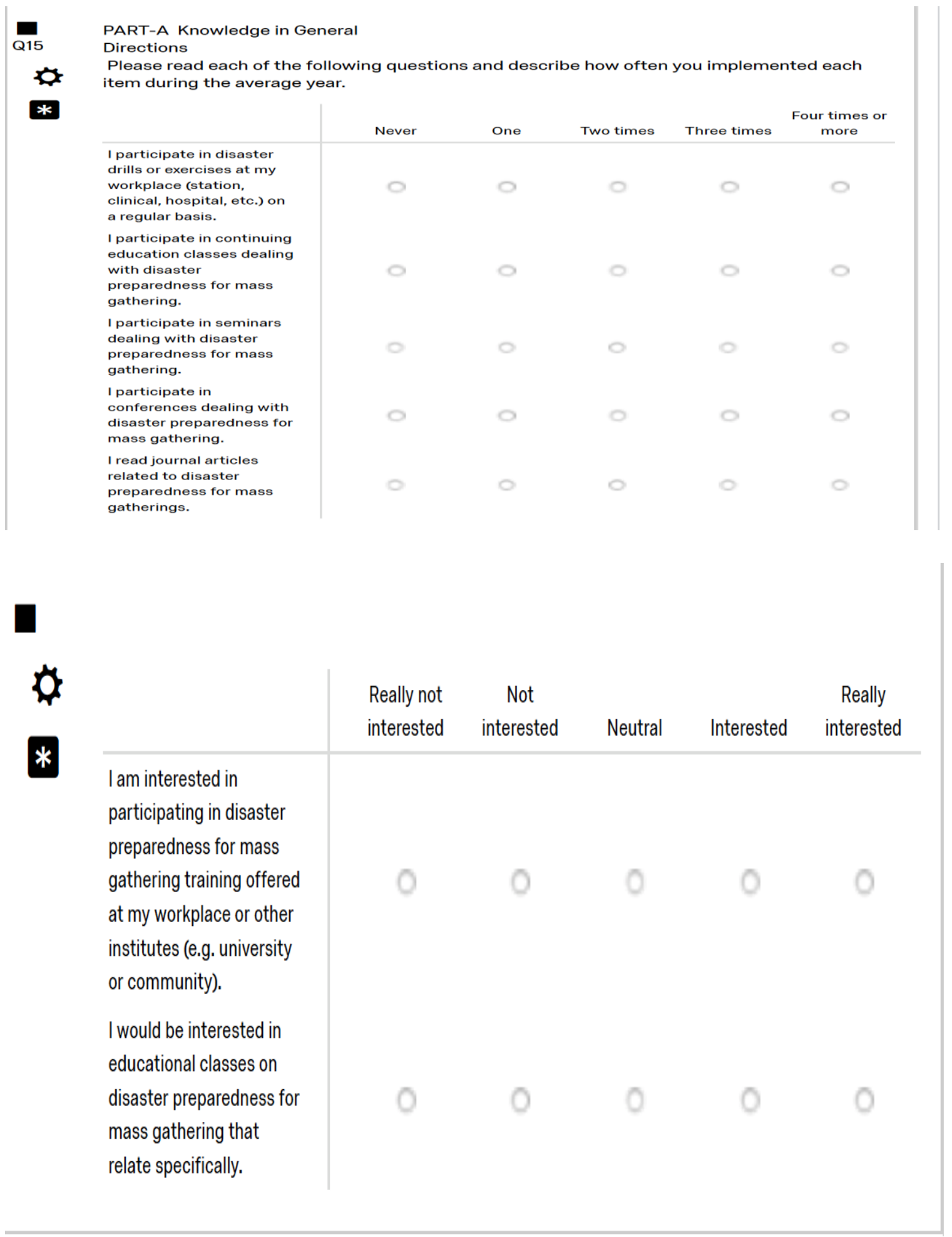




Finding relevant
information about
disaster preparedness for
mass gathering related to
Hajj season needs is an
obstacle to my level of
preparedness.
I know where to find
relevant research or
information related to
disasters preparedness
for mass gathering in Hajj
season to fill in gaps in
my knowledge.
I find that literature on
disaster preparedness for
mass gathering and
management is easily
accessible.
I find that literature on
disaster preparedness for
mass gatherings is
understandable.
During disaster, I am able
to refer cases to the
correct medical
department.

Neither

Agree nor Disagree

Agree

SA

Finding relevant

SD

Disagree

Disagree

.




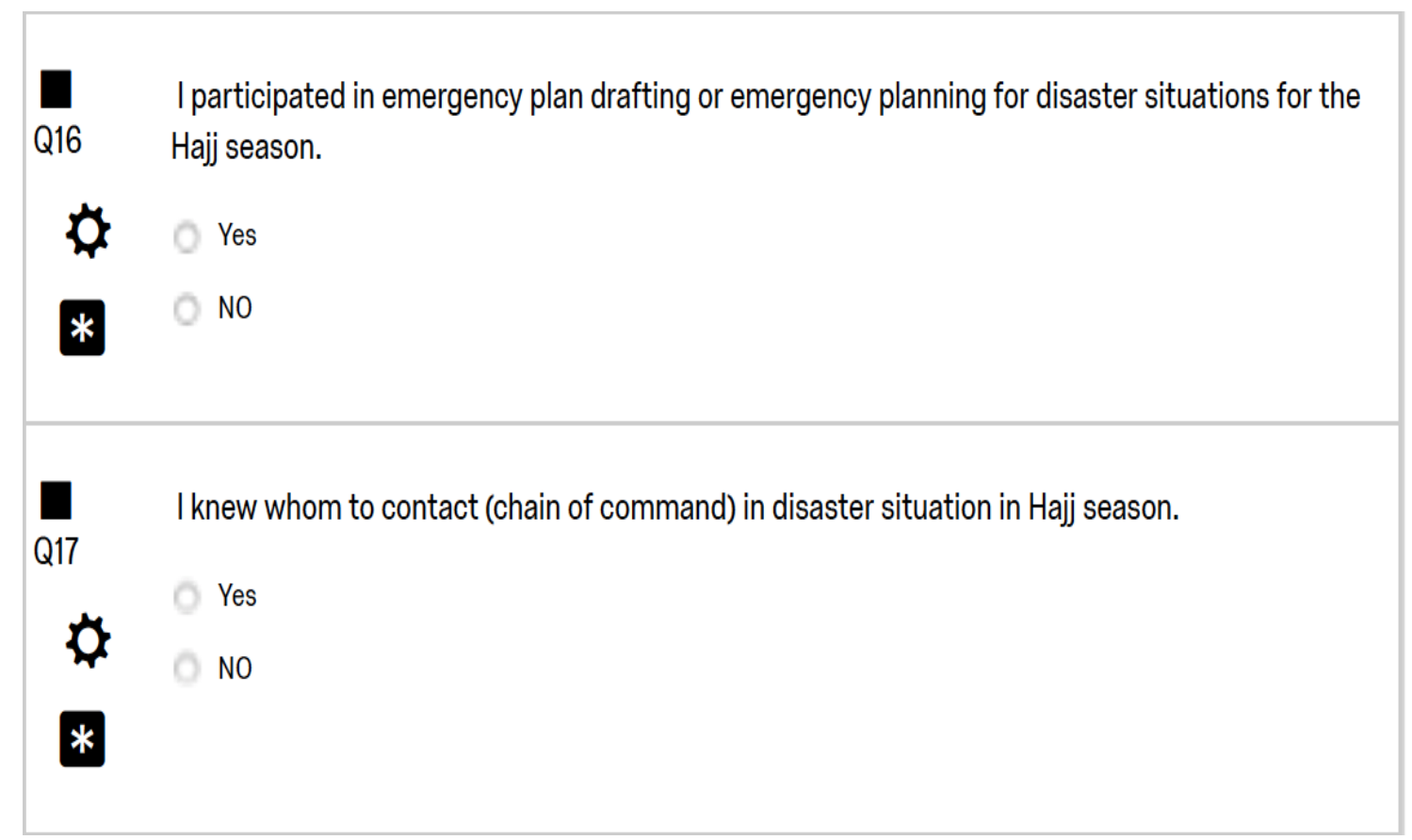



disagree by checking the appropriate choice.

\begin{tabular}{|c|c|c|c|c|c|}
\hline & $\mathrm{SD}$ & Disagree & $\begin{array}{l}\text { Neither } \\
\text { Agree nor } \\
\text { Disagree }\end{array}$ & Agree & SA \\
\hline $\begin{array}{l}\text { My knowledge about } \\
\text { disaster preparedness for } \\
\text { mass gathering about the } \\
\text { Hajj season } 2016 \text { was } \\
\text { sufficient. }\end{array}$ & 0 & 0 & 0 & 0 & 0 \\
\hline $\begin{array}{l}\text { In my experience during } \\
\text { Hajj of } 2016 \text {, there was } \\
\text { sufficient equipment to } \\
\text { respond to accidents. }\end{array}$ & 0 & 0 & 0 & 0 & 0 \\
\hline $\begin{array}{l}\text { In my experience during } \\
\text { Hajj of } 2016 \text {, the police } \\
\text { presence was sufficient. }\end{array}$ & 0 & 0 & 0 & 0 & 0 \\
\hline $\begin{array}{l}\text { In my experience during } \\
\text { Hajj of } 2016 \text {, the presence } \\
\text { of the fire department } \\
\text { was sufficient. }\end{array}$ & 0 & 0 & 0 & 0 & 0 \\
\hline $\begin{array}{l}\text { I am aware of the } \\
\text { potential risks in Hajj } \\
\text { season (e.g. stampede, } \\
\text { floods, terror, fire, etc.). }\end{array}$ & 0 & 0 & 0 & 0 & 0 \\
\hline $\begin{array}{l}\text { I knew the limits of my } \\
\text { knowledge, skills, and } \\
\text { authority as an EMS } \\
\text { provider to act in disaster } \\
\text { situations in Hajj season }\end{array}$ & 0 & 0 & 0 & 0 & 0 \\
\hline
\end{tabular}

Q19

For which of the following disaster was your work place ready to respond? (multiple choice)

D.

Fire disasters

*

Transport disasters

Building collapse disasters

Flood disasters

Epidemic disasters

Stampede disasters

2 Bioterrorism/Biological and Chemical disasters

None of above 


\begin{tabular}{|c|c|c|c|c|c|c|}
\hline Q20 & \multicolumn{6}{|c|}{$\begin{array}{l}\text { Please indicate which source o } \\
=\text { least useful, } 5=\text { most useful }\end{array}$} \\
\hline 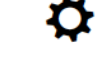 & & 1 & 2 & 3 & 4 & 5 \\
\hline & Drills practice & 0 & 0 & 0 & 0 & 0 \\
\hline & Real disaster & 0 & 0 & 0 & 0 & 0 \\
\hline & Continuing education & 0 & 0 & 0 & 0 & 0 \\
\hline & $\begin{array}{l}\text { Institution or University } \\
\text { courses }\end{array}$ & 0 & 0 & 0 & 0 & 0 \\
\hline & $\begin{array}{l}\text { Media (TV, social Media, } \\
\text { Radio, internet) }\end{array}$ & 0 & 0 & 0 & 0 & 0 \\
\hline & $\begin{array}{l}\text { Co-workers, friends, or } \\
\text { family }\end{array}$ & 0 & 0 & 0 & 0 & 0 \\
\hline Q21 & \multicolumn{6}{|c|}{$\begin{array}{l}\text { If the following were developed how useful would they be in improving your knowledge about } \\
\text { disaster preparedness? } \quad 1=\text { least useful, } 5=\text { most useful }\end{array}$} \\
\hline & & 1 & 2 & 3 & 4 & 5 \\
\hline & Drills practice & 0 & 0 & 0 & 0 & 0 \\
\hline & Disaster mang protocol & 0 & 0 & 0 & 0 & 0 \\
\hline & Information website & 0 & 0 & 0 & $\theta$ & 0 \\
\hline & Onsite visit & 0 & 0 & 0 & 0 & 0 \\
\hline & Disaster mang courses & 0 & 0 & 0 & 0 & 0 \\
\hline & Information pamphlets & 0 & 0 & 0 & 0 & 0 \\
\hline Q22 & \multicolumn{6}{|c|}{$\begin{array}{l}\text { In your opinion which of the following educational courses that should be taken in preparing } \\
\text { for disaster by EMS provider: } 1=\text { least useful, } 5=\text { most useful }\end{array}$} \\
\hline$\phi$ & & 1 & 2 & 3 & 4 & 5 \\
\hline \multirow{8}{*}{ * } & First Aid & 0 & 0 & 0 & 0 & 0 \\
\hline & Field triage & 0 & 0 & 0 & 0 & o \\
\hline & BLS & a & a & 0 & o & o \\
\hline & ACLS & 0 & $\circ$ & $\circ$ & 0 & 0 \\
\hline & PHTLS & 0 & 0 & 0 & 0 & 0 \\
\hline & ATLS & $\circ$ & 0 & $\circ$ & 0 & o \\
\hline & Infection Control & $\circ$ & a & $\circ$ & $\circ$ & $\circ$ \\
\hline & $\begin{array}{l}\text { Incident command } \\
\text { system }\end{array}$ & O & $\circ$ & $\circ$ & O & 0 \\
\hline
\end{tabular}

Add Block 
Appendix C

Survey Instrument (Arabic Version)

\begin{tabular}{|c|c|}
\hline |لببانات الاولية - - & Block Options $\smile$ \\
\hline & ا ـ ماهو عمرث؟ \\
\hline D. & ما اقل من هب عام \\
\hline$*$ & ra-roo \\
\hline & $r \leq-r \cdot O$ \\
\hline & ra-roo \\
\hline & $\varepsilon \varepsilon-\varepsilon \cdot \sigma$ \\
\hline & $\leq 9-\leqslant 00$ \\
\hline & O م م فاكثر \\
\hline & ץ. ماهي حالتك الاجتماعية؟ \\
\hline Q & ام اعزب \\
\hline * & م متزوع \\
\hline & O O مطق \\
\hline & ل مارمل \\
\hline & זـ مـاهي جنسيتك؟ \\
\hline & 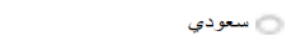 \\
\hline$*$ & O خير سعودي \\
\hline
\end{tabular}




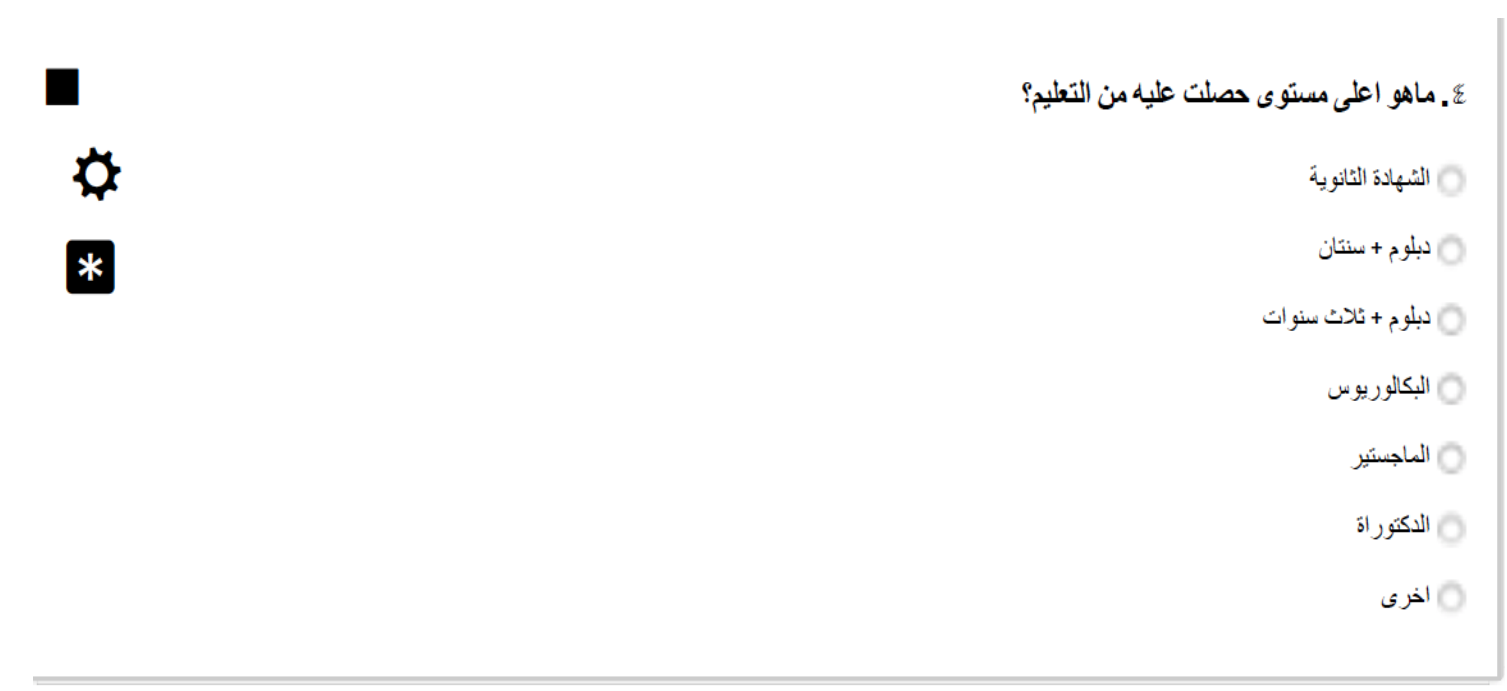

Add Block

" استُعداد مقدمي الخدمات الطبية الطارئة وخبرة التُعامل مع الحستود الضخمة

*

ש

to

*
آ ـ من اي مؤسسة تعليمية تخرجت بطب الطوارئ.

O

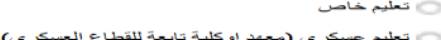
مانم تعليم خار ع المسكرة

ها - كم عدد سنوات النبرة لك في الهلال الاحمر السعودي كمقدم للخدمات الطبية الطارنةو

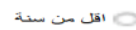

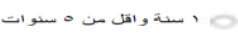

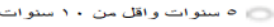

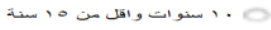

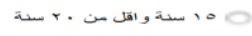

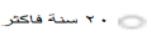




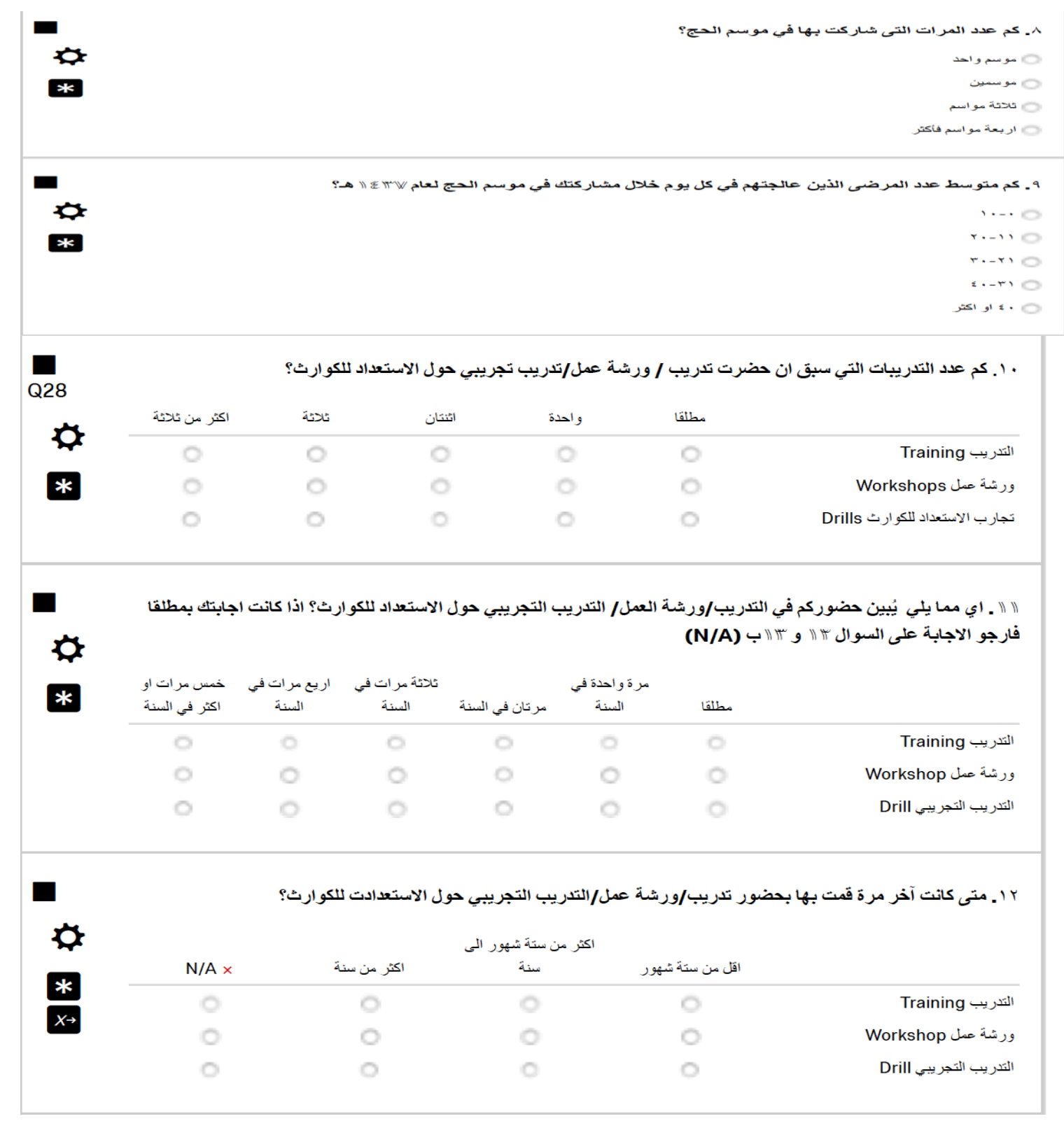




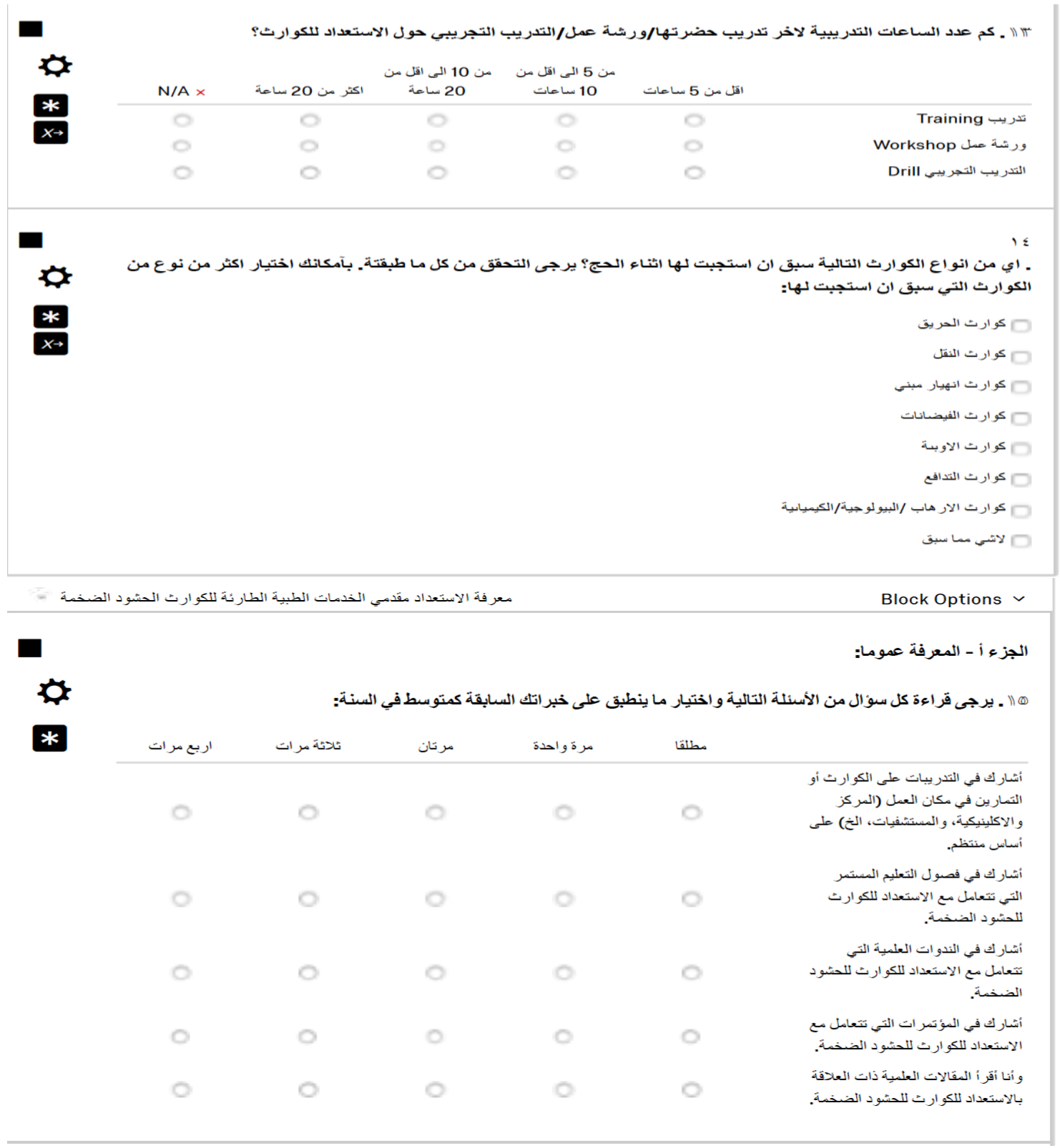




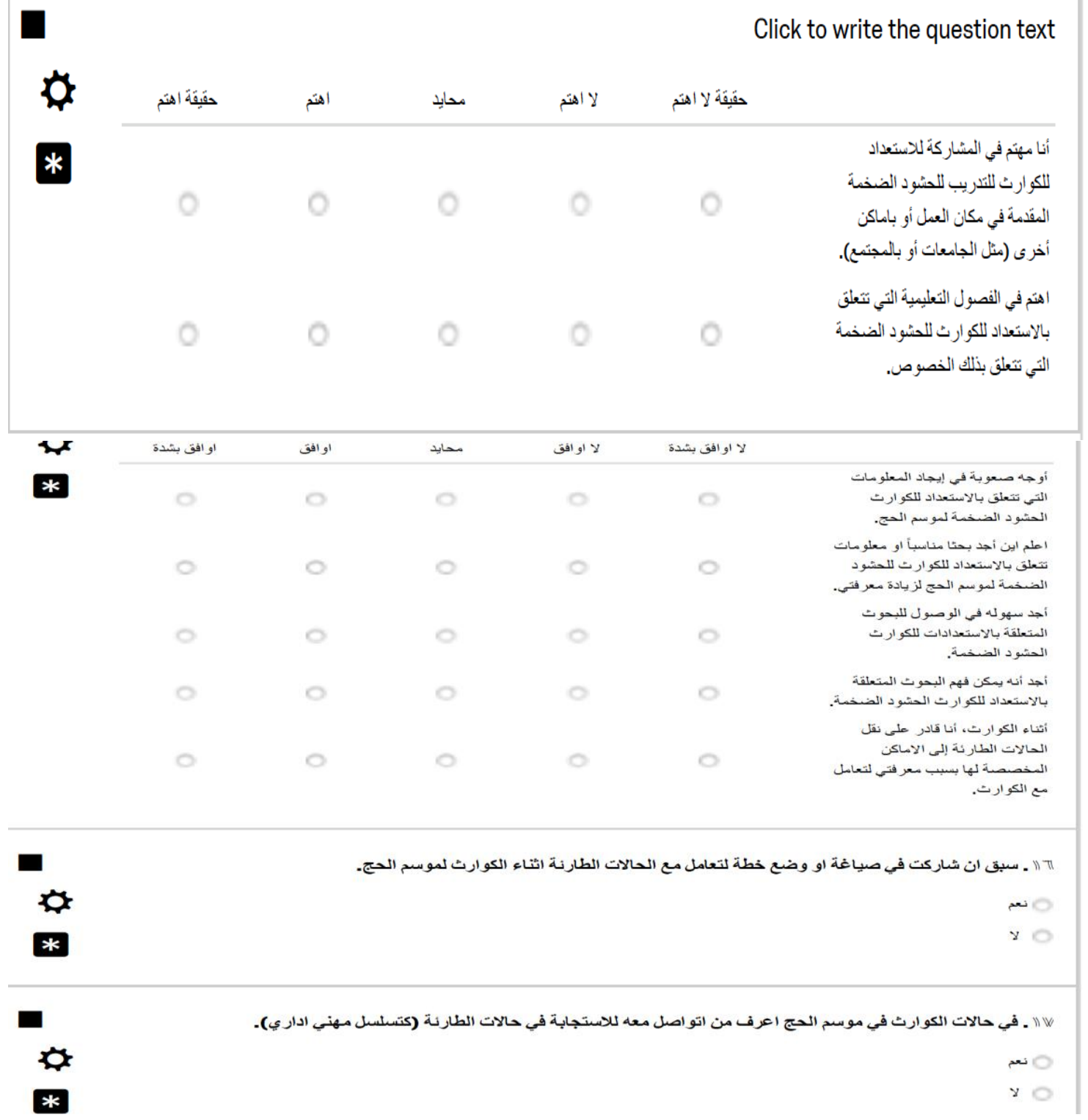




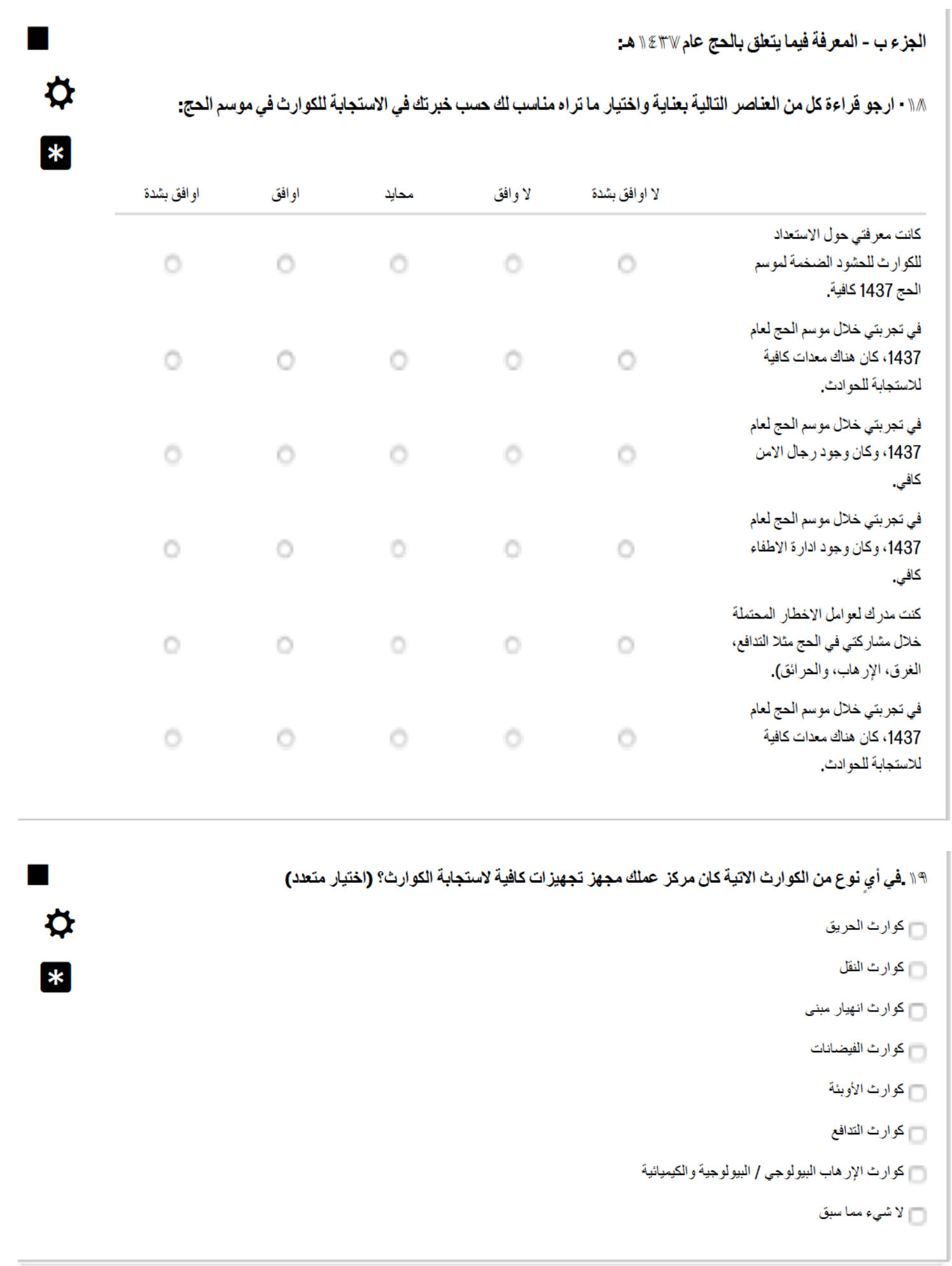




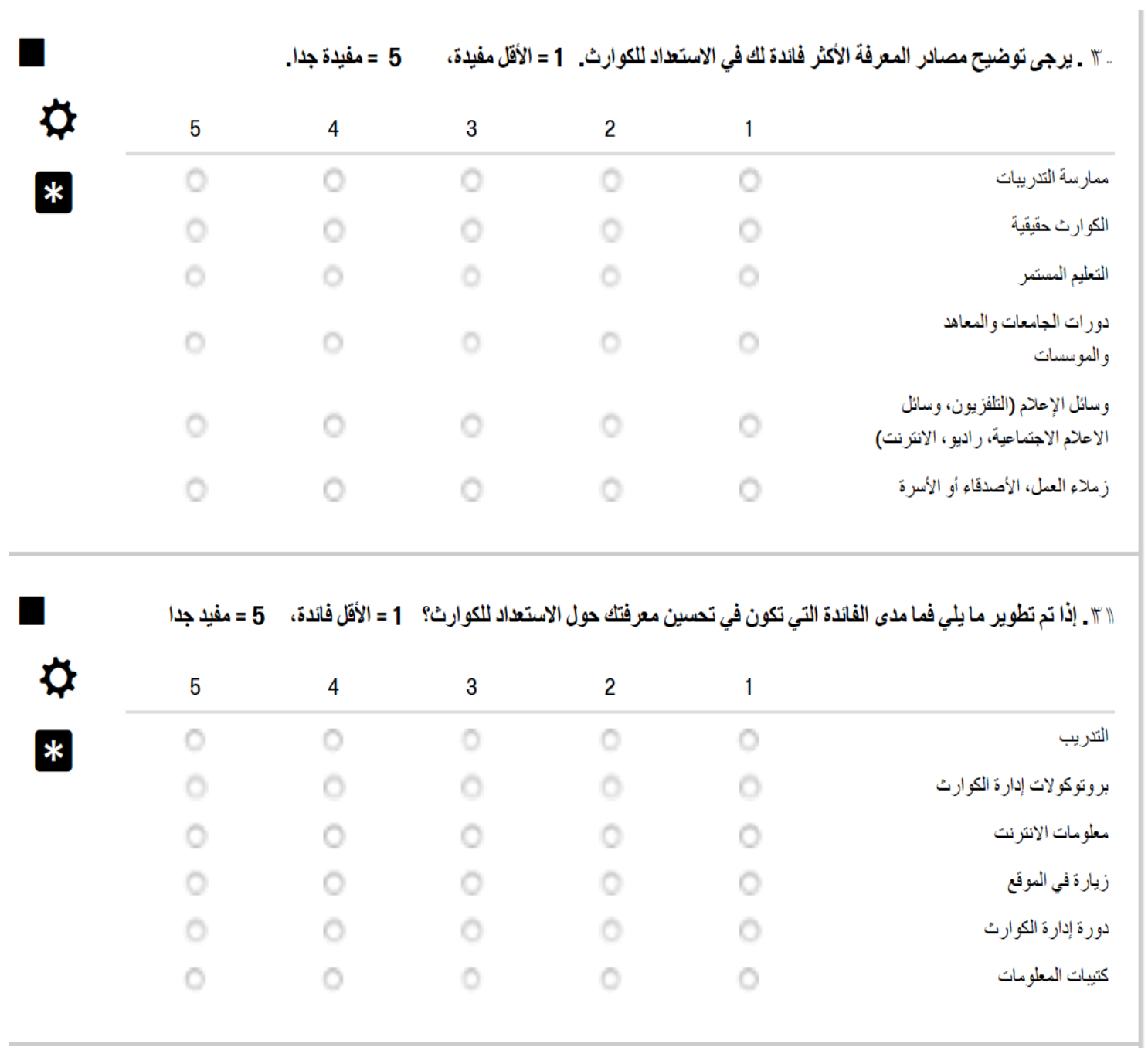




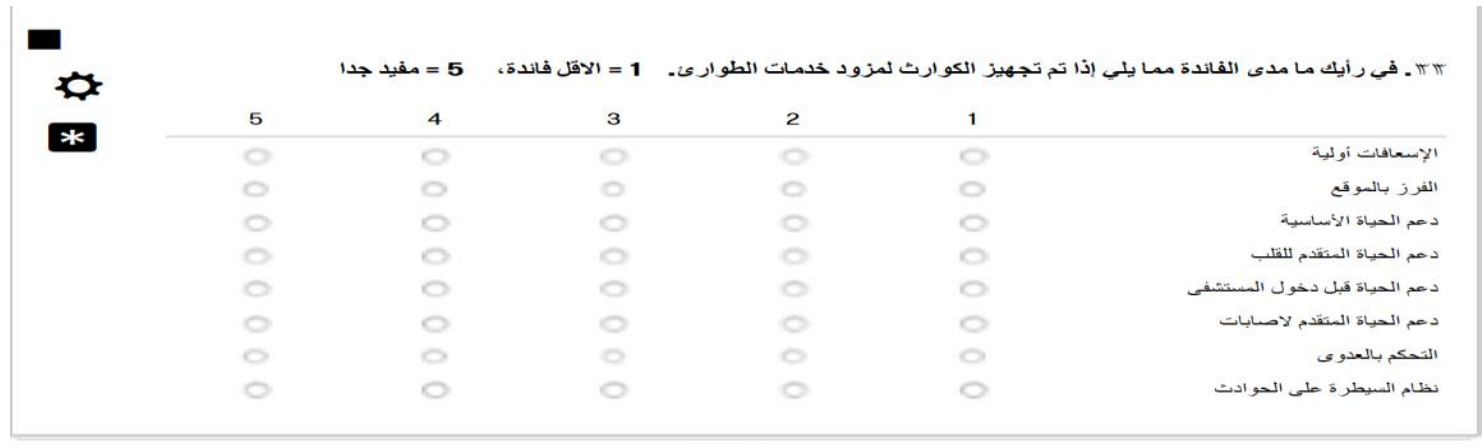

Add Block

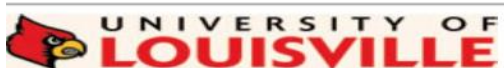
It's Happening Here.

Qualtrics.com Contact Information Legal
} 


\title{
Appendix D
}

\section{Consent Form to Participate in Research (English Version)}

\section{UNIVERSITY OF \\ LOUISVILLE.}

Jofl. Institutional Review Boards IRB NUMBER: 17.0120

IRB APPROVAL DATE: 03/03/2017

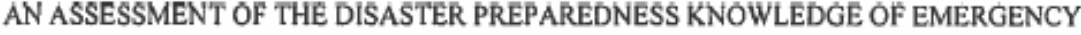 \\ MEDICAL SERVICES PROVIDERS IN HAJJ OF 2016
}

Date: $1 / 23 / 2017$

Dear Participant:

You are being invited to participate in a research study by answering the attached survey about an assessment of the disaster preparedness knowledge of EMS providers in Hajj of 2016. There are no known risks for your participation in this research study. The information collected may not benefit you directly. The information learned in this study may be helpful to others. The information you provide will help identify the level of knowledge of EMS providers at Saudi Red Crescent Authority in Hajj of 2016. Your completed survey will be stored at School of Public Health and Information Sciences (SPHIS) in a locked file drawer. The survey will take approximately 20-25 minutes time to complete.

Individuals from the Department of SPHIS, the Institutional Review Board (IRB), the Human Subjects Protection Program Office (HSPPO), and other regulatory ageneies may inspeot these reoords. In all other respects, however, the data will be held in confidence to the extent permitted by law. Should the data be published, your identity will not be disclosed.

Taking part in this study is voluntary. By completing this survey you agree to take part in this research study. You do not have to answer any questions that make you uncomfortable. You may choose not to take part at all. If you decide to be in this study you may stop taking part at any time. If you decide not to be in this study or if you stop taking part at any time, you will not lose any benefits for which you may qualify.

If you have any questions, concerns, or complaints about the research study, please contact: Ahmed Alotaibi at: +966555712196, +1(703) 9393-3154 or e-mail at: a0alot01@louisville.edu or Susan Allen, $\mathrm{PhD}$ at 502-852-1824, susan.allen@louisville.edu

If you have any questions about your rights as a research subject, you may call the Human Subjects Protection Program Office at (502) 852-5188. You can discuss any questions about your rights as a research subject, in private, with a member of the Institutional Review Board (IRB). You may also call this number if you have other questions about the research, and you cannot reach the research staff, or want to talk to someone else. The IRB is an independent committee made up of people from the University community, staff of the institutions, as well as people from the community not connected with these institutions. The IRB has reviewed this research study.

If you have concerns or complaints about the research or research staff and you do not wish to give your name, you may call 1-877-852-1167. This is a 24 -hour hot line answered by people who do not work at the University of Louisville.

Sincerely,

Susan Allen, PhD, Principal Investigator Assistant Professor, SPHIS

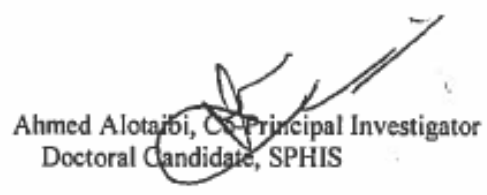




\title{
Appendix E
}

Consent Form to Participate in Research (Arabic Version)

UNIVERSITY ÓF

Uof. Institutional Review Boards

IRB NUMBER: 17.0120

LOUISVILLE.

IRB APPROVAL DATE: 03/03/2017

\author{
بسم اللهُ الرحن الرحيم

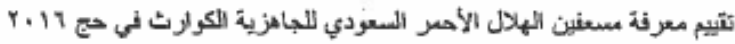

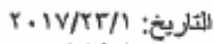

عزيزي العشارله

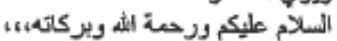

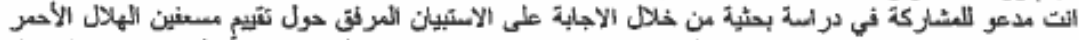

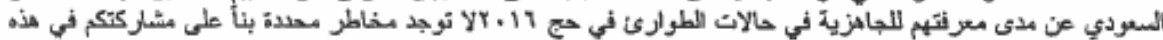

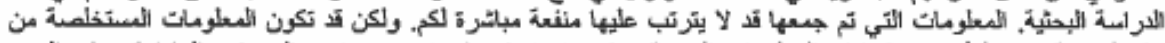

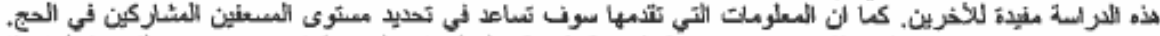

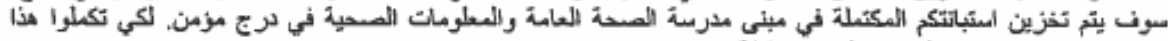

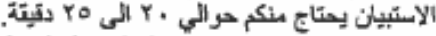

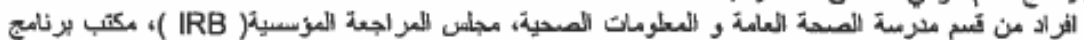

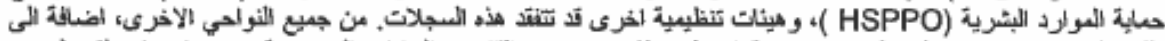

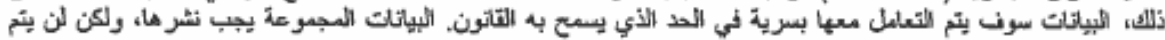

الكثيف عن هويتكم.

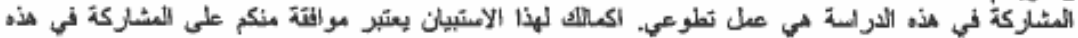

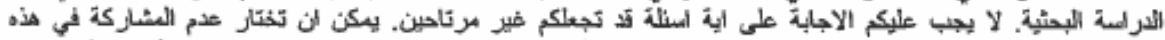

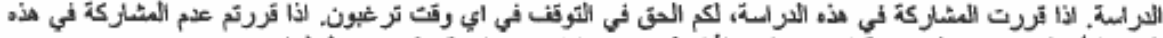

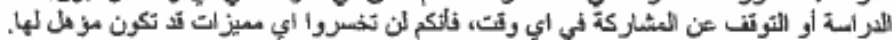

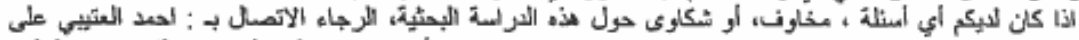
الأرتام التالية: a0alot01@louisville susan.allen@louisville.edu :اتئلى

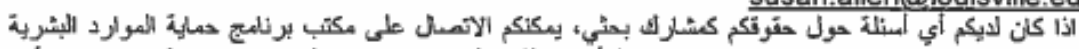

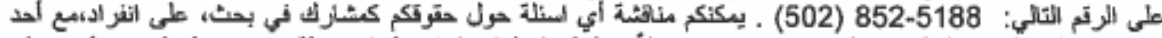

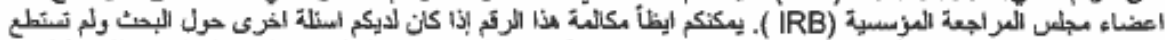

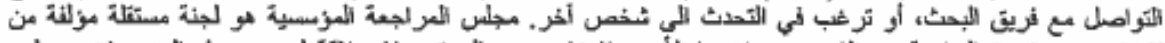

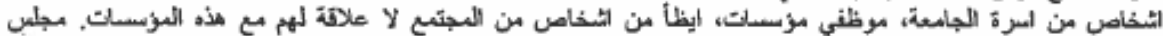

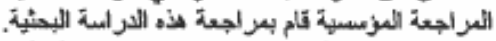

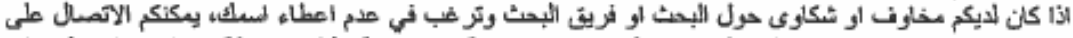

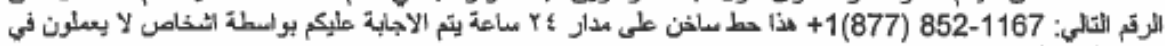

جالمعة لويزفيل.

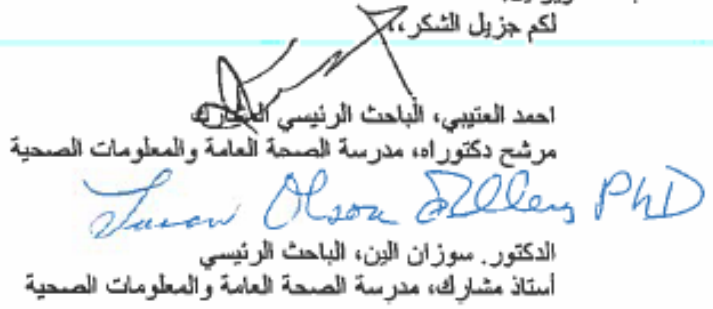




\section{Appendix F}

The Results of the "One Way ANOVA" of the difference in general knowledge of disaster preparedness for mass gatherings between different categories of EMS providers based on their age.

\section{Multiple Comparisons}

Dependent Variable: Q15

Bonferroni

\begin{tabular}{|c|c|c|c|c|c|c|}
\hline \multirow[b]{2}{*}{$\begin{array}{l}\text { (I) } 1 . \text { Age of EMS } \\
\text { provider }\end{array}$} & \multirow[b]{2}{*}{$\begin{array}{l}\text { (J) 1. Age of EMS } \\
\text { provider }\end{array}$} & \multirow{2}{*}{$\begin{array}{c}\text { Mean } \\
\text { Difference (I- } \\
\mathrm{J}) \\
\end{array}$} & \multirow[b]{2}{*}{$\begin{array}{l}\text { Std. } \\
\text { Error }\end{array}$} & \multirow[b]{2}{*}{ Sig. } & \multicolumn{2}{|c|}{ 95\% Confidence Interval } \\
\hline & & & & & $\begin{array}{l}\text { Lower } \\
\text { Bound }\end{array}$ & $\begin{array}{l}\text { Upper } \\
\text { Bound }\end{array}$ \\
\hline \multirow[t]{6}{*}{ Less than 25 years } & $25-29$ & .33411 & .27926 & 1.000 & -.5174 & 1.1857 \\
\hline & $30-34$ & .17996 & .27893 & 1.000 & -.6706 & 1.0305 \\
\hline & $35-39$ & -.06049 & .28185 & 1.000 & -.9200 & .7990 \\
\hline & $40-44$ & .01412 & .29067 & 1.000 & -.8722 & .9005 \\
\hline & $45-49$ & -.01488 & .30726 & 1.000 & -.9518 & .9220 \\
\hline & 50 and above & -.00694 & .31234 & 1.000 & -.9594 & .9455 \\
\hline \multirow[t]{6}{*}{$25-29$} & Less than 25 years & -.33411 & .27926 & 1.000 & -1.1857 & .5174 \\
\hline & $30-34$ & -.15415 & .06883 & .534 & -.3640 & .0557 \\
\hline & $35-39$ & $-.39460^{*}$ & .07984 & .000 & -.6381 & -.1511 \\
\hline & $40-44$ & -.31998 & .10686 & .060 & -.6458 & .0059 \\
\hline & $45-49$ & -.34899 & .14608 & .360 & -.7944 & .0965 \\
\hline & 50 and above & -.34105 & .15648 & .622 & -.8182 & .1361 \\
\hline \multirow[t]{6}{*}{$30-34$} & Less than 25 years & -.17996 & .27893 & 1.000 & -1.0305 & .6706 \\
\hline & $25-29$ & .15415 & .06883 & .534 & -.0557 & .3640 \\
\hline & $35-39$ & $-.24045^{*}$ & .07871 & .049 & -.4805 & -.0004 \\
\hline & $40-44$ & -.16583 & .10602 & 1.000 & -.4891 & .1574 \\
\hline & $45-49$ & -.19484 & .14547 & 1.000 & -.6384 & .2487 \\
\hline & 50 and above & -.18690 & .15591 & 1.000 & -.6623 & .2885 \\
\hline \multirow[t]{6}{*}{$35-39$} & Less than 25 years & .06049 & .28185 & 1.000 & -.7990 & .9200 \\
\hline & $25-29$ & $.39460^{*}$ & .07984 & .000 & .1511 & .6381 \\
\hline & $30-34$ & $.24045^{*}$ & .07871 & .049 & .0004 & .4805 \\
\hline & $40-44$ & .07462 & .11348 & 1.000 & -.2714 & .4206 \\
\hline & $45-49$ & .04561 & .15099 & 1.000 & -.4148 & .5060 \\
\hline & 50 and above & .05355 & .16107 & 1.000 & -.4376 & .5447 \\
\hline \multirow[t]{3}{*}{$40-44$} & Less than 25 years & -.01412 & .29067 & 1.000 & -.9005 & .8722 \\
\hline & $25-29$ & .31998 & .10686 & .060 & -.0059 & .6458 \\
\hline & $30-34$ & .16583 & .10602 & 1.000 & -.1574 & .4891 \\
\hline
\end{tabular}




\begin{tabular}{|c|c|c|c|c|c|c|}
\hline & $35-39$ & -.07462 & .11348 & 1.000 & -.4206 & .2714 \\
\hline & $45-49$ & -.02901 & .16686 & 1.000 & -.5378 & .4798 \\
\hline & 50 and above & -.02107 & .17604 & 1.000 & -.5579 & .5157 \\
\hline \multirow[t]{6}{*}{$45-49$} & Less than 25 years & .01488 & .30726 & 1.000 & -.9220 & .9518 \\
\hline & $25-29$ & .34899 & .14608 & .360 & -.0965 & .7944 \\
\hline & $30-34$ & .19484 & .14547 & 1.000 & -.2487 & .6384 \\
\hline & $35-39$ & -.04561 & .15099 & 1.000 & -.5060 & .4148 \\
\hline & $40-44$ & .02901 & .16686 & 1.000 & -.4798 & .5378 \\
\hline & 50 and above & .00794 & .20226 & 1.000 & -.6088 & .6247 \\
\hline \multirow[t]{6}{*}{50 and above } & Less than 25 years & .00694 & .31234 & 1.000 & -.9455 & .9594 \\
\hline & $25-29$ & .34105 & .15648 & .622 & -.1361 & .8182 \\
\hline & $30-34$ & .18690 & .15591 & 1.000 & -.2885 & .6623 \\
\hline & $35-39$ & -.05355 & .16107 & 1.000 & -.5447 & .4376 \\
\hline & $40-44$ & .02107 & .17604 & 1.000 & -.5157 & .5579 \\
\hline & $45-49$ & -.00794 & 20226 & 1.000 & -.6247 & .6088 \\
\hline
\end{tabular}




\section{Appendix G}

The Results of the "One Way ANOVA" of the difference in Hajj knowledge of disaster preparedness for mass gatherings between different categories of EMS providers based on their age.

\section{Multiple Comparisons}

Dependent Variable: Q18

Bonferroni

\begin{tabular}{|c|c|c|c|c|c|c|}
\hline \multirow[b]{2}{*}{$\begin{array}{l}\text { (I) } 1 \text {. Age of EMS } \\
\text { provider }\end{array}$} & \multirow{2}{*}{$\begin{array}{l}\text { (J) 1. Age of EMS } \\
\text { provider }\end{array}$} & \multirow{2}{*}{$\begin{array}{c}\text { Mean } \\
\text { Difference (I- } \\
\mathrm{J})\end{array}$} & \multirow{2}{*}{$\begin{array}{l}\text { Std. } \\
\text { Error }\end{array}$} & \multirow{2}{*}{ Sig. } & \multicolumn{2}{|c|}{ 95\% Confidence Interval } \\
\hline & & & & & Lower & $\begin{array}{l}\text { Upper } \\
\text { Bound }\end{array}$ \\
\hline \multirow[t]{6}{*}{ Less than 25 years } & $25-29$ & -.38151 & .35410 & 1.000 & -1.4613 & .6983 \\
\hline & $30-34$ & -.42919 & .35369 & 1.000 & -1.5077 & .6493 \\
\hline & $35-39$ & -.62205 & .35739 & 1.000 & -1.7119 & .4678 \\
\hline & $40-44$ & -.50928 & .36857 & 1.000 & -1.6332 & .6146 \\
\hline & $45-49$ & -.73214 & .38961 & 1.000 & -1.9202 & .4559 \\
\hline & 50 and above & -.35615 & .39605 & 1.000 & -1.5638 & .8515 \\
\hline \multirow[t]{6}{*}{$25-29$} & Less than 25 years & .38151 & .35410 & 1.000 & -.6983 & 1.4613 \\
\hline & $30-34$ & -.04768 & .08728 & 1.000 & -.3138 & .2185 \\
\hline & $35-39$ & -.24054 & .10124 & .373 & -.5493 & .0682 \\
\hline & $40-44$ & -.12778 & .13550 & 1.000 & -.5410 & .2854 \\
\hline & $45-49$ & -.35064 & .18524 & 1.000 & -.9155 & .2142 \\
\hline & 50 and above & .02536 & .19842 & 1.000 & -.5797 & .6304 \\
\hline \multirow[t]{6}{*}{$30-34$} & Less than 25 years & .42919 & .35369 & 1.000 & -.6493 & 1.5077 \\
\hline & $25-29$ & .04768 & .08728 & 1.000 & -.2185 & .3138 \\
\hline & $35-39$ & -.19286 & .09980 & 1.000 & -.4972 & .1115 \\
\hline & $40-44$ & -.08009 & .13443 & 1.000 & -.4900 & .3298 \\
\hline & $45-49$ & -.30296 & .18445 & 1.000 & -.8654 & .2595 \\
\hline & 50 and above & .07304 & .19769 & 1.000 & -.5298 & .6759 \\
\hline \multirow[t]{6}{*}{$35-39$} & Less than 25 years & .62205 & .35739 & 1.000 & -.4678 & 1.7119 \\
\hline & $25-29$ & .24054 & .10124 & .373 & -.0682 & .5493 \\
\hline & $30-34$ & .19286 & .09980 & 1.000 & -.1115 & .4972 \\
\hline & $40-44$ & .11276 & .14389 & 1.000 & -.3260 & .5515 \\
\hline & $45-49$ & -.11010 & .19146 & 1.000 & -.6939 & .4737 \\
\hline & 50 and above & .26590 & .20424 & 1.000 & -.3569 & .8887 \\
\hline \multirow[t]{3}{*}{$40-44$} & Less than 25 years & .50928 & .36857 & 1.000 & -.6146 & 1.6332 \\
\hline & $25-29$ & .12778 & .13550 & 1.000 & -.2854 & .5410 \\
\hline & $30-34$ & .08009 & .13443 & 1.000 & -.3298 & .4900 \\
\hline
\end{tabular}




\begin{tabular}{|c|c|c|c|c|c|c|}
\hline & $35-39$ & -.11276 & .14389 & 1.000 & -.5515 & .3260 \\
\hline & $45-49$ & -.22286 & .21158 & 1.000 & -.8680 & .4223 \\
\hline & 50 and above & .15313 & .22322 & 1.000 & -.5275 & .8338 \\
\hline \multirow[t]{6}{*}{$45-49$} & Less than 25 years & .73214 & .38961 & 1.000 & -.4559 & 1.9202 \\
\hline & $25-29$ & .35064 & .18524 & 1.000 & -.2142 & .9155 \\
\hline & $30-34$ & .30296 & .18445 & 1.000 & -.2595 & .8654 \\
\hline & $35-39$ & .11010 & .19146 & 1.000 & -.4737 & .6939 \\
\hline & $40-44$ & .22286 & .21158 & 1.000 & -.4223 & .8680 \\
\hline & 50 and above & .37599 & .25647 & 1.000 & -.4061 & 1.1581 \\
\hline \multirow[t]{6}{*}{50 and above } & Less than 25 years & .35615 & .39605 & 1.000 & -.8515 & 1.5638 \\
\hline & $25-29$ & -.02536 & .19842 & 1.000 & -.6304 & .5797 \\
\hline & $30-34$ & -.07304 & .19769 & 1.000 & -.6759 & .5298 \\
\hline & $35-39$ & -.26590 & .20424 & 1.000 & -.8887 & .3569 \\
\hline & $40-44$ & -.15313 & .22322 & 1.000 & -.8338 & .5275 \\
\hline & $45-49$ & -.37599 & 25647 & 1.000 & -1.1581 & .4061 \\
\hline
\end{tabular}




\section{Appendix $\mathrm{H}$}

The Results of the "One Way ANOVA" of the Difference in General Knowledge of

Disaster Preparedness for Mass Gatherings between Different Categories of EMS

Providers Based on their Level of Education.

\section{Multiple Comparisons}

Dependent Variable: Q15

Bonferroni

\begin{tabular}{|c|c|c|c|c|c|}
\hline $\begin{array}{l}\text { (I) } 4 \text {. Highest level of } \\
\text { education completed, not } \\
\text { including EMS training }\end{array}$ & $\begin{array}{l}\text { (J) } 4 \text {. Highest level of } \\
\text { education completed, not } \\
\text { including EMS training }\end{array}$ & $\begin{array}{c}\text { Mean } \\
\text { Difference } \\
(\mathrm{I}-\mathrm{J}) \\
\end{array}$ & $\begin{array}{l}\text { Std. } \\
\text { Error }\end{array}$ & Sig. & $\begin{array}{l}\text { Confidence } \\
\text { Interval } \\
\text { Lower Bound } \\
\end{array}$ \\
\hline \multirow[t]{5}{*}{ High school } & Diploma + 2 yrs & -.16110 & .10525 & 1.000 & -.4711 \\
\hline & Diploma +3yrs & -.19550 & .10284 & .866 & -.4984 \\
\hline & BS & $-.74211^{*}$ & .10711 & .000 & -1.0576 \\
\hline & MS & $-1.27258^{*}$ & .16914 & .000 & -1.7708 \\
\hline & Other & -.76026 & .31625 & .247 & -1.6918 \\
\hline \multirow[t]{5}{*}{ Diploma + 2 yrs } & High school & .16110 & .10525 & 1.000 & -.1489 \\
\hline & Diploma +3yrs & -.03440 & .06409 & 1.000 & -.2232 \\
\hline & BS & $-.58101^{*}$ & .07074 & .000 & -.7894 \\
\hline & MS & $-1.11148^{*}$ & .14879 & .000 & -1.5497 \\
\hline & Other & -.59916 & .30586 & .758 & -1.5000 \\
\hline \multirow[t]{5}{*}{ Diploma +3yrs } & High school & .19550 & .10284 & .866 & -.1074 \\
\hline & Diploma +2 yrs & .03440 & .06409 & 1.000 & -.1544 \\
\hline & BS & $-.54661^{*}$ & .06710 & .000 & -.7443 \\
\hline & MS & $-1.07708^{*}$ & .14710 & .000 & -1.5103 \\
\hline & Other & -.56476 & .30504 & .968 & -1.4632 \\
\hline \multirow[t]{5}{*}{ BS } & High school & $.74211^{*}$ & .10711 & .000 & .4266 \\
\hline & Diploma + 2 yrs & $.58101^{*}$ & .07074 & .000 & .3727 \\
\hline & Diploma +3yrs & $.54661^{*}$ & .06710 & .000 & .3490 \\
\hline & MS & $-.53046^{*}$ & .15012 & .007 & -.9726 \\
\hline & Other & -.01815 & .30650 & 1.000 & -.9209 \\
\hline \multirow[t]{5}{*}{ MS } & High school & $1.27258^{*}$ & .16914 & .000 & .7744 \\
\hline & Diploma + 2 yrs & $1.11148^{*}$ & .14879 & .000 & .6732 \\
\hline & Diploma +3yrs & $1.07708^{*}$ & .14710 & .000 & .6438 \\
\hline & BS & $.53046^{*}$ & .15012 & .007 & .0883 \\
\hline & Other & .51232 & .33328 & 1.000 & -.4693 \\
\hline Other & High school & .76026 & .31625 & .247 & -.1712 \\
\hline
\end{tabular}




\begin{tabular}{l|r|r|r|r}
\hline Diploma +2 yrs & .59916 & .30586 & .758 & -.3017 \\
\hline Diploma +3yrs & .56476 & .30504 & .968 & -.3337 \\
\hline BS & .01815 & .30650 & 1.000 & -.8846 \\
\hline MS & -.51232 & .33328 & 1.000 & -1.4940 \\
\hline
\end{tabular}

\section{Multiple Comparisons}

Dependent Variable: Q15

\section{Bonferroni}

$\begin{array}{lll}\text { (I) 4. Highest level of education completed, } & \text { (J) 4. Highest level of education completed, } 95 \% \text { Confidence Interval }\end{array}$ not including EMS training not including EMS training Upper Bound

\section{High school}

Diploma +2 yrs

1489

Diporater

Diploma +2 yrs

Diploma $+3 y$ rs .1074

BS $-.4266$

MS $-.7744$

Other .1712

High school .4711

BS

Diploma +3yrs .1544

BS $-.3727$

MS

$-.6732$

Other .3017

Diploma $+3 y r s$

High school .4984

Diploma +2 yrs .2232

BS $-.3490$

MS $-.6438$

BS

Other .3337

High school 1.0576

MS

MS

Diploma +2 yrs .7894

Diploma +3yrs .7443

MS $-.0883$

Other .8846

High school 1.7708

Diploma +2 yrs 1.5497

Diploma +3yrs 1.5103

BS .9726

Other 1.4940

Other

High school 1.6918

Diploma + 2 yrs 1.5000 


\begin{tabular}{llr}
\hline & Diploma +3yrs & 1.4632 \\
\cline { 2 - 3 } & BS & .9209 \\
\cline { 2 - 3 } & MS & .4693 \\
\hline
\end{tabular}




\section{Appendix I}

The Results of the "One Way ANOVA" of the Difference in Hajj Knowledge of Disaster Preparedness for Mass Gatherings between Different Categories of EMS Providers Based on their Level of Education.

\section{Multiple Comparisons}

Dependent Variable: Q18

Bonferroni

\begin{tabular}{|c|c|c|c|c|c|}
\hline $\begin{array}{l}\text { (I) } 4 \text {. Highest level of } \\
\text { education completed, not } \\
\text { including EMS training }\end{array}$ & $\begin{array}{l}\text { (J) } 4 \text {. Highest level of } \\
\text { education completed, not } \\
\text { including EMS training }\end{array}$ & $\begin{array}{c}\text { Mean } \\
\text { Difference (I-J) }\end{array}$ & Std. Error & Sig. & $\begin{array}{l}\text { Confidence } \\
\text { Interval } \\
\text { Lower Bound } \\
\end{array}$ \\
\hline \multirow[t]{5}{*}{ High school } & Diploma +2 yrs & -.27376 & .14140 & .799 & -.6902 \\
\hline & Diploma $+3 y r s$ & -.26216 & .13817 & .873 & -.6691 \\
\hline & BS & $-.43540^{\star}$ & .14390 & .039 & -.8593 \\
\hline & MS & $-1.14688^{*}$ & .22724 & .000 & -1.8162 \\
\hline & Other & -.96282 & .42489 & .356 & -2.2143 \\
\hline \multirow[t]{5}{*}{ Diploma +2 yrs } & High school & .27376 & .14140 & .799 & -.1427 \\
\hline & Diploma +3yrs & .01160 & .08610 & 1.000 & -.2420 \\
\hline & BS & -.16164 & .09503 & 1.000 & -.4416 \\
\hline & MS & $-.87312^{*}$ & .19990 & .000 & -1.4619 \\
\hline & Other & -.68906 & .41091 & 1.000 & -1.8994 \\
\hline \multirow[t]{5}{*}{ Diploma +3yrs } & High school & .26216 & .13817 & .873 & -.1448 \\
\hline & Diploma +2 yrs & -.01160 & .08610 & 1.000 & -.2652 \\
\hline & BS & -.17324 & .09015 & .826 & -.4388 \\
\hline & MS & $-.88472^{*}$ & .19763 & .000 & -1.4668 \\
\hline & Other & -.70066 & .40981 & 1.000 & -1.9077 \\
\hline \multirow[t]{5}{*}{ BS } & High school & $.43540^{*}$ & .14390 & .039 & .0116 \\
\hline & Diploma +2 yrs & .16164 & .09503 & 1.000 & -.1183 \\
\hline & Diploma $+3 y r s$ & .17324 & .09015 & .826 & -.0923 \\
\hline & MS & $-.71147^{\star}$ & 20168 & .007 & -1.3055 \\
\hline & Other & -.52742 & .41178 & 1.000 & -1.7403 \\
\hline \multirow[t]{5}{*}{ MS } & High school & $1.14688^{*}$ & .22724 & .000 & .4776 \\
\hline & Diploma + 2 yrs & $.87312^{*}$ & .19990 & .000 & .2843 \\
\hline & Diploma +3yrs & $.88472^{*}$ & .19763 & .000 & .3026 \\
\hline & BS & $.71147^{*}$ & 20168 & .007 & .1174 \\
\hline & Other & .18406 & .44777 & 1.000 & -1.1348 \\
\hline Other & High school & .96282 & .42489 & .356 & -.2886 \\
\hline
\end{tabular}




\begin{tabular}{l|l|r|r|r|r}
\hline Diploma +2 yrs & .68906 & .41091 & 1.000 & -.5212 \\
\hline Diploma +3yrs & .70066 & .40981 & 1.000 & -.5064 \\
\hline BS & .52742 & .41178 & 1.000 & -.6854 \\
\hline MS & -.18406 & .44777 & 1.000 & -1.5029 \\
\hline
\end{tabular}

\section{Multiple Comparisons}

Dependent Variable: Q18

\section{Bonferroni}

(I) 4. Highest level of education completed,

(J) 4. Highest level of education completed, 95\% Confidence Interval not including EMS training not including EMS training Upper Bound

High school

Diploma +2 yrs

.1427

Diploma +3yrs .1448

Diplomat

Diploma +2 yrs

BS $-.0116$

MS

$-.4776$

Other .2886

High school .6902

Diploma +3yrs .2652

BS

.1183

MS $-.2843$

Diploma $+3 y$ rs

Other .5212

High school .6691

DS

BS

Diploma +2 yrs .2420

BS .0923

MS $-.3026$

Other

.5064

High school .8593

MS

Diploma +2 yrs .4416

Diploma $+3 y$ rs .4388

MS $-.1174$

Other .6854

MS

High school 1.8162

Diploma +2 yrs

1.4619

Diploma +3yrs 1.4668

BS 1.3055

Other 1.5029

Other

High school 2.2143

Diploma +2 yrs 1.8994

Diploma +3yrs 1.9077 


\begin{tabular}{|c|c|c|}
\hline & BS & 1.7403 \\
\hline & & \\
\hline
\end{tabular}




\section{Appendix J}

The Results of the "One Way ANOVA" of the Difference in General Knowledge of Disaster Preparedness for Mass Gatherings between Different Categories of EMS Providers Based on their Level of EMS.

\section{Multiple Comparisons}

Dependent Variable: Q15

Bonferroni

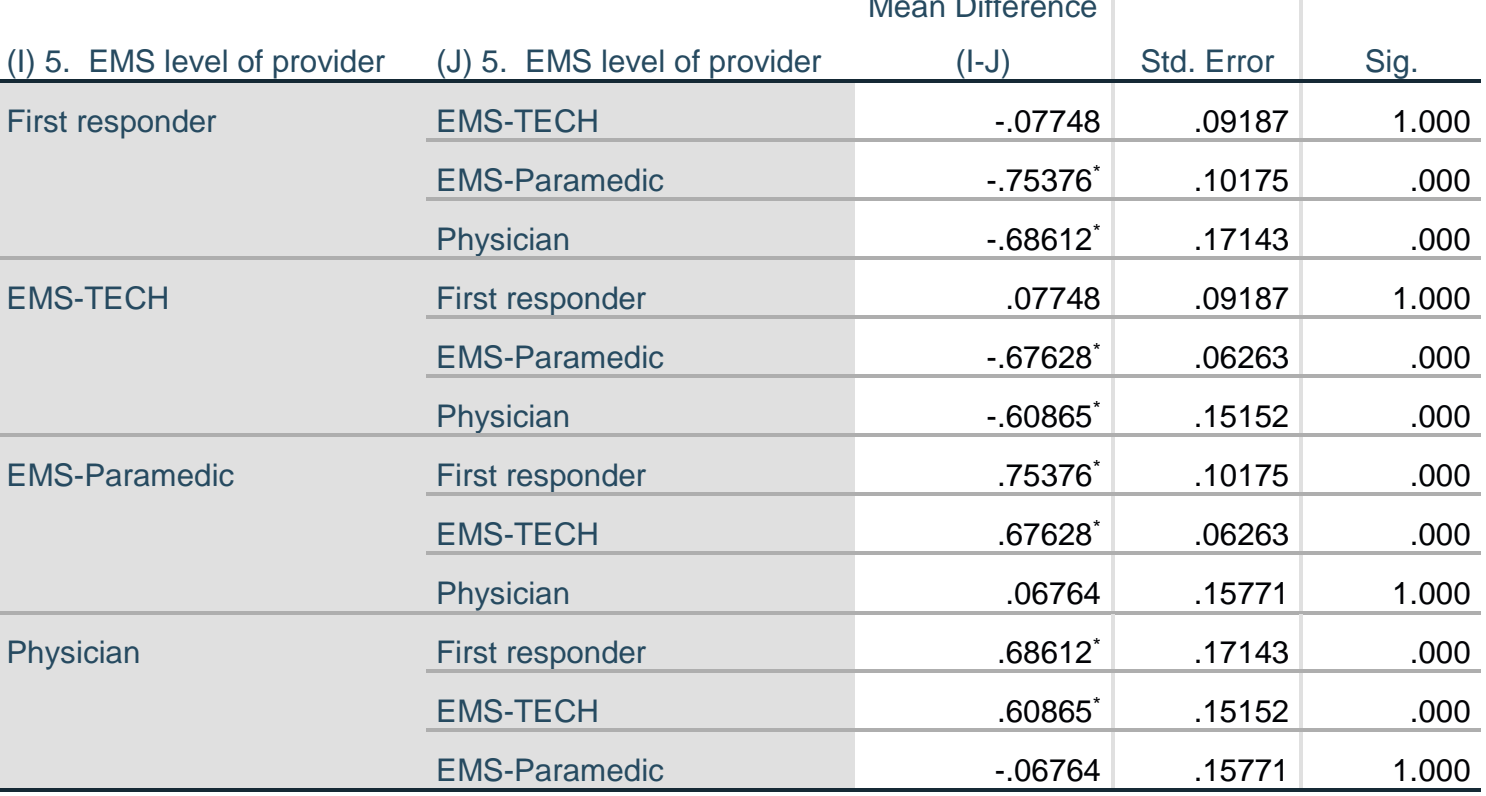

\section{Multiple Comparisons}

Dependent Variable: Q15

Bonferroni

95\% Confidence Interval

(I) 5. EMS level of provider

(J) 5. EMS level of provider

Lower Bound Upper Bound

First responder EMS-TECH

$-.3206$
.1656

EMSTECH

EMS-TECH

EMS-Paramedic $-1.0230$ $-.4845$

Physician

First responder

$-1.1397$ .2325

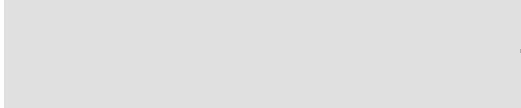

EMS-Paramedic EMS-Paramedic

Physician

First responder

$-.1656$ .3206

Ph⿻ician

Physician

EMS-TECH

Physician

First responder

EMS-TECH $-.8420$ $-.5106$ $-.2078$ $-1.0095$ 1.0230 .4845 .5106 .8420 $-.3496$ .4849

.2325

2078 1.0095 


\section{Appendix K}

The Results of the "One Way ANOVA" of the Difference in Hajj Knowledge of Disaster Preparedness for Mass Gatherings between Different Categories of EMS Providers Based on their Level of EMS.

\section{Multiple Comparisons}

Dependent Variable: Q18

Bonferroni

\begin{tabular}{|c|c|c|c|c|}
\hline (I) 5 . EMS level of provider & (J) 5 . EMS level of provider & $\begin{array}{c}\text { Mean Difference } \\
(I-J)\end{array}$ & Std. Error & Sig. \\
\hline \multirow[t]{3}{*}{ First responder } & EMS-TECH & -.22907 & .12364 & .386 \\
\hline & EMS-Paramedic & $-.41806^{*}$ & .13694 & .014 \\
\hline & Physician & $-.89491^{*}$ & .23072 & .001 \\
\hline \multirow[t]{3}{*}{ EMS-TECH } & First responder & .22907 & .12364 & .386 \\
\hline & EMS-Paramedic & -.18899 & .08429 & .152 \\
\hline & Physician & $-.66584^{*}$ & .20391 & .007 \\
\hline \multirow[t]{3}{*}{ EMS-Paramedic } & First responder & $.41806^{*}$ & .13694 & .014 \\
\hline & EMS-TECH & .18899 & .08429 & .152 \\
\hline & Physician & -.47684 & .21224 & .150 \\
\hline \multirow[t]{3}{*}{ Physician } & First responder & $.89491^{*}$ & .23072 & .001 \\
\hline & EMS-TECH & $.66584^{*}$ & .20391 & .007 \\
\hline & EMS-Paramedic & .47684 & .21224 & .150 \\
\hline
\end{tabular}

\section{Multiple Comparisons}

Dependent Variable: Q18

Bonferroni

95\% Confidence Interval

(I) 5. EMS level of provider

(J) 5. EMS level of provider

Lower Bound Upper Bound

First responder

\begin{tabular}{lr|r}
\hline EMS-TECH & -.5562 & .0981 \\
\hline EMS-Paramedic & -.7804 & -.0557 \\
\hline Physician & -1.5053 & -.2845 \\
\hline First responder & -.0981 & .5562 \\
\hline EMS-Paramedic & -.4120 & .0340 \\
\hline Physician & -1.2054 & -.1263 \\
\hline First responder & .0557 & .7804 \\
\hline EMS-TECH & -.0340 & .4120 \\
\hline Physician & -1.0384 & .0847 \\
\hline First responder & .2845 & 1.5053 \\
\hline EMS-TECH & .1263 & 1.2054 \\
\hline
\end{tabular}


Appendix L

The Results of the "One Way ANOVA" of the Difference in General Knowledge of

Disaster Preparedness for Mass Gatherings between Different Categories of EMS

Providers Based on the EMS Training Received.

\section{Multiple Comparisons}

Dependent Variable: Q15

Bonferroni

(I) 6. Current EMS training

(J) 6. Current EMS training

Mean Difference

that recieved

that recieved

$(\mathrm{I}-\mathrm{J})$

Std. Error Sig.

Gov sector

Private sector

\begin{tabular}{l|l|l|}
.07208 & .05920 & 1.000 \\
\hline
\end{tabular}

然

Private sector

Military secto

Outside of the KSA

\begin{tabular}{r|r|r}
$-.65186^{*}$ & .10004 & .000 \\
\hline
\end{tabular}

促

Military sector

Gov sector

Military sector

Outside of the KSA

Gov sector

\begin{tabular}{l|r|r|}
$-.46728^{*}$ & .11583 & .000 \\
\hline
\end{tabular}

(a)

Outside of the KSA

Private sector

Outside of the KSA

Gov sector

Private sector

Military sector

Multiple Comparisons

Dependent Variable: Q15

Bonferroni

(I) 6. Current EMS training that

recieved

(J) 6. Current EMS training that recieved

95\% Confidence Interval

\begin{tabular}{l|l|r|r|}
\hline \multirow{2}{*}{ Gov sector } & Private sector & -.0845 & .2287 \\
\cline { 2 - 4 } & Military sector & -.9165 & -.3872 \\
\cline { 2 - 4 } & Outside of the KSA & -.7737 & -.1608 \\
\hline Private sector & Gov sector & -.2287 & .0845 \\
\cline { 2 - 4 } & Military sector & -.9788 & -.4691 \\
\cline { 2 - 4 } & Outside of the KSA & -.8374 & -.2413 \\
\hline Military sector & Gov sector & .3872 & .9165 \\
\cline { 2 - 4 } & Private sector & .4691 & .9788 \\
\cline { 2 - 4 } & Outside of the KSA & -.1820 & .5511 \\
\hline Outside of the KSA & Gov sector & .1608 & .7737 \\
\hline
\end{tabular}




\section{Appendix M}

The Results of the "One Way ANOVA" of the Difference in Hajj Knowledge of Disaster Preparedness for Mass Gatherings between Different Categories of EMS Providers Based on the EMS Training Received.

\section{Multiple Comparisons}

Dependent Variable: Q18

Bonferroni

(I) 6. Current EMS training

(J) 6. Current EMS training

Mean Difference

that recieved

that recieved

(I-J)

Std. Error Sig.

Gov sector

Private sector

\begin{tabular}{ll|l|l|}
-.04680 & .07751 & 1.000 \\
\hline
\end{tabular}

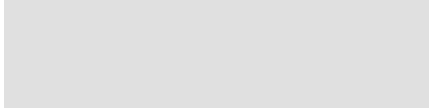

Private sector

Military secto

\begin{tabular}{l|l|l|}
\hline-16738 & .13099 & 1.000 \\
\hline
\end{tabular}

Outside of the KSA

\begin{tabular}{lll|l|}
-.33025 & .15166 & .179 \\
\hline
\end{tabular}

P

Military sector

Gov sector

Military sector

Outside of the KSA

Gov sector

Private sector

Outside of the KSA

Gov sector

Private sector

Military sector

Multiple Comparisons

Dependent Variable: Q18

Bonferroni

(I) 6. Current EMS training that

recieved

(J) 6. Current EMS training that recieved

95\% Confidence Interval

\begin{tabular}{l|l|r|r}
\hline \multirow{2}{*}{ Gov sector } & Private sector & -.2519 & .1583 \\
\cline { 2 - 4 } & Military sector & -.5139 & .1792 \\
\cline { 2 - 4 } & Outside of the KSA & -.7315 & .0710 \\
\hline \multirow{2}{*}{ Private sector } & Gov sector & -.1583 & .2519 \\
\cline { 2 - 4 } & Military sector & -.4543 & .2132 \\
\cline { 2 - 4 } & Outside of the KSA & -.6737 & .1068 \\
\hline Military sector & Gov sector & -.1792 & .5139 \\
\cline { 2 - 4 } & Private sector & -.2132 & .4543 \\
\cline { 2 - 4 } & Outside of the KSA & -.6428 & .3170 \\
\hline Outside of the KSA & Gov sector & -.0710 & .7315 \\
\cline { 2 - 4 } & Private sector & -.1068 & .6737 \\
\hline
\end{tabular}




\section{Appendix N}

The Results of the "One Way ANOVA" of the Difference in General Knowledge of

Disaster Preparedness for Mass Gatherings between Different Categories of EMS

Providers Based on Years of Experience.

\section{Multiple Comparisons}

Dependent Variable: Q15

Bonferroni

(I) 7. Experience EMS

providers in Saudi Red

(J) 7. Experience EMS

Crescent

providers in Saudi Red

Under one yr

Crescent

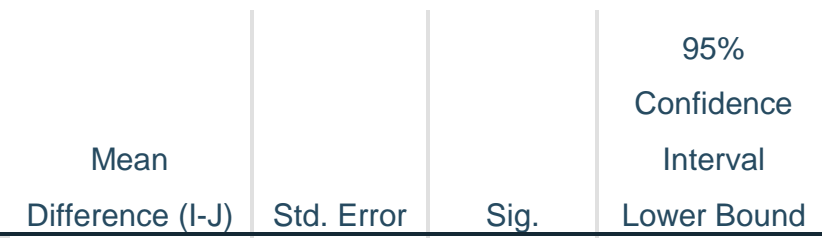

10

1- under 5 yrs

1- under 5 yrs

$-.09377$

5-under 10 yrs

$-.14932$

10-under 15 yrs

$-.29756$

15-under 20 yrs

$-.56019$

$20 \mathrm{yrs}$ and above

$-.19428$

Under one yr

.09377

$-.05555$

5-under $10 \mathrm{yrs}$

$-.20379$

10 -under 15 yrs

$-.20379$

15-under 20 yrs

$-.46641$

20 yrs and above

$-.10050$

Under one yr

.14932

1- under 5 yrs

.0555

10-under 15 yrs

$-.14823$

.24881

1.000

$-.8266$

5-under 10 yrs

15-under 20 yrs

$-.41086$

.24773

1.000

$-8790$

.25144

44

1.000

$-1.0382$

20

10-under 15 yrs

20 yrs and above

$-.04495$

.25983

83

.471

$-1.3255$

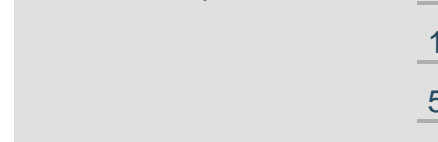

Under one yr

.29756

1- under 5 yrs

20379

5-under $10 \mathrm{yrs}$

.14823

.26244

1.000

$-.9673$

$15-$ under 20 yrs

15 -under 20 yrs

15-under $20 \mathrm{yrs}$

$20 \mathrm{yrs}$ and above

$-.26263$

Under one yr

.10328

\section{1- under 5 yrs}

.56019

.24881

1.000

$-.6391$

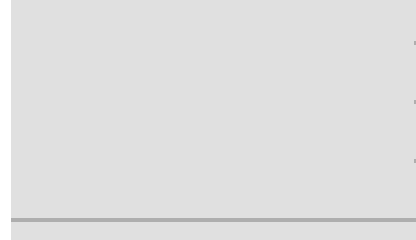

$20 \mathrm{yrs}$ and above

5-under $10 \mathrm{yrs}$

10-under 15 yrs

$20 \mathrm{yrs}$ and above

Under one yr

.46641

.07001

001

1.000
$-.2618$

\begin{tabular}{|l|l|l|}
\hline .08218 & .201 & -.4458 \\
\hline
\end{tabular}

\begin{tabular}{|l|l|l|}
.10508 & .000 & -.7759 \\
\hline
\end{tabular}

.11137

37

$1.000 \quad-.4285$

\begin{tabular}{|l|l|l|}
\hline .24773 & 1.000 & -.5804 \\
\hline
\end{tabular}

\begin{tabular}{|l|l|l|}
\hline .07001 & 1.000 & -.1506 \\
\hline
\end{tabular}

\begin{tabular}{|l|l|l|}
\hline .07886 & .908 & -.3805 \\
\hline
\end{tabular}

.10250

\begin{tabular}{|r|r|r|}
\hline & .001 & -.7128 \\
\hline & 1.000 & -.3658 \\
\hline
\end{tabular}




\begin{tabular}{l|l|r|r|r|r}
\hline 1- under 5 yrs & .10050 & .11137 & 1.000 & -.2275 \\
\hline 5-under 10 yrs & .04495 & .10894 & 1.000 & -.2759 \\
\hline 10-under 15 yrs & -.10328 & .11714 & 1.000 & -.4483 \\
\hline 15-under 20 yrs & -.36591 & .13420 & .098 & -.7612 \\
\hline
\end{tabular}

\section{Multiple Comparisons}

Dependent Variable: Q15

Bonferroni

(I) 7. Experience EMS providers in Saudi Red Crescent

Under one yr

1- under 5 yrs

5-under 10 yrs

10-under 15 yrs

15-under 20 yrs

20 yrs and above
(J) 7. Experience EMS providers in Saudi Red Crescent

1- under 5 yr

5-under 10 yrs

10-under 15 yrs

15-under 20 yrs

20 yrs and above

Under one yr

5-under 10 yrs

10-under 15 yrs

15-under 20 yrs

20 yrs and above

Under one yr

1- under 5 yrs

10-under 15 yrs

15-under 20 yrs

20 yrs and above

Under one yr

1- under 5 yrs

5-under 10 yrs

15-under 20 yrs

20 yrs and above

Under one yr

1- under 5 yrs

5-under 10 yrs

10-under 15 yrs

20 yrs and above

Under one yr

1- under 5 yrs

5-under 10 yrs
95\% Confidence Interval Upper Bound .6391 .5804 .4430 .2051 .5787 .8266 .1506 .0383 $-.1569$ .2275 .8790 .2618 .0840 $-.1090$ .2759 1.0382 .4458 .3805 .0648 .4483 1.3255 .7759 .7128 .5901 .7612 .9673 .4285 .3658 


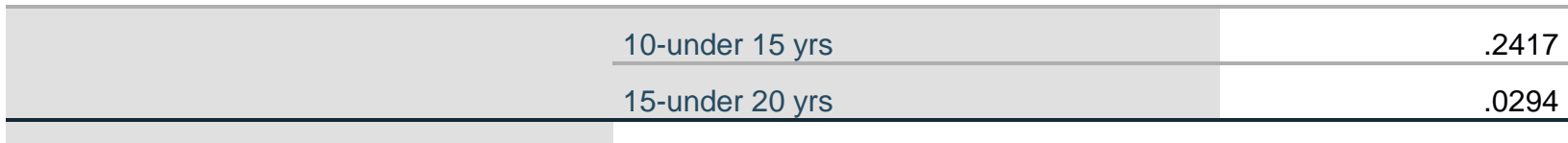




\section{Appendix O}

The Results of the "One Way ANOVA" of the Difference in Hajj Knowledge of Disaster Preparedness for Mass Gatherings between Different Categories of EMS Providers Based on Years of Experience.

\section{Multiple Comparisons}

Dependent Variable: Q18

Bonferroni

(I) 7. Experience EMS providers in Saudi Red

Crescent

Under one yr

1- under 5 yrs

5-under 10 yrs

10-under 15 yrs

15-under 20 yrs

20 yrs and above
(J) 7. Experience EMS providers in Saudi Red Crescent 1- under 5 yrs

5-under 10 yrs

10-under 15 yrs

15-under 20 yrs

20 yrs and above

Under one yr

5-under 10 yrs

10-under 15 yrs

15-under 20 yrs

20 yrs and above

Under one yr

1- under 5 yrs

10-under 15 yrs

15-under 20 yrs

20 yrs and above

Under one yr

1- under 5 yrs

5-under 10 yrs

15-under 20 yrs

20 yrs and above

Under one yr

1- under 5 yrs

5-under 10 yrs

10-under 15 yrs

20 yrs and above

Under one yr

\begin{tabular}{|c|c|c|c|}
\hline $\begin{array}{c}\text { Mean } \\
\text { Difference (I-J) } \\
\end{array}$ & Std. Error & Sig. & $\begin{array}{c}95 \% \\
\text { Confidence } \\
\text { Interval } \\
\text { Lower Bound } \\
\end{array}$ \\
\hline-.66175 & .31245 & .518 & -1.5820 \\
\hline-.64747 & .31110 & .567 & -1.5638 \\
\hline-.78577 & .31576 & .196 & -1.7158 \\
\hline$-1.06742^{*}$ & .32629 & .017 & -2.0285 \\
\hline-.64209 & .32956 & .777 & -1.6128 \\
\hline .66175 & .31245 & .518 & -.2585 \\
\hline .01429 & .08791 & 1.000 & -.2447 \\
\hline-.12402 & .10320 & 1.000 & -.4280 \\
\hline$-.40567^{*}$ & .13195 & .033 & -.7943 \\
\hline .01967 & .13985 & 1.000 & -.3923 \\
\hline .64747 & .31110 & .567 & -.2688 \\
\hline-.01429 & .08791 & 1.000 & -.2732 \\
\hline-.13831 & .09903 & 1.000 & -.4300 \\
\hline$-.41995^{\star}$ & .12872 & .017 & -.7991 \\
\hline .00538 & .13681 & 1.000 & -.3976 \\
\hline .78577 & .31576 & .196 & -.1443 \\
\hline .12402 & .10320 & 1.000 & -.1799 \\
\hline .13831 & .09903 & 1.000 & -.1534 \\
\hline-.28164 & .13960 & .661 & -.6928 \\
\hline .14369 & .14710 & 1.000 & -.2896 \\
\hline $1.06742^{*}$ & .32629 & .017 & .1064 \\
\hline $.40567^{\star}$ & .13195 & .033 & .0170 \\
\hline $.41995^{*}$ & .12872 & .017 & .0408 \\
\hline .28164 & .13960 & .661 & -.1295 \\
\hline .42533 & .16852 & .177 & -.0710 \\
\hline .64209 & .32956 & .777 & -.3286 \\
\hline
\end{tabular}




\begin{tabular}{l|l|r|r|r|r}
\hline 1- under 5 yrs & -.01967 & .13985 & 1.000 & -.4316 \\
\hline 5-under 10 yrs & -.00538 & .13681 & 1.000 & -.4083 \\
\hline 10-under 15 yrs & -.14369 & .14710 & 1.000 & -.5769 \\
\hline $15-$-under 20 yrs & -.42533 & .16852 & .177 & -.9217 \\
\hline
\end{tabular}

\section{Multiple Comparisons}

Dependent Variable: Q18

Bonferroni

(I) 7. Experience EMS providers in Saudi

Red Crescent

Under one yr

1- under 5 yrs

5-under 10 yrs

10-under 15 yrs

15-under 20 yrs

20 yrs and above
(J) 7. Experience EMS providers in Saudi Red Crescent

1- under 5 yrs

5-under 10 yrs

10-under 15 yrs

15-under 20 yrs

20 yrs and above

Under one yr

5-under 10 yrs

10-under 15 yrs

15-under 20 yrs

20 yrs and above

Under one yr

1- under 5 yrs

10-under 15 yrs

15-under 20 yrs

20 yrs and above

Under one yr

1 - under 5 yrs

5-under 10 yrs

15-under 20 yrs

20 yrs and above

Under one yr

1 - under 5 yrs

5-under 10 yrs

10-under 15 yrs

20 yrs and above

Under one yr

1- under 5 yrs

5-under 10 yrs
95\% Confidence Interval Upper Bound .2585 .2688

.1443

$-.1064$

.3286

1.5820

.2732

.1799

$-.0170$

.4316

1.5638

.2447

.1534

$-.0408$

.4083

1.7158 .4280

.4300
.1295

.5769

2.0285

.7943

.7991 .6928

.9217
1.6128 .3923 .3976 


\begin{tabular}{lll}
\hline & 10 -under 15 yrs & .2896 \\
\cline { 2 - 3 } & 15 -under 20 yrs & .0710 \\
\hline
\end{tabular}




\section{Appendix $\mathrm{P}$}

The Results of the "One Way ANOVA" of the Difference in General Knowledge of

Disaster Preparedness for Mass Gatherings between Different Categories of EMS

Providers Based on Years of Experience (number of times worked in Hajj).

\section{Multiple Comparisons}

Dependent Variable: Q15

Bonferroni

(I) 8. How many times have

(J) 8. How many times have Mean Difference

you worked at Hajj?

you worked at Hajj?

(I-J)

Std. Error Sig.

One season

Two season

$(-\mathrm{l})$

$08699 \quad 062$

The

Two season

Three season

$-.22351$

Four season or more

\begin{tabular}{l|l|l|}
-.16074 & .08995 & .446 \\
\hline
\end{tabular}

作

Three season

One season

\begin{tabular}{ll|l|l|}
$-.28834^{*}$ & .07893 & .002 \\
\hline
\end{tabular}

Three season

.22351

Four season or more

One season

\begin{tabular}{l|l|l|}
\hline .06482 & .07289 & 1.000 \\
\hline
\end{tabular}

Three season

Four season or more

\begin{tabular}{lr|r|r}
\hline Two season & -.06277 & .08470 & 1.000 \\
\hline Four season or more & -.12760 & .07639 & .572 \\
\hline One season & $.28834^{*}$ & .07893 & .002 \\
\hline Two season & .06482 & .07289 & 1.000 \\
\hline Three season & .12760 & .07639 & .572 \\
\hline
\end{tabular}

\section{Multiple Comparisons}

Dependent Variable: Q15

Bonferroni

(I) 8. How many times have you worked at Hajj?

(J) 8. How many times have you

95\% Confidence Interval

\begin{tabular}{l|l|r|r} 
worked at Hajj? & worked at Hajj? & Lower Bound & Upper Bound \\
\hline One season & Two season & -.4537 & .0067 \\
\cline { 2 - 4 } & Three season & -.3987 & .0772 \\
\cline { 2 - 4 } & Four season or more & -.4972 & -.0795 \\
\hline Two season & One season & -.0067 & .4537 \\
\cline { 2 - 4 } & Three season & -.1613 & .2869 \\
\cline { 2 - 4 } & Four season or more & -.2577 & .1280 \\
\hline Three season & One season & -.0772 & .3987 \\
\cline { 2 - 4 } & Two season & -.2869 & .1613 \\
\hline & Four season or more & -.3297 & .0745 \\
\hline Four season or more & One season & .0795 & .4972 \\
\hline
\end{tabular}




\section{Appendix Q}

The Results of the "One Way ANOVA" of the Difference in Hajj Knowledge of Disaster Preparedness for Mass Gatherings between Different Categories of EMS Providers Based on Years of Experience (number of times worked in Hajj).

\section{Multiple Comparisons}

Dependent Variable: Q18

Bonferroni

(I) 8. How many times have

you worked at Hajj?

(J) 8. How many times have Mean Difference

One season you worked at Hajj?

(I-J)

Std. Error Sig.

Or

Two season

Two season

$-.14615$

Three season

$-.03241$

Four season or more

$-.22130$

One season

\begin{tabular}{l|l|l|}
.14615 & .10934 & 1.000 \\
\hline
\end{tabular}

Fe

Three season

Three season

\begin{tabular}{l|l|l|}
.11374 & .10645 & 1.000 \\
\hline
\end{tabular}

Four season or more

\begin{tabular}{ll|l|}
-.07515 & .09162 & 1.000 \\
\hline
\end{tabular}

One season

\begin{tabular}{ll|l|l|}
.03241 & .11305 & 1.000 \\
\hline
\end{tabular}

Four season or more

Four season or more

Two season

$-.11374$

Four season or more

$-.18889$

One season

.22130

.07515

Two season

\section{Multiple Comparisons}

Dependent Variable: Q18

Bonferroni

(I) 8 . How many times have you

(J) 8. How many times have you

95\% Confidence Interval

worked at Hajj? worked at Hajj? Lower Bound

Upper Bound

\begin{tabular}{l|r|r|r}
\hline \multirow{2}{*}{ One season } & Two season & -.4354 & .1431 \\
\cline { 2 - 4 } & Three season & -.3315 & .2667 \\
\cline { 2 - 4 } & Four season or more & -.4838 & .0412 \\
\hline \multirow{2}{*}{ Two season } & One season & -.1431 & .4354 \\
\cline { 2 - 4 } & Three season & -.1679 & .3954 \\
\cline { 2 - 4 } & Four season or more & -.3176 & .1673 \\
\hline Three season & One season & -.2667 & .3315 \\
\cline { 2 - 4 } & Two season & -.3954 & .1679 \\
\cline { 2 - 4 } & Four season or more & -.4429 & .0652 \\
\hline Four season or more & One season & -.0412 & .4838 \\
\hline
\end{tabular}




\begin{tabular}{llr|r}
\hline & Two season & -.1673 & .3176 \\
\cline { 2 - 4 } & Three season & -.0652 & .4429 \\
\hline
\end{tabular}




\section{Appendix R}

The Results of the "One Way ANOVA" of the Difference in General Knowledge of

Disaster Preparedness for Mass Gatherings between Different Categories of EMS

Providers Based on Number of Training, Workshop, and Drill EVER Attended.

\section{Multiple Comparisons}

Dependent Variable: Q15

Bonferroni

(I) 10. How many

trainings/workshops/drills

about disaster preparedness

have you ever been

attended? - Training

Never

(

One

One

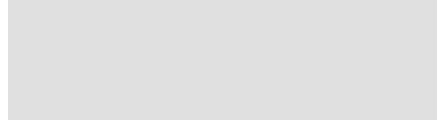

Two

Two

Three

Three

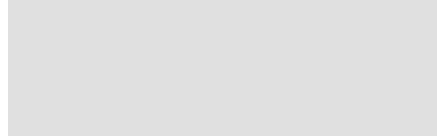

More than Three

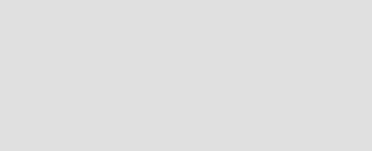

$\longrightarrow$

\section{Dependent Variable: Q15}

Bonferroni
(J) 10. How many

trainings/workshops/drills

about disaster preparedness

have you ever been

attended? - Training

Two

Three

More than Three

Never

Two

Three

More than Three

Never

One

Three

More than Three

Never

One

Two

More than Three

Never

One

Two

Three

\section{Multiple Comparisons}

Std. Error Sig.

$\begin{array}{lll}-.20910 & 07627 & .063\end{array}$

\begin{tabular}{l|l|l|}
$-.55159^{*}$ & .07990 & .000 \\
\hline
\end{tabular}

\begin{tabular}{ll|l|l|}
$-.69354^{*}$ & .08910 & .000 \\
\hline
\end{tabular}

\begin{tabular}{ll|l}
$-.64763^{*}$ & .07382 & .000 \\
\hline
\end{tabular}

\begin{tabular}{|l|l|l|}
\hline .20910 & .07627 & .063 \\
\hline
\end{tabular}

\begin{tabular}{ll|l|}
$-.34249^{*}$ & .08462 & .001 \\
\hline
\end{tabular}

\begin{tabular}{ll|l|l|}
$-.48443^{*}$ & .09335 & .000 \\
\hline
\end{tabular}

\begin{tabular}{ll|l|l|}
$-.43852^{*}$ & .07890 & .000 \\
\hline
\end{tabular}

\begin{tabular}{|l|l|l|}
$.55159^{*}$ & .07990 & .000 \\
\hline
\end{tabular}

\begin{tabular}{ll|l|}
$.34249^{*}$ & .08462 & .001 \\
\hline
\end{tabular}

\begin{tabular}{ll|l|l|}
-.14194 & .09634 & 1.000 \\
\hline
\end{tabular}

\begin{tabular}{|l|l|l|}
\hline-.09603 & .08241 & 1.000 \\
\hline
\end{tabular}

\begin{tabular}{|l|l|l|}
$.69354^{*}$ & .08910 & .000 \\
\hline
\end{tabular}

\begin{tabular}{ll|l}
$.48443^{*}$ & .09335 & .000 \\
\hline
\end{tabular}

\begin{tabular}{|l|l|l|}
.14194 & .09634 & 1.000 \\
\hline
\end{tabular}

\begin{tabular}{|l|l|l|}
.04591 & .09136 & 1.000 \\
\hline
\end{tabular}

\begin{tabular}{l|l|l|}
$.64763^{*}$ & .07382 & .000 \\
\hline
\end{tabular}

\begin{tabular}{l|l|l|}
$.43852^{*}$ & .07890 & .000 \\
\hline
\end{tabular}

\begin{tabular}{|l|l|l|}
.09603 & .08241 & 1.000 \\
\hline-.04591 & .09136 & 1.000 \\
\hline
\end{tabular}

95\% Confidence Interval 
(I) 10. How many

trainings/workshops/drills about

disaster preparedness have you

ever been attended? - Training

(J) 10. How many

Never

One

One

Two

Two

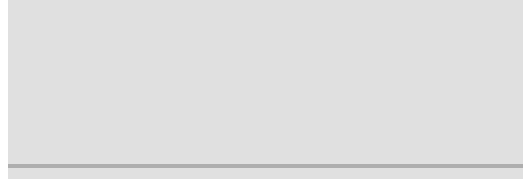

Three

rore

More than Three

\begin{tabular}{l} 
Never \\
One \\
\hline Two \\
\hline Three
\end{tabular}

\section{Multiple Comparisons}

Dependent Variable: Q15

\section{Bonferroni}

(I) 10. How many

trainings/workshops/drills

about disaster preparedness

have you ever been

attended? - Workshops

Never
(J) 10. How many

trainings/workshops/drills

about disaster preparedness

have you ever been Mean Difference

attended? - Workshops

\begin{tabular}{lc|c|c}
\hline One & $-.34647^{*}$ & .06667 & .000 \\
\hline Two & $-.70749^{*}$ & .07018 & .000 \\
\hline Three & $-.53868^{*}$ & .09818 & .000 \\
\hline More than Three & $-.86861^{*}$ & .08697 & .000
\end{tabular}

Lower Bound

Upper Bound

.0057

$-.3266$

.4426

.4398

.4239

$-.1042$

$-.2215$

$-.2164$

.7766

5808

.1294

.1360

.9445

.7473

.4133

.3032

.8555 .6607 .3281 $-.1360$ 


\begin{tabular}{|c|c|c|c|c|}
\hline \multirow[t]{4}{*}{ One } & Never & $.34647^{*}$ & .06667 & .000 \\
\hline & Two & $-.36102^{*}$ & .07907 & .000 \\
\hline & Three & -.19221 & .10471 & .668 \\
\hline & More than Three & $-.52214^{*}$ & .09429 & .000 \\
\hline \multirow[t]{4}{*}{ Two } & Never & $.70749^{*}$ & .07018 & .000 \\
\hline & One & $.36102^{*}$ & .07907 & .000 \\
\hline & Three & .16881 & .10699 & 1.000 \\
\hline & More than Three & -.16112 & .09681 & .965 \\
\hline \multirow[t]{4}{*}{ Three } & Never & $.53868^{*}$ & .09818 & .000 \\
\hline & One & .19221 & .10471 & .668 \\
\hline & Two & -.16881 & .10699 & 1.000 \\
\hline & More than Three & -.32993 & .11868 & .056 \\
\hline \multirow[t]{4}{*}{ More than Three } & Never & $.86861^{*}$ & .08697 & .000 \\
\hline & One & $.52214^{*}$ & .09429 & .000 \\
\hline & Two & .16112 & .09681 & .965 \\
\hline & Three & .32993 & .11868 & .056 \\
\hline
\end{tabular}

Multiple Comparisons

Dependent Variable: Q15

\section{Bonferroni}

\begin{tabular}{|c|c|c|c|}
\hline \multirow{2}{*}{$\begin{array}{l}\text { (I) 10. How many } \\
\text { trainings/workshops/drills about } \\
\text { disaster preparedness have you } \\
\text { ever been attended? - Workshops }\end{array}$} & \multirow{2}{*}{$\begin{array}{l}\text { (J) 10. How many } \\
\text { trainings/workshops/drills about } \\
\text { disaster preparedness have you } \\
\text { ever been attended? - Workshops }\end{array}$} & \multicolumn{2}{|c|}{ 95\% Confidence Interval } \\
\hline & & Lower Bound & Upper Bound \\
\hline \multirow[t]{4}{*}{ Never } & One & -.5342 & -.1587 \\
\hline & Two & -.9051 & -.5099 \\
\hline & Three & -.8151 & -.2622 \\
\hline & More than Three & -1.1135 & -.6237 \\
\hline \multirow[t]{4}{*}{ One } & Never & .1587 & .5342 \\
\hline & Two & -.5837 & -.1384 \\
\hline & Three & -.4871 & .1027 \\
\hline & More than Three & -.7877 & -.2566 \\
\hline \multirow[t]{4}{*}{ Two } & Never & .5099 & .9051 \\
\hline & One & .1384 & .5837 \\
\hline & Three & -.1325 & .4701 \\
\hline & More than Three & -.4337 & .1115 \\
\hline \multirow[t]{2}{*}{ Three } & Never & .2622 & .8151 \\
\hline & One & -.1027 & .4871 \\
\hline
\end{tabular}




\begin{tabular}{llr|r}
\hline & Two & -.4701 & .1325 \\
\cline { 2 - 4 } & More than Three & -.6641 & .0043 \\
\hline \multirow{2}{*}{ More than Three } & Never & .6237 & 1.1135 \\
\cline { 2 - 4 } & One & .2566 & .7877 \\
\hline & Two & -.1115 & .4337 \\
\hline & Three & -.0043 & .6641 \\
\hline
\end{tabular}

\section{Multiple Comparisons}

Dependent Variable: Q15

\section{Bonferroni}

(I) 10. How many

trainings/workshops/drills

about disaster preparedness

have you ever been

attended? - Drills

Never

Tw

One

Two

Two

Three

Three

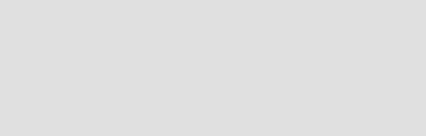

More than Three

Dependent Variable: Q15

Bonferroni
(J) 10. How many

trainings/workshops/drills

about disaster preparedness

have you ever been Mean Difference

attended? - Drills

(I-J)

Std. Error

Sig.

One

Two

Three

More than Three

Never

Two

Three

More than Three

Never

One

Three

More than Three

Never

One

Two

More than Three

Never

One

Two

Three

\section{Multiple Comparisons}

\begin{tabular}{ll|l}
$-.35966^{*}$ & .06857 & .000 \\
\hline
\end{tabular}

\begin{tabular}{ll|l|l|}
$-.74409^{*}$ & .07655 & .000 \\
\hline
\end{tabular}

\begin{tabular}{ll|l|l|}
$-.56517^{*}$ & .09748 & .000 \\
\hline
\end{tabular}

\begin{tabular}{lll|l}
$-.75445^{*}$ & .07616 & .000 \\
\hline
\end{tabular}

\begin{tabular}{ll|l}
$.35966^{*}$ & .06857 & .000 \\
\hline
\end{tabular}

\begin{tabular}{ll|l}
$-.38443^{*}$ & .07903 & .000 \\
\hline
\end{tabular}

\begin{tabular}{lll|l|}
-.20551 & .09944 & .391 \\
\hline
\end{tabular}

\begin{tabular}{ll|l|l|}
$-.39479^{*}$ & .07866 & .000 \\
\hline
\end{tabular}

\begin{tabular}{l|l|l|}
$.74409^{*}$ & .07655 & .000 \\
\hline
\end{tabular}

\begin{tabular}{ll|l|l|}
$.38443^{*}$ & .07903 & .000 \\
\hline
\end{tabular}

\begin{tabular}{|l|l|l|}
.17892 & .10510 & .892 \\
\hline
\end{tabular}

\begin{tabular}{ll|r|}
-.01036 & .08570 & 1.000 \\
\hline
\end{tabular}

\begin{tabular}{l|l|l|}
$.56517^{\star}$ & .09748 & .000 \\
\hline
\end{tabular}

\begin{tabular}{|l|l|l|}
.20551 & .09944 & .391 \\
\hline
\end{tabular}

\begin{tabular}{ll|l|l|}
\hline-17892 & .10510 & .892 \\
\hline
\end{tabular}

\begin{tabular}{l|l|l|}
-.18928 & .10482 & .714 \\
\hline
\end{tabular}

\begin{tabular}{|r|r|r}
$.75445^{\star}$ & .07616 & .000 \\
\hline $.39479^{*}$ & .07866 & .000 \\
\hline .01036 & .08570 & 1.000 \\
\hline .18928 & .10482 & .714 \\
\hline
\end{tabular}

95\% Confidence Interval 
(I) 10. How many

trainings/workshops/drills about disaster preparedness have you

ever been attended? - Drills

Never

One

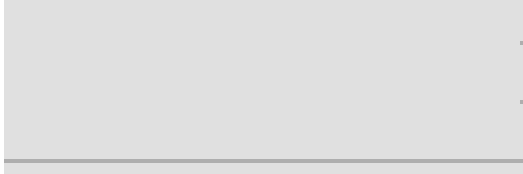

Two

(2)

Three

(J) 10. How many

trainings/workshops/drills about

disaster preparedness have you ever been attended? - Drills Lower Bound Upper Bound

One

Two

Three

More than Three

Never

Two

Three

More than Three

Never

One

Three

More than Three

Never

One

Two

More than Three

Never

One

Two

Three

$-.1059$ $-.1666$ $-.5285$ .2907 $-.5400$ .5528 $-.1619$ .0745 $-.1733$ .9597 .6070 .4749 .2310 .8397 .4855 .1171 .1059 .9689 .6163 .2517 4845 


\section{Appendix S}

The Results of the "One Way ANOVA" of the Difference in General Knowledge of

Disaster Preparedness for Mass Gatherings between Different Categories of EMS

Providers Based on Number of Training, Workshop, and Drill Attended.

\section{Multiple Comparisons}

Dependent Variable: Q15

Bonferroni

$\begin{array}{ll}\text { (I) } 11 . \text { Which of the } & \text { (J) 11. Which of the }\end{array}$

following best describes following best describes

your attendance at a your attendance at a

trainings/workshops/dril trainings/workshops/dril

Is about disaster

preparedness? If not

Is about disaster

select N/A - Training

Never

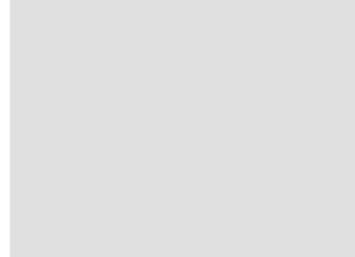

One time per year

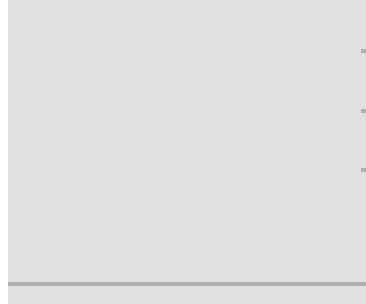

Two times per year

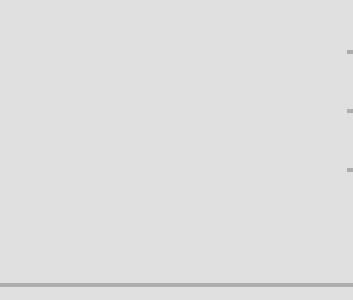

Three times per year preparedness? If not select N/A - Training

One time per year

Two times per year

Three times per year

Four times per year

Five times or more per

year

Never

Two times per year

Three times per year

Four times per year

Five times or more per

year

Never

One time per year

Three times per year

Four times per year

Five times or more per year

Never

One time per year

Two times per year

Four times per year

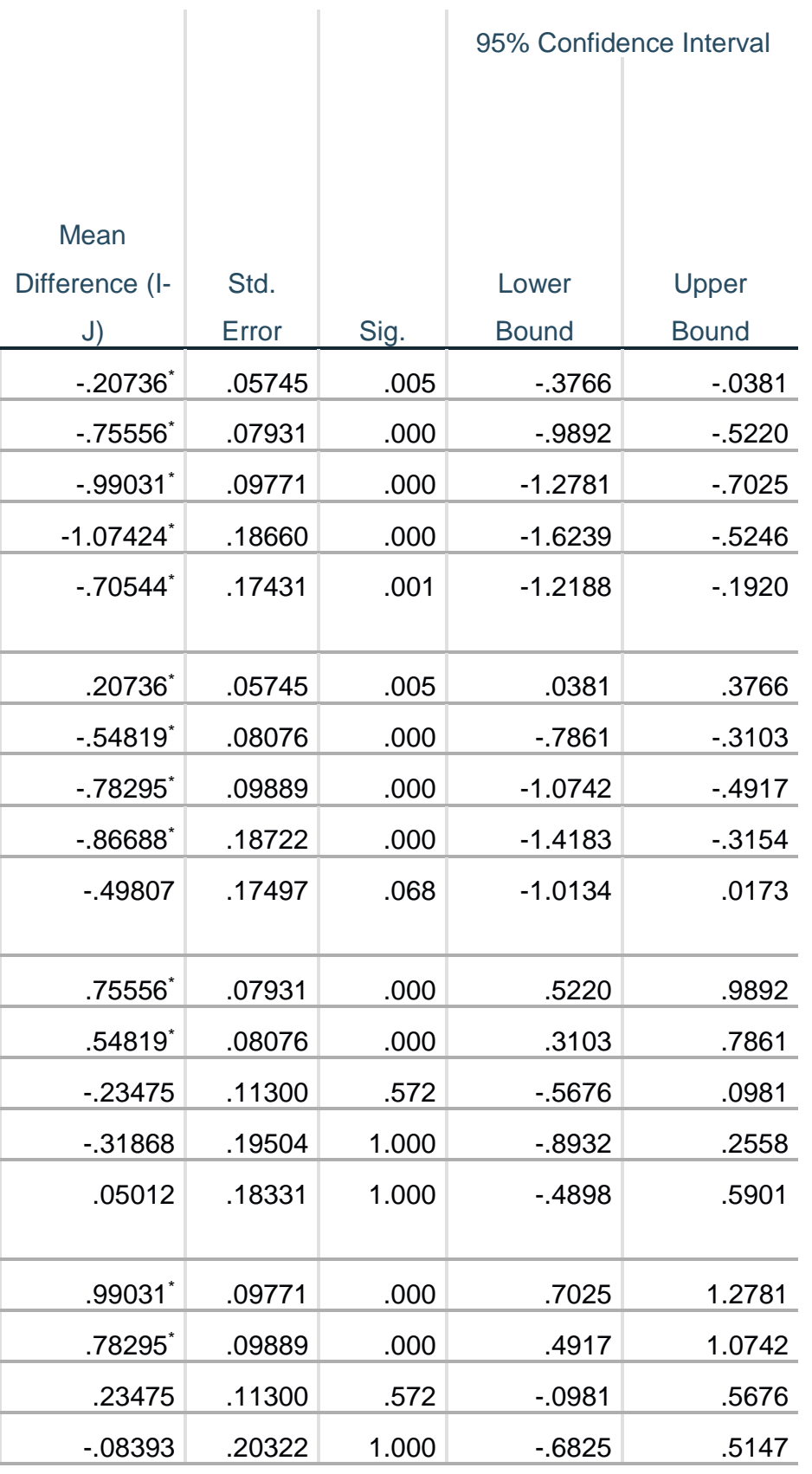




\begin{tabular}{ll|r|r|r|r|r}
\hline & $\begin{array}{l}\text { Five times or more per } \\
\text { year }\end{array}$ & .28488 & .19199 & 1.000 & -.2806 & .8504 \\
\hline \multirow{2}{*}{ Four times per year } & Never & $1.07424^{*}$ & .18660 & .000 & .5246 & 1.6239 \\
\cline { 2 - 7 } & One time per year & $.86688^{*}$ & .18722 & .000 & .3154 & 1.4183 \\
\hline & Two times per year & .31868 & .19504 & 1.000 & -.2558 & .8932 \\
\hline & Three times per year & .08393 & .20322 & 1.000 & -.5147 & .6825 \\
\hline & Five times or more per & .36880 & .24927 & 1.000 & -.3654 & 1.1030 \\
\hline \multirow{2}{*}{$\begin{array}{l}\text { Five times or more per } \\
\text { year }\end{array}$} & & & & & \\
\cline { 2 - 7 } & Never & $.70544^{*}$ & .17431 & .001 & .1920 & 1.2188 \\
\hline & One time per year & .49807 & .17497 & .068 & -.0173 & 1.0134 \\
\hline & Two times per year & -.05012 & .18331 & 1.000 & -.5901 & .4898 \\
\hline
\end{tabular}

Multiple Comparisons

Dependent Variable: Q15

\section{Bonferroni}

$\begin{array}{lll}\text { (I) 11. Which of the } & \text { (J) 11. Which of the }\end{array}$

following best describes following best describes

your attendance at a your attendance at a

trainings/workshops/dril trainings/workshops/dril

Is about disaster

preparedness? If not

select N/A - Workshop

Never

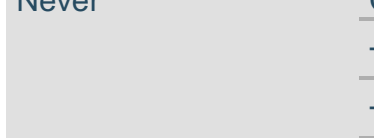

One time oer vear

One time per year

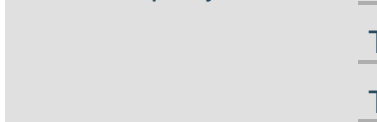

2nd

Two times per year

\begin{abstract}
Is about disaster
\end{abstract}
preparedness? If not

select N/A - Workshop

One time per year

Two times per year

Three times per year

Four times per year

Five times or more per

year

Never

Two times per year

Three times per year

Four times per year

Five times or more per

year

Never

One time per year

Three times per year

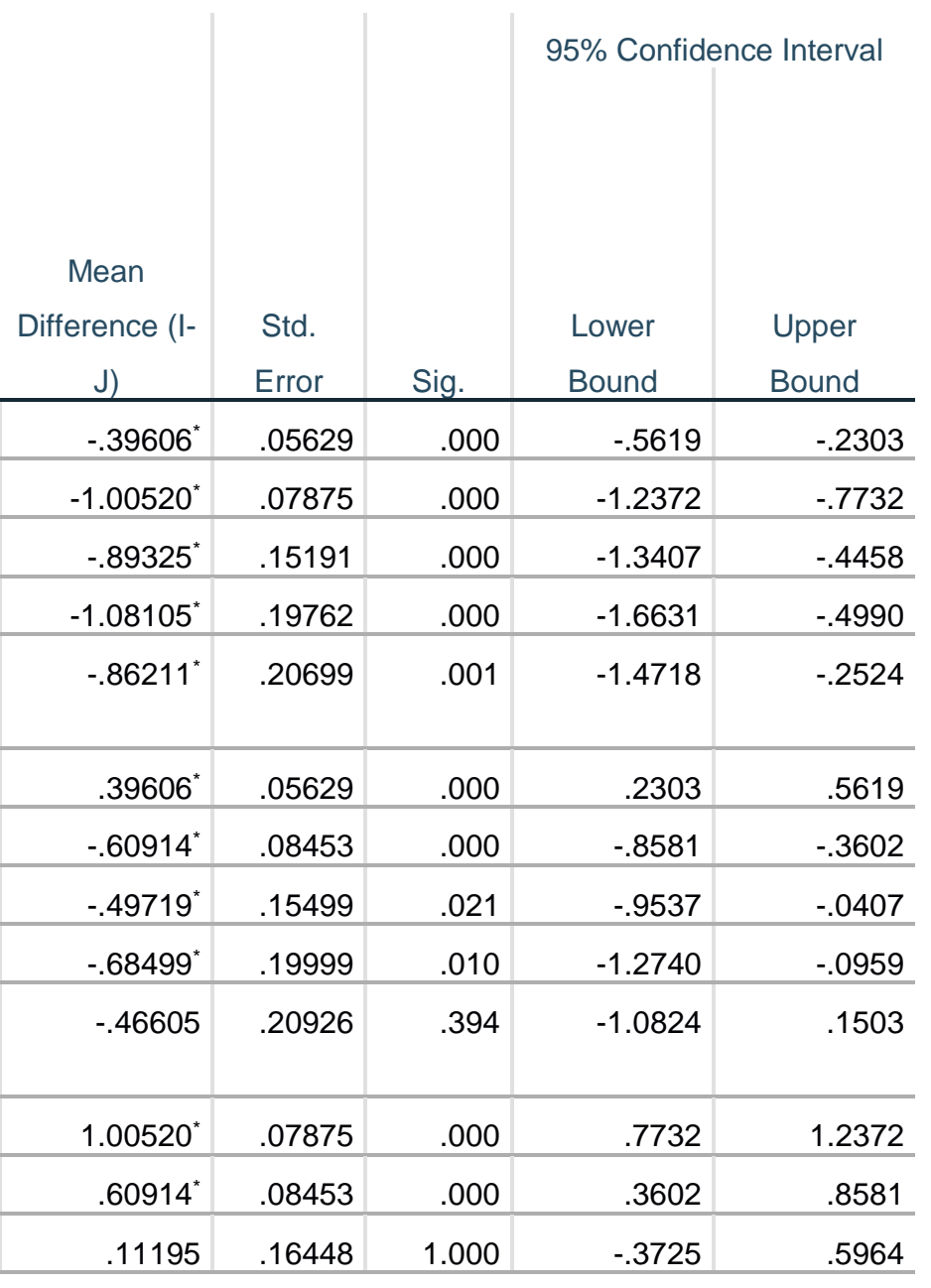




\begin{tabular}{|c|c|c|c|c|c|c|}
\hline & Four times per year & -.07585 & .20743 & 1.000 & -.6868 & .5351 \\
\hline & $\begin{array}{l}\text { Five times or more per } \\
\text { year }\end{array}$ & .14309 & .21638 & 1.000 & -.4942 & .7804 \\
\hline \multirow[t]{5}{*}{ Three times per year } & Never & $.89325^{\star}$ & .15191 & .000 & .4458 & 1.3407 \\
\hline & One time per year & $.49719^{*}$ & .15499 & .021 & .0407 & .9537 \\
\hline & Two times per year & -.11195 & .16448 & 1.000 & -.5964 & .3725 \\
\hline & Four times per year & -.18780 & .24475 & 1.000 & -.9087 & .5331 \\
\hline & $\begin{array}{l}\text { Five times or more per } \\
\text { year }\end{array}$ & .03114 & .25238 & 1.000 & -.7122 & .7745 \\
\hline \multirow[t]{5}{*}{ Four times per year } & Never & $1.08105^{\star}$ & .19762 & .000 & .4990 & 1.6631 \\
\hline & One time per year & $.68499^{*}$ & .19999 & .010 & .0959 & 1.2740 \\
\hline & Two times per year & .07585 & .20743 & 1.000 & -.5351 & .6868 \\
\hline & Three times per year & .18780 & .24475 & 1.000 & -.5331 & .9087 \\
\hline & $\begin{array}{l}\text { Five times or more per } \\
\text { year }\end{array}$ & .21894 & .28226 & 1.000 & -.6124 & 1.0503 \\
\hline \multirow{5}{*}{$\begin{array}{l}\text { Five times or more per } \\
\text { year }\end{array}$} & Never & $.86211^{*}$ & .20699 & .001 & .2524 & 1.4718 \\
\hline & One time per year & .46605 & .20926 & .394 & -.1503 & 1.0824 \\
\hline & Two times per year & -.14309 & .21638 & 1.000 & -.7804 & .4942 \\
\hline & Three times per year & -.03114 & .25238 & 1.000 & -.7745 & .7122 \\
\hline & Four times per year & -.21894 & .28226 & 1.000 & -1.0503 & .6124 \\
\hline
\end{tabular}

Multiple Comparisons

Dependent Variable: Q15

Bonferroni

$\begin{array}{ll}\text { (I) 11. Which of the } & \text { (J) 11. Which of the }\end{array}$

following best describes following best describes

your attendance at a your attendance at a

trainings/workshops/dril trainings/workshops/dril

Is about disaster

preparedness? If not

select N/A - Drill

Never

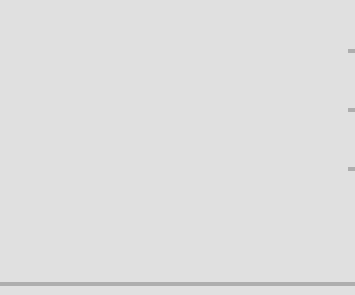

One time per year
Is about disaster

preparedness? If not select N/A - Dril

One time per year

Two times per year

Three times per year

Four times per year

Five times or more per

year

Never

Two times per year

\begin{tabular}{|c|c|c|c|c|}
\hline \multirow[b]{2}{*}{$\begin{array}{c}\text { Mean } \\
\text { Difference (I- } \\
\mathrm{J})\end{array}$} & \multirow[b]{2}{*}{$\begin{array}{l}\text { Std. } \\
\text { Error }\end{array}$} & \multirow[b]{2}{*}{ Sig. } & \multicolumn{2}{|c|}{ 95\% Confidence Interval } \\
\hline & & & $\begin{array}{l}\text { Lower } \\
\text { Bound }\end{array}$ & $\begin{array}{l}\text { Upper } \\
\text { Bound }\end{array}$ \\
\hline$-.39576^{*}$ & .05668 & .000 & -.5627 & -.2288 \\
\hline$-.87202^{*}$ & .08384 & .000 & -1.1190 & -.6251 \\
\hline$-.64196^{*}$ & .12036 & .000 & -.9965 & -.2875 \\
\hline$-1.14768^{*}$ & .22550 & .000 & -1.8119 & -.4835 \\
\hline$-.97110^{*}$ & .18218 & .000 & -1.5077 & -.4345 \\
\hline $.39576^{*}$ & .05668 & .000 & .2288 & .5627 \\
\hline$-.47626^{*}$ & .08632 & .000 & -.7305 & -.2220 \\
\hline
\end{tabular}




\begin{tabular}{|c|c|c|c|c|c|c|}
\hline & Three times per year & -.24621 & .12210 & .662 & -.6058 & .1134 \\
\hline & Four times per year & $-.75193^{\star}$ & .22643 & .014 & -1.4189 & -.0850 \\
\hline & $\begin{array}{l}\text { Five times or more per } \\
\text { year }\end{array}$ & $-.57534^{*}$ & .18333 & .027 & -1.1153 & -.0354 \\
\hline \multirow[t]{5}{*}{ Two times per year } & Never & $.87202^{*}$ & .08384 & .000 & .6251 & 1.1190 \\
\hline & One time per year & $.47626^{*}$ & .08632 & .000 & .2220 & .7305 \\
\hline & Three times per year & .23005 & .13684 & 1.000 & -.1730 & .6331 \\
\hline & Four times per year & -.27567 & .23471 & 1.000 & -.9670 & .4157 \\
\hline & $\begin{array}{l}\text { Five times or more per } \\
\text { year }\end{array}$ & -.09908 & .19346 & 1.000 & -.6689 & .4707 \\
\hline \multirow[t]{5}{*}{ Three times per year } & Never & $.64196^{*}$ & .12036 & .000 & .2875 & .9965 \\
\hline & One time per year & .24621 & .12210 & .662 & -.1134 & .6058 \\
\hline & Two times per year & -.23005 & .13684 & 1.000 & -.6331 & .1730 \\
\hline & Four times per year & -.50572 & .25009 & .653 & -1.2423 & .2309 \\
\hline & $\begin{array}{l}\text { Five times or more per } \\
\text { year }\end{array}$ & -.32913 & .21186 & 1.000 & -.9531 & .2949 \\
\hline \multirow[t]{5}{*}{ Four times per year } & Never & $1.14768^{*}$ & .22550 & .000 & .4835 & 1.8119 \\
\hline & One time per year & $.75193^{*}$ & .22643 & .014 & .0850 & 1.4189 \\
\hline & Two times per year & .27567 & .23471 & 1.000 & -.4157 & .9670 \\
\hline & Three times per year & .50572 & .25009 & .653 & -.2309 & 1.2423 \\
\hline & $\begin{array}{l}\text { Five times or more per } \\
\text { year }\end{array}$ & .17659 & .28504 & 1.000 & -.6630 & 1.0162 \\
\hline \multirow{5}{*}{$\begin{array}{l}\text { Five times or more per } \\
\text { year }\end{array}$} & Never & $.97110^{*}$ & .18218 & .000 & .4345 & 1.5077 \\
\hline & One time per year & $.57534^{*}$ & .18333 & .027 & .0354 & 1.1153 \\
\hline & Two times per year & .09908 & .19346 & 1.000 & -.4707 & .6689 \\
\hline & Three times per year & .32913 & .21186 & 1.000 & -.2949 & .9531 \\
\hline & Four times per year & -.17659 & .28504 & 1.000 & -1.0162 & .6630 \\
\hline
\end{tabular}




\section{Appendix T}

The Results of the "One Way ANOVA" of the Difference in General Knowledge of

Disaster Preparedness for Mass Gatherings between Different Categories of EMS

Providers Based on Number of Training, Workshop, and Drill Last Time Attended.

\section{Multiple Comparisons}

Dependent Variable: Q15

Bonferroni

(I) 12. When was the last

(J) 12. When was the last

time you attended a

time you attended a

trainings/ workshops/ drills

trainings/ workshops/ drills

about disaster

about disaster

Mean Difference

preparedness? - Training

preparedness? - Training

(I-J)

Std. Error Sig.

Less than six months ago

Six months ago-A year ago

$-.05663$

.07871
1.000

N/A

Six months ago-A year ago

More than one year ago

\begin{tabular}{l|l|l|}
$.27579^{*}$ & .07745 & .002 \\
\hline
\end{tabular}

$\mathrm{N} / \mathrm{A}$

$58551^{*}$

Less than six months ago

.05663

.07450

.000

N

More than one year ago

More than one year ago

$\mathrm{N} / \mathrm{A}$

.33243

.07871

1.000

Less than six months ago

$.64215^{*}$

.07497
.000

N/A

N/A

\begin{tabular}{ll|l|l|l}
\hline Six months ago-A year ago & $-.33243^{*}$ & .07497 & .000 \\
\hline N/A & $.30972^{*}$ & .07053 & .000 \\
\hline Less than six months ago & $-.58551^{*}$ & .07450 & .000 \\
\hline Six months ago-A year ago & $-.64215^{*}$ & .07192 & .000 \\
\hline More than one year ago & $-.30972^{*}$ & .07053 & .000 \\
\hline
\end{tabular}

\section{Multiple Comparisons}

Dependent Variable: Q15

Bonferroni

(I) 12. When was the last time you

attended a trainings/ workshops/

drills about disaster preparedness?

- Training

Less than six months ago

Six months ago-A year ago
(J) 12. When was the last time you attended a trainings/ workshops/

drills about disaster preparedness?

- Training

Six months ago-A year ago

More than one year ago

$N / A$

Less than six months ago

More than one year ago

$N / A$
95\% Confidence Interval Lower Bound

Upper Bound

\begin{tabular}{r|r}
-.2649 & .1516 \\
\hline .0709 & .4807 \\
\hline .3884 & .7826 \\
\hline-.1516 & .2649 \\
\hline .1341 & .5308 \\
\hline .4519 & .8324
\end{tabular}




\begin{tabular}{llr|r}
\hline More than one year ago & Less than six months ago & -.4807 & -.0709 \\
\hline & Six months ago-A year ago & -.5308 & -.1341 \\
\hline N/A & .1231 & .4963 \\
\hline N/A & Less than six months ago & -.7826 & -.3884 \\
\hline Six months ago-A year ago & -.8324 & -.4519 \\
\hline & More than one year ago & -.4963 & -.1231 \\
\hline
\end{tabular}

\section{Multiple Comparisons}

Dependent Variable: Q15

\section{Bonferroni}

(I) 12. When was the last time you attended a

(J) 12. When was the last

trainings/ workshops/ drills time you attended a

about disaster

trainings/ workshops/ drills about disaster

preparedness? - Workshop

preparedness? - Workshop (I-J)

Std. Error Sig.

Less than six months ago

Six months ago-A year ago \begin{tabular}{l|r|r}
$-.34411^{*}$ & .08628 & .000 \\
\hline
\end{tabular}

N/A

Six months ago-A year ago

More than one year ago

N/A

\begin{tabular}{l|l|r|}
.01945 & .08837 & 1.000 \\
\hline
\end{tabular}

Less than six months ago .47210

.07981

.000

N/A

More than one year ago

More than one year ago

$\mathrm{N} / \mathrm{A}$

Less than six months ago

.34411

.36356

.08628

.000

More than one year ago

Six months ago-A year ago

N/A

N/A

\begin{tabular}{ll|l|l|l}
\hline Less than six months ago & $-.47210^{*}$ & .07981 & .000 \\
\hline Six months ago-A year ago & $-.81621^{*}$ & .06416 & .000 \\
\hline More than one year ago & $-.45265^{*}$ & .06695 & .000 \\
\hline
\end{tabular}

Multiple Comparisons

Dependent Variable: Q15

Bonferroni

(I) 12. When was the last time you attended a trainings/ workshops/ drills about disaster preparedness?

- Workshop

Less than six months ago

a

Six months ago-A year ago
(J) 12. When was the last time you attended a trainings/ workshops/ drills about disaster preparedness? - Workshop

Six months ago-A year ago

More than one year ago

N/A

Less than six months ago

More than one year ago
95\% Confidence Interval

Lower Bound Upper Bound

\begin{tabular}{r|r}
-.5724 & -.1158 \\
\hline-.2144 & .2533 \\
\hline .2609 & .6833 \\
\hline .1158 & .5724 \\
\hline .1663 & .5608 \\
\hline
\end{tabular}




\begin{tabular}{llr|r}
\hline & N/A & .6465 & .9860 \\
\hline \multirow{2}{*}{ More than one year ago } & Less than six months ago & -.2533 & .2144 \\
\cline { 2 - 4 } & Six months ago-A year ago & -.5608 & -.1663 \\
\hline & N/A & .2755 & .6298 \\
\hline \multirow{2}{*}{ N/A } & Less than six months ago & -.6833 & -.2609 \\
\hline & Six months ago-A year ago & -.9860 & -.6465 \\
\cline { 2 - 4 } & More than one year ago & -.6298 & -.2755 \\
\hline
\end{tabular}

Multiple Comparisons

Dependent Variable: Q15

\section{Bonferroni}

(I) 12. When was the last

(J) 12. When was the last

time you attended a time you attended a

trainings/ workshops/drills

trainings/ workshops/drills

about disaster about disaster

Mean Difference

preparedness? - Drill preparedness? - Drill (I-J)

Std. Error

Sig.

\begin{tabular}{|c|c|c|c|c|}
\hline \multirow[t]{3}{*}{ Less than six months ago } & Six months ago-A year ago & $-.32148^{*}$ & .08289 & .001 \\
\hline & More than one year ago & .03718 & .08375 & 1.000 \\
\hline & $\mathrm{N} / \mathrm{A}$ & $.48065^{*}$ & .07919 & .000 \\
\hline \multirow[t]{3}{*}{ Six months ago-A year ago } & Less than six months ago & $.32148^{*}$ & .08289 & .001 \\
\hline & More than one year ago & $.35866^{*}$ & .07114 & .000 \\
\hline & $\mathrm{N} / \mathrm{A}$ & $.80213^{*}$ & .06572 & .000 \\
\hline \multirow[t]{3}{*}{ More than one year ago } & Less than six months ago & -.03718 & .08375 & 1.000 \\
\hline & Six months ago-A year ago & $-.35866^{\star}$ & .07114 & .000 \\
\hline & $N / A$ & $.44347^{*}$ & .06679 & .000 \\
\hline \multirow[t]{3}{*}{$N / A$} & Less than six months ago & $-.48065^{*}$ & .07919 & .000 \\
\hline & Six months ago-A year ago & $-.80213^{*}$ & .06572 & .000 \\
\hline & More than one year ago & $-.44347^{*}$ & .06679 & .000 \\
\hline
\end{tabular}

\section{Multiple Comparisons}

Dependent Variable: Q15

\section{Bonferroni}

(I) 12. When was the last time you

attended a trainings/ workshops/

drills about disaster preparedness?

- Drill

Less than six months ago

Six months ago-A year ago
(J) 12. When was the last time you attended a trainings/ workshops/

drills about disaster preparedness? - Drill

Six months ago-A year ago

More than one year ago

N/A

Less than six months ago
95\% Confidence Interval Lower Bound Upper Bound

\begin{tabular}{r|r}
-.5408 & -.1022 \\
\hline. .1844 & .2588 \\
\hline .2711 & .6902 \\
\hline .1022 & .5408 \\
\hline
\end{tabular}




\begin{tabular}{llr|r}
\hline & More than one year ago & .1704 & .5469 \\
\cline { 2 - 4 } & N/A & .6282 & .9760 \\
\hline \multirow{2}{*}{ More than one year ago } & Less than six months ago & -.2588 & .1844 \\
\cline { 2 - 4 } & Six months ago-A year ago & -.5469 & -.1704 \\
\hline N/A & Less than six months ago & .2668 & .6202 \\
\hline & Six months ago-A year ago & -.6902 & -.2711 \\
\hline & More than one year ago & -.9760 & -.6282 \\
\hline
\end{tabular}




\section{Appendix U}

The Results of the "One Way ANOVA" of the Difference in General Knowledge of

Disaster Preparedness for Mass Gatherings between Different Categories of EMS

Providers Based on duration of the last time attended Training, Workshop, and Drill.

\section{Multiple Comparisons}

Dependent Variable: Q15

Bonferroni

\begin{tabular}{|c|c|c|c|c|c|}
\hline $\begin{array}{l}\text { (I) 13. What was the } \\
\text { duration of the last } \\
\text { trainings/workshops/drills } \\
\text { about disaster that you } \\
\text { attended? - Training }\end{array}$ & $\begin{array}{l}\text { (J) 13. What was the } \\
\text { duration of the last } \\
\text { trainings/workshops/drills } \\
\text { about disaster that you } \\
\text { attended? - Training }\end{array}$ & $\begin{array}{c}\text { Mean } \\
\text { Difference (I-J) }\end{array}$ & Std. Error & Sig. & $\begin{array}{l}95 \% \\
\text { Confidence } \\
\text { Interval } \\
\text { Lower Bound }\end{array}$ \\
\hline \multirow[t]{4}{*}{ Less than 5 hours } & $\begin{array}{l}\text { From } 5 \text { hours but less than } \\
10 \text { hours }\end{array}$ & $-.28225^{*}$ & .07169 & .001 & -.4841 \\
\hline & $\begin{array}{l}\text { From } 10 \text { hours but less } \\
\text { than } 20 \text { hours }\end{array}$ & .03139 & .11484 & 1.000 & -.2920 \\
\hline & 20 hours or more & -.19835 & .11160 & .759 & -.5126 \\
\hline & N/A & $.40203^{\star}$ & .06511 & .000 & .2187 \\
\hline \multirow{4}{*}{$\begin{array}{l}\text { From } 5 \text { hours but less than } \\
10 \text { hours }\end{array}$} & Less than 5 hours & $.28225^{*}$ & .07169 & .001 & .0804 \\
\hline & $\begin{array}{l}\text { From } 10 \text { hours but less } \\
\text { than } 20 \text { hours }\end{array}$ & .31363 & .12024 & .093 & -.0250 \\
\hline & 20 hours or more & .08390 & .11715 & 1.000 & -.2460 \\
\hline & N/A & $.68428^{*}$ & .07422 & .000 & .4753 \\
\hline \multirow{4}{*}{$\begin{array}{l}\text { From } 10 \text { hours but less } \\
\text { than } 20 \text { hours }\end{array}$} & Less than 5 hours & -.03139 & .11484 & 1.000 & -.3548 \\
\hline & $\begin{array}{l}\text { From } 5 \text { hours but less than } \\
10 \text { hours }\end{array}$ & -.31363 & .12024 & .093 & -.6522 \\
\hline & 20 hours or more & -.22974 & .14755 & 1.000 & -.6452 \\
\hline & N/A & $.37064^{*}$ & .11643 & .015 & .0428 \\
\hline \multirow[t]{4}{*}{20 hours or more } & Less than 5 hours & .19835 & .11160 & .759 & -.1159 \\
\hline & $\begin{array}{l}\text { From } 5 \text { hours but less than } \\
10 \text { hours }\end{array}$ & -.08390 & .11715 & 1.000 & -.4138 \\
\hline & $\begin{array}{l}\text { From } 10 \text { hours but less } \\
\text { than } 20 \text { hours }\end{array}$ & .22974 & .14755 & 1.000 & -.1858 \\
\hline & N/A & $.60038^{*}$ & .11324 & .000 & .2815 \\
\hline \multirow[t]{2}{*}{$\mathrm{N} / \mathrm{A}$} & Less than 5 hours & $-.40203^{*}$ & .06511 & .000 & -.5854 \\
\hline & $\begin{array}{l}\text { From } 5 \text { hours but less than } \\
10 \text { hours }\end{array}$ & $-.68428^{*}$ & .07422 & .000 & -.8933 \\
\hline
\end{tabular}




\begin{tabular}{l|l|l|l|l|l|}
\hline $\begin{array}{l}\text { From } 10 \text { hours but less } \\
\text { than } 20 \text { hours }\end{array}$ & $-.37064^{*}$ & .11643 & .015 & -.6985 \\
\hline 20 hours or more & $-.60038^{*}$ & .11324 & .000 & -.9193 \\
\hline
\end{tabular}

\section{Multiple Comparisons}

Dependent Variable: Q15

Bonferroni

(I) 13. What was the duration of the last

(J) 13. What was the duration of the last

95\% Confidence Interval trainings/workshops/drills about disaster trainings/workshops/drills about disaster

that you attended? - Training that you attended? - Training

Upper Bound

Less than 5 hours

From 5 hours but less than 10 hours

$-.0804$

the

From 10 hours but less than 20 hours .3548

20 hours or more

.1159

From 5 hours but less than 10 hours

N/A .5854

From 10 hours but less than 20 hours

Less than 5 hours .4841

From 10 hours but less than 20 hours .6522

20 hours or more .4138

From 10 hours but less than 20 hours

$\mathrm{N} / \mathrm{A}$ .8933

Frc

Less than 5 hours .2920

From 5 hours but less than 10 hours $\quad 0250$

N/A

20 hours or more .1858

20 hours or more

Less than 5 hours .6985

N/A

N/A

\begin{tabular}{ll} 
From 5 hours but less than 10 hours & .2460 \\
\hline From 10 hours but less than 20 hours & .6452 \\
\hline N/A & .9193
\end{tabular}

Less than 5 hours
From 5 hours but less than
From 10 hours but less than
20 hours or more
Multiple Comparisons

Dependent Variable: Q15

\section{Bonferroni}

(I) 13. What was the

duration of the last

trainings/workshops/drills

about disaster that you

attended? - Workshop
(J) 13. What was the

duration of the last

trainings/workshops/drills

about disaster that you

attended? - Workshop

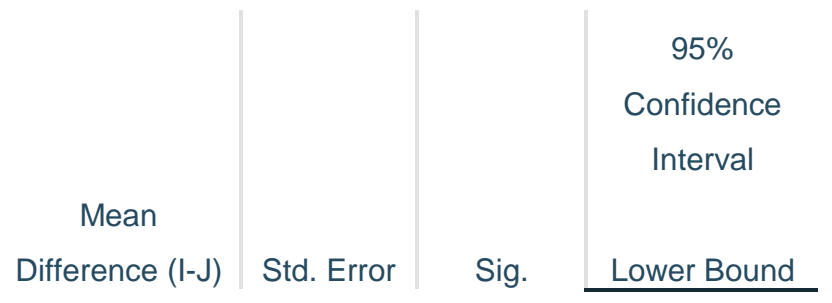




\begin{tabular}{|c|c|c|c|c|c|}
\hline \multirow[t]{4}{*}{ Less than 5 hours } & $\begin{array}{l}\text { From } 5 \text { hours but less than } \\
10 \text { hours }\end{array}$ & $-.37601^{*}$ & .07306 & .000 & -.5817 \\
\hline & $\begin{array}{l}\text { From } 10 \text { hours but less } \\
\text { than } 20 \text { hours }\end{array}$ & -.28212 & .10520 & .075 & -.5784 \\
\hline & 20 hours or more & $-.51206^{*}$ & .14093 & .003 & -.9089 \\
\hline & $N / A$ & $.37049^{*}$ & .06662 & .000 & .1829 \\
\hline \multirow{4}{*}{$\begin{array}{l}\text { From } 5 \text { hours but less than } \\
10 \text { hours }\end{array}$} & Less than 5 hours & $.37601^{*}$ & .07306 & .000 & .1703 \\
\hline & $\begin{array}{l}\text { From } 10 \text { hours but less } \\
\text { than } 20 \text { hours }\end{array}$ & .09389 & .10297 & 1.000 & -.1961 \\
\hline & 20 hours or more & -.13605 & .13927 & 1.000 & -.5283 \\
\hline & N/A & $.74650^{*}$ & .06303 & .000 & .5690 \\
\hline \multirow{4}{*}{$\begin{array}{l}\text { From } 10 \text { hours but less } \\
\text { than } 20 \text { hours }\end{array}$} & Less than 5 hours & .28212 & .10520 & .075 & -.0141 \\
\hline & $\begin{array}{l}\text { From } 5 \text { hours but less than } \\
10 \text { hours }\end{array}$ & -.09389 & .10297 & 1.000 & -.3839 \\
\hline & 20 hours or more & -.22994 & .15852 & 1.000 & -.6763 \\
\hline & N/A & $.65261^{*}$ & .09850 & .000 & .3752 \\
\hline \multirow[t]{4}{*}{20 hours or more } & Less than 5 hours & $.51206^{*}$ & .14093 & .003 & .1152 \\
\hline & $\begin{array}{l}\text { From } 5 \text { hours but less than } \\
10 \text { hours }\end{array}$ & .13605 & .13927 & 1.000 & -.2562 \\
\hline & $\begin{array}{l}\text { From } 10 \text { hours but less } \\
\text { than } 20 \text { hours }\end{array}$ & .22994 & .15852 & 1.000 & -.2164 \\
\hline & $\mathrm{N} / \mathrm{A}$ & $.88255^{*}$ & .13601 & .000 & .4996 \\
\hline \multirow[t]{4}{*}{ N/A } & Less than 5 hours & $-.37049^{*}$ & .06662 & .000 & -.5581 \\
\hline & $\begin{array}{l}\text { From } 5 \text { hours but less than } \\
10 \text { hours }\end{array}$ & $-.74650^{\star}$ & .06303 & .000 & -.9240 \\
\hline & $\begin{array}{l}\text { From } 10 \text { hours but less } \\
\text { than } 20 \text { hours }\end{array}$ & $-.65261^{*}$ & .09850 & .000 & -.9300 \\
\hline & 20 hours or more & $-.88255^{*}$ & .13601 & .000 & -1.2655 \\
\hline
\end{tabular}

Multiple Comparisons

Dependent Variable: Q15

Bonferroni

(I) 13. What was the duration of the last trainings/workshops/drills about disaster that you attended? - Workshop

(J) 13. What was the duration of the last

95\% Confidence Interval trainings/workshops/drills about disaster that you attended? - Workshop Upper Bound

Less than 5 hours From 5 hours but less than 10 hours $-.1703$

From 10 hours but less than 20 hours .0141

20 hours or more $-.1152$

N/A .5581 


\begin{tabular}{llr}
\hline \multirow{2}{*}{ From 5 hours but less than 10 hours } & Less than 5 hours & .5817 \\
\cline { 2 - 3 } & From 10 hours but less than 20 hours & .3839 \\
\hline & 20 hours or more & .2562 \\
\hline & N/A & .9240 \\
\hline From 10 hours but less than 20 hours & Less than 5 hours & .5784 \\
\cline { 2 - 3 } & From 5 hours but less than 10 hours & .1961 \\
\hline & 20 hours or more & .2164 \\
\hline N/A & .9300 \\
\hline \multirow{2}{*}{20 hours or more } & Less than 5 hours & .9089 \\
\hline & From 5 hours but less than 10 hours & .5283 \\
\hline & From 10 hours but less than 20 hours & .6763 \\
\hline N/A & 1.2655 \\
\hline N/A & Less than 5 hours & -.1829 \\
\hline & From 5 hours but less than 10 hours & -.5690 \\
\hline & From 10 hours but less than 20 hours & -.3752 \\
\hline & 20 hours or more & -.4996 \\
\hline
\end{tabular}

Dependent Variable: Q15

\section{Bonferroni}

\begin{tabular}{|c|c|c|c|c|c|}
\hline $\begin{array}{l}\text { (I) } 13 . \text { What was the } \\
\text { duration of the last } \\
\text { trainings/workshops/drills } \\
\text { about disaster that you } \\
\text { attended? - Drill }\end{array}$ & $\begin{array}{l}\text { (J) 13. What was the } \\
\text { duration of the last } \\
\text { trainings/workshops/drills } \\
\text { about disaster that you } \\
\text { attended? - Drill }\end{array}$ & $\begin{array}{c}\text { Mean } \\
\text { Difference (I-J) } \\
\end{array}$ & Std. Error & Sig. & $\begin{array}{c}95 \% \\
\text { Confidence } \\
\text { Interval } \\
\text { Lower Bound }\end{array}$ \\
\hline \multirow[t]{4}{*}{ Less than 5 hours } & $\begin{array}{l}\text { From } 5 \text { hours but less than } \\
10 \text { hours }\end{array}$ & $-.26762^{*}$ & .07514 & .004 & -.4792 \\
\hline & $\begin{array}{l}\text { From } 10 \text { hours but less } \\
\text { than } 20 \text { hours }\end{array}$ & $-.44564^{*}$ & .07934 & .000 & -.6691 \\
\hline & 20 hours or more & $-.55155^{*}$ & .13489 & .000 & -.9314 \\
\hline & N/A & $.38563^{*}$ & .06582 & .000 & .2003 \\
\hline \multirow{4}{*}{$\begin{array}{l}\text { From } 5 \text { hours but less than } \\
10 \text { hours }\end{array}$} & Less than 5 hours & $.26762^{*}$ & .07514 & .004 & .0560 \\
\hline & $\begin{array}{l}\text { From } 10 \text { hours but less } \\
\text { than } 20 \text { hours }\end{array}$ & -.17802 & .08320 & .327 & -.4123 \\
\hline & 20 hours or more & -.28393 & .13719 & .389 & -.6703 \\
\hline & N/A & $.65325^{*}$ & .07042 & .000 & .4549 \\
\hline \multirow{2}{*}{$\begin{array}{l}\text { From } 10 \text { hours but less } \\
\text { than } 20 \text { hours }\end{array}$} & Less than 5 hours & $.44564^{*}$ & .07934 & .000 & .2222 \\
\hline & $\begin{array}{l}\text { From } 5 \text { hours but less than } \\
10 \text { hours }\end{array}$ & .17802 & .08320 & .327 & -.0563 \\
\hline
\end{tabular}




\begin{tabular}{|c|c|c|c|c|c|}
\hline & 20 hours or more & -.10591 & .13954 & 1.000 & -.4989 \\
\hline & $\mathrm{N} / \mathrm{A}$ & $.83127^{*}$ & .07489 & .000 & .6204 \\
\hline \multirow[t]{4}{*}{20 hours or more } & Less than 5 hours & $.55155^{*}$ & .13489 & .000 & .1717 \\
\hline & $\begin{array}{l}\text { From } 5 \text { hours but less than } \\
10 \text { hours }\end{array}$ & .28393 & .13719 & .389 & -.1024 \\
\hline & $\begin{array}{l}\text { From } 10 \text { hours but less } \\
\text { than } 20 \text { hours }\end{array}$ & .10591 & .13954 & 1.000 & -.2870 \\
\hline & $\mathrm{N} / \mathrm{A}$ & $.93718^{*}$ & .13231 & .000 & .5646 \\
\hline \multirow[t]{4}{*}{$N / A$} & Less than 5 hours & $-.38563^{*}$ & .06582 & .000 & -.5710 \\
\hline & $\begin{array}{l}\text { From } 5 \text { hours but less than } \\
10 \text { hours }\end{array}$ & $-.65325^{*}$ & .07042 & .000 & -.8516 \\
\hline & $\begin{array}{l}\text { From } 10 \text { hours but less } \\
\text { than } 20 \text { hours }\end{array}$ & $-.83127^{\star}$ & .07489 & .000 & -1.0422 \\
\hline & 20 hours or more & $-.93718^{*}$ & .13231 & .000 & -1.3098 \\
\hline
\end{tabular}

Dependent Variable: Q15

\section{Bonferroni}

(I) 13. What was the duration of the last trainings/workshops/drills about disaster that you attended? - Drill

\begin{tabular}{l}
\hline Less than 5 hours \\
\hline From 5 hours but less than 10 hours \\
\hline From 10 hours but less than 20 hours \\
\hline 20 hours or more \\
\hline N/A \\
\hline
\end{tabular}

\section{Multiple Comparisons}

(J) 13. What was the duration of the last trainings/workshops/drills about disaster that you attended? - Drill

From 5 hours but less than 10 hours

From 10 hours but less than 20 hours 20 hours or more

N/A

Less than 5 hours

From 10 hours but less than 20 hours

20 hours or more

N/A

Less than 5 hours

From 5 hours but less than 10 hours

20 hours or more

N/A

Less than 5 hours

From 5 hours but less than 10 hours

From 10 hours but less than 20 hours

N/A

Less than 5 hours

From 5 hours but less than 10 hours
95\% Confidence Interval Upper Bound

$\begin{array}{r}-.0560 \\ -.2222 \\ -.1717 \\ .5710 \\ .4792 \\ .0563 \\ .1024 \\ .8516 \\ .6691 \\ .4123 \\ .2870 \\ \hline 1.0422 \\ .9314 \\ .6703 \\ \hline .4989 \\ \hline 1.3098 \\ \hline .2003 \\ \hline .4549 \\ \hline\end{array}$




\section{Appendix V}

The Results of the "One Way ANOVA" of the Difference in Hajj Knowledge of Disaster Preparedness for Mass Gatherings between Different Categories of EMS Providers Based on Number of Training, Workshop, and Drill EVER Attended.

\section{Multiple Comparisons}

Dependent Variable: Q18

Bonferroni

(I) 10. How many

(J) 10. How many

trainings/workshops/drills

trainings/workshops/drills

about disaster preparedness

have you ever been

about disaster preparedness

attended? - Training

have you ever been

Mean Difference

attended? - Training

(I-J)

Never

One

$-.13527$

Std. Error

Sig.

Never

Two

$-.33702$

.10095

1.000

One

Three

$-.47849$

One

More than Three

$-.42865^{*}$

.10576 .015

Never

.13527

.11794

.001

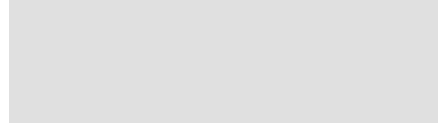

Two

$-.20176$

Three

$-.34322$

More than Three

$-.29339$

Two

Never

.33702

One

.20176

Three

$-.14146$

More than Three

Three

Never

$-.09163$

.09770

.000

Three

More than Three

One

Two

More than Three

Never

One

$.47849^{\star}$

.34322

.14146

.04983

.42865

.29339

Two

.09163

$-.04983$

$.10095 \quad 1.000$

Three

Multiple Comparisons

Dependent Variable: Q18

Bonferroni 
(I) 10. How many

trainings/workshops/drills about

disaster preparedness have you

ever been attended? - Training

Never

(n)

One

(n)

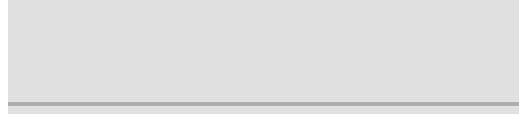

Two

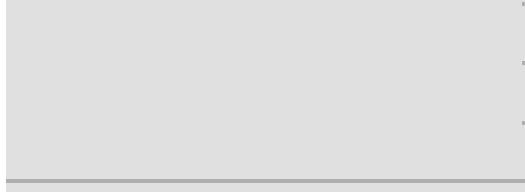

Three

rorethan Three

More than Three

\begin{tabular}{l} 
Never \\
One \\
Two \\
\hline Three
\end{tabular}

\section{Multiple Comparisons}

\section{Dependent Variable: Q18}

\section{Bonferroni}

(I) 10. How many

trainings/workshops/drills

about disaster preparedness

have you ever been

attended? - Workshops

(J) 10. How many

trainings/workshops/drills

about disaster preparedness

have you ever been

attended? - Workshops

Mean Difference

Never

One

Two

Three

More than Three

One

disaster preparedness have you
Lower Bound

Upper Bound

\begin{tabular}{|c|c|}
\hline Lower Bound & Upper Bound \\
\hline-.4196 & .1490 \\
\hline-.6348 & -.0392 \\
\hline-.8106 & -.1464 \\
\hline-.7038 & -.1535 \\
\hline-.1490 & .4196 \\
\hline-.5172 & .1136 \\
\hline-.6912 & .0047 \\
\hline-.5875 & .0007 \\
\hline .0392 & .6348 \\
\hline-.1136 & .5172 \\
\hline-.5006 & .2176 \\
\hline-.3988 & .2155 \\
\hline .1464 & .8106 \\
\hline-.0047 & .6912 \\
\hline-.2176 & .5006 \\
\hline-.2907 & .3903 \\
\hline .1535 & .7038 \\
\hline-.0007 & .5875 \\
\hline-.2155 & .3988 \\
\hline-.3903 & .2907 \\
\hline
\end{tabular}

2907

$-.0047$
(J) 10. How many

Two

Three

Never

Three

More than Three

One

Three

More than Three

One

\begin{tabular}{l|l|r|r|r}
\hline \multirow{2}{*}{ Never } & One & $-.34354^{*}$ & .09043 & .002 \\
\hline Two & $-.41118^{*}$ & .09519 & .000 \\
\hline Three & -.34678 & .13316 & .094 \\
\hline More than Three & $-.55624^{*}$ & .11796 & .000 \\
\hline \multirow{2}{*}{ One } & Never & $.34354^{*}$ & .09043 & .002 \\
\hline
\end{tabular}




\begin{tabular}{|c|c|c|c|c|}
\hline & Three & -.00325 & .14203 & 1.000 \\
\hline & More than Three & -.21271 & .12789 & .967 \\
\hline \multirow[t]{4}{*}{ Two } & Never & $.41118^{*}$ & .09519 & .000 \\
\hline & One & .06764 & .10724 & 1.000 \\
\hline & Three & .06439 & .14511 & 1.000 \\
\hline & More than Three & -.14507 & .13130 & 1.000 \\
\hline \multirow[t]{4}{*}{ Three } & Never & .34678 & .13316 & .094 \\
\hline & One & .00325 & .14203 & 1.000 \\
\hline & Two & -.06439 & .14511 & 1.000 \\
\hline & More than Three & -.20946 & .16097 & 1.000 \\
\hline \multirow[t]{4}{*}{ More than Three } & Never & $.55624^{*}$ & .11796 & .000 \\
\hline & One & .21271 & .12789 & .967 \\
\hline & Two & .14507 & .13130 & 1.000 \\
\hline & Three & .20946 & .16097 & 1.000 \\
\hline
\end{tabular}

Multiple Comparisons

Dependent Variable: Q18

Bonferroni

(I) 10. How many

trainings/workshops/drills about

disaster preparedness have you

ever been attended? - Workshops

Never

One

One

Two

Two

reng

Three

(J) 10. How many

trainings/workshops/drills about

disaster preparedness have you

ever been attended? - Workshops

One

Two

Three

More than Three

Never

Two

Three

More than Three

Never

One

Three

More than Three

Never

One

Two

More than Three
95\% Confidence Interval Lower Bound

Upper Bound

$-.5982$

$-.6792$ $-.0889$ $-.1431$ .0282 $-.7218$ .2241 5982 2344 .3967 1474 6792 3696 .4730 .2247 .7218 .4032 .3442 .2438 


\begin{tabular}{l|l|r|r}
\hline More than Three & Never & .2241 & .8884 \\
\cline { 2 - 4 } & One & -.1474 & .5728 \\
\hline Two & -.2247 & .5148 \\
\hline Three & -.2438 & .6627 \\
\hline
\end{tabular}

\section{Multiple Comparisons}

Dependent Variable: Q18

Bonferroni

\begin{tabular}{|c|c|c|c|c|}
\hline $\begin{array}{l}\text { (I) } 10 \text {. How many } \\
\text { trainings/workshops/drills } \\
\text { about disaster preparedness } \\
\text { have you ever been } \\
\text { attended? - Drills }\end{array}$ & $\begin{array}{l}\text { (J) } 10 \text {. How many } \\
\text { trainings/workshops/drills } \\
\text { about disaster preparedness } \\
\text { have you ever been } \\
\text { attended? - Drills }\end{array}$ & $\begin{array}{c}\text { Mean Difference } \\
(\mathrm{I}-\mathrm{J})\end{array}$ & Std. Error & Sig. \\
\hline \multirow[t]{4}{*}{ Never } & One & $-.36133^{*}$ & .09049 & .001 \\
\hline & Two & $-.54158^{*}$ & .10102 & .000 \\
\hline & Three & $-.66464^{*}$ & .12864 & .000 \\
\hline & More than Three & $-.64040^{*}$ & .10051 & .000 \\
\hline \multirow[t]{4}{*}{ One } & Never & $.36133^{*}$ & .09049 & .001 \\
\hline & Two & -.18025 & .10429 & .844 \\
\hline & Three & -.30331 & .13123 & .211 \\
\hline & More than Three & -.27908 & .10380 & .073 \\
\hline \multirow[t]{4}{*}{ Two } & Never & $.54158^{*}$ & .10102 & .000 \\
\hline & One & .18025 & .10429 & .844 \\
\hline & Three & -.12307 & .13870 & 1.000 \\
\hline & More than Three & -.09883 & .11310 & 1.000 \\
\hline \multirow[t]{4}{*}{ Three } & Never & $.66464^{*}$ & .12864 & .000 \\
\hline & One & .30331 & .13123 & .211 \\
\hline & Two & .12307 & .13870 & 1.000 \\
\hline & More than Three & .02424 & .13833 & 1.000 \\
\hline \multirow[t]{4}{*}{ More than Three } & Never & $.64040^{*}$ & .10051 & .000 \\
\hline & One & .27908 & .10380 & .073 \\
\hline & Two & .09883 & .11310 & 1.000 \\
\hline & Three & -.02424 & .13833 & 1.000 \\
\hline
\end{tabular}

Multiple Comparisons

Dependent Variable: Q18

Bonferroni 
(I) 10. How many

trainings/workshops/drills about disaster preparedness have you

ever been attended? - Drills

Never

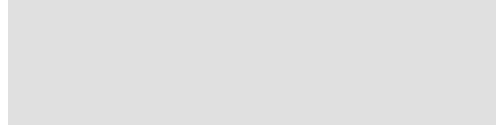

One

(n)

Two

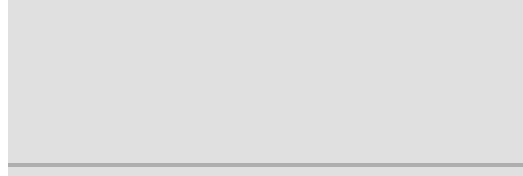

Three

.

More than Three
(J) 10. How many

trainings/workshops/drills about

disaster preparedness have you ever been attended? - Drills Lower Bound Upper Bound

One $\quad-.6161$

Two $-.8261$

Three

More than Three

Never

Two

Three

More than Three

Never

One

Three

More than Three

Never

One

Two

More than Three

Never

One

Two

Three $-.1065$ $-.2571$ $-.3024$ $-3574$ .6161 .1134 .0662 .0132 .8261 .4739 .2675 .2197 .0269 .6729 .5136 .4138 .9234 .5714 .4173 3653 


\section{Appendix W}

The Results of the "One Way ANOVA" of the Difference in Hajj Knowledge of Disaster Preparedness for Mass Gatherings between Different Categories of EMS Providers Based on Number of Training, Workshop, and Drill Attended.

\section{Multiple Comparisons}

Dependent Variable: Q18

Bonferroni

$\begin{array}{lll}\text { (I) } 11 . \text { Which of the } & \text { (J) } 11 \text {. Which of the }\end{array}$ following best describes following best describes your attendance at a your attendance at a trainings/workshops/dril trainings/workshops/dril Is about disaster preparedness? If not select N/A - Training

Never

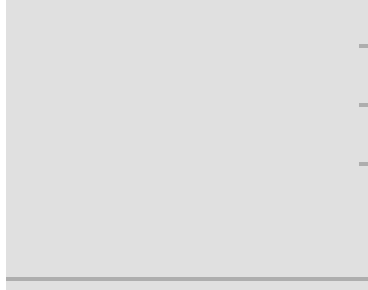

One time per year

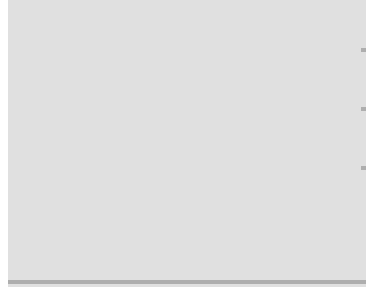

Two times per year

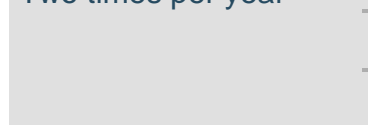

Is about disaster

preparedness? If not select N/A - Training

One time per year

Two times per year

Three times per year

Four times per year

Five times or more per

year

Never

Two times per year

Three times per year

Four times per year

Five times or more per

year

Never

One time per year

Three times per year

Four times per year

Five times or more per

year

Neve

One time per year

Two times per year

Four times per year

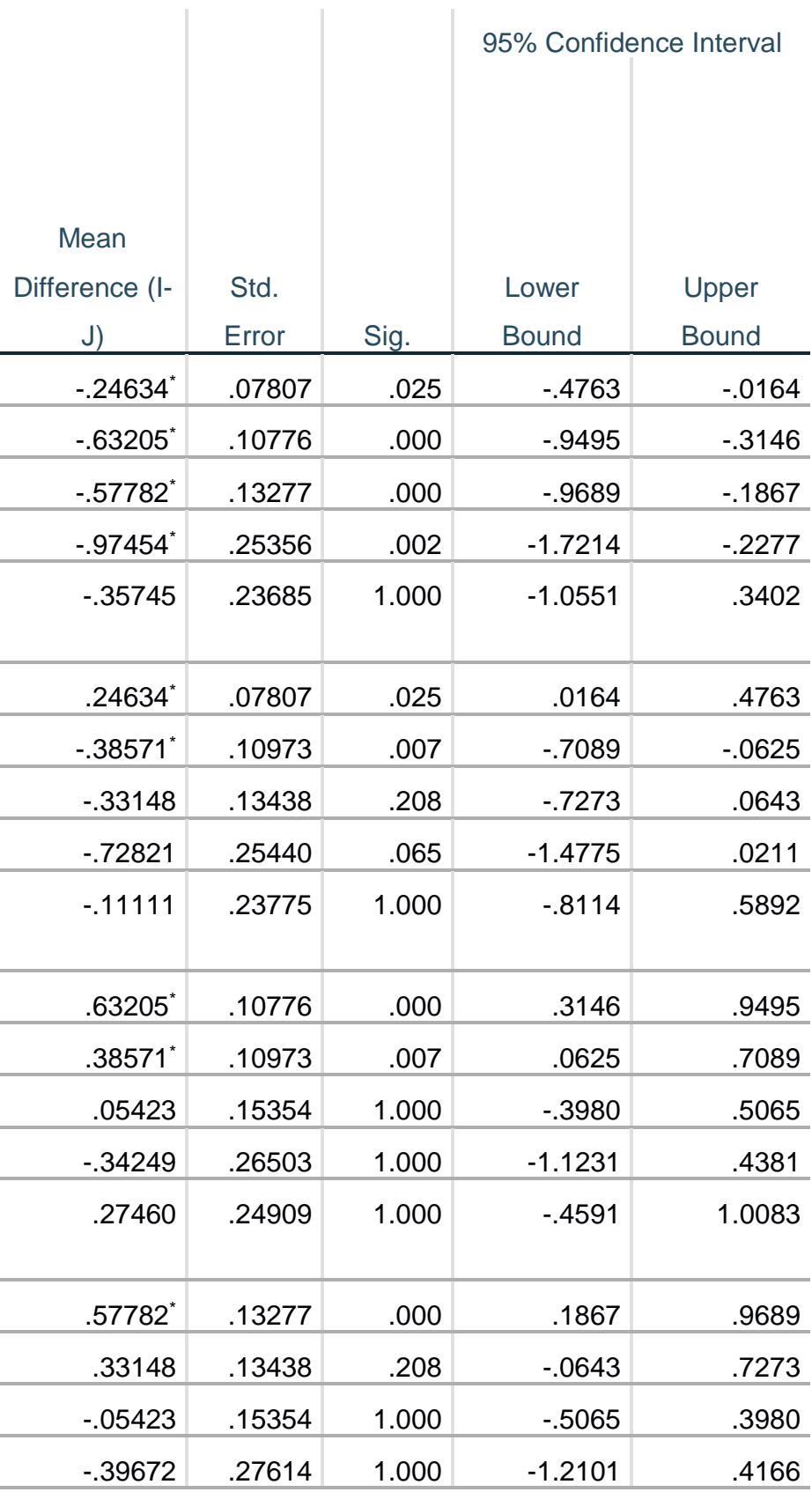




\begin{tabular}{|c|c|c|c|c|c|c|}
\hline & $\begin{array}{l}\text { Five times or more per } \\
\text { year }\end{array}$ & .22037 & .26089 & 1.000 & -.5480 & .9888 \\
\hline \multirow[t]{5}{*}{ Four times per year } & Never & $.97454^{*}$ & .25356 & .002 & .2277 & 1.7214 \\
\hline & One time per year & .72821 & .25440 & .065 & -.0211 & 1.4775 \\
\hline & Two times per year & .34249 & .26503 & 1.000 & -.4381 & 1.1231 \\
\hline & Three times per year & .39672 & .27614 & 1.000 & -.4166 & 1.2101 \\
\hline & $\begin{array}{l}\text { Five times or more per } \\
\text { year }\end{array}$ & .61709 & .33871 & 1.000 & -.3805 & 1.6147 \\
\hline \multirow{5}{*}{$\begin{array}{l}\text { Five times or more per } \\
\text { year }\end{array}$} & Never & .35745 & .23685 & 1.000 & -.3402 & 1.0551 \\
\hline & One time per year & .11111 & .23775 & 1.000 & -.5892 & .8114 \\
\hline & Two times per year & -.27460 & .24909 & 1.000 & -1.0083 & .4591 \\
\hline & Three times per year & -.22037 & .26089 & 1.000 & -.9888 & .5480 \\
\hline & Four times per year & -.61709 & .33871 & 1.000 & -1.6147 & .3805 \\
\hline
\end{tabular}

Multiple Comparisons

Dependent Variable: Q18

\section{Bonferroni}

$\begin{array}{lll}\text { (I) 11. Which of the } & \text { (J) 11. Which of the }\end{array}$

following best describes following best describes

your attendance at a your attendance at a

trainings/workshops/dril trainings/workshops/dril

Is about disaster

preparedness? If not

select N/A - Workshop

Never

Never

One time oer vear

One time per year

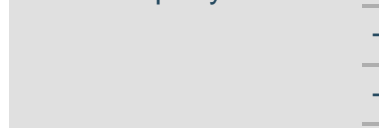

Is about disaster

preparedness? If not

select N/A - Workshop

One time per year

Two times per year

Three times per year

Four times per year

Five times or more per

year

Never

Two times per year

Three times per year

Four times per year

Five times or more per

year

Two times per year

\begin{tabular}{lr|r|r|r|r}
\hline Never & $.57012^{*}$ & .10898 & .000 & .2491 & .8911 \\
\hline One time per year & .17329 & .11697 & 1.000 & -.1712 & .5178 \\
\hline Three times per year & .14741 & .22761 & 1.000 & -.5230 & .8178 \\
\hline
\end{tabular}

95\% Confidence Interval

Lower Upper Bound Bound

\begin{tabular}{l|l|l|l|l|}
$-.39683^{*}$ & .07790 & .000 & -.6263 & -.1674 \\
\hline
\end{tabular}

\begin{tabular}{l|l|l|l|l|}
$-.57012^{*}$ & .10898 & .000 & -.8911 & -.2491 \\
\hline
\end{tabular}

\begin{tabular}{|l|r|r|r|r|}
\hline-.42271 & .21022 & .671 & -1.0419 & .1965 \\
\hline
\end{tabular}

\begin{tabular}{l|l|l|l|l|l|}
$-.88683^{*}$ & .27346 & .019 & -1.6923 & -.0814 \\
\hline
\end{tabular}

\begin{tabular}{|l|l|l|l|l|}
-.79289 & .28644 & .087 & -1.6366 & .0508 \\
\hline
\end{tabular}

\begin{tabular}{|l|l|l|l|l|}
\hline $39683^{*}$ & .07790 & .000 & .1674 & .6263 \\
\hline
\end{tabular}

\begin{tabular}{l|l|l|l|l|}
-.17329 & .11697 & 1.000 & -.5178 & .1712 \\
\hline
\end{tabular}

\begin{tabular}{l|l|l|l|l|}
-.02588 & .21447 & 1.000 & -.6576 & .6058 \\
\hline
\end{tabular}

\begin{tabular}{|l|l|l|l|r|}
-.49000 & .27674 & 1.000 & -1.3051 & .3251 \\
\hline
\end{tabular}

\begin{tabular}{|l|l|l|l|r|}
\hline-.39606 & .28957 & 1.000 & -1.2490 & .4568 \\
\hline
\end{tabular}




\begin{tabular}{|c|c|c|c|c|c|c|}
\hline & Four times per year & -.31670 & .28705 & 1.000 & -1.1622 & .5288 \\
\hline & $\begin{array}{l}\text { Five times or more per } \\
\text { year }\end{array}$ & -.22276 & .29943 & 1.000 & -1.1047 & .6592 \\
\hline \multirow[t]{5}{*}{ Three times per year } & Never & .42271 & .21022 & .671 & -.1965 & 1.0419 \\
\hline & One time per year & .02588 & .21447 & 1.000 & -.6058 & .6576 \\
\hline & Two times per year & -.14741 & .22761 & 1.000 & -.8178 & .5230 \\
\hline & Four times per year & -.46411 & .33869 & 1.000 & -1.4617 & .5335 \\
\hline & $\begin{array}{l}\text { Five times or more per } \\
\text { year }\end{array}$ & -.37018 & .34925 & 1.000 & -1.3989 & .6585 \\
\hline \multirow[t]{5}{*}{ Four times per year } & Never & $.88683^{*}$ & .27346 & .019 & .0814 & 1.6923 \\
\hline & One time per year & .49000 & .27674 & 1.000 & -.3251 & 1.3051 \\
\hline & Two times per year & .31670 & .28705 & 1.000 & -.5288 & 1.1622 \\
\hline & Three times per year & .46411 & .33869 & 1.000 & -.5335 & 1.4617 \\
\hline & $\begin{array}{l}\text { Five times or more per } \\
\text { year }\end{array}$ & .09394 & .39060 & 1.000 & -1.0565 & 1.2444 \\
\hline \multirow{5}{*}{$\begin{array}{l}\text { Five times or more per } \\
\text { year }\end{array}$} & Never & .79289 & .28644 & .087 & -.0508 & 1.6366 \\
\hline & One time per year & .39606 & .28957 & 1.000 & -.4568 & 1.2490 \\
\hline & Two times per year & .22276 & .29943 & 1.000 & -.6592 & 1.1047 \\
\hline & Three times per year & .37018 & .34925 & 1.000 & -.6585 & 1.3989 \\
\hline & Four times per year & -.09394 & .39060 & 1.000 & -1.2444 & 1.0565 \\
\hline
\end{tabular}

Multiple Comparisons

Dependent Variable: Q18

Bonferroni

$\begin{array}{lll}\text { (I) } 11 . \text { Which of the } & \text { (J) 11. Which of the }\end{array}$

following best describes following best describes

your attendance at a your attendance at a

trainings/workshops/dril trainings/workshops/dril

Is about disaster

Is about disaster

preparedness? If not

preparedness? If not

select N/A - Drill

select N/A - Dril

\begin{tabular}{|c|c|c|c|c|}
\hline \multirow[b]{2}{*}{$\begin{array}{l}\text { Mean } \\
\text { ference (I- } \\
\mathrm{J})\end{array}$} & \multirow[b]{2}{*}{$\begin{array}{l}\text { Std. } \\
\text { Error }\end{array}$} & \multirow[b]{2}{*}{ Sig. } & \multicolumn{2}{|c|}{ 95\% Confidence Interval } \\
\hline & & & $\begin{array}{l}\text { Lower } \\
\text { Bound }\end{array}$ & $\begin{array}{l}\text { Upper } \\
\text { Bound }\end{array}$ \\
\hline$-.44976^{*}$ & .07431 & .000 & -.6686 & -.2309 \\
\hline$-.79734^{*}$ & .10993 & .000 & -1.1211 & -.4735 \\
\hline-.28027 & .15782 & 1.000 & -.7451 & .1846 \\
\hline$-1.25467^{*}$ & .29568 & .000 & -2.1256 & -.3838 \\
\hline$-.90282^{*}$ & .23887 & .003 & -1.6064 & -.1992 \\
\hline $.44976^{*}$ & .07431 & .000 & .2309 & .6686 \\
\hline$-.34758^{*}$ & .11318 & .033 & -.6809 & -.0142 \\
\hline
\end{tabular}




\begin{tabular}{|c|c|c|c|c|c|c|}
\hline & Three times per year & .16949 & .16010 & 1.000 & -.3021 & .6410 \\
\hline & Four times per year & -.80491 & .29690 & .103 & -1.6794 & .0696 \\
\hline & $\begin{array}{l}\text { Five times or more per } \\
\text { year }\end{array}$ & -.45306 & .24038 & .898 & -1.1611 & .2550 \\
\hline \multirow[t]{5}{*}{ Two times per year } & Never & $.79734^{*}$ & .10993 & .000 & .4735 & 1.1211 \\
\hline & One time per year & $.34758^{*}$ & .11318 & .033 & .0142 & .6809 \\
\hline & Three times per year & .51706 & .17943 & .061 & -.0114 & 1.0455 \\
\hline & Four times per year & -.45734 & .30776 & 1.000 & -1.3638 & .4491 \\
\hline & $\begin{array}{l}\text { Five times or more per } \\
\text { year }\end{array}$ & -.10549 & .25367 & 1.000 & -.8526 & .6417 \\
\hline \multirow[t]{5}{*}{ Three times per year } & Never & .28027 & .15782 & 1.000 & -.1846 & .7451 \\
\hline & One time per year & -.16949 & .16010 & 1.000 & -.6410 & .3021 \\
\hline & Two times per year & -.51706 & .17943 & .061 & -1.0455 & .0114 \\
\hline & Four times per year & $-.97440^{*}$ & .32793 & .046 & -1.9403 & -.0085 \\
\hline & $\begin{array}{l}\text { Five times or more per } \\
\text { year }\end{array}$ & -.62255 & .27779 & .380 & -1.4408 & .1957 \\
\hline \multirow[t]{5}{*}{ Four times per year } & Never & $1.25467^{*}$ & .29568 & .000 & .3838 & 2.1256 \\
\hline & One time per year & .80491 & .29690 & .103 & -.0696 & 1.6794 \\
\hline & Two times per year & .45734 & .30776 & 1.000 & -.4491 & 1.3638 \\
\hline & Three times per year & $.97440^{*}$ & .32793 & .046 & .0085 & 1.9403 \\
\hline & $\begin{array}{l}\text { Five times or more per } \\
\text { year }\end{array}$ & .35185 & .37375 & 1.000 & -.7490 & 1.4527 \\
\hline \multirow{5}{*}{$\begin{array}{l}\text { Five times or more per } \\
\text { year }\end{array}$} & Never & $.90282^{*}$ & .23887 & .003 & .1992 & 1.6064 \\
\hline & One time per year & .45306 & .24038 & .898 & -.2550 & 1.1611 \\
\hline & Two times per year & .10549 & .25367 & 1.000 & -.6417 & .8526 \\
\hline & Three times per year & .62255 & .27779 & .380 & -.1957 & 1.4408 \\
\hline & Four times per year & -.35185 & .37375 & 1.000 & -1.4527 & .7490 \\
\hline
\end{tabular}




\section{Appendix X}

The Results of the "One Way ANOVA" of the Difference in Hajj Knowledge of Disaster Preparedness for Mass Gatherings between Different Categories of EMS Providers Based on Number of Training, Workshop, and Drill Last Time Attended.

\section{Multiple Comparisons}

Dependent Variable: Q18

Bonferroni

(I) 12. When was the last

(J) 12. When was the last time you attended a time you attended a

trainings/ workshops/ drills trainings/ workshops/ drills about disaster about disaster

preparedness? - Training preparedness? - Training (I-J) Std. Error Sig. Less than six months ago Six months ago-A year ago \begin{tabular}{l|l|l|}
-.01227 & .10312 & 1.000 \\
\hline
\end{tabular}

(

Six months ago-A year ago More than one year ago $N / A$ \begin{tabular}{l|l|l|}
.22452 & .10147 & .163 \\
\hline
\end{tabular}

Less than six months ago

$.43376 * \quad .09761$
.000

N/A

More than one year ago More than one year ago $\mathrm{N} / \mathrm{A}$ \begin{tabular}{|l|l|l|}
.01227 & 10312 & 1.000 \\
\hline
\end{tabular}

\begin{tabular}{lr|r|r}
\hline Less than six months ago & -.22452 & .10147 & .163 \\
\hline Six months ago-A year ago & -.23679 & .09821 & .097 \\
\hline N/A & .20924 & .09241 & .143 \\
\hline Less than six months ago & $-.43376^{*}$ & .09761 & .000 \\
\hline Six months ago-A year ago & $-.44603^{*}$ & .09422 & .000 \\
\hline More than one year ago & -.20924 & .09241 & .143 \\
\hline
\end{tabular}

\section{Multiple Comparisons}

Dependent Variable: Q18

Bonferroni

(I) 12. When was the last time you attended a trainings/ workshops/ drills about disaster preparedness?

- Training

Less than six months ago

Six months ago-A year ago
(J) 12. When was the last time you attended a trainings/ workshops/ drills about disaster preparedness? - Training Six months ago-A year ago More than one year ago

$\mathrm{N} / \mathrm{A}$

Less than six months ago More than one year ago N/A
95\% Confidence Interval Lower Bound Upper Bound

\begin{tabular}{r|r}
-.2851 & .2606 \\
\hline-.0439 & .4930 \\
\hline .1755 & .6920 \\
\hline-.2606 & .2851 \\
\hline-.0231 & .4966 \\
\hline .1967 & .6953 \\
\hline
\end{tabular}




\begin{tabular}{llr|r}
\hline More than one year ago & Less than six months ago & -.4930 & .0439 \\
\hline & Six months ago-A year ago & -.4966 & .0231 \\
\hline N/A & -.0353 & .4537 \\
\hline N/A & Less than six months ago & -.6920 & -.1755 \\
\hline Six months ago-A year ago & -.6953 & -.1967 \\
\hline & More than one year ago & -.4537 & .0353 \\
\hline
\end{tabular}

\section{Multiple Comparisons}

Dependent Variable: Q18

\section{Bonferroni}

(I) 12. When was the last time you attended a

trainings/ workshops/drills about disaster

preparedness? - Workshop

(J) 12. When was the last time you attended a trainings/ workshops/drills about disaster

Mean Difference preparedness? - Workshop Less than six months ago

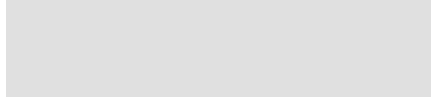

Six months ago-A year ago

Six months ago-A year ago (I-J) Std. Error Sig. More than one year ago N/A

\begin{tabular}{r|r|r}
\hline (I-J) & Std. Error & \multicolumn{1}{c}{ Sig. } \\
\hline. .08582 & .11693 & 1.000 \\
\hline .12167 & .11977 & 1.000 \\
\hline $.43324^{*}$ & .10817 & .000 \\
\hline .208582 & .11693 & 1.000 \\
\hline $.51907^{*}$ & .08696 & .000 \\
\hline-.12167 & .11977 & 1.000 \\
\hline-.20749 & .10103 & .242 \\
\hline $.31158^{*}$ & .09074 & .004 \\
\hline$-.43324^{*}$ & .10817 & .000 \\
\hline$-.51907^{*}$ & .08696 & .000 \\
\hline$-.31158^{*}$ & .09074 & .004 \\
\hline
\end{tabular}

\section{Multiple Comparisons}

\section{Dependent Variable: Q18}

\section{Bonferroni}

(I) 12. When was the last time you attended a trainings/ workshops/ drills about disaster preparedness?

- Workshop

Less than six months ago

Less than six month ago

Six months ago-A year ago
(J) 12. When was the last time you attended a trainings/ workshops/ drills about disaster preparedness? - Workshop

Six months ago-A year ago More than one year ago $N / A$

Less than six months ago More than one year ago
95\% Confidence Interval Lower Bound Upper Bound

\begin{tabular}{r|r}
\hline-.3952 & .2236 \\
\hline-.1952 & .4386 \\
\hline .1470 & .7194 \\
\hline-.2236 & .3952 \\
\hline-.0598 & .4748 \\
\hline
\end{tabular}




\begin{tabular}{llr|r}
\hline & N/A & .2890 & .7491 \\
\hline \multirow{2}{*}{ More than one year ago } & Less than six months ago & -.4386 & .1952 \\
\cline { 2 - 4 } & Six months ago-A year ago & -.4748 & .0598 \\
\cline { 2 - 4 } & N/A & .0715 & .5517 \\
\hline \multirow{2}{*}{ N/A } & Less than six months ago & -.7194 & -.1470 \\
\hline & Six months ago-A year ago & -.7491 & -.2890 \\
\cline { 2 - 4 } & More than one year ago & -.5517 & -.0715 \\
\hline
\end{tabular}

Multiple Comparisons

Dependent Variable: Q18

Bonferroni

(I) 12. When was the last

(J) 12. When was the last

time you attended a time you attended a

trainings/ workshops/drills

trainings/ workshops/ drills

about disaster about disaster

Mean Difference

preparedness? - Drill

preparedness? - Drill

(I-J)

Std. Error Sig.

\begin{tabular}{lll|r|r}
\hline \multirow{2}{*}{ Less than six months ago } & Six months ago-A year ago & -.17778 & .10940 & .628 \\
\cline { 2 - 5 } & More than one year ago & .14678 & .11053 & 1.000 \\
\cline { 2 - 5 } & N/A & $.50623^{*}$ & .10452 & .000 \\
\hline \multirow{2}{*}{ Six months ago-A year ago } & Less than six months ago & .17778 & .10940 & .628 \\
\cline { 2 - 5 } & More than one year ago & $.32457^{*}$ & .09389 & .003 \\
\cline { 2 - 5 } & N/A & $.68401^{*}$ & .08673 & .000 \\
\hline More than one year ago & Less than six months ago & -.14678 & .11053 & 1.000 \\
\cline { 2 - 5 } & Six months ago-A year ago & $-.32457^{*}$ & .09389 & .003 \\
\hline & N/A & $.35944^{*}$ & .08815 & .000 \\
\hline N/A & Less than six months ago & $-.50623^{*}$ & .10452 & .000 \\
\cline { 2 - 5 } & Six months ago-A year ago & $-.68401^{*}$ & .08673 & .000 \\
\cline { 2 - 5 } & More than one year ago & $-.35944^{*}$ & .08815 & .000 \\
\hline
\end{tabular}

\section{Multiple Comparisons}

Dependent Variable: Q18

\section{Bonferroni}

(I) 12. When was the last time you

attended a trainings/ workshops/

drills about disaster preparedness?

- Drill

Less than six months ago

Six months ago-A year ago
(J) 12. When was the last time you attended a trainings/ workshops/

drills about disaster preparedness?

- Drill

Six months ago-A year ago

More than one year ago

N/A

Less than six months ago
95\% Confidence Interval Lower Bound Upper Bound

\begin{tabular}{r|r}
-.4672 & .1117 \\
\hline-.1457 & .4392 \\
\hline .2297 & .7828 \\
\hline-.1117 & .4672 \\
\hline
\end{tabular}




\begin{tabular}{llr|r}
\hline & More than one year ago & .0762 & .5730 \\
\cline { 2 - 4 } & N/A & .4545 & .9135 \\
\hline \multirow{2}{*}{ More than one year ago } & Less than six months ago & -.4392 & .1457 \\
\hline & Six months ago-A year ago & -.5730 & -.0762 \\
\hline N/A $/ A$ & Less than six months ago & .1262 & .5927 \\
\hline & Six months ago-A year ago & -.7828 & -.2297 \\
\hline & More than one year ago & -.9135 & -.4545 \\
\hline
\end{tabular}




\section{Appendix Y}

The Results of the "One Way ANOVA" of the Difference in Hajj Knowledge of Disaster Preparedness for Mass Gatherings between Different Categories of EMS Providers Based on duration of the last time attended Training, Workshop, and Drill.

\section{Multiple Comparisons}

Dependent Variable: Q18

Bonferroni

(I) 13. What was the duration

of the last

(J) 13. What was the duration

trainings/workshops/drills

about disaster that you

of the last

attended? - Training

trainings/workshops/drills

Less than 5 hours

about disaster that you

Mean Difference

attended? - Training

(I-J)

From 5 hours but less than

$-.15038$

Std. Error

Sig.

thats

10 hours

From 10 hours but less than

\begin{tabular}{l|l|r|}
-.02837 & .15039 & 1.000 \\
\hline
\end{tabular}

20 hours

From 5 hours but less than

From 5 hours but less than

10 hours

Less than 5 hours

From 10 hours but less than

.12667

.14615

1.000

20 hours or more

.31159

.15038

.08527

.003

From 10 hours but less than

From 10 hours but less than

20 hours

20 hours

\begin{tabular}{|l|l|r|}
\hline .12200 & .15746 & 1.000 \\
\hline
\end{tabular}

20 hours or more

27704

N/A

$.46196^{*}$

.15341

.714

Less than 5 hours

.02837

.09720
.000

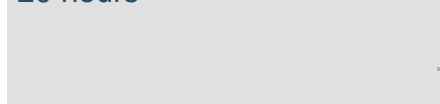

From 5 hours but less than

\begin{tabular}{l|l|l|}
-.12200 & .15746 & 1.000 \\
\hline
\end{tabular}

10 hours

20 hours or more

20 hours or more

\begin{tabular}{|l|r|r|r}
\hline 20 hours or more & .15504 & .19323 & 1.000 \\
\hline N/A & .33996 & .15248 & .261 \\
\hline
\end{tabular}

Less than 5 hours

$-.12667$

.14615

1.000

\section{From 5 hours but less than}

10 hours

From 10 hours but less than

$-.2770$

.714

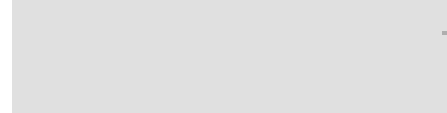

N/A

N/A

20 hours

N/A

Less than 5 hours

From 5 hours but less than

10 hours 


\begin{tabular}{l|l|l|l}
$\begin{array}{l}\text { From } 10 \text { hours but less than } \\
20 \text { hours }\end{array}$ & -.33996 & .15248 & .261 \\
\hline 20 hours or more & -.18492 & .14830 & 1.000 \\
\hline
\end{tabular}

\section{Multiple Comparisons}

Dependent Variable: Q18

\section{Bonferroni}

(I) 13. What was the duration of the (J) 13. What was the duration of the last trainings/workshops/drills about last trainings/workshops/drills about disaster that you attended? disaster that you attended? -

Training Training Lower Bound Upper Bound

Less than 5 hours

From 5 hours but less than 10 hours

ther

From 5 hours but less than 10

hours

From 10 hours but less than 20

95\% Confidence Interval

hours

20 hours or more

N/A

$-.4148$

1140

Less than 5 hours

$-28$

From 10 hours but less than 20

$-$.

From 10 hours but less than 20

From 10 hours but less than 20
hours

20 hours or more

hours

\begin{tabular}{lr|r}
\hline 20 hours or more & -.1550 & .7091 \\
\hline N/A & .1883 & .7357 \\
\hline
\end{tabular}

Less than 5 hours

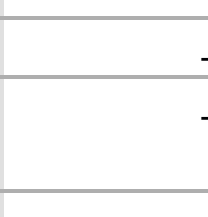

hours
20 hours or more
N/A

$-.3951$
.4519

$\begin{array}{ll}-.5654 & .3214\end{array}$

N/A

Less than 5 hours
From 5 hours but less than 10
hours
From 10 hours but less than 20
hours
N/A

N/A

Less than 5 hours
From 5 hours but less than 10
hours
From 10 hours but less than 20
hours

\begin{tabular}{r|r}
\hline-.2327 & .6025 \\
\hline-.5517 & -.0715 \\
\hline-.7357 & -.1883 \\
\hline & .0894 \\
\hline
\end{tabular}




\section{Multiple Comparisons}

Dependent Variable: Q18

Bonferroni

\begin{tabular}{|c|c|c|c|c|c|}
\hline $\begin{array}{l}\text { (I) 13. What was the } \\
\text { duration of the last } \\
\text { trainings/workshops/drills } \\
\text { about disaster that you } \\
\text { attended? - Workshop }\end{array}$ & $\begin{array}{l}\text { (J) 13. What was the } \\
\text { duration of the last } \\
\text { trainings/workshops/drills } \\
\text { about disaster that you } \\
\text { attended? - Workshop }\end{array}$ & $\begin{array}{c}\text { Mean } \\
\text { Difference (I-J) }\end{array}$ & Std. Error & Sig. & $\begin{array}{c}95 \% \\
\text { Confidence } \\
\text { Interval } \\
\text { Lower Bound }\end{array}$ \\
\hline \multirow[t]{4}{*}{ Less than 5 hours } & $\begin{array}{l}\text { From } 5 \text { hours but less than } \\
10 \text { hours }\end{array}$ & .02343 & .09947 & 1.000 & -.2567 \\
\hline & $\begin{array}{l}\text { From } 10 \text { hours but less } \\
\text { than } 20 \text { hours }\end{array}$ & .00097 & .14324 & 1.000 & -.4024 \\
\hline & 20 hours or more & -.12652 & .19189 & 1.000 & -.6669 \\
\hline & $\mathrm{N} / \mathrm{A}$ & $.41945^{*}$ & .09070 & .000 & .1640 \\
\hline \multirow{4}{*}{$\begin{array}{l}\text { From } 5 \text { hours but less than } \\
10 \text { hours }\end{array}$} & Less than 5 hours & -.02343 & .09947 & 1.000 & -.3035 \\
\hline & $\begin{array}{l}\text { From } 10 \text { hours but less } \\
\text { than } 20 \text { hours }\end{array}$ & -.02246 & .14020 & 1.000 & -.4173 \\
\hline & 20 hours or more & -.14995 & .18963 & 1.000 & -.6839 \\
\hline & N/A & $.39602^{*}$ & .08582 & .000 & .1543 \\
\hline \multirow{4}{*}{$\begin{array}{l}\text { From } 10 \text { hours but less } \\
\text { than } 20 \text { hours }\end{array}$} & Less than 5 hours & -.00097 & .14324 & 1.000 & -.4043 \\
\hline & $\begin{array}{l}\text { From } 5 \text { hours but less than } \\
10 \text { hours }\end{array}$ & .02246 & .14020 & 1.000 & -.3723 \\
\hline & 20 hours or more & -.12749 & .21583 & 1.000 & -.7353 \\
\hline & N/A & $.41847^{*}$ & .13412 & .019 & .0408 \\
\hline \multirow[t]{4}{*}{20 hours or more } & Less than 5 hours & .12652 & .19189 & 1.000 & -.4138 \\
\hline & $\begin{array}{l}\text { From } 5 \text { hours but less than } \\
10 \text { hours }\end{array}$ & .14995 & .18963 & 1.000 & -.3840 \\
\hline & $\begin{array}{l}\text { From } 10 \text { hours but less } \\
\text { than } 20 \text { hours }\end{array}$ & .12749 & .21583 & 1.000 & -.4803 \\
\hline & $\mathrm{N} / \mathrm{A}$ & $.54597^{*}$ & .18518 & .033 & .0245 \\
\hline \multirow[t]{4}{*}{$\mathrm{N} / \mathrm{A}$} & Less than 5 hours & $-.41945^{*}$ & .09070 & .000 & -.6749 \\
\hline & $\begin{array}{l}\text { From } 5 \text { hours but less than } \\
10 \text { hours }\end{array}$ & $-.39602^{*}$ & .08582 & .000 & -.6377 \\
\hline & $\begin{array}{l}\text { From } 10 \text { hours but less } \\
\text { than } 20 \text { hours }\end{array}$ & $-.41847^{*}$ & .13412 & .019 & -.7961 \\
\hline & 20 hours or more & $-.54597^{*}$ & .18518 & .033 & -1.0674 \\
\hline
\end{tabular}

Multiple Comparisons

Dependent Variable: Q18 


\section{Bonferroni}

(I) 13. What was the duration of the last trainings/workshops/drills about disaster that you attended? - Workshop

Less than 5 hours

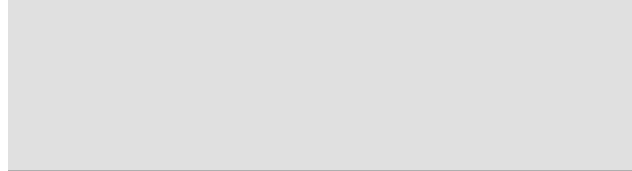

From 5 hours but less than 10 hours

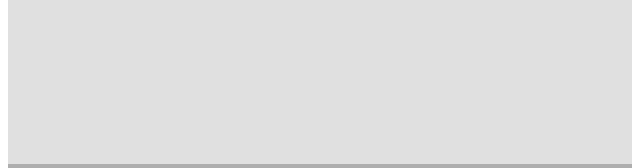

From 10 hours but less than 20 hours

20 hours or more

N/A

20 hours or more

N/A

(J) 13. What was the duration of the last trainings/workshops/drills about disaster that you attended? - Workshop

From 5 hours but less than 10 hours

From 10 hours but less than 20 hours

20 hours or more

$\mathrm{N} / \mathrm{A}$

Less than 5 hours

From 10 hours but less than 20 hours

20 hours or more

$\mathrm{N} / \mathrm{A}$

Less than 5 hours

From 5 hours but less than 10 hours

20 hours or more

N/A

Less than 5 hours

From 5 hours but less than 10 hours

From 10 hours but less than 20 hours

N/A

Less than 5 hours

From 5 hours but less than 10 hours

From 10 hours but less than 20 hours

20 hours or more

\section{Multiple Comparisons}

Dependent Variable: Q18

\section{Bonferroni}

(I) 13. What was the

duration of the last

trainings/workshops/drills

about disaster that you

attended? - Drill

Less than 5 hours
(J) 13. What was the

duration of the last

trainings/workshops/drills

about disaster that you

attended? - Drill

From 5 hours but less than

10 hours

From 10 hours but less

than 20 hours

20 hours or more

N/A
95\% Confidence Interval

Upper Bound

.3035

.4043

.4138

.6749

.2567

.3723

.3840

.6377

.4024

.4173

.4803

.7961

.6669

.6839

.7353

1.0674

$-.1640$

$-.1543$

$-.0408$

$-.0245$

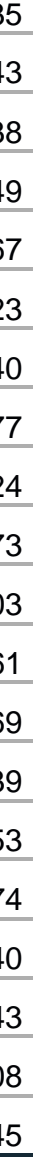




\begin{tabular}{|c|c|c|c|c|c|}
\hline \multirow{4}{*}{$\begin{array}{l}\text { From } 5 \text { hours but less than } \\
10 \text { hours }\end{array}$} & Less than 5 hours & .03286 & .10101 & 1.000 & -.2516 \\
\hline & $\begin{array}{l}\text { From } 10 \text { hours but less } \\
\text { than } 20 \text { hours }\end{array}$ & .03584 & .11185 & 1.000 & -.2791 \\
\hline & 20 hours or more & -.04524 & .18442 & 1.000 & -.5646 \\
\hline & $\mathrm{N} / \mathrm{A}$ & $.56027^{*}$ & .09467 & .000 & .2937 \\
\hline \multirow{4}{*}{$\begin{array}{l}\text { From } 10 \text { hours but less } \\
\text { than } 20 \text { hours }\end{array}$} & Less than 5 hours & -.00298 & .10666 & 1.000 & -.3033 \\
\hline & $\begin{array}{l}\text { From } 5 \text { hours but less than } \\
10 \text { hours }\end{array}$ & -.03584 & .11185 & 1.000 & -.3508 \\
\hline & 20 hours or more & -.08108 & .18757 & 1.000 & -.6093 \\
\hline & $\mathrm{N} / \mathrm{A}$ & $.52444^{*}$ & .10067 & .000 & .2409 \\
\hline \multirow[t]{4}{*}{20 hours or more } & Less than 5 hours & .07810 & .18132 & 1.000 & -.4325 \\
\hline & $\begin{array}{l}\text { From } 5 \text { hours but less than } \\
10 \text { hours }\end{array}$ & .04524 & .18442 & 1.000 & -.4741 \\
\hline & $\begin{array}{l}\text { From } 10 \text { hours but less } \\
\text { than } 20 \text { hours }\end{array}$ & .08108 & .18757 & 1.000 & -.4471 \\
\hline & $N / A$ & $.60551^{*}$ & .17786 & .007 & .1046 \\
\hline \multirow[t]{4}{*}{$\mathrm{N} / \mathrm{A}$} & Less than 5 hours & $-.52742^{*}$ & .08848 & .000 & -.7766 \\
\hline & $\begin{array}{l}\text { From } 5 \text { hours but less than } \\
10 \text { hours }\end{array}$ & $-.56027^{\star}$ & .09467 & .000 & -.8269 \\
\hline & $\begin{array}{l}\text { From } 10 \text { hours but less } \\
\text { than } 20 \text { hours }\end{array}$ & $-.52444^{*}$ & .10067 & .000 & -.8079 \\
\hline & 20 hours or more & $-.60551^{*}$ & .17786 & .007 & -1.1064 \\
\hline
\end{tabular}

\section{Multiple Comparisons}

Dependent Variable: Q18

\section{Bonferroni}

(I) 13. What was the duration of the last trainings/workshops/drills about disaster that you attended? - Drill

Less than 5 hours

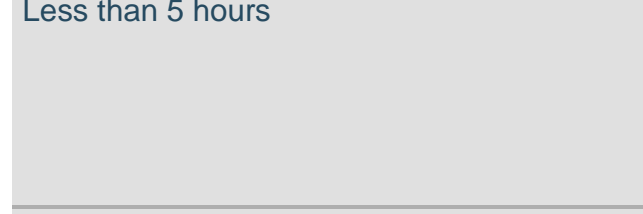

From 5 hours but less than 10 hours
(J) 13. What was the duration of the last

95\% Confidence Interval trainings/workshops/drills about disaster that you attended? - Drill

Upper Bound

From 5 hours but less than 10 hours

From 10 hours but less than 20 hours

20 hours or more

N/A

Less than 5 hours

From 10 hours but less than 20 hours

20 hours or more

N/A

Less than 5 hours

From 5 hours but less than 10 hours
.2516 .3033 .4325 .7766 .3173 .3508 .4741 .8269 .2974 .2791 


\begin{tabular}{|c|c|c|}
\hline & 20 hours or more & .4471 \\
\hline & $\mathrm{N} / \mathrm{A}$ & .8079 \\
\hline \multirow[t]{4}{*}{20 hours or more } & Less than 5 hours & .5887 \\
\hline & From 5 hours but less than 10 hours & .5646 \\
\hline & From 10 hours but less than 20 hours & .6093 \\
\hline & $\mathrm{N} / \mathrm{A}$ & 1.1064 \\
\hline \multirow[t]{4}{*}{$N / A$} & Less than 5 hours & -.2783 \\
\hline & From 5 hours but less than 10 hours & -.2937 \\
\hline & From 10 hours but less than 20 hours & -.2409 \\
\hline & 20 hours or more & -.1046 \\
\hline
\end{tabular}




\title{
CURRICULUM VITAE
}

\author{
Ahmed M Alotaibi, PhD, MSHSA, BSEMS-P \\ School of Public Health and Information Sciences \\ University of Louisville \\ Phone: 703-939-3154 \\ ahmalotaibi@ksu.edu.sa
}

\section{EDUCATIONAL BACKGROUND}

Ph.D., Health Sciences Management

Expected May 2018

- University of Louisville, Louisville, KY

G.P.A 3.65

- Dissertation: AN ASSESSMENT OF THE DISASTER PREPAREDNESS KNOWLEDGE OF EMS PROVIDER IN THE HAJJ 2016.

M.S. Health Services Administration

May 2011

- University of Evansville, Evansville, IN

G.P.A. 3.9

B.S. Emergency Medical Care

May 2009

- Eastern Kentucky University, Richmond, KY

Dean list, two terms, G.P.A. 3.8

Diploma Emergency Medical Technician

December 2005

- Prince Sultan Military College of Health Sciences, Saudi Arabia

G.P.A $3.47 / 5.0$

\section{TEACHING EXPERIENCE}

Teaching Assistant, Health Science Management Dept.

Fall 2017

School of Public Health Sciences Informatics, University of Louisville

- Taught master level health management classes (15 students)

- Instructor of AHA at Medical Education in Hospital of Louisville

Adjunct Professor, Prince Sultan Bin Abdalziz College for EMS (PSACEMS)

January 2011- Present

King Saudi University, Saudi Arabia

- Instruct advanced emergency medical care, Public health, and health management courses.

- Teach undergraduate level EMS track (50 students)

- Serve as advisor for EMS undergraduate level

- Coordinate AHA certification courses.

- Supervise the Student Affairs office in organizing student-centered program.

Graduate study department at University of Evansville

2011 


\section{EXPERIENCES}

King Fahd Armed Forces Hospital Jeddah, Saudi Arabia

Health Coordinator

- Coordinated the screening process of new military and navy recruits

- Assisted screening physicians and performed clerical duties.

\section{Advance Medical provider}

2005- 2006

- Performed assessment and emergency care to patients admitted in emergency room.

- Instructed a First Aid and CPR courses at the hospital for staff and local community.

- Worked for Saudi Red Crescent as part of an internship in ambulance to provide emergency medical treatment during transport to hospital.

\section{SKILLS}

- Emergency Medical Response Management

- Critical Care Transport

- Airway Management

- Disaster planning

- Emergency Public Health

- ECG skills

- Strong problem solving and analytical abilities

- Microsoft Office Package

- SPSS and Data analysis

- Research Methods

- Quantitative Methodology

- Clinical Research

- Experience in hands on training of other

- Fluent in English and Arabic Language

- Healthcare Management

- Public Health Sciences

- Health policy

\section{RESEARCH}

- Researched, prepared and presented an overview of the incidence of health care medical error in Emergency Room treatment in the United States 
- Led health care statistics lesson on the prevalence and treatment of diabetes in the U.S.

- Evaluated the current state of health care delivery system in the Kingdom of Saudi Arabia; strengths, weaknesses, opportunities and threats.

- Book reviewer: Transformation of EMS for Red Crescent Authority.

\section{COURSES}

- Advance Topics in Health Analysis

- Complex Health Organization and Leadership

- Complexity and Health Systems

- Epidemiology Methods

- Methods in Health Service Research

- Public Budgeting and Finance

- Public Health Data Management using SPSS

- Public Health and the built Environment

- Research Methods

- Human Recourses Management

- Organizational Behavior in Health care

- Seminar in Public Health Management

\section{CONFERENCES \& WORKDHOPS}

Mass gathering Medicine Summit 2018

- Poster and Speaker in conference

\section{Kentucky EMS Conference and Expo 2017}

- Leading, motivating, and Evaluating Employees.

- The pentagon Attack Lessons Learned: An eye witness account and lessons learned.

- KBEMS Educator Orientation

- Stop sweating it! 15 action steps to reduce the stress from living the Ambulance industry life style.

- Legislative Update

- If life is worth saving it must be worth living

- KBEMS EMS Evaluator course.

- Hot car death \& treating heat stroke.

- Enhanced Medicaid reimbursement project- The overview

- Your off-duty behavior could impact you while on duty

- Bridging the Gap-changes in EMS education.

- Research for EMS: Investigation 101.

$2^{\text {nd }}$ EMS Education Conference in Riyadh, Saudi Arabia

- Attended the conference and update last method for teaching. 
$1^{\text {st }}$ EMS Education Conference in Riyadh, Saudi Arabia

- Scientific committee of the conference and head of public relation.

Emergency Medical Care Conference

- Reviewed and updated emergency response skills and practice, medical technology.

Asthma day

- Attended Asthma Day conference learning to properly care for patients with asthma in emergency setting.

Workshop of Porter Starke Services 2010

- Team building

- Time management

- Leadership

\section{VOLUNTEER EXPERIENCE}

President, Saudi Student Association, University of Louisville

2016- Present

- Organizing social events.

- Advise new students

- Introduce the culture of Saudi Arabia in campus

Vice President, American International Relation Club

- Organizing social events

- Many activities in UofL campus

\section{Simulation center at Medical Education (School of Medicine at UofL)}

2016-Present

- Serve as simulation technician

- Preparing lab activities and simulation

- Prepares equipment, supplies, and physical set-up and breakdown for lab and simulation exercises with students

- Works with faculty to create simulation activities 